\title{
Tools of care : explorations into the semiotics of medical technology
}

\author{
Citation for published version (APA):
}

Willems, D. L. (1995). Tools of care : explorations into the semiotics of medical technology. [Doctoral Thesis, Maastricht University]. Rijksuniversiteit Limburg. https://doi.org/10.26481/dis.19950608dw

Document status and date:

Published: 01/01/1995

DOI:

$10.26481 /$ dis. $19950608 d w$

Document Version:

Publisher's PDF, also known as Version of record

\section{Please check the document version of this publication:}

- A submitted manuscript is the version of the article upon submission and before peer-review. There can be important differences between the submitted version and the official published version of record.

People interested in the research are advised to contact the author for the final version of the publication, or visit the DOI to the publisher's website.

- The final author version and the galley proof are versions of the publication after peer review.

- The final published version features the final layout of the paper including the volume, issue and page numbers.

Link to publication

\footnotetext{
General rights rights.

- You may freely distribute the URL identifying the publication in the public portal. please follow below link for the End User Agreement:

www.umlib.nl/taverne-license

Take down policy

If you believe that this document breaches copyright please contact us at:

repository@maastrichtuniversity.nl

providing details and we will investigate your claim.
}

Copyright and moral rights for the publications made accessible in the public portal are retained by the authors and/or other copyright owners and it is a condition of accessing publications that users recognise and abide by the legal requirements associated with these

- Users may download and print one copy of any publication from the public portal for the purpose of private study or research.

- You may not further distribute the material or use it for any profit-making activity or commercial gain

If the publication is distributed under the terms of Article $25 \mathrm{fa}$ of the Dutch Copyright Act, indicated by the "Taverne" license above, 


\section{TOOLS OF CARE}

Explorations into the semiotics of medical technology 
The publication of this work has been made possible in part through the support of Astra Pharmaceuticals. 


\section{TOOLS OF CARE}

Explorations into the semiotics of medical technology

\section{ACADEMISCH PROEFSCHRIFT}

ter verkrijging van de graad van doctor aan de Rijksuniversiteit Limburg te Maastricht op gezag van de Rector Magnificus Prof. Mr. M.J. Cohen, volgens het beshuit van College van Dekanen, in het openbaar te verdedigen op douderdag 8 juni 1995 om 14.00 uur.

Derk Ludolf Willems

geboren te Grootegast op 1 september 1954 


\section{Promotoren}

Prof Dr. Ir. G.H. de Vries

Prof Dr. E. Schadé

Beoordelingscommissie

Prof. Dr. W.E. Bijker (voorzitten)

Dr. M. Akrich (Ecole des Mines de Paris)

Prof H.D. Banta (TNO - Preventie en Gezondheid, afdeling MTA)

Prof. Dr. H.F.M.J. Crebolder

Prof. Dr. E.F.M. Wouters 
Voor Hester 
\&.

$\therefore$

( $\cdots$

$\because$ 
1. Medical technology and its users

1. Praise and criticism of technology in medicine 3

2. Philosophy and history 4

3. MTA: toward a policy of medical technology

3.I Technology assessment in health care 7

3.2 Twa examples of MTA 9

3.3 Norms and values 11

4. Science and technology studies 13

4.1 Dynamics of science and technology 13

4.2 Actor-networks 16

4.3 The user in the device: scripts and scenarios $\quad 20$

4.4 Material culture

5. The question: technology and its users 21

6. Aims, materials and methods $\quad-22$

6.1 Breathlessness

6.2 Studying one's own practice $\quad 24$

2. Names of a disease $\quad 27$

1. Introduction 27

2. Pullmonology "mired the mud of semantics". 30

3. Splitting and lumping; the quandaries of unification

3.1 The fortunes of CNSLD $\quad 35$

4. Transports and translations 37

4.1 Journals 38

4.1.1 Propagation 38

4.1.2 Uses: research and diagnosis

4.2 "Amice" 39

5. Changing practice $\quad 41$

6. John and Said: differences and similarities 41

7. Conclusion: diagnosing chronicity 43

3. Measuring breath $\quad 47$

1. Introduction $\quad 47$

2. A special kind of diary 48

3. Testing lungs $\quad 50$

3.1 Drums and tribes

3.2 Whistles and tubes: looking for smaller devices

3.2.1 Sounds 53

3.2.2 Pointers 54

3.3 New ways of measuring new phenomena 55

3.4 Keeping devices in line by connecting them.

4. Building scripts into the object $\quad 58$

4. I Creating an interesting device $\quad 58$

4.2 Stimulating proper use $\quad 59$

5. Subjective numbers, objective stories $\quad 60$

6. "A peak flow meter on every desk" $\quad 62$

7. Conclusion: scripts and descriptions 64 
1. The proliferation of drug inhalers $\quad 67$

2. Jeffrey and Johniny $\quad 68$

3. Paving a way into the airways $\quad 69$

$\begin{array}{ll}\text { 3.I Sprays } & 69\end{array}$

3.1.1 Winning time and space $\quad 72$

3.1.2 The air 73

3.2 Powders 73

3.2.1 Turbo powders $\quad 76$

4. Inscribed properties or: What is simple? 78

5. Different routes or changing maps? 79

5.1 Increassing precision $\quad 80$

5.2 Making the airways local $\quad 81$

6. Conclusion: shaping patients, physicians, and airways : 83

5. Drugs and the variable ontology of airways and airway disease $\quad 85$

$\begin{array}{ll}\text { 1. Introduction } & 85\end{array}$

2. Drugs and airways obstruction $\quad 86$

3. Carl's sequence of airway drugs $\quad 88$

3.1. Cramped aimways $\quad 88$

3.1.1. Salbutamol $\quad 88$

3.1.2 Anticholinerg drugs $\quad 89$

3.2. Instable cells.... $\quad 90$

3.3. Inflammation $\quad 92$

4. Mythologies and narratives $\quad 94$

5. Representations or reorganisations 96

5.1 Redefining airways obstruction by treating it $\quad 99$

6. Making various airways $\quad 100$

$\begin{array}{ll}\text { 7. Living with different airways } & 102\end{array}$

$\begin{array}{ll}\text { 7.1. Timing } & 102\end{array}$

7.2. Values 103

$\begin{array}{ll}\text { 8. Differences and similarities } & 104\end{array}$

6. "Keep an eye on your airways" - self management and technology of the body

1. Introduction

2. Watching one's ainways $\quad 109$

3. The high tidle of control: monitoring and CNSLD 110

4. Different practices 111

4.1. Different meanings of symptoms $\quad 111$

4.2. Different devices 113

4.3. Organisation 113

4.4. Responsibilities 114

4.5. Different diseases 115

5. Treating one's own airways $\quad 116$

6. Self-mamagement, delegation, and patient empowerment 118

7. Self-mamagement, body technique and technologies of self $\quad 119$

8. New patients, new doctors $\quad 123$ 
7. Advice and device - the technology of compliance

1. Introduction: patient compliance as a problem in the treatment of chronic disease

2. Do you take your medicine? 127

2.I Methads for measuring non-compliance $\quad 128$

$\begin{array}{ll}2.2 \text { Some limitations } & 129\end{array}$

2.3. Explaining non-compliance 130

3. Compliance-enhancement 131

3.1 Theories on compliance enhancement 132

3.2 Is non-compliance really surprising?

4. Allying instead of complying 134

5. Compliance in actor-networks 136

5.1 Compliance in people and in ainways $\quad 137$

5.2 Compliant subjects and compliant objects $\quad 138$

6. Conchusion: patient compliance and the organisation of flexible networks

8. Conclusion: technology in chronic disease

1. Introduction

2. The dehumanization thesis revisited

3. Assessing technology - MTA revisited

4. Norms in the device - ethics revisited

4. 1. Prescriptions

4.2. Responsibilities

5. Second thoughts on semiotics of (medical) technology

6. Prospects

Summary

Samenvatting

Literature 


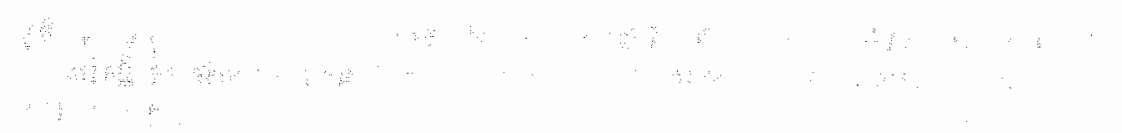




\section{Preface}

The American family physician and poet William Carlos Williams, in 1931, ended his book Imaginations with the following lines: "Living in a backward country, as all which are products of the scientific and philosophic centuries must be, I am satisfied, since I prefer not to starve, to live by the practice of medicine, which combines the best features of both science and philosophy with that imponderable and enlightening element, disease, unknown in its normality to either:"

Writing this book gave me the feeling of having found some kind of a combination of philosophy and medicall practice that Williams seems to talk about. So it was somewhat surprising to hear most people to whom I tried to explain the work over a glass of wine, or in a telephone conversation, express their view that there did not seem to be a lot of philosopliy in the subject. Philosophy still has the image of being about the ultimate questions of life, and of being entirely detached from the day-to-day slugging through the consultations in general practice. To be sure, it is about important questions of life, but it needs to look at the mundane and sometimes insignificant details of practices.

Making this book has taken a lot of time, but I was never tired of it. It may have become a bit more of a life's work than my supervisor Gerard de Vries would have wanted, but I have rarely been prey to those notorious feelings of despair that seem to be part of almost every thesis. One of the things, however, that made me doubt profoundly, sometimes, is the great trouble I had in explaining "in a few words' what I was doing. I always tried to convince myself that that was a mark of profoundness, but it mostly did not help.

What did help, however, was the support from many people. First, of course, my supervisors Gerard de Vries and Bert Schadé. Gerard, who was the only supervisor during the first phases of the work, has frequently kept me from taking impractical side-ways and was always very unambiguous in his comments. Bert, who became the second supervisor at the same time as becoming my supervisor for the SGO programme, monitored the medical part of the work and, above all, kept me from indefinitely revising the texts.

This book would not have been started or finished without the help of Annemarie Mol. From the beginning, she has read many of the very nudimentary pages, and, to my surprise, always managed to find something interesting in them, without hesitating to call what was rubbish by its name. That, too, kept me on the road.

Bemike Pasveer has read a few of the chapters with extreme precision and helped me take out many unclear sentences and loose ends. Rein Vos and Robert Dillmann also took the trouble of criticising some of the chapters.

Bruno Latour has discussed a few of the first texts with me - this helped very much to shape my ideas. Later on, in the somewhat stretcleed latest phase of this work, a discussion at his 'seminar' in the Centre de Sociologie de l'Innovation has been very helpfull.

Another helper from Paris was Nicolas Dodier, who has commented upon various stages of some of the texts. The opportunity to present some of my 
material at his "seminar' was very beneficial. The same is true for the 'seminar" of Laurent Thevenot.

The comments from the, alas, too short-lived 'underground' group of philosophers-and-the-like, 'MUNGA', have provided important corrections for this work.

I want to thank Lorraine Weber for correcting my often clumsy English in a most meticulous way - she cured me of the idea that my English could do without correction (she did not have the opportunity to correct this preface, so the reader can judge the difference).

My colleagues at the Wijkgezondheidscentrum Bovenmaat had to bear much of the side-effects of writing a thesis: even if physically present, I know I was elsewhere, sometimes.

Panline van der Hoeven, if most readers do like I do and read only the beginning and the end of the preface of a book, this is a good place to thank you. You haven't been involved with the contents of this thesis (but you explained it on the telephone much better than I did), but you kept me from submerging in it, and from becoming a bermit. That was what was most needed. 


\section{Medical technology and its users}

\section{Praise and criticism of technology in medicine}

The continuous expansion of medical technology inspires both excitement and criticism. Enthusiasm about the rise of technology stresses the ever-increasing possibilities of treating disease, of prevention, and extending life-expectancy and improving quality of life. From the tertiary care hospital to the general practitioner's office, this expansion of medical possibilities, both in the sense of sophistication and of distribution, is acclaimed as an improvement.

On the other hand, criticism is often couched in statements like loss of the human aspects of medical care', 'treatment of physiological values instead of illness', 'making the person invisible'. This line of thought was initiated by Ivan Illich, who pointed to the increasing frequency of iatrogenic illness as a consequence of the expansion of medical technology (Illich 1975). Also, the soaring cost of health care is usually attributed to the increase in ever-more expensive forms of technology. What the fear about technology hovers around is a distinction between the human experience of disease and what, in technology, tends to threaten that human element and replace it by non-human, objectivist notions.

These points of view co-exist and physicians often feel torn between trying everything available and avoiding exaggerated dependence on technology. This dichotomy seems difficult to reconcile and often gives rise to either blanket rejection of technology or blind acceptance of everything new. The harshness of the two positions impoverishes discussions about the growth of medical technology. In this book, no position will be taken either in favour of or against this expansion, rather, the problems addressed lie before or even outside such positions. The central question of this book is: How can the relationship between medical technology and its users be described?

Both rejection and unreflective embracing of medical technology reflect an unsophisticated view of the intricateness of the relationship between the two spheres: briefly, these positions overlook what is human in technology and what is technological in what we call human. This is especially clear when one looks at the role of medical technology in chronic diseases. The question this book poses is particularly relevant for the treatment of chronic disease, where interaction between patient, physician, and diagnostic and therapeutic technology often is long-term and where, since the early Sixties, patients themselves increasingly manipulate medical technology on a daily basis.

What then is the relationship between humans (patients, physicians, families) and medical technology in chronic disease? To what extent and in which way does the use of technology include changes in relationships and behaviour of physicians as well as patients?

To what extent, to put it differently, does technology regulate and prescribe behaviour to both physicians and patients? And are such prescriptions no more than the reformulation into device characteristios of the advice physicians give to patients or does technology have a prescriptive function independent of what the physician orders? Do technological imovations, on the contrary, give patients and 
physicians a larger degree of self-determination? In other words, is technology a moral agent? In medical ethics do we have to take it into account as an agent? Would medical ethics, then, become a matter not only of the rules and principles guiding physicians' and patients' behaviour, or of the virtues a physician needs to have, but also of analyzing the extent to which technology guides this behaviour and defines these virtues?

These questions can be subsumed under the guiding question of this book: How do changes in medical technology alter the behoviour and relationships between users, either patients, physicians or others involved? How do they transform the way we are, the way we relate, how do they transform our very bodies? These questions will be asked, not with regard to large, spectacular forms of medical technology such as MRI-scanners and liver tramsplantations, but concerning the smaller, more modest techmiques and procedures found in general practice.

In this introductory chapter, three approaches to the study of medical technology that touch on these questions and to some extent take them as their starting point will be discussed. The first is the early historical and philosophical work of Stanley Joel Reiser, the second approach is represented by the research developed recently under the name of Medical Technology Assessment (MTA), and lastly the field of social studies of technollogy will be looked at. It will be argued that the latter offers the most promising tools to tackle the kinds of questions indicated above and specified at the end of the chapter.

\section{Philosophy and history}

One of the first scholars to devote large parts of his work to historical and philosophical questions concerning technology in medicime was Stanley Reiser. His early work represents a current form of philosophical criticism dealing with medical technology, because he makes use of a vocabulary in which technical objects and human beings are classified as distinct; it is the vocabulary of the 'Great Divide' between objects and technology on the one hand, and people on the other.

In his groundbreaking work, Medicine and the Reign of Technology (Reiser 1978), he seems to consider technology as synonymous with 'machinery' and discusses such devices as the stethoscope, the microscope, laboratory diagnostics and computers. He frequently opposes the language of machines to more traditional ways of gathering information about the condition of a patient such as "listening to the patient's experiences and views" (Reiser 1984). There is little doubt that in his more recent work, he extends the meaning of the term "technology" to procedures as well as to devices, but since the identificaton of technology with machines is still not uncommon, it seems useful to mention this early work.

In this book, conversational techniques will be considered no less a technology than technical objects such as an NMR-scanner, standard questionnaires, and memorized chacklists, devices used to gather information from patients. Like these impressive machines, less dramatic technology may change the way we think about disease and human suffering, and it may change the way 
people we with each other. Moreover, it may do so to a larger extent because of its widespread use in everyday medical practice.

A second, more basic opposition pervades Reiser's work; the one between diagnostic machmery and 'unaided' listening. The phrase, "I can't hear you while Im listening" (Baron 1985) is an expression of this. There is a similar opposition between technical therapeutics and compassion; more generally, the distinction between the technical and the human, although widespread and generally accepted; is, at the same time, a rather puzzling element in this type of thinking. In the introduction to Medicine and the Reign of Technology, Reiser states the following:

"[...] modern medicine has now evolved to a point where diagnostic judgments based on 'subjective' evidence - the patient's sensations and the physician's own observations of the patient - are being supplanted by judgments based on 'objective' evidence, provided by laboratory procedures and by mechanical and electronic devices. The book attempts to trace the history of how this happened, and, along with the resulting gains, points out the potential losses to the sick patient, to the physician as clinician, and to society." (Reiser 1978, p DX)

Such statements raise the problem of the definition of what is technical and what is not. Maybe drawing a distinction between technology and humanity blurs the links between the two because it presupposes some type of pre-existing humanity on the one side, and a pre-existing technicality on the other that prevent us from seeing the two as evolving together.

There is something peculiar to the historical perspective employed in Reiser's work. Reiser, to be sure, studies the 'reign of technology' from a historical point of view and describes the development of each of the technology he discusses. But his developmental scheme is one in which an innovation is essentially a modification of a previous type of a device - his history is largely internalistic. Thus, in Reiser's account, René Laennec"s prototype of the stethoscope which consisted of a rolled newspaper is followed, employing a sort of internal logic, by various other forms of auscultation devices, ending with the stethoscope as we know it. To say the same thing differently: the driving force within his history is technology itself, and it is probably just this technological determinism that leads to the fear that the caring relationship, the last resort of human values in medicine, will disappear.

Reiser's message is that, impressive achievements notwithstanding, there is a constant risk that excessive use of medical technology could quash the care and compassion that should be the basis of medicine. It is argued that medical technology, although invaluable in the treatment of disease, potentially has the negative side of destroying what is basic to medicine: the caring relationship. Physicians, Reiser says, are continuously risk treating numbers and laboratory results instead of suffering people.

In a later paper, Reiser notes, in terms remarkably similar to the ones used above, that the study of technology, be it medical high-technology or a simple device such as the blood pressure meter, should focus on "the alteration of our perceptions, the establishment of certain connections between events, the creation of a point of view about patients, illoess, and pathology, effects all the more 
powerful because unexplained" (Reiser 1986). According to Reiser, exploring this type of effects of medical technology is crucial, but there do not seem many tools available to tackle this type of questions.

Thus, although Reiser might agree that the questions that were raised in the introduction are those that ought to be studied, there is no tool to be found, in his work, to effectively start tackling them. This book endeavours to develop what might be useful tools. But before that, it is necessary to give an overview of the most influential field of study of medical technology, and a field that Reiser considers himself part of: Medical Technology Assessment.

\section{MTA: toward a policy of medical technology}

The last two decades have witnessed the creation of a new field of enquiry in medicine, Medical Technology Assessment. Another denomination in use is Health Care Technology Assessment, a name that is used by the International Society for researchers in the area. Although the latter term, because it covers medicine as well as other professions in health care, is more complete, the more commonly used former term will be used in this book.

Most Western countries have specific institutions active in this field and, as mentioned above, there is an international journal devoted to MTA. But what, to begin, is technology assessment (TA)?

"Technology assessment is seen as a comprehensive form of policy research that examines the short- and long-term social consequences (for example, societal, economic, ethical, legal) of the application of technology. Thus, technology assessment is an analysis of primarily social rather than technical issues, and is particularly concerned with unintended, indirect, or delayed social impacts." (Banta and Luce 1993, p 59)

Several elements of this definition merit close inspection. First, TA is presented as a form of policy research. It is performed to provide the information base policymakers need to determine the direction to be taken in the development of technology. Technology assessment is a tool for policy-making. It was the US Congress, in 1972, that created the Office for Technology Assessment which indicates its links to political decision-making. Second, in its original formulation, technology assessment focuses on the social instead of technical issues. In an analogy to side effects of drugs, these non-technical effects are also called secondary effects of innovations. New technologies were seen to have unintended, and, it is implied, sometimes undesired social consequences. The use of the term consequence fits into the image that technology and society are two distinct spheres that influence each other, and that there is a cause-and-effect relationship between technology and its social aspects. Apart from this, the nature of the link between the two sorts of issues remains obscure: they influence each other, but where and how they connect is unclear. One of the aims of this book is precisely to explore this interface of man and machine in an area of contemporary medicine (this point will be developed in sections 4.2 and 4.3 ). 
The definition of technology assessment given above relates to the questions outlined in the first section. Concern about the impact of technology on users and on society was the motivating factor to implement TA-research. Therefore, a closer analysis of the way in which technology assessment appronches these issues in its application to health care is appropriate.

\subsection{Technology assessment in health care}

In 1975, the Office for Technology Assessment started a health programme. According to H.D. Banta and B.R. Luce, the health benefits of medical technology were the focus of research in this field from the beginning (Banta and Luce 1993). This focus on health benefits distinguishes MTA from other forms of TA, because it implies that MTA is not only concerned with 'secondary', "undesired" effects of medical technology, but primarely with its intended effects.

Medical Technology Assessment can hardly be called an academic discipline. The existence of university chairs and a scientific journal notwithstanding, it is a conglomerate of different types of research: physicians, sociologists, economists, psychologists, epidemiologists can all be called upon in an assessment. As a consequence, it is somewhat hasardous to try to define the field. Different researchers can be expected to put different emphases on elements of this conglomerate. Thus, some consider cost-effectiveness research as the core of MTA (Elsinga and Rutten 1995), while others stress the importance of social studies of technology (Goodman 1992). It may very well be that the description given in this section shows some Dutch bias.

Moreover, according to Banta and Luce, there has been a shift in emphasis during the 25 years the field is in existence. In the Seventies, efficacy and safety were stressed, while in the Eighties, the focus was the economic aspsctes of technology. In the Nineties, they expect the emphasis to be on social aspects of technology. They state that these broad issues like the economical impact of medical technology, and societal and social effects need to be researched and studied to a larger extent. They quote a list of questions that the OTA, in a 1976 report, suggested as important to this type of analysis. A selection of the most important ones for the purpose of this book is as follows (table 1). 
What are the implication of the techwology for the patient's life?

(a) What will be the quality of life of the patient? Normally active? Moderately restricted? Physically crippled?

(b) What psychological effects can be anticipated? Guilt (because of burdens on the familly)? Anxiety? Feelings of dehumanization? Dependency?

What are the implications for the patient's famly?

(a) What will be the costs to the family, both financial and non-financial? How will the technology affect family structure? Will there be any physical dangers to the immediate: family? Will the device or the procedure be psychologically acceptable to the family? Will active co-operation or assistance of family members be necessary on a contiauing basis?

What are the implications for society in gewerat?

(a) Will the technology affect demographic characteristics of the society? [..]

(b) Will use of the technology by an individual create threats to the environment?

(c) Will introduction of the technology challenge important beliefs and values of the society about birth, gender, bodily integrity, personal identity, marriage and procreation, respect for life, right to live, right to die, responsibility for each other? Will introduction of the technology result in change in any of these values?

(d) Will the technology alter any basic institutions of society (e.g. schools, recreational facilities, prisons)?

What are the implications for legal and political systems?

(a) Will problems of justice, access, or fairness arise? Will they lead to legal action?

(b) Will the manufacturer be liable for damages resulting from failure of the technology.

(in the case of devices or drugs)?[.]

(c) Will the use of the technology require changes in legal definition of such concepts as death or suicide?

Table 1. Questions for Technology Assessment

In order to answer those questions, MTA takes the following steps: first, a selection is made of technologies that are candidates for assessment, mainly on the basis of knowledge about the burden of illness and its potential for reduction, the costs of the technology, and the size of the population affected. A quantitative model for priority setting has been developed by Eddy in the United States (Technology Assessment Priority Setting System).

The second step involves a study of the efficacy, that is, the result of the use of a technology in an experimental situation - randomized clinicall trials are considered the best method for obtaining such information. Then, as a third step, the effectiveness in non-ideal circumstances (common medical practice) is assessed. The results of the third step may be combined with a cost-effectiveness analysis. Lastly, an analysis may be made of the diffusion of the technology into medical practice.

Often, this stepping-stone approach to technology assessment is presented as a loop in which the impact of the technology on the burden of illness is re-assessed at regular intervals and a new technology is introduced at step one (Feeny et al. 1986). The process then repeats itself (the "TA-loop"). 


\subsection{Two examples of $M T A$}

Medical Technology Assessment as a field of enquiry combines a variety of approaches to study a number of questions concerning medical technology. The papers published in the last three issues of the International Journal of Technology Assessment in Health Care can grossly be divided into the following main categories:

1. questions concerning efficacy and safety of devices and procedures;

2. questions around effectiveness related to cost;

3. the diffusion, transfer, and implementation of medical technology, both in the Western countries and in poorer parts of the world;

4. social effects of technological developments, for instance concerning the quality of life of patients and their relatives;

5. ethical and legal aspects, problems of a just distribution, and the like;

6. the history and development of medical innovations;

7. general articles on the methodology of MTA.

Quantitatively, the first three categories of articles are the most important. Social and ethical effects of technology do not seem to be among the most frequent subjects for research, although in many of the articles from the other categories such elements are addressed.

In order to highlight some of the ellements that TA consists of, two examples will be briefly discussed. They were chosen because they clearly take social effects of the technology as part of the assessment.

In 1989, an MTA report on screening for cervical cancer was published in the Netherlands in which the costs and effects of different screening programmes were compared (Habbema et al. 1989). The central question of the assessment was: How often and by whom should women be recruited for participation in order to obtain optimal cost-effectiveness?

Screening for cervical cancer involves making a cervical smear according to the method developed by Papanicolau. The question of this MTA was, What is the best method of organisation to obtain the maximum effect in a population-based screening programme against minimum cost? Four types of organisational methods were compared in simulation studies; no early detection, centrally-organised detection, only unorganised early detection, and a combination of the latter two.

Social costs, in the report, were defined as "an expression of all the resources that society as a whole has to spend in order to have the programme finction". These costs, the report specifies, are not only of a financial nature, but they comprise, for example, the time women have to spend to participate in the programme. Effects are divided into gain or loss in life-expectancy and gain or loss in quality of life - the report states that the latter can only be speculated about in this type of screening programme.

The second example is a study in the area of chronic airways obstruction. Economic evaluations in this area are rare (Rutten-Van Möllken et al. 1992). In this study by a group of Swedish researchers, the following approach was taken: two types of home oxygen treatment for patients with chronic obstructive pulmonary disease were evaluted by comparison (Ström et al. 1990). The focus of the anialysis was on quality of life and coping abilities and on the differences that might result 
from using either large and potentially explosive high-pressure gas cylinders or smaller and less risky oxygen concentrators. In order to measure the overall impact on quality of life of oxygen treatment, a group of 41 patients was investigated using the Sickness Impact Profile questionnaire, which asks patients to score 136 items covering 12 "dimemsions' such as physical well-being, sleep and rest, mobility, and social interaction. For each of these dimensions, a cumulative score indicating the percentage of impairment of function was calculated. Compared with normal subjects, the use of home oxygen was associated with a significant impairment in all domains of the quality of life and there was no clear difference between the two types of equipment.

A second set of questions was devised especially for the investigation and concerned the daily management of the equipment. The list contained questions such as who handled the equipment, and how patients scored the ease or difficulty in using it. Here a clear difference was seen between the bigger and the smaller equipment, to the advantage of the latter.

In a separate investigation cost issues were addressed, the result of which showed that the smaller equipment was twice as inexpensive as the bigger and more cumbersome machine.

Several features of these examples deserve specific attention. A first conspicuous element in the two analyses is the restriction of social elements to either costs or organisational problems. There is scant reference to social aspects of a technology such as the increasing submission of healthy bodies to unpleasant medical procedures or the growing fear about insidious diseases that may go on unnoticed. Thus, many of the issues listed in Table 1 have not been attended to in these two MTA's, while the bature of both technologies would have amply jusitified doing so. In the next section it will be argued that the lack of cousideration for these social aspects reflects a general problem about the relationship between the technical and the social realm.

Second, ethical or moral considerations are scarcely addressed in both these reports. This is the more remarkable, because ethical aspects figure prominently in the original concepts of technology assessment, and still do in descriptions of the field. Again, the reason for this could be that it is problematic to integrate such elements into an assessment because the tools to do this are lacking.

As can be seen in the Swedish example, medical effectiveness, in this type of analysis, is increasingly conceptualised, not only in terms of physiological parameters, but also in terms of the quality of life of patients. At first glance, it may seem that this is exactly the type of analysis needed to answer the question of how the lives of users of medical technology are transformed in the process of its development and modification. If one wants to study the role of medical innovations in shaping the lives of people and their relationships, that would seem to be the first area to look at. Indeed, within MTA, social evaluation is sometimes equated with quality-of-life evaluatoin (Nord et al. 1993).

Let us take a closer look at quality-of-life research. Several ways of measuring the impact of medical procedures on the quality of life have been developed (Guyatt et al. 1993). They are generally classified umder the terms generic and specific. Generic measurement instruments may use general questionnaires such as the Sickness Impact Profile. Another form of generic 
instrument is utility measurement in which the usefulness of a new technology is weighed against its adverse effects and ranked on a scale going from perfect health to death:

Specific measurements try to elucidate elements that are thought to be specific to the disease in question, for example, the quality-of-life aspects of longterm medications or of dietary restrictions in hypertension. Such measures also involve the impact of semi-continuous measurement on aspects like anxiety or mobility. Quality-of-life research focuses on quality in rellation to the disease and the treatment in question; it is concerned with "health-related quality of life" (Revicki 1993).

Quality-of-life research in this form is part of effectiveness analysis. It asks to what extent the technology in question will enhance not only the duration, but also the value of the patient's life. In such analyses, the quality-of-life gains or losses of one innovation are compared with those of amother.

The investigation presented here addresses a different question. The concern is not primarely with the quality of life, but (more generally) with the sort of life that is associated with the use of medical technology. Moreover, as has been said before, the approach is different: this study focuses less on effects of a technology once it is put into use, as on the way a specific form of life is built into the technology. Thus, it tries to develop a form of, as Banta and Luce call it, prospective technology assessment (or constructive $T A$, as it is also called [Schot 1992]). It focuses on the choices that are made - though more often than not implicitly - with respect to the characteristics of the user, how she/he should behave, and so forth. It asks for the sort of life that is created within a specific type of medical practice.

Various authors from inside the field of medical techmology assessment have pointed to the fact that the focus of MTA on health outcomes meant a departure from, or at least an unwarranted restriction of, the original aims of technology assessment. Insufficient attention, they say, has been paid to what was the basis of technology assessment the social and ethical issues (Fuchs and Garber 1990; Goodman 1992, Greenfield yr?). Banta and Luce, for instance, state that the analysis of the social impact of medical technology "should be a much more active and dyniamic field of assessment" (Banta and Luce 1993, p 132). They say that the methods for describing social implications are underdeveloped and, also, that there are "few mechanisms to take action based on the results of such evaluations."

Some of the questions specified in the list cited in Table 1 are related to those formulated in the first section. They have, however, not been systematically addressed within MTA, even though, according to Banta and Luce, opinions on the social effects of technology clearly influence policy decisions. "Still, there is no body of literature that could be characterised as a serious attempt to study the social aspects of health care technology." (Banta and Luce 1993, p 140)

\subsection{Norms and values}

It was suggested, in the last section ${ }_{n}$ that the examples lacked an explicit discussion of ethical issues. The role of ethics is described by the Dutch Council for Health Research (Raad voor het Gezondheids Onderzoek) as the assessment of the extent 
to which a new technology "directly or indirectly touches upon fundamental norms, values and juridical primciples" (Raad voor Gezondheidsonderzoelk 1988). According to the Council, important ethical questions are those concerning the autonomy of patients and the choice of candidates for scarce technology. The American Institutes of Health, in 1985, made a list of ethical questions associated with health-care technology assessment: "Who is affected or is not affected by a technology? What ethical principles are involved in testing and use of a technology? What might be the unintended consequences or side-effects of a technology? How does the technology fit into larger cultural political contexts? What values affect the application of the results?" (Institute of Medicine 1985).

One of the examples of research where ethical issues were highlighted concerned life-sustaining treatment of the elderly (U.S. Congress 1987). Five types of technology, all at different levels of complexity, were assessed: resuscitation, mechanical ventilation, dialysis, nutritional support, and life-sustaining treatment with antibiotics. In the report, the ethical issues are divided into two groups: those concerning the care of individual patients, and the moral questions involved in the allocation of this type of technology.

On the level of the individual patient, the report states that the existence of sophisticated life-saving technology raises questions concerning withholding and withdrawing treatment. Some of the important ethical issues are: Who decides when to stop applying life-sustaining treatment, and Where is the frontier between allowing a patient to die and euthanasia.

On the societal level, there is an on-going discussion about who is entitled to benefit from the often expensive life-sustaining techniques and procedures. Should the financial status of the patient be considered, or should the utility of the treatment be the determining factor? And then, how and by whom should utility be established? According to the OTA report one proposal is to use age as a criterion for allocation.

In this example, the study of the moral concerms associated with medical technology is still restricted. Although more or less standard issues like decisions regarding the end of life are approached, concerns, for instance, about how such a technology affects family life, how it madifies the possibilities and responsibilities of patients, physicians, and family members, are conspicuously absent from the assessment.

Apart from that, the moral issues raised in this MTA are the ones that arise only after the technology is completed and being produced and distributed. One reason for this may be that ethics conform to the general tendency to confine MTA research to the application of techniques and procedures after they have been developed. In the language of the sociology of science and technology, it tends to treat new devices as 'black boxes' (for instance, De Wachter 1989): the devices and procedures themselves are not subjected to moral analysis, but only the conditions of their implementation and effects are. Turning technology into black boxes leaves ethicists in the powerless position of being the last experts to express their views, or, as Renée Fox and Judith Swazey have argued, of becoming a sort of moral loincloth (Fox and Swazey 1992).

What would be needed for ethics to play a significant role in MTA, is to study the developmental phase of new technology. In other words: ethics would 
have to become part of what has been called Constructive Technology Assessment (CTA), and which is "(..) based on the idea that during the course of technological development, choices are constantly being made about the form, the function, and the use of technology (...)" (Schot 1992).

This would mean a re-orientation of ethics. It would involve doing ethnographic fieldwork in laboratories and in climicians' offices, and would demand closer relationships with analysts who study the development of new technology and the functioning of a technology in everyday medical practice (De Vries 1989). It would imply that ethicists observe of the evolution of innovations. This need for closer relationships between ethnographic fieldwork and moral analysis has been argued from within the field of bioethics (Jennings 1991; Hoffimaster 1992).

To realise that goal, the division of labour between ethicists and sociologists or anthropologists of technology would need to be revised or even dissolved. In the latter fields, a subject returned to in section 4, meticulous studies of the development and function of technology in different areas have been conducted that should provide important clues to ethical investigations of medical technology.

Many researchers within the field of Medical Techmology Assessmient seem to be sympathetic to the questions raised in this book, and are, as far as possible, incorporating these issues into their research. But as has bbeen stated, the methods to do this are scarce. One of the aims of this book is to attempt to provide a tool that may be helpfiul for such research. In order to do that, this work will focus less on the social effects than on the social components of technology.

In order to do this, the next section looks to a field of research in which mainly non-medical technology has been studied: social studies of science and technology (SST).

\section{Science and technology studies}

The social study of technology, though burgeoning, is still in its youth. After a short summary of the main strands of analysis one of them, the actor-network approach, in which semiotical methods are important, will be discussed in particular. This approach, with its recent focus on the context of use of technology, offers the most promising approach to the questions posed in the first section. However it would be impossible to understand it witliout comparing it with other approaches in the same field. In the earlier years of social studies of technology the main challenge was to show how social factors affected technical developments and how they guided the innovation process, but recently, attention has been drawn to the way in which technology, by its very nature, changes and reconstructs society.

\subsection{Dynamics of science and technology}

In a recent review of what he calls socio-historical technology studies (Bijker forthcoming), W. Bijker provides a useful distimction between three approaches in the description of the development of technology: mechanist, which regards techmology development as autonomous and driven by largely internal forces (Reiser's history of medical technology falls into this category); cognitivist, in 
which the continuous emergence of new problems is considered to be the driving force behind technological innowation, and, a socio-historical approach that explains it as related, in various ways, to social phenomena. The most recent approaches of the latter strand of research describe innovation processes in terms of socio-technical ensembles, that is, mixtures of social and technical elements. Here again, Bijker distinguishes three basic types of theory. Finst, the systems approach, usually applied to larger technologicall systems and which considers technology as "heterogeneous systems which acquire in the course of their development (.) a certain autonony" (Bijker forthcoming, $\mathbf{p} 21$ ). In the second instance, Bijker mentions the actor-network approach, which will be expanded on in section 4.2. Lastly, he discusses social constructivist approaches, developed together with T. Pinch which take the imteraction between "relevant social groups and technological frames' as the two poles between which socio-technical enisembles evolve.

During the last three decades, the field has developed aside and largely independent from Technology Assessment, on the basis of historical and economical analyses of technology. In the Netherlands particularly, there were strong links with leftist political criticism of science and technology:

Until now, the development of the fielld has occurred largely through casestudies, the majority of which concern the development of industrial and military technology. Until recently, medical examples constituted a minority. This changed, to some extent, with the publication of Stuart Blume's book on the development of imaging technology (Blume 1992), Blume describes the constitution of technology like ultrasound, CT-scanning, and MRI - all examples of heavy diagnostic machinery. An example of how social and technical elements of innovation are brought together in the analysis can be seen in a brief discussion of one of Blume's examples: diagnostic ultrasound.

Ultrasound, according to Blume, was constituted as a result of social as well as physical or technical mechanisms. In the early Thirties, experiments were carried out in aireraft and submarine industries, where ultrasound was used to discover flaws in metal constructions. It moved in the direction of biological and medical imaging in the Forties and Fifties. This shift of emphasis from the metal industry to medicine resulted, according to Blume, from contact between interested physicians and physicists. These physicians came from a variety of specialisations; either cardiology, neurosurgery, or obstetrics. They were interested in creating images of the body structure that was pertinent to their specialty, either because x-rays were insufficient (neurosurgery) or too dangerous (obstetrics): In his description, Blume shows the continuous slift from technological changes - for instance, the transformation of a one-dimensional rendering of ultrasound pictures comparable to ECG-lines to two-dimensional pictures - to developments in the social, or, as he calls them, inter-organisational structures involved in developing the technology. The fact that ultrasound was developed in co-operation with various medical specialisations and not particularly with radiologists, ultimately led to its dispersion to the various hospital departments and to the development of devices adapted to each specialisation, for instance ophthalmology and cardiology.

Blume distinguishes four phases in the development of medical technologies: first, the exploratory phase, in which medical uses for ultrasound are being tried in 
all sorts of directions, most of them ultimately tuming out to be blind alleys. The next phase is development, where industry plays a major role alongside physioists and physicians: the commercial possibilities of a device will influence not only whether it will be developed, but also its content. This was particularly clear, according to Blume, in the development of what has become the calling card of ultrasound, obstetrical imaging. The possibility of developing ultrasound into the routine screening procedure in pregnancy made it extremely interesting for various enterprises, and it turned its applicability in everyday practice into a paramount concern. Blume refers to the third phase in the dynamics of technology as diffusion and assessment. In this phase a technology spreads into medical practice: companies decide to produce it on a large scale and hospital services are restructured to accommodate it. The last phase, feedback, concerns the on-going improvement of the device, and its continuous expansion to new areas.

In all his examples, Blume stresses the complexity of the interrelationship between different professions and industries that results in the constitution of a working piece of technology.

Two aspects of his work are particularly important and can be viewed as an original contribution to the study of medical technology: first, the development perspective; and second, the intricate relationship between technical and social factors in the evolution of devices. Analyses like Blume's help us understand not only the processes involved in the development of new technology, but also which social elements motivate the direction an innovation takes. The phrase used to describe this and similar historical approaches is 'opening the black box'. The main advantage of these studies is that they show that medical technology "might have been otherwise" (Bijker and Law 1992). That is, as was already suggested, the promise of Constructive TA.

With regard to the devices and procedures analyzed in this book; studies like Blume's can be helpful in showing the various points at which their development took one direction rather than another. Different versions of devices that were tested out during the exploratory phase can be discussed and the success of one of them can be explained, not so much as the result of its intrinsic qualities, but as the outcome of technical and social processes. Distribution can be discussed in order to outline the forces needed to ensure that a device reaches its proper destination. And finally, the importance of feedback in the further development of a device can be analyzed.

All this is helpful in showing what goes into the production of medical innovations in terms of technical problem-solving, scientific theories, and distribution. This book will, at some points, follow a line that resembles Blume's, but for one important point: it will leave out all attempts at giving social explanations for technological developments. The reason being that the hypothesis of this book is that social and technical developments are simultaneous, they are part of the same innovation process, consequently, neither can systematically explain the other. The next section turns to another promising approach which is based on this assumption, the semiotics of technology as it has been developed within the framework of the actor-network theory. 


\subsection{Actor-networks}

One of the most distinctive strands of social studies of technology is the actornetwork approach. It is often referred to as Actor-Network Theory (ANT), but this seemis too broad a title which even contradicts some basic tenets of the work done from this perspective. Instead of being an actual theory, the concepts of ANT provide a heuristics. Thus, it would be preferable to refer to an actor-network approach or, to remain in the technological vocabulary, the tool box of actortietworks.

The following description is given of the term actor-network:

"The structure and operation of an actor-world: an interrelated set of entities that have been successfully translated or enrolled by an actor that is thereby able to borrow their force and speak or act on their behalf or with their support. The entities may be seen as forming a network of simplified points whose simplicity is maintained by virtue of the fact that they are juxtaposed with others. The actor who speaks or acts with the support of these others also forms a part of the metwork. Hence the term actor-metwork, for the actor is both the network and a point therein. [..]" (Callon et al. 1986, p xvi)

Actors are defined within the network, but the network is defined by the actors: "[...] for any given actor, there is nothing beyond the network which it has created, which constitutes it, and of which it forms a part".

Basic to the work of researchers at the Centre de Sociologie de l'Innovation in Paris, the cradle and principal home of this approach, is the importance attached to ethnography. The relationship between social actors and technollogical development, their fundamental tenet says, can best be grasped in careful observations of engineers at work. Research has been devoted to writing ethnographies in such disparate fields as public and private transport, scallop fishing, and electricity supplies. To date, no medical innovations have been investigated with the tools of this approach, and therefore the examples mentioned in this section will be non-medical.

One of the discoveries resulting from fieldwork was the impossibility of distinguishing clearly between social and technical factors. Observing engineers in the process of designing an electric car, Michel Callon noted that they were continuously mixing sociological ideas with technical ones (Callon 1987). Thus, the creation of an electric vehicle, according to Callon, is not limited to finding an appropriate set of material elements (batteries, engines, car-bodies), but also involves 'designing" new types of vehicle-users: for example, users are supposed to agree that environmental issues will have to take precedence over speed. Callon states that what these engineers essentially did was create a network of heterogeneous entities; batteries, consumers, electrons, car manufacturers, and so forth. Therefore, technical innovation, in this approach, becomes identical to network-building.

But the networks that are depicted in this type of analysis are somewhat strange and even counter-intuitive; again, no distinction is made between human or social elements on the one hand and technical or material ones on the other. 
'Network' is a rather specific metaphor. It is difficult to find an explicit justification as to why this term and not 'system' or 'organisation' was chosen, but possibly two advantages were important. First, networks are non-hierarchical, the image is one of a flat, egalitarian complex of relationships.

The second advantage is that network is an 'empty', abstract metaphor. For that reason, it is a fruitful heuristics because it does not exclude beforehand any type of elements from being part of the ensemble.

As a consequence of their symmetrical treatment of human and non-human elements, actor-network sociologists state that neither social nor technical factors can satisfactorily explain innovation because neither remain stable during the process. Callon ends up calling the innovators engineers-sociologists (maybe engineer-politician would have been the better term?) and goes so far as to consider the sociology of these engineers on a par with that of one of France's most respected academic sociologists, A Touraine.

The realisation that it is difficult or impossible to distinguish, except with hindsight, between social and technical elements within a technological development has become a basic tenet of actor-network heuristios. At the same time it is this characteristic that has been attacked most: the abolishment of firm distinctions between what is human and what is teclunical in a given technological situation. If any such distinctions apply, actor-network theory says, they have to be regarded as the result of rather than as an explanation for technology development. Technical objects and human beings (and in some cases animals (Callon 1986) and microbes (Latour 1988)) are described, in this vein, as being active elements in technical innovation - they are all actors. Their role and place in the network is defined by their relationship to other actors; devices define and regulate the roles of other devices, but also of human beings; and vice versa, the devices are defined and regulated by their users. In this book, an attempt will be made to show how the peak flow meter, for instance, defines the role of the physician in the treatment of asthma as much as the opposite, the physician defining the role of the device.

It is the - sometimes polemic - use of the term actor for both human beings and objects in the actor-network appreach that has come under attack. It has also contributed to a certain dislike of the actor-network approach within SST, where 'French jargon' is the qualification the actor-network vocabulary sometimes receives. The use of the term 'actor' or 'actant' stems from semiotics, notably from the French-Romanian semiotician A. Greimas, who defines an actant as any element of a story that "can be thought of as that which accomplishes or undergoes an act" (Greimas and Courtés 1984). An actant can be a human being, a collective, or an object. Clearly, the term 'actor' as used in actor-network approaches is derived from the concept of an actant. To avoid the kind of misunderstandings that the term 'actor' invokes, actant will be preferred in this book.

The use of the actant concept frees the actor-network approach from any social or technological determinism, or, for that matter, from any type of determinism tout court. According to this approach, innovations are co-evolutions of characteristics of devices and their users. In the words of Callon, investigations in social studies of science and technology should focus on "the simultaneous production of knowledge and construction of a network of relationships in which 
social and maturall entities mutually control who they are and what they want ${ }^{\text {t" }}$ (Callon 1986, p 203). The relationship between elements of socio-technical networks are by nature semiotical, they mutually and simultaneously define each other instead of causing one another.

\begin{abstract}
"Semiotics", Latour and Akrich write, "is the study of how meaning is built, but the word 'meaning' is taken in its original non-textual and non-linguistic interpretation: how one privileged trajectory is built out of an indefinite number of possibilities; in that sense, semiotics is the study of order-building or of path-building and may be applied to settings, machines, bodies, programming languages or texts; [..]" (Akrich and Latour 1992, p 259)
\end{abstract}

The different stages of an innovation have been described by Latour and others as the continuous attempt to translate human characteristics into those of machines (Latour et al 1992). In the example of the electric vehicle, the wishes of carowners as well as their objections are translated into a stronger battery. At the same time, the demands of an electric vehicle are translated into the characteristics of the social actors involved. Renault, to retum to Callon's example, is required to give up its long-standing aspirations to be Europe's foremost manufacturer of conventional cars in order for the electric car to be developed.

In a text on seat-belts, Bruno Latour states that the resistance to wearing seat-belts may be overcome either by verbal injunctions, or by translating these into, first, beeps and warning lights, and, if that does not work, into a device preventing the car from starting when belts are not wom (Latour 1992). This has also been formullated as an element of the design, within devices, of programmes regulating the behaviour of users. The development of the device, then, is regarded as a series of reactions to anti-programmes on the part of users. The programme of red warning lights is to induce the driver to wear seat-belts. The antiprogramme is to ignore them. The next programme, 'continuous beeping when belt is not worn', persuades the driver to put on the belts, and again, the driver may either ignore or circumvent it. Thus, the development of technology is described as a continuous alternation of programmes and anti-programmes.

The difficulty with using of terms like programmes and anti-programmes is that they suggest the presence of an intention to regulate behaviour, and, on the other hand, to resist such regulation. The intentionalistic overtone of this wocabulary is a contradiction of the basic premise of semiotic analysis which considers artifacts as actants in their own right, instead of an expression of their makers' intentions. If, like engineers, physicians, and patients, devices are actants, then they regulate the behaviour of their human counterparts as much as the contrany - making an intentional term like 'programme' difficult to apply.

Another objection can be raised against using the couple programme - antiprogramme to describe what could be called the dialectics of innovation. That is that divergent and nonconformist uses of technical devices do not necessarily have to be called anti-programmes. Instead of using this negative term, which seems linked to the ideal of a smoothly functioning programme, there is the possibility of regarding them as inventive and largely unforeseeable ways of dealing with technollogy. 
It is important to note that, in this type of description, the term translation is used in a somewhat idiosyncratical way. It does not refer merely to the process of saying the same thing in a different language, but involves two important other elements: first, it most often, although not always, as will seen in chapters 6 and 7 . involves a change in medium; from language to things, from verbally-expressed interests and desires to the material elements of a device. Second, translation encompasses the physical sense of shifting; thus, translations, almost inevitably, are also transformations. This is clearly illustrated in the phase of diffusion of a device or a technology. What a device does, how it works, and what it looks like, are constantly negotiated as it spreads to new practices. "Translating interests means at once offering new interpretations of these interests and chamnelling people in different directions." (Latour 1987)

The building of a socio-technical network involves, as Callon calls it, interesting people and things, showing that adhering to the network would make a difference for them. The root of the term is 'inter-esse', which means being in between'. Building a network implies placing an actant in between another one and its goals and desires. Thus, the goal of the elements of the network is to become what is called 'obligatory passage points' for each other. Building the electric car involves establishing the fact that the conservation of the environment necessitates passing through just this particular device, and it entails showing Renault that becoming the champion car-maker involves passing through making the right battery for the electric car.

The use of concepts like obligatory passage points may represent networks as inherently stable. Recently, the actor-network programme has been criticised for an implicit predilection for stability, exemplified precisely by the use of terms like 'network' (Brown and Lee 1993). More specifically, V. Singleton and M. Michael; in their work on cervical screening programmes in the UK, argue that very fow passage points in the practices they describe are in any strong sense obligatory (Singleton and Michael 1993). If these practices are to be called networks at all, it would only be in a very 'fluid' sense (Mol and Law, forthcoming).

The shaping of a network like the electric vehicle is not finished once the object is sent into the world (which never happened in this case). The strength of a statement and the effectiveness of a technology are always in jeopardy. There are many ways the programme embodied in a piece of machinery may be obstructed (Latour 1992). Actants that look like reliable parts of a socio-technical network are at risk of being hured away ('interested') into another network. In other words, once a network has been constituted, its components have to be kept in line, they have to be made compliant (Law 1986), to use a term familiar to doctors, and the subject of a separate chapter in this book.

As has been stated previously, the idea of considering things as actors in a technological development has given rise to heated discussions, mainly directed at the alleged anthropomorphism, that is, giving now-human elements human characteristics (Collins and Yearley 1992). Suggesting that batteries and electrons are actors in the actor-network of the electric vehicle appears to attribute to them plans, or a will, or other psychological characteristics usually reserved for human beings. Or, inversely, it suggests that human beings, in this type of analysis, are stripped of these properties and regarded as little more than inanimate actors. 
The main argumemt of Latour and Callon against such criticisms is that a serious anthropologist of science and technology has no reason to take any distinction for granted, not even that between what is essentially human and what is not. The world, they say, consists of actors of various sorts, and any definition of an actor, as powerful or powerless, human or non-human, stupid or intelligent, as provided with volition or not, is negotiated within these networks (Callon and Latour 1992).

\subsection{The user in the device: scripts and scenarios}

Whereas the initial work in ANT was developed to describe the process of technological innovation, more recent studies have investigated the context of use, more specifically the manner in which proper use of the device is ensured. The most obvious way this is done is by providing written directions. A step further is the incorporation of these directions into the device itself. The focus of some of the research within ANT is on this process, in which technical objects set the standards for human behaviour and help to reinforce them.

Artifacts, as Akrich (Akrich 1992) has set out to show, ensure being used properly by incorporating within them scenarios or scripts. They contain, in other words, inscribed users; the characteristics of the people that are going to use them are inscribed into and distributed together with the artefact:

An example Latour uses to illustrate this approach is hotel keys. If a hotel owner wants to keep the room keys on the premises, he has several options: he may entreat his guests to leave them at the desk; or he may put a sign to remind them every time they go out; or, and that is the technologically more sophisticated solution, he may inscribe his wish in the key by attaching a ball-shaped weight to it, which makes it uncomfortable to stroll through town in possession of the key (Latour 1993). In this way, the hotel owner inscribes a scenario into the object, which tells the hotel guest exactly what to do.

This type of analysis has strong links to linguistics and the analysis of texts. What is original to this approach is the use of methods, which were developed in the investigation of language, to study objects and artifacts. 'Read the device as a script' is the basic idea which is indebted to the work of another semiotician, $U$. Eco. In various texts, Eco has developed the concept of an "Ideal Reader", who is, in his view, constructed together with the text: "[..] prévoir son Lecteur Modèle ne signifie pas uniquement 'espérer' qu'ill existe, cela signifie aussi agir sur le texte de façon de construire." (Eco 1985) Eco goes on to suggest that the construction of the ideal reader may involve different degrees of freedom; some texts allow for one type of reader only, others grant their readers a wider scope of possibilities.

The semiotics of technical objects is essentially looking for the 'Ideal User' that is produced with the device. Thus, it may help to bring ethics back into the realm of SST. If devices contain behavioural prescriptions for users, then they might be considered moral actors as much as human beings, as Akrich has shown in the example of an electricity kit installed in Guatemala which demanded from its users a certain constancy in electricity consumption (Akrich 1992). Users of the device were persuaded to become rational energy-users, not by discussion and moral argumentation, but by what these kits dictated. 
This is a crucial point: a user representation is inscribed into a device which, in performing its technical function, also performs (in Austin's sense [Austin 1975]) this representation. Moreover, Latour's sometimes suggests that, in general, devices are more reliable than moral arguments in performing this task (Latour, in press); thus, cautioning a patient to adhere to a treatment for elevated blood pressure could be less effective than giving him a blood pressure meter for home use.

However, there is no need to suppose, in principle, a difference in effectivity, and indeed, there is a danger in that supposition: it reintroduces technological determinism on the user level. Users rarely comply entirely with the programmes that are part of machines. As is illustrated in the case-studies in this book, they tinker, experiment and invent creative usages of all kinds, and they may at times comply more readily with spoken or written advice.

The core of the work developed in this book will be semiotical in the sense described in this section: it looks at the way texts and devices lay out new connections or modify existing ones between both human and non-lhuman elements of medical practice. It is in this sense also that varying elements of medical practice will be described, sometimes in a somewhat unusual way, as actors in their own right.

\subsection{Material culture}

The work presented in this book owes a great deal to the semiotical branch of science and technology studies. However, it also has links with other strands of research in philosophy as well as in the social sciences. One field of study which is congenial to this book is archaeology.

In archaeological investigation, or, more generally, the study of material culture, objects are the focus of investigation. "Too seldom", the editors of a collection of essays in this field state, "do we try to read objects as we read books to understand the people and times that created them, used them, and discarded them." (Lubar and Kingery 1993) Objects, here, are presented as mirrors of social and cultural institutions that can be read like stories in a book (Rahtz 1991). They translate social reality. Since translation is always in part interpretation, the objects can be said to interpret us and our institutions in the same way we give meaning to the objects. Apart from this theoretical convergence, what can be learned from archaeology is the ability to reconstruct a world from an object such as a potsherd and its environment. Like archaeologists succeed in describing past civilizations from a few scattered objects, technology studies try to understand regions of modem culture from the artifacts they produce.

\section{The question: technology and its users}

In previous sections, an approach has been outlined in which to study the relationship between medical technology and its users. The main characteristic of this approach is that both the development and the use of technology are regarded as simultaneously technical and social developments. The development and 
distribution of new devices and procedures in medicine cam best be described as the development of a socio-technical ensemble. The most conspicuous property of such ensemibles is that their constituents mutually define each other's role and place. The physician defines the role of the patient and vice versa, the patient defines the role of the diagnostic device and vice versa, the device defines the role of the physician and vice versa. Viewed abstractly, any element of a network has equal definitory power over any other. In less abstract networks that will be described in this book, this is not necessarily the case. More often than not, one element takes precedence over the others. The value a network approach lies in the fact that it shows such differences to be historical, the result of developments, negotiations, and struggles.

In socio-technical networks, neither the human nor the technical side is stable. Instead, developing an innovation involves the transformation of materials and objects as well as human beings. Contrary to most of the work on the social impact of technology, including that done in MTA, there is no hypothesis of a stable set of relationships between people that technology impacts on. Human relationships, this approach supposes, are made and transformed in the very process of technology development. Technology development, then, is not regarded as the cause of changes in society, norms and values, but these changes are considered a part of one socio-technical process.

A heuristics like this, which harbours no preconceptions about the relationships between human beings and technical innovations is likely to be a powerful tool for the study of such relationships. It provides the possibility of exploring what has been depicted, in section 3 , as uncharted territory, the area where technology and user are adapted to each other. As will be seen in the remainder of the book, such adaptations may go into the very structure of the body. This approach may assist in understanding the links between human beings and techuology and provide a way out of the dilemma of either embracing or rejecting the 'technological drive' in medicine.

\section{Aims, materials and methods}

Although the theoretical framework of this book stems from SST, it distinguishes itself from the usual work in that field in one important sense: it does not take a piece of technology or a technological system but a clinical syndrome as the starting point of analysis. The focus is not on bicycles, nuclear missiles, subway trains, echography, nor is it on lung function devices or inhalation machinery, it is on chronic obstructive lung diseases. This means that the techinical and social ramifications of a socio-technical ensemble are not described in their own right, but rather a part of the network of different technologies that is connected to this particular dissease.

Taking a disease as the starting point has important consequences. It requires studying an array of different types of technology involved, and it means abandoning the focus of SST on straightforward material techinology and studying technologies that are less obviously material, such as compliance enthancement and self-management programmes. Only recently, researchers in the field of SST have devoted themselves to what they call social technology (Pinch et al. 1992). In this 
respect, Social Studies of Technology lags behind Medical Technology Assessment, where procedures and guidelines, and even the health system as a whole are taken to belong to medical technology, and consequently subject to assessment.

In this book then, the role of various types of medical technology is studied in a well-defined, but still large segment of medicine, the management of obstructive lung diseases in general practice. The approach used is a version or translation, to remain in the proper terminology, of the semiotics of techinology described above.

The method employed in this book is entirely qualitative in nature. Although quantitative research may be important in the field of technology and semiotics, the main reason for choosing a qualitative approach is that no earlier work in this direction has been done in medicine. But 'qualitative' is too general a term. The analysis of texts and objects in this book incorporates three different approaches. First, in each chapter, one or more typical case-studies of the practice involving the techinology will be examined. They will serve as examples but also illustrate and specify the questions posed in the chapter. Second, most chapters include a literature search done either by electronic means (MEDLINE), or by more traditional means, such as searching on the basis of review articles. The latter approach has especially been used for phillosophical and sociological texts. Lastly, most chapters contain a brief description of the history of the device or procedure that is studied.

In a study of six of the most common technology incorporated in the diagnosis and management of chronic obstructive lung disease, different scenarios and ontologies that emerge with the use of them will be analyzed: scenarios for the behaviour of physicians, patients, family members and other people involved; ontologies of disease, of lungs and airways, but also of doctors and patients. 'Worldmaking', to use the term introduced by the philosopher Nelson Goodman, (Goodman 1978) is integral to making and introducing medical innovations. Technology performs not only in the sense of fulfilling its defined function, but also in the sense of realising scenarios and making them work.

\section{I Breathlessness}

The case-histories in this book will be taken from the area of obstructive respiratory diseases. These diseases, also called asthma, chronic bronchitis and emphysema, are among the most common chronic diseases in the Western world. In the Netherlands, frequency estimates indicate a prevalence of about 8 per cent of the population younger than 65 years, depending on what is defined as a diagnosis of the disease (Stuurgroep Toekomstscenario's Gezondheidszorg 1990).

The main complaints associated with obstruetive airways disease are episodic or continuous breathlessness and coughing, with or without sputum production. There is a wide scope in the seriousness of these symptoms, ranging from short episodes of coughing to living in continuous need of oxygen supply.

Diagnosis is not established at one point in time: one episode of breathlessness or coughing is never enough to confirm it. Only after repeated 
episodes would a physician diagnose obstructive hung disease and order further investigations. Currently, the disease is mainly treated with drugs that can be inhaled.

Various aspects of the disease make it a very attractive area for sociotechnical fieldwork. First, its prevalence: the number of people diagnosed as having chronic airways obstruction is expected to rise considerably in the coming decades due to various factors, among which is a raise in attentiveness in the medical profession. Second, both the diagnosis and treatment entail the use of several varieties of medical technology, both by the physician and the patient. Lung function and inhalation are areas where the miniaturisation of medical technology is well under way, (Steering Committee on Future Health Scenarios 1988) making these diseases an interesting field for technology studies. Diagnosis and monitoring usually involve some sort of lung function analysis, most often peak flow measurement.

Peak flow meters, the subject of chapter 3, are small, simple devices designed for usage by patients at home. The changes these devices have helped bring about in the distribution of diagnostic skills and responsibilities between physicians and patients will be elaborated on in chapter 3 .

Once airways obstruction has been diagnosed, treatment frequently involves the inhalation of either bronchodilators or anti-inflammatory drugs. In the last decade, a variety of sophisticated small inhalation devices have been developed. Chapters 4 and 5 call into question the forms of treatment; the former concentrating on the inhaler devices, the latter discussing the different forms of drugs, focusing on what they reveal about the disease, the airways, and their relationship.

Another aspect of airways obstruction which makes it an interesting subject for technology studies is the long-term character of medical interventions. Persons with airways obstruction are required to use drugs for long periods, often for years, regardless of complaints and symptoms. Long-term treatment is known to generate the problem of patient compliance. The desire to improve patient compliance with treatment regimes has led to the creation of a technology of its own that will be discussed in chapter 7 . This will be an occasion to test the semiotic approach to technology on an example that is not, at least superficially, a material technology. Medical practice, in this chapter, will be described as a technology of long-distance control.

The same applies to monitoring techniques, a form of technology closely linked to compliance improvement but which focuses on the airways instead of people. How can lung function be kept ander control to allow for quick intervention when signs of deterioration are present? For this purpose various types of self-management programmes have been developed. These will be the subject of chapter 6 . Here, the focus will be on the type of diagnostic practice generated in this form of semi-continuous diagnosis.

\subsection{Studying one's own practice}

One of the peculiarities of this book is that its author is actively involved in the practices that are described. This is a well-known problem in the sociall sciences 
(sociologists often study the society they are part of) and it is not entirely unknown in medicime: until quite recently, physicians started their research with experiments upon themselves or upon next-of-kin. The results often were the starting shot for further research.

Thus, in the moming, the author would find himself instructing a patient in the use of a peak flow meter and in the aftemoon he would strive to uncover the built-in scenario that had been guiding them. This, however, did not prevent him from using it again, the following morning.

Stated this way, it may appear as if the book's research has been based on introspection, this, however, is not the case; the focus is on the devices and procedures used. But even so, the question of nearness versus distance that is common to fieldwork in sociology (Hughes 1960) is raised, with the difference that instead of struggling to become close enough to understand the practice under scrutiny, research in one's own practice carries the risk of being too close to what is going on to see the relevant features. Being an insider has the advantage of knowing the field, but the potential disadvantage of taking too much for granted. As a general practitioner, I often have to keep the black boxes shut that, in this book, I have been trying to open.

There is another study that was done from the same position: Ken Bassett, a Canadian physician and anthropologist, has studied the use of an electronic fetal heart monitor in the hospital where he was working. He writes: "The problem with this type of analysis was not overcoming strangeness or understanding strangers, rather the problem was familiarity and how to make the familiar strange." (Bassett 1993, p 30) He is not explicit, however, about how this problem was overcome. The way in which this was avoided was by having every chapter be read at least once by persons from outside the medical profession. 


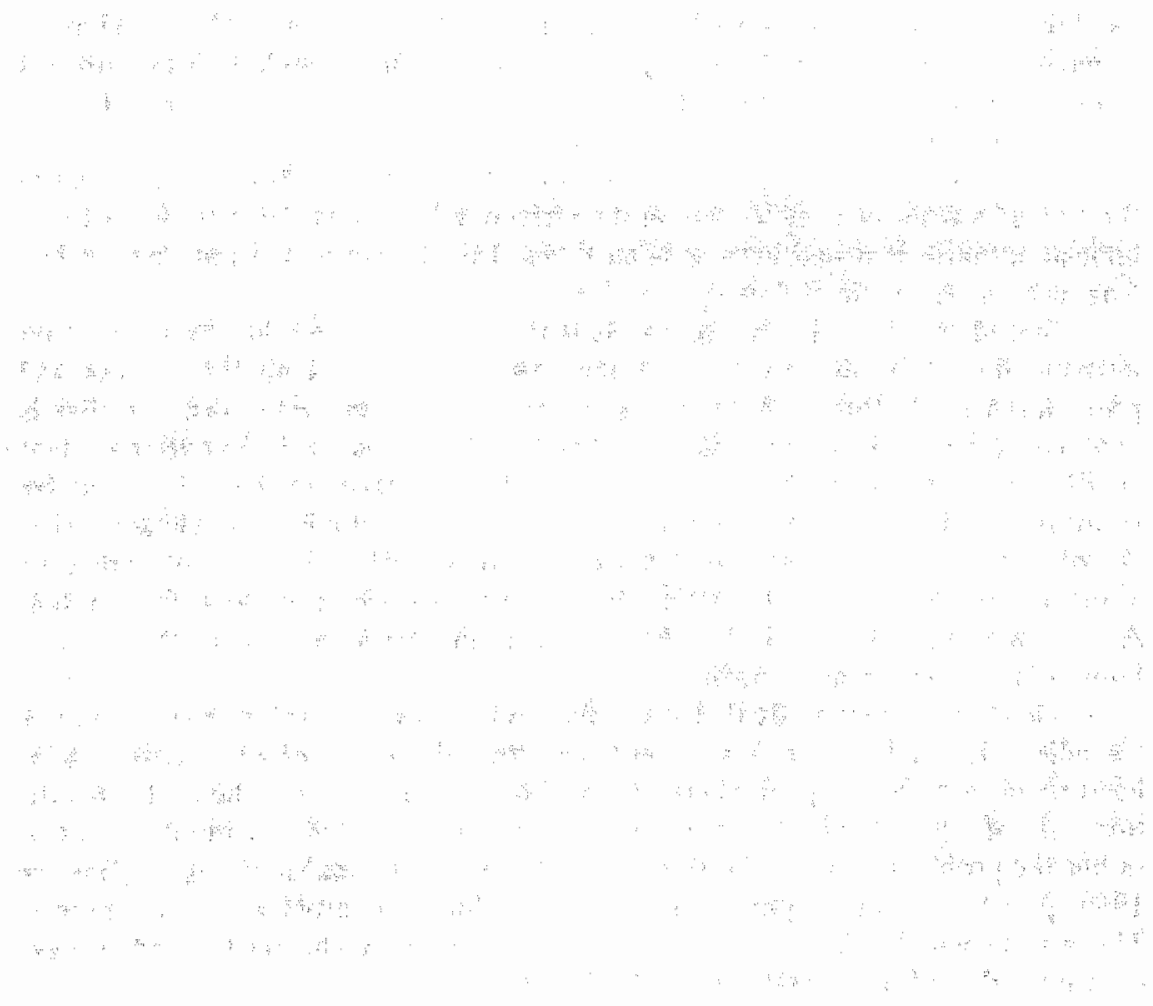


"We were to consider, you will remember, some cases and senses (onily some, Heaven help usl) in which to say something is to do something; or in which in saying something or by saying something we are doing something."

(Austin, 1962)

\section{Names for a disease}

\section{Introduction}

Since the beginning of Western medicine, asthma, primarily been characterized by breathlessness, has figured among the most important diseases (Keeney 1964). In the second century AD, a disease called 'asthma' was described by the Cappadocian physician Aretaeus: "If from ruming, gymnastic exercises, or any other work, the breathing becomes difficult, it is called Asthma; and the disease Orthopnoea is also called Asthma, for in the paroxysms the patients also pant for breath.(.) The cause is a coldness and humidity of the spirit (Pneuma); but the materiel is a thick and viscid humour." (Aretaeus 1856)

In Greek, the word asthma means "being out of breath",'panting'. Aretaeus distinguishes two forms of asthma that, until the 20 th century, have been referred to as bronchial and cardiac asthma. Nowadays, the unqualified term asthma is mainly used for pulmonary symptoms due to disease of the airways.

At the same time, asthma gradually became distinguished from other pulmonary diseases which may involve shortage of breath mainly chronic bronchitis and emphysema. Chronic bronchitis refers to an inflammatory process, whereas emphysema indicates a loss of elasticity of the lungs. These three terms have been, for a long time, among the tools for determining a diagnosis and deciding upon a treatment for the patient, and many physicians still use them in their daily practice (Pride et al 1989).

However, since the end of the Fifties, a growing number of lung specialists expressed dissatisfaction with the words asthma, chromic bronchitis, and emphysema. They discovered that the use of the terms varied greatly, and they were concerned that the inaccurate employment of the terms would become an obstacle to the scientific study of hing diseases.

From the Sixties until now, defining an appropriate terminology for obstructive diseases of the airways has been a priority of pulmonary medicine. And the discussion is not yet closed, as was witnessed by a 1989 symposium organised by the Nederlands Astma Fonds (Netherlands Asthmia Foundation) on the subject of differences between asthma and the other obstructive hing diseases, where a number of important specialists in the field gathered. A more recent example is an article in the Nederlands Tijdschrift voor Geneeskunde (Dutch Joumal of Medicine) which specifically discusses the terminological issues (Van Schayk 1994).

The history of the asthma concept has been studied from a sociological point of view by John Gabbay. Concentrating on the work of Sir John Floyer in the beginning of the eighteenth century, he argues that the different forms of the concept reflect or embody the social origins of their designers. Medical concepts, 
he states, are "deeply rooted in, and formed from, their author's general worldview, itself part and parcel of social, cultural and historical circumstances." (Gabbay 1982) At the end of the article, Gabbay writes that it is extremely difficult to describe precisely the link between the social world and medical concepts.

Gabbay's approach is different from the one followed in this book. He tries to explain medical concepts from their social environment, thereby assuming a causal relationship going from social elements to medical concepts. In this chapter it will be argued that the production of medical classifications and social orderings are one and the same process.

Before formulating the questions this chapter addresses, two related casehistories may serve as an illustration of the role terminology plays in everyday consultations.

Said is a fourteen-year-old Moroccan boy who was born in The Netherlands and who, until he was six years old, was an infrequent visitor to the general practitioner's office.

The first time his mother took him to the doctor for respiration problems was at the end of 1986. He was coughing and sniffing and with the aid of his stethoscope the physician could hear some wheezing over his lungs. Said was diagnosed as having a common cold which subsequently developed into bronchitis and was treated with an expectorant.

After five consultations during the following year, in which coughing and tightness of chest alternated, the physician explains to Said's parents that the boy might be suffering from a disease named CNSLD, previously called asthma. He adds that he had hoped to be able to covoid this diagnosis, since it means that Said's disease will stay with him for a long time, possibly his entire life. In december 1987, the abbreviation 'CNSLD' is written down in the patient record and an inhaler device containing bronchodilators, to be used four times daily, is introduced in the treatment of his complaints.

John comes into the office complaining of increasing breathlessness on exertion. Although he is fifty-six-years old, as a trainer of the local junior football team, he has always been able to join in the games. Since a few months, we feels that his endurance has decreased. Initially, he attributed it to the effects of age, but soon recognised that if the problem continued to aggravate at this rate, in a few months, he would no longer be able to train his boys. Moreover he had developed a nasty cold which made him cough almost continuously with production of slime. Because of this, he has been forced to stop smoking his daily pack of cigarettes - which he supposes his doctor will not disapprove of.

When asked whether he has had periods like this before, he answers in the affirmative, but never as bad as this. Every three or four months, he feels a shortage of breath which lasts for a week or two, but he never thinks it is severe enough to visit a doctor for. He dimly remembers having had similar periods when he was one of the juniors footballers himself.

John is examined by his physician in the same way as Said: a stethoscope is moved over his chest and the doctor tells him he hears wheezing all over his 
lungs. He actwally has a serious bronchitis. "Moreover," his doctor sals, "upon hearing your story, I am inclined to see this episode as part of a long-standing problem, you might howe CNSLD. In plain wards: I am afraid you have a chronic problem in your ainways. To be sure about that, however, further investigations are necessary, but for the moment, $I$ will treat your problem. We will talk about the rest in a week"

There are obvious similarities and important differences between Joln and Said. The former is fifty-six-years old, the latter only fourteen and could be one of Jolnn's football players. Both of them complain of breathlessness and coughing; John smokes cigarettes, Saild doesn't. Both are treated with bronchodilators through an inhaler. They are both, although with considerable caution, labelled with the same acronym: Chronic Non Specific Lung Diseases, CNSLD (in Dutch: Chronische Aspecifieke Respiratoire Aandoeningen, CARA).

This latter point is particularly interesting because it is a local or, more precisely, a national similarity between the two patients. John and Sald would almost certainly have received different labels in countries outside the Netherlands and the Dutch-speaking part of Belgium. In English- and French-speaking countries John's condition would have been called Chronic Obstructive Pulmonary Disease (COPD) or chronic bronchitis (Pride et al. 1989) while Safd would probably have been told that he was suffering from asthma.

In mildly-afflicted patients like Said, the term CNSLD is mot used readily. The very definition of the disease prevents this; symptoms like coughing and breathlessness should be present at least five times a year (Dirksen et all 1992). But even though such was the case with Said, his general practitioner felt reluctant to call him a CNSLD-patient. Using this term in reference to his complaints meant saying that he had a chronic disease. This entails the start of long-term medical treatment, it often means considerable adaptations in the home-environment, and, possibly, changes in Saird's activities. Given the initial uncertainty surrounding the diagnosis, the physician faces a dilemma: should he make a diagnosis for which evidence is available, but which is far from conclusive, and, moreover, has considerable consequences; or should he simply treat the illness and postpone the more drastic labelling?

The first question addressed in this chapter is: Where does the term CNSLD, with the differences and identities it performs (see chapter 1, section 4.3), come from, and how did it install itself in the practice of this particular physician? The second, more important one follows from the first: does it make a difference whether doctors speak of asthma or of CNSLD? As in Saïd's case, it could very well be that the $\mathrm{C}$ of chronic would make an important difference.

The third question refers to the types of chronicity that are constituted by introducing this new terminology. One of the problems is what criteria should be used to decide about the sameness of apparently different diseases; symptoms, pathophysiology, or the natural course, and what should determine the differences between prima facie identical ones.

The terminological discussions that will be analyzed here are frontier skirmishes in which the disputed borders are those that distinguish obstructive lung diseases from other, similar diseases on the one hand, and those that establish 
distinctions within the group of diseases, on the other. We will see, moreover, that drawing boundaries around and within CNSLD involves another distinction: the one between medical practice and medical science.

The creation of a terminology is one possible way of drawing frontiers, in subsequent chapters it is shown that the making of devices is another. This chapter suggests that the very denomination CNSLD helps persuade physicians to follow a specific line of action. Thus, the term is a tool, it is an instrument to separate and bring together patients; symptoms, and lung function results. It is, in other words, a technology that lends itself to the type of study that was presented in chapter 1; semiotical anallysis. Terms organise a world, they organise the lives of people; whether a physician uses the word asthma or the acronym CNSLD not only inffuences his velocity of speech, but it has an impact on the organisation of the life of the person the label is attached to.

This chapter begins with a description of the controversy as it still rages (admittedlly, the raging sometimes resembles murmuring) and proceeds to discuss the way the terms have been transported and translated into Dutch general practice and ends in a discussion of the differences the use of this terminology can make.

\section{Pulmonology "mired the mud of semantics"}

In the beginning of the Eighties, while discussing the definitions of asthma and chronic airways disease, a pulmonologist asked "What is this thing called love?", thereby exemplifying his view on the difficulty or even impossibility of defining asthma (Gross 1980). The world of airways disease is full of "anachronistic acronyms", another author complained (Kanner 1978). "What's in a name?" was the title of an editorial in one of the leading American journals discussing the same issue (Petty 1978). All these articles started by stating that terminology in the field was in a dismal state, and that researchers from different centres ran a fair risk of misunderstanding each other because they used different diagnostic labels. Research results, as a consequence, were difficult to translate from one place to another. This was the state of affairs in the Eighties, and, though with some differences, is still so in the Nineties.

The debate was launched almost four decades ago when various publications showed a lack of coherence in the terminology used by different hospital centres for airway diseases:

"In 1959 one of the writers lectured in Chicago on the clinical picture of chronic bronchitis in Great Britain and the other, on hearing him, came to the conclusion that there was little difference between the description of patients attending a 'bronchitis' clinic in London and those attending his own "emphysema' clinic in Chicago" (Fletcher et al. 1964)

In the subsequent investigation carried out in the two clinics, there proved to be little difference between their patients, even though different diagnostic labels were used. The authors conclude that "the distinction between British bronchitis and American emphysema is largely semantic." 
Their study was one of the first attempts to organise terminology in chronic lung disease, a terminology that was, as lhad been stated, in a state of confusion.

The terminological confusion was the reason, in 1958 , to convene a conference devoted to aligning the various uses of the word emphysema in relation to bronchitis.

"At present the word emplyysema is used to indicate various morbid states of the lung differing widely in their pathology, symptomatology, and prognosis. This results in confusion and misunderstanding between imvestigators working in different centres and in different branches of medicine and thus retards advance in knowledge of a group of common and often seriously disabling diseases." (CIBA Guest Symposium 1959).

\footnotetext{
Asthma: periods of breathlessness

1. intrinsic

2. extrinsic
}

Chronic bronchitis: cough, expectoration (?), breathlessness ('American emphysema')

Emphysema: continuous breathlessness, especially on exertion, cough ('British bronchitis')

Asthmatic bronchitis: breathlessness, cough

Chronic obstructive bronchitis: cough + expectoration, persistent breathlessness

Table 2 Terminology of chronic lung diseases at the time of the CIBASymposium, 1958

The twenty British participants, mainly pathologists and chest physicians, proceeded in a way that shows similarities to what is now known as consensus conferences. They presented informal proposals which, after two days of discussion, led to the drafting of a proposal for terminology for emphysema and the various related clinical syndromes. This proposal (table 2) was endorsed by all, although with minor reservations by some participants. It was explicitly announced as a provisional terminology, to be improved upon in further investigations.

The results of this conference were twofold. In the first part of the report it was proposed that the term emphysema be excluded from clinical use and relegated to where it came from and where it belonged; namely in pathological anatomy. Emphysema can only, the participants stated, be shown in pathological examinations and therefore "the clinical use of the word emphysema should be regarded as presumptive and should only be applied to those cases in which, in the observer's opinion, the defined morbid anatomical changes of emphysema can confidently be asserted to be present." (CIBA Guest Symposium 1959, p 286) 
The second part of the conference report contains a discussion about the clinical syndromes that may be, although always hypothetically, related to emphysema. The terms asthma and chronic bronchitis are taken to designate two members of a group of related and often hardly distinguishable diseases. These are subsumed under the umbrella term, chronic non-specific hung disease (CNSLD), defined as "comprising one or more of the following: chronic cough with expectoration, and paroxysmall or persistent excessive breathlessness, which are not solely attributable to ... "[follows a list of 7 disorders to be excluded in diagnosis, such as tbe, heart failure, and others] (CIBA Guest Symposium 1959, p 295). Within this group of diseases, a division is made into two major diagnostic labels: chronic mucus secretion (chronic bronchitis) and generalised obstruction. The latter, according to this proposal, should be divided into a reversible (asthma) and an irreversible form.

According to this terminological proposal, which the participants stressed to be designed with the intention of inducing clinicians to develop a definitive taxonomy, chronic bronchitis and asthma form a group of kindred diseases. The former is predominantly a disease of middle-aged men and is strongly associated with smoking cigarettes and with living in highly-polluted areas, while the latter is a condition that can be found at all ages and in all environments, but with a preference for children and young adults, The kinship is visible, according to the participants, on two levels: patients often display identical symptoms (cough, expectoration, and excessive breathlessness) and also similar lung function impairments. The report stresses, however, that these similarities do not diminish the need for the subdivisions shown in table 2 to be used in the assessment of individual patients.

\begin{tabular}{|c|c|}
\hline & $\begin{array}{c}\text { CNSLD } \\
\text { (Chronic Non-Specific Lung Disease) }\end{array}$ \\
& $\begin{array}{l}\text { Generalised Obstructive Lung } \\
\text { Disease (GOLD) } \\
\text { Reversible obstruction: asthma } \\
\text { Persistent obstruction }\end{array}$ \\
\hline (abnormally increased air space distal to terminal bronchiole) \\
\hline
\end{tabular}

Table 3 New terminology, as developed at CIBA-Symposium, 1958 
At the time, the idea that the different syndromes subsumed under the umbrella term might be different expressions of the same disease was not yet formulated, that would happen a few years later.

\section{Splitting and lumping; the quandaries of unification}

Such a more radical 'one-disease' version of the CNSLD concept emerged from the Netherlands and has, since its formulation in $196 \|$ come to be known as the Dutch Hypothesis (Orie 1961; Orie et al 1980). It was developed by a group of researchers and clinicians at the Groningen University Hospital. In informal language, it is called the lumping approach, to distinguish it from the so-called splitting definitions used to suppont the existence of essential differences between the CNSLD subgroups. Protagonists in the discussion have been called 'humpers' and 'splitters', accordingly. The Dutch Hypothesis, supported by lumpers, states that within the group of diseases subsumed under the CNSLD umbrella, distinctions are not essential in any way. At most, they are of a quantitative nature, and thus may be useful for everyday communication between physicians, but in reality chronic bronchitis, asthma and any other names designated to indicate groups of patients with similar symptoms refer to the same underlying dysfunction. The essence of these diseases, according to the Dutch Hypothesis, is most likely to be found in a complex, and not yet identified, genetic modification.

\begin{tabular}{|l|}
\hline \multicolumn{1}{c|}{$\begin{array}{c}\text { CNSLD } \\
\text { (CARA) }\end{array}$} \\
(Chronic Non-Specific Lung Diseases) \\
$\begin{array}{l}\text { No fundamental, but only quantitative differences between asthma } \\
\text { (entirely or almost entirely reversible obstruction), chronic bron- } \\
\text { chitis (expectoration + entirely, or almost entirely reversible } \\
\text { obstruction) and emphysemal (expectoration + almost entirely } \\
\text { irreversible obstruction). }\end{array}$ \\
\hline
\end{tabular}

Table 4 Dutch Hypothesis

The first argument lumpers present for their hypothesis is the difficulty in drawing a sharp line between patients with diseases like asthmia, chronic bronchitis and emphysema. This argument is similar to the one brought forward at the CIBASymposium in 1958. They acknowledge, also, that this difficulty in itself would be a weak argument for their hypothesis, because the obvious rejoinder would be that the distinction will ultimately prove to be valid as time and research go on.

However, the proponents of the Dutch Hypothesis have other arguments at their disposal. As a second argument, they claim that there is, and will remain, considerable overlap between the different forms of patho-physiological mechanisms. Splitting views claim that one of the differences between asthma and 
chronic bronchitis lies in the extent to which disturbances are reversible: asthma being completely reversible, chronic bronchitis having an irreversible part. In the Dutch Hypothesis, this claim is challenged. Almost any patient, it says, with allegedly irreversible lung function decline shows a small degree of reversibility and, inversely, many patients whose lung function declime is said to be completely reversible do show, on closer scrutiny, the beginnings of irreversible damage (Sluiter and De Vries 1974). Even in patients who after an attack of asthma feel completely recovered, some traces remain. And in patients where the damage is so massive that there does not seem to be any hope of improvement, there is a possibility for recovery, however small According to this view, pure, complletely reversible asthma and severe, entirely irreversible chronic bronchitis are two extremes on a continum of hung finction loss. This continuum, which is one of the foundations for the one-disease-concept, is linked to the existence of precise and reliable lung function machines. Thus, developing the concept of CNSLD is, in part, the work of building more precise and reliable devices.

The difference between the Dutch Hypothesis and its opponents comes down to the question of what (ir)reversibility is. In a patient who blows abnormal lung function tests, how much improvement should there be after inhallation of drugs to speak of a reversible lung function disturbance? And, in a more metaphysical sense, the difference between himpers and splitters might be in their answers to the question: Are traces in the body ever completely effaced? Lumpers take complete reversibility of pathological events inside the body to be impossible, while splitters seem to take the opposite view.

The third reason for the protagonists of the Dutch Hypothesis to deny a difference between asthma and chronic bronchitis can be regarded as the core of the lumping argument: it is its theory about the causation of chronic airways obstruction. According to this hypothesis, asthma and chronic bronchitis, the two 'characters' under the umbrella CNSLD, are caused by the same, but as yet not identified genetic modification. A physiological disturbance, the 'host factor' (Orie et al. 1961), is responsible for the disease, which develops when patients come into contact with dust, tobacco smoke, air pollution, or nutritional factors. According to the Dutch, evidence for this common genetic causation is accumulating. Its immediate expression is bromchial hyperresponsiveness to ihhaled triggers (Sluiter et al. 1991; Meyers et al. 1989).

Opponents of the Dutch theory present various criticisms (Fletcher and Pride 1980). P. Vermeire and N. Pride, in a recent contribution to the debate, say, first, that the fact that the neat distinctions of theory do not always mirror messy reality does not warrant giving up the endeavour to distinguish. After all, overlap and restricted applicability of diagnostic criteria are a common feature in medicine. Second, they argue that the existence of common features does not imply a common pathogenesis. And, finally, contrary to what the Dutch say, their opponents hold that physiological evidence against the one-disease concept is mounting; there is increasing evidence, they say, for different pathogenesis of asthma on the one hand and chronic bronchitis/COPD on the other (Vermeire and Pride 1991). 


\subsection{The fortunes of CNSLD}

More than thirty years have passed since the 1958 CIBA-conference. Despite a "truly enormous" (Sluiter et al. 1991) amount of research, various obscurities and controversial issues remain. As two of the participants of the CIBA-conference stated in a review article twenty-five years later, there still is no suitable term for irreversible airways obstruction, in the meantime two proposals liave surfaced and submerged again: chronic obstructive bronchitis and small airways disease (Fletcher and Pride 1984). In the United States, Chronic Obstructive Pulmonary Disease (COPD) is in current usage to indicate the subgroup of CNSLD that was originally called General Obstructive Lung Disease (GOLD). But them again, according to the general view in the United States and Great Britain, COPD and asthma are two distinct diseases. One can safely say that the controversy over terminology is not closed.

This is visible in many of the consensus statements and guidelines that have been issued in the last fow decades. The American guidelines for the treatment of asthma indicate that some terminological quandaries still await their solution, but the authors of the guidelines do not hesitate to take a firm stand in favour of splitting asthma and COPD (National Asthma Education Program 1991). In accordance with the position of the British in the terminological controversy, their guidelines have also taken the approach of distinguishing between the two (British Thoracic Society 1990).

In 1989 , an international study concerning the use of terminology by specialists from the field showed that "the classical terms asthma, chronic bronchitis and emphysema still predominated in clinical practice" (Pride 1989). An extremely small proportion of specialists said they used the term CNSLD to refer to patients, and, although this has not been investigated explicitly, it may be assumed that the majority of those users can be found in the Netherlands and the Dutch-speaking part of Belgium (Vermeire and Pride 1991).

The guidelines that have been developed by and for Dutch general practitioners have resolved the problem in an original way; when dealing with children, they speak of asthma (Dirksen et al, 1992), reserving the umbrella term CNSLD (CARA) for adults (Bottema et al. 1992; Van der Waart et al. 1992). This shows, by the way, how relative the 'Dutch' of the Dutch Hypothesis is, adherence to the CNSLD concept is far from unanimous.

An example of how controversial the use of this terminology was, even among Dutch researchers, can be seen in the first research by general practitioners on CNSLD published in a series of three articles in 1977 (Huygen et al. 1977a; $1977 \mathrm{~b} ; 1977 \mathrm{c})$. In an investigation of the prevalence of CNSLD in the population of one general practice, more people seemed to be suffering from the disease than the physician was aware of, because most of the people with light to mild CNSLD never went to the doctor. But instead of considering these people as an unknown group of CNSLD-patients, the authors take the finding as a reason to critisize the terminology that led to the result.

This series of articles meets with an vehement critique from the researchers at the Groningen clinic. Their commentary can be summarised in three points: general practitioners do not know what they are talking about (epidemiology and 
clinics of CNSLD), they did methodologically bad research, and they drew rash conclusions (Var der Lende et al. 1978).

The interesting point for the argument of this chapter is the defense of the general practitioner, who states: "Essentially, our opposition is to the concept of CNSLD, which suggests unity, where in reality it contains a number of heterogeneous symptoms and afflictions that can have very different natural histories" [author's translation]. Furthermore, he criticises the suggestion that CNSLD is an extremely frequent disease: "[.] ]one gets the impression that large parts of the population are suffering from a serious progressive disease. This is suggested by the division of CNSLD into grades 1 to 5 , which reminds one of scalles of progression used in the grading of carcinomas." (Huygen 1978) [author's translation].

The debate here revolves around two notions mentioned in the quotation: the heterogeneity of symptoms and the alleged exaggeration of the seriousness of the disease. Both these arguments are different from the ones used in the controversy described in section 2 . there is no concern here with patho-physiological identity or difference, or the difficulty in establishing exact diagnoses. Huygen's concern is with the variable natural history of the different syndromes catalogued under CNSLD. He is also concemed with the link that is forged, through the gradation system, between this disease and (as the quotation implies) more threatening ones like eancer. Several years later, another physician warns for a medicalising effect of terms like CNSLD. About 25 per cent of the population have at least some symptoms of CNSLD, which according to him do not have to be treated in all cases; these people run the risk of being subjected to unnecessary treatment and control. Calling them CNSLD-patients creates a risk of over-treatment, the exact opposite of the idea expressed in specialist circles that this type of disease is constantly under-diagnosed in general practice (Bartelds 1982). Whereas a specialist has to make sure a patient doesn't suffer from any lung disease other than CNSLD, the general practitioner wants to be certain the patient has a lung disease at all - the concern is over-treatment is as strong as the under-treatment feared by specialists (Speight et al. 1983).

For general practitioners, CNSLD is a not very frequent, mostly mild disease which is generally diagnosed by history-taking and simple examination; establishing a diagnosis usually takes months or even years (as in the example of Said). According to these physicians, treatment, especially over a long period, is not always necessary in the milder cases, and should treatment be prescribed, it can mostly be periodical. Only in a minority of eases are frequent controls along with long-tern treatment necessary.

Within specialist care it is a frequent, often seriously disabling disease, diagnosed with the help of advanced medical technology. Continuous treatment over the long term together with frequent comtrols are necessary in most of the cases.

It is clear that the debate between specialists and general practitioners is different from that between scientific lumpers and splitters; thus, the controversy surrounding CNSLD involves not one, but at least two different discussions. 


\section{Transports and translations}

From the point of view of the analysis of scientific and technological controversies as it has become cornmon in science studies (Latour 1987; Collins 1985), a surprising feature of this controversy is that the ongoing discussion has not hindered the provisional results and compromises from moving into medical practice. Apparently, in this case at least, the closure of the controversy is of minor importance for the spreading of the disputed terminologies.

CNSLD is a concept that grew out of the attempt to turn pulmonology into a science. As a term used in epidemiological research, it had to make large-scale comparative studies of the course of obstructive lung diseases possible; it allowed taking as subjects of investigation persons with superficially dissimilar complaints (like Saïd and John) but, it was supposed, fundamentally similar diseases.

But in order to be used in everydlay medical practice, the terminology had to be transported to the ordinary chest physician and to general practice. As the focus of this book is on primary care technologies, the implications for general practice will be highlighted.

The term CNSLD, despite its supposed impracticable character, appears in thousands of medical records, in letters exchanged between specialists and general practitioners, in patient education brochures, and in the advertisements of drug companies. The controversy around terminology is not restricted to the circle of specialists invited at the conferences, but includes physicians in their everyday work. The creation of new terminology involves not only making similarities and differences, but also organising their distribution.

New scientific concepts, recent work in science studlies argues, do not spread through the world of their own accord, but like every innovation, they need to be transported actively from the centres where they have been developed (Latour 1984). The distribution of medical innovations, in the sense of medical devices, has been investigated in the last few decades (Gordon and Fisher 1975; Banta and Luce 1993), often as an ellement of Technology Assessment procedures. Research in this area has focused mainly on adopter characteristics, and on the time frame of diffusion of innovations. Rogers discusses some early examples of sociological research on diffusion of new drugs; the classic example being the study by Coleman et all (Rogers 1962). The channels of communication of innovations, however, have received less consideration. Banta states: "Little attention has been paid to the nature of the communication." (Banta 1984)

One can distinguish, generally speaking, three communication channels through which innovations come to the individual physician: medical joumals and related forms of continuous education (these will be discussed in 4.1); correspondence between physicians (4.2); and face-to-face contact.

One problematic aspect of the existing innovation research is the use of a diffusion model which assumes that the technologies or theories in question remain identical in the process. As we will see in the following sections, which give a rough sketch of the spread of CNSLD as a new term, transport is also transformation or translation, to use the actor-network term again. 


\subsection{Journals}

\subsection{Propagation}

In the Netherlands, the Nederlands Tijdschrift voor Geneeskunde (Dutch Joumal of Medicine) is the most widely read medical publication (Lagerwij 1993). Intended to serve both specialists and general practitioners, its contributors are mainly medical specialists. Although the number of articles by general practitioners has increased over the last few years, it mainly functions as a channel for information from hospitals and research centres to, among others, general practitioners.

How, in this journal, are readers interested in these conceptual refinements? Since the Sixties till now, a recurrent theme, has been 'under-treatment". "CNSLD is generally under-treated" is the typical phrase that, in all its cool detachment, will compel the common physician to read the article. Another way of attracting attention involves emphasising the increasing importance of the disease: it is a modern epidemic. No conscientious general practitioner dares to miss the latest developments if they are announced this way.

From the beginning of the Sixties, articles have appeared nearly every year in which the definition of CNSLD and its rellationship to individual diagnosis and therapy and to epidemiological research are explained, and justifications are given for the use of the term. That the Groningen group regards this as necessary is not surprising: although the journal is published in the cradle of the Dutch Hypothesis, the lack of termimological consensus is all too apparent.

In the Sixties and Seventies, the founders of the new terminology go out of their way to expound on their new piece of medical theory: they explain and justify, article after article, their use of terms. They are clearly not yet at the stage of proving hypotheses or of convincing others of results of investigations (although some articles tend to go in that direction), but they continue working at establishing a common vocabulary. Sometimes, particularly in the reports of the scientific associations, there are open clashes. In 1966, at a meeting of the Association for Allergy, the chairman accused the Groningen group of wanting to reduce disease to a set of scientifically-established variables, whereas he, as an allergologist, believed the whole human being is involved, and therefore should be studied (Voorhorst 1966).

Articles on CNSLD, in which the words asthma, bronchitis and emphysema appear only for the authors to deplore their continued prevalence in scientific publications and in day-to-day practice, are followed, sometimes in the same issue, by articles that bear the old names in their titles (Meyboon 1984; Terpstra et al. 1984), and in which the term CNSLD appears either not at all, or only as lipservice to the authorities in the field. In the register of the 1990-1991. issue of the Nederlands Tijdschrift voor Geneeskunde, the terms CARA (CNSLD) and asthma appear with about equal frequency. 


\subsubsection{Uses: research and diagriasis}

Contrary to the definition of CNSLD, which is repeated yearly without notable changes, diagnostic procedures continue to be discussed. Sluiter, a pulmonollogy professor at Groningen University who became the most avid advocate of the CNSLD concept, has repeated many times: CNSLD is not a diagnosis in itself; but a preliminary step. A diagnosis, the argued, should describe, as precisely and completely as necessary and possible, the condition of the individual patient. Thus, in diagnosis, which is a preliminary to treatment, the statement that a patient is a member of the CNSLD-group would in itself be no more than an indication of the specific diagnostic procedures to be applied: tests of allergy and hyperreactivity, measurement of lung function and of the degree of reversibility. "CNSLD is not a diagnosis. The individual patient should be characterised by means of unmistakeable and controllable criteria, such as the extent of reversibility of the bronchial obstruction, the presence of eosinophilia, allergy, and the like." (Sluiter and De Vries 1974) [author's translation]. In clinical practice, then, the term CNSLD places the patient and the physician in a series, or a network, of diagnostic and therapeutic procedures - it is a pragmatic term, in Austin's sense.

This description of the diagnostic features of the term CNSLD is interesting, because it involves the demarcation of medical science and practice. For scientific research, the term CNSLD may be used as an adequate description of a test subject - accompanied by a gradation in degrees of severity, if necessary - but in clinical practice it is no more than a tool for further investigation and treatment.

\section{2 "Amice"}

Apart from joumals, there are other bridges between the specialist and primarycare practitioners. The scientific press is but one way to carry a concept from the specialist centre to the general periphery, or maybe better from the specialist periphery to the general practitioner centre. More complex, but less visible channels exist between the family doctor in his consulting room and the pulmonologist in his: every day, the former receives letters from specialists in which they describe what they have done with the patients general practitioners refer to them. These letters are attractive documents for the sociology of science and technology: they constitute one of the ways in which concepts, techniques, and therapies are spread throughout the field of medicime. The following is a letter a general practitioner received about bis patient.

"Dear colleague, amice,

Today I bave seen your patient Mr. David S. with complaints of continuous coughing.

History Repeated periods of coughing, mainly during the night, no apparent breathlessness, no sputum production. Your initial examination showed no abnormalities.

Examination On auscultation and percussion no apparent abnormalities, expiration not strongly prolonged; no extraordinary sounds. 
X-rays No suspect shadows, no signs of infiltration or of bronchitis.

Lung function FEV1 1.66 before and 3.09 after medication (norm: 4.19 )

FEV1/FVC 0.47 before and 0.61 after (norm: 0.77 )

Blood exam BSE 15, Hb 7.9, diff count 2-7-25-60-6

Conclusion CNSLD with disturbed lung function, mainly expiratory impairment, incompletely reversible. Most probably chronic bronchitis. Therapy: Becotide $0.4 \mathrm{mg}$ $2 \mathrm{x}$ daily; to be continued.

I will see him back in about a year, in order to repeat lung function tests.".

In this letter, the term CNSLD is linked to a series of diagnostic and therapeutic interventions. The frequency and manner of lung function investigations may be a point of scientific debate, if the general practitioner sees the lung specialist perform elaborate investigations on every patient, it is strongly suggested that he should talke what happens with John to be the appropriate treatment. Thus, the letter functions as a form of continuous medical education. However sceptical the physician may be towards the use of technology in medicine, the repeated use of new diagnostic technologies and treatment methods in the management of his patients contribute to eventual acceptance.

It is the standardised style of these letters that makes them effective transporters of scientific and technical innovations. A standardised style is appropriate for conveying standard information, therefore, these letters prescribe as much as they describe. In these letters, the use of the technologies is not explained or justified, only the results are given, it is, to use the term from technology studies, blackboxed. Through such letters, CNSLD comes to mean all the activities that are described in it. It is defined as the use of X-rays, of machines to measure lung volumes, of still other machines to count blood cells and to establish the amount of oxygen taken up by the blood; it involves even the necessity of regular re-visits. Apart from telling the general practitioner what happened to the patient, these letters show to which elements of diagnostic techmology a patient is consecutively connected: to a stethoscope, an X-ray lab, to lung function machines and the people that operate them, to a blood lab with all its different techniques. This whole trajectory is transported to the general practitioner as a standard for diagnosis and treatment. If the question: "What is all this needed for?" was asked, the answer would be: "Well, it's obvious: that is what it takes to be a CNSLD-patient!" The letter not only informs the general practitioner, it also performs a description of CNSLD.

In the terminology used by Latour and Akrich to explicate their semiotic approach (Akrich and Latour 1992), the term CNSLD can be said to construct a privileged trajectory through medicine, it ties actors of different types together. Thus, it establishes the type of links, both between people (patients, doctors, X-ray technicians, lab assistants) and between people and things (patients, lumg function machines, and so forth), that are studied in this book with the help of semiotical 
methods. The use of the term CNSLD in John's case is not so mud the revelation of a truth that underlies his symptoms, as the constitution of a new sort of world or network, that will be the space that John will be living in, at least partly, from then on.

\section{Changing practice}

In scientific journals, at education meetings, and in the everyday communication between general practitioner and specialist; the transport of the CNSLD concept continued; medical practice slowly, but certainly changed. Through the years, general practitioners have gained access to more diagnostic facilities, both in their own consulting rooms (peak flow meters, for instance) and in hospital laboratories. Tests for allergies, $\mathrm{X}$-ray investigations, and, in some places, more elaborate lung function measurement can be done at the request of the general practitioner. In other words, they obtained the facilities to have patients follow the pathway sketched above. They acquired the possibility to perform CNSLD.

Along with diagnostic techniques, the goals of treatment changed. The physician of the Fifties, who was powerless up to a point where CNSLD was an area "that a decent plyysician did not venture into", (Orie 1953) is replaced by one who still may not be able to cure CNSLD, but who tries, as part of the care for people with CNSLD, to do what is necessary to curb the course of the disease.

Moreover, the standards for proper treatment changed. The criteria for the good doctor changed along with the introduction of the concept of CNSLD. Although important, it is no longer sufficient to simply alleviate the asthmatic attack, to bring an end to ceaseless coughing, or to give air to the contimuously breathless patient; the standard for good treatment has become anticipation. This is where an important aspect of the CNSLD-concept enters into the equation: it is, at least in principle; a lifelong disease with a lifelong follow-up, and that is what makes anticipation of exacerbations essential.

At this point it is interesting to return to the two patients, John and Saild, to determine what, if any, difference all this may make to them.

\section{John and Saïd: differences and similarities}

A bit more than a week after the first consultation described, Salid comes back to hove the results of his therapy checked. He feels a lot better, he says. He doesn't wake up in the middle of the night any more, and his coughing has eased. In fact, he feels fine. His physician listens to his chest again, and after the examination says he agrees. He hands him a small device "to test his lung function", and after Said has blown into it several times, the doctor tells his mother that although he feels fine, and some progress has undoubtedly been made, the measurements still indicate a moderate loss of lung function.

Said has to take the device home and measure his blowing force two times a day, and come back after a month.

Two months later Sald returns. He still feels fine. He gives the physician a list of results. After having examined the list, the doctor tells Sald and his 
parents that some of the figures in the list are too low compared to what Satd showld be able to blow. This constitutes additional evidence that he has CNSLD, and that, although he feels fine; he could objectively be better: further improvement of the functioning of his lungs seems possible. Although Said hos a fair chance of being without complaints for a long time, CNSLD is a chronic disease, and therefore he would recommend longterm treatment with an inhaler device containing a protective substance which prevents aimways obstruction. It should be used on a regular basis, 2 to 3 times a doy. Moreover, the boy has to keep the measuring device he was given a few months ago and use it in case his complaints increase. The last advice to Said is to come back every three months for a check of his: airways.

John, too, comes back to see his physician. He is a bit less jubilant about his situation. Although he has improwed, he camnot say he is his old self again. He still cannot finish a football game, but on the whole his complaints worry him less. The main improvement is that the cough has disappeared. He feels the inhaler he uses helps, but only for a short time.

After howing listened to his chest, the physicion tells him there is nothing left of what he heard previously. This, however, does not mean that John is: completely recovered, the function of his lungs probably is still impaired. He asks John to forcefully blow into the peak flow meter that; as he says, serves as a crude indication of lung function. When he sees the results the tells John that more elaborate tests are wecessary, and that these have to be done in hospital:

A few weeks later, after taking the lung function tests, lom comes back to discuss the results. There is little doubt, his physician says, that John has CNSLD. And whereas the damage done to his lungs is not completely repairable, it can be healed to a large extent. However, John absolutely has: to quit smoking, and he will have to use inhaled drugs for a long time, maybe even forever. The inhaler prescribed to him contains a protective drug which does not help instantaneously, but only after several weeks of contimous use. Consequently, it should never be forgotten. The measuring device may be used in times of worsening complaints.

Since the condition of his airways needs regular surveillance, he is invited to come to the office every three months:

Since John and Said are living in the Netherlands, they were lumped together on a diagnostic level An important question is whether it makes a difference if one is labelled CNSLD or not. What differences (and similarities) are made in practice? In other words: What is the pattern of distinctions and identities that is formed in the practice of treating CNSLD-patients?

John and Said receive highly-similar treatments, at first they are treated with bronchodilators only, and after further testing both are subjected to long-term inhaler treatment. But the investigations they undergo are different: Saïd only blows into a peak flow meter, while John, apart from taking his peak flow, visits the hospital to blow into bigger and more sophisticated equipment. Both are 
informed that they have a chronic disease that may continue to cause symptoms of breathlessness for the rest of their lives, but John is told his lung function decline is almast, but not wholly repairable, while the physician tells Said he may be completely well between periods of deterioration. They walk around with an inhaler, and have to find a not-too-visible occasion at work or school to take inhalations. Both are advised to see their physician on a regular basis in order to have their airways checked by tests, mostly on the peak flow meter. Both are, to use the terms of the sociologist De Swaan put under a moderate medical regime; they live under medical supervision, but not under constant surveillance (De Swaan 1982). Said may, one day, escape from it altogether, while John is likely to remain under medical control. They are advised about smoking; John is encouraged to quit, while Said is persuaded never to start - in his case, the parents should stop smoking. While Said's house is visited by a nurse to inspect it for the presence of dust-mites, this is not the case for John, because in his case, cigarette smoke is taken to be the main cause of his problems.

Here, too, a pattern of differences and similarities emerges, but this time, they are of a practical or technological nature. The similarities between John and Said may be in the cause of their problems (that is what the Dutch Hypothesis says), but there are at least as many similarities in the type of devices they will have to live with, and in the type of investigations they are subjected to. Similarities also in the lifestyle advices given to them; namely, refrain from smoking, do your best to remain in good condition, and avoid known triggers. The differences may be located in the individual pattern of symptoms, but they are just as much in the exact number of rules, the types of lung function devices, and the severity of the regime they are subjected to.

Therefore, if one wants to know whether CNSLD is one disease or not, it is useful to read about it in a textbook, but it is as important to watch and compare the practices that patients and physicians become involved in. The practices that surround people with airways obstruction as well as theoretical texts and debates co-construct the differences and similarities between them.

\section{Conclusion: diagnosing chronicity}

The first question addressed in this chapter dealt with the origins of the term CNSLD. It was developed in epidemiology and subsequently was restricted to Dutch medicine, and though even there, it had its difficulties, it materialised in everyday medical practice in the Netherlands. The buzz-words in the controversy over asthma and COPD are 'difference', 'similarity', and 'identity'. It is a debate on the possibility and desirability of drawing distinctions between types of diseases that imply breathlessness and coughing as their main complaints. It is also about the existence and type of connections, not only between forms of dysfunction, but also between groups of patients, and between periods in the life of a person. The line of demarcation between seience and practice is re-drawn in the process, as is that between specialist and general medicine.

Lumping and splitting are appropriate terms to describe this controversy because they rightly suggest that the making of a distinction is actually doing something, not only mentally, but in the world as well; namely, it means performing 
a large number of lung function tests, sabjecting people to questionnaires, taking care of the machines and the assistants who operate them, ensuring that patients take the test medication properly, and so forth. Lumping and splitting symptoms and aetiologies are physical activities as much as thought processes. They are things that one does with the hands as much as with the mind.

The second point was: Does it matter at all if there is difference or identity? In the two cases that were analyzed, it does. The term CNSLD, when used in clinical practice, functions as one of the devices that bring together two previously different groups of patients. Children suffering from similar complaints are grouped together, but also children and middle-aged persons, Saîd and John, suffering from cough, expectoration and breathlessness. In the chronological line it brings together Saild the boy suffering from epusodes of breathlessness with Said at sixty years old potentially suffering from continuous lack of breath. This linking of people and practices constitute what may be called the sociology of the term CNSLD.

From the case-histories, it is obvious that it takes time to establish the diagnosis. Contrary to diabetes, for example, CNSLD cannot be confirmed or excluded by a single unambiguous test. Labelling someone a CNSLD-patient is felt, more overtly than in other diseases, to be a doctor's decision. A decision with far-reaching consequences.

Lastly, the meaning of the term chronic as used CNSLD was analyzed. Under this definition, patients are expected to visit the physician for regular control. They are required to come not only when feeling badly, but also when they feel good: Most probably, if treated in agreement with recent guidelines, they will have to use medicine for a long time, maybe forever, to diminish the frequency of attacks and to prevent deterioration of their lung functiom. As early as 1960, one of the designers of the term CNSLD explained the necessary transformations in the physician's approach in these terms:

"In these patients, the therapeutical situation differs from the one we are used to in treating many ill people. Here, we are not concerned with relieving a patient of his ailment, or helping him go through a difficult period, but we are concermed with creating, in a lasting way, the best possible circumstances and to avoid, as good as we can, any exacerbation of the disease: Literally, in this case we have to treat a disease and not a diseased person. [..] This is a mental attitude that the physician will increasingly have to make his own." (Orie 1960) [author's translation]

The treatment of the diseases subsumed under CNSLD is the focus of modern pulmonology more so than the treatment of a patient's complaints, and as CNSLD is a group of chronic diseases, control and treatment are continuous:

One of the major components of the Dutch Hypothesis is that CNSLD is a lifelong disease: Children with asthma have the same disease as their grandfather with COPD. They run a high risk, depending on the environmental factors, of developing COPD with increasing age. This means the necessity of long-term, in principle lifelong, medical surveillance and intervention. "The general practitioner 
has to realise that the diagnosis CNSLD may mean years of medical attendance." (Neijens et al. 1982) [author's transiation].

There are different definitions of chronic disease. For instance, a distinction is sometimes made between an epidemiological definition of chronicity, a clinician's and a patient's definition, and what has been called a humane definition (Schadé and IJzerman 1989; Voorn 1983). Epidemiologists consider that chronic disease is defined by the existence of non-finite episodes; clinicians define chromic diseases as those that lead to repeated physician consultations; patients have still another definition, that is based on the continuous character of complaints not doctor visits; and the "humane' definition is a combination of the latter two.

Here, a different approach to the definition of chronioity is taken. The introduction of the umbrella term CNSLD in medical practice entails and produces different forms of chronicity. The first one is the causal form of chronicity: asthma, physicians tell their patients nowadays, is a disease linked to a disturbance in genetic make-up. It is a tendency to hyperreactivity that is innate and will not disappear. Asthma cannot be outgrown, is the main message of the Dutch Hypothesis. Physicians who say the contrary are offering unjustified reassurances and often insufficient treatment. That asthma is a lifelong disease, however, does not mean that it will express itself in symptoms throughout a lifetime. The amount and severity of symptoms strongly depends on concomitant circumstances like smoking, air pollution, and contact with allergens.

The second form of chronicity that is part of the CNSLD concept is that of the irreversibility of change. According to this form, asthma attacks, cigarette smoke and other harm done to the airways leave their traces. Irreversibility can take the form of continuous symptoms but also of irreparable loss of lung function. In the latter, which is the accepted definition of the term, irreversibility is literally performed by having a patient do a test twice, first without bronchodilators, and again after inhalation of a bronchodilator. If this does not make a difference, there is a high probability of irreversible function loss. Irreversibility, in this particular form, is a product of lung function technology. It could not exist without the possibility of measuring the expiration force in some way.

Chronicity in this case is not absolute, but is a typically gradual phenomenon. There is a corresponding vagueness about the limits of reversibility and its opposite: Exactly how much improvement is needed to call a disturbance reversible? In this version of chronicity , categorising asthma as a chronic disease is paramount to saying that complete reversibility is nonexistent and that every attack of asthma leaves at least some traces in the airways. Thus, the alleged irreversibility of the damage done by each and every asthtna attack comes close to a philosophy of the historicity of the body that would merit to be spelled out - at moments the theme comes up in the work of French philosopher Michel Serres (Serres 1986).

Protagonists of CNSLD (lumpers) regard airways obstruction from its first presentation as a lifelong chronic disease. Splitters, on the other hand, maintain a different view of chronicity. As they see no more than a superficiall similarity between the subgroups of CNSLD, it makes no sense to them to say that the asthmatic child will end up as the typical COPD sufferer. Asthma may be a chronic disease, but it may be temporary nonetheless. It can, in other words, pass or be outgrown. This is the third form of chronicity that is part of the difference between 
CNSLD and its altematives. The Dutch standard for general practitioners states. this view of chronicity by saying that asthma in children is a chronic disease, but that it can be outgrowm in about 50 per cent of cases.

CNSLD as a concept establishes, entails, and produces a lifelong disease, while the asthma-COPD couple allows for more differentiated forms of chronicity. Of course, the adoption of a term does not in itself tum a disease into a lifelong burden, it is no more than an element. The concept of CNSLD in combination with the fact that the therapeutics and devices used in the treatment of asthma and in COPD are identical makes the one-disease concept particularly strong. If the continuously breathless fitty-six-years old neighbour of Saidd uses the same type of inhaler as he does, if he possesses the same type of little blowpipe, and if the same diagnostic terms have been used by his physician, than it looks very much like if the two had the same disease. 


\section{Measuring breath ${ }^{1}$}

\section{Introduction}

Since the focus of this book is on the developinent of mundane forms of medical technology, this chapter on the measurement of breath will be concerned with the construction and the functions of the archetype of everyday diagnosis and control in obstructive airways disease: the peak flow meter and its variants. This unpretentious device is among the notable examples of size reduction and simplification in medical technology.

The Dutch guideline for general practitioners aftirms that the peak flow meter belongs to the family doctor's standard equipment (Bottema et al. 1992). Most doctors possess at least two one for use in the office and another to lend to patients who, like Said in the previous chapter, receive instructions for lome-use. The role of the device in various self-management programmes indicates that it is on its way of becoming the standard equipment for patients, as well.

In this chapter two questions concerning this device will be posed: What makes it into an object that provides information on the airways? And how does its introduction in the management of patients with obstructive airways change medical practice and the relationships of people involved? The first question introduces a discussion about the characteristics of different forms of flow measurement in CNSLD, and leads to questions about programmes incorporated in devices (sections 3-5). The second, which is closely related to the first, leads to the consideration of the distinctions between the lay-person's and the professional's knowledge and between subjectivity and objectivity (section 7).

After an introductory case-history, in which the use of a peak flow meter is depicted, the variety in types of miniature peak flow devices will be reviewed (section 3). The central theme of the chapter will be an analysis of the scripts inscribed in these machines (section 4). Scripts, as explained in chapter 1, not only describe the extent to which users have to adapt their behaviour to the devices, but also play a major role in determining the behaviour of different users, such as physicians and patients. Attention will be paid to what can be regarded as one of the main functions of the device, that of establishing and distributing now relationships between symptoms and dysfunctions and, also, establishing new, individualised forms of normallity (section 5).

1

A modified version of this chapter was published as: Susan's Breathlessness. The Construct ion of Professionals and Laypersons. In: Lachmuind J, Stollberg G (eds). 1992. A French version will be published in Techniques et Cultures. 


\section{A special kind of diary}

Susan is a, mostly healthy, eighteen-years-old. She goes to school and lives with her parents in an average new neighbourhood in the urbanised countryside not far from Amsterdam.

From the age of fourteen she has been suffering from periods of breathlessness, which not only keep her awake at night, but also prevent her from participating fully in school gymmastics. Her sensitivity to smoke keeps her away from some of the cafes she would like to go to. About four years ago, shortage of breath took her to see her general practitioner. As her complaints reoccurred these visits were repeated often in the following years. Sisan and her family physician are in the fifth consultation about breathing problems. Susan infrequently uses salbutamol, a bronchodilator, but she is not satisfied with this, since attacks of breathlessness keep coming back unexpectedly.

"The first thing", the physician says "is to thy to get a precise image of the course of your disease." The problem, he goes on to explain is that Susan, as with many asthma patients, has trouble feeling what is really going on in her airways. If she feels fine, that does not always mean that her aimwoys are clear, and feeling breathless does not always mean her airways are obstructed. So Stisan needs to measure her breathing capacity, enabling her to recognise symptoms as early as passible. Susan is given the device, the peak flow meter, and the physician shows her how to use it. This, he says, should help awoid severe attacks and assist in choosing the earliest possible moment for taking extra medication. It is a small cylinder, blue and grey, in which when blown into as hard as possible, a pointer moves in a numbered slot. The higher the number, the better the lung function at that particular moment. "It is simple," the doctor says, "but you need to feel how to do it. You should give a short blow with all your might." Susan blows into the tube somewhat hesitantly. "No, that's not it. You should do it like this, watch me. Take a deep breath", and he says and breathes in and then out, with a short forced puff, "and then, as you saw me do, blow out really quickly." After a few rehearsal blows, which in the end satisfy the physician, because they show increasingly high values, she is given the device and a leaflet with the words 'respiration diary' written on it.

Susan starts using the cylinder twice a day, she uses the diary for her results and adapts her use of salbutamol to them. 


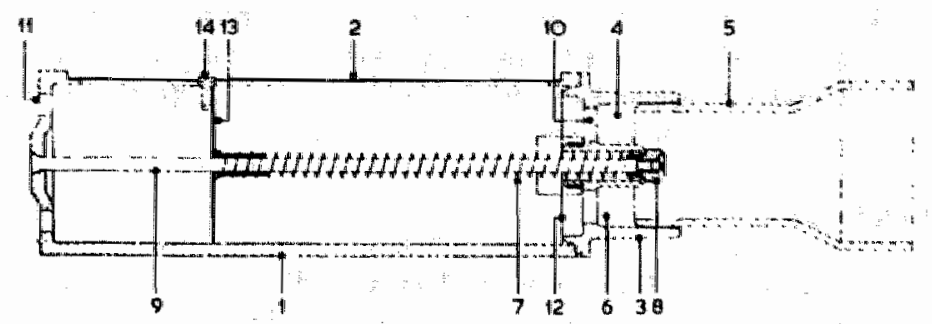

Picture 1. Mmi-peak flow meter

One of the remarkable things about this case description is the replacement of symptoms, and of what Susan feels, by measurements. There are at least two ways of accounting for this phenomenon: in medical anthropology this is called a shift from the language of illness to the language of disease. This distinction between languages is linked to the actors involved: illness is the realm of the subjective accounts of patients, while disease falls in the competence of the bio-medically trained physician. This connection can be shown to break down with the increased usage of bio-medical technology by patients. In section 5 , we will return to the disease-illness distinction as it has been developed in medical anthropology.

In a different vocabulary, the semiotic one used in parts of the sociology of technology, what happens in this consultation would be called a shift from language into devices. The semiotic vocabulary does not presuppose the distinction between patients' and plrysicians' perspective, and thus it seems more appropriate to describe what happens when patients start using diagnostic technology.

In the case decribed above, Susam's symptoms lose part of their capacity to give insight into what happens inside her airways. The description Susan gives of her complaints is an indication of how she feels rather than a sign of what is actually going on in her airways. Her complaints may, at best, be regarded as an expression of the degree to which she is hindered by her disease. Inversely, a lack of reported symptoms may indicate that Susan has an insufficient feeling of what goes on inside her body or it may point to inappropriate illness behaviour on her part. Thus, the case-history describes a shift in the meaning of symptoms: the extent to which Susan reports symptoms gives more information about coping mechanisms than about disease. Generally speaking, the introduction of a peak flow meter is justified by the explanation that symptoms give insufficient, imprecise 
information. They do not speak for the lungs in a reliable way. It becomes the function of the device to assume this role. If one wants to know how Susan is doing, one might decide simply to ask her, but the information from the pealk flow meter is considered more reliable, not in the least by Susan herself.

What makes the peak flow meter speak with such authority about Susan's airways? What was involved in its construction, what processes turned it into a trustworthy yard-stick of lung function? And which translations were necessary to convert Susan's desire to decrease the number of attacks of breathlessmess into the necessity of regular peak flow measurement?

\section{Testing lungs}

Measuring the maximum distance from which a candle can be blown out was once a convenient, but now outmoded way of testing llung fumction (Wright and McKerrow 1959). Today, lung function measurements either take place in a laboratory with various types of sophisticated devices, often with the aid of computers, or they are done in the family practitioner's office or even in the homes of patients. The most frequently-used device in the lung function lab is the spirometer, which, in its simplest form, consists of a large extendable air-tight cylinder that the subject has to bllow into. The airflow causes a movement of the top part that is transcribed by a pencil attached to it onto a piece of paper, producing a graph. The more recent devices operate according to the same principle, but the graph is produced on a computer screen. Specially-trained assistants are needed to encourage patients to blow in various ways into the hoses connected to these machines. In a spirometry lab, patients are linked to the device by the mouth and an assistant, usually clad in white, repeatedly tries, with exclamations and breathing gestures, to get the patient to blow in the correct way. "There you go! You take a deep breath, yes, like that, and then off it goes, as hard as you can.. Alright, but now keep blowing out, you've got some more in there, keep on keep on keep on... Oh, that's a pity, you stopped to soon!" And, showing the graph, the assistant points to a long horizontal line and says: "You see, this could have been longer! Let's try again once you've recuperated!" The spirometer could not function without assistants. Ome difference between the physician showing Susan how to use the peak flow meter and this brief exercise in spirometry is that the spirometry assistant has a graph to point to as proof of insufficient blowing. The shape of the curve is a translation, not only of the quality of the airways, but also of the blowing technique. In the example of Susan, the physician can only judge her skill by looking at the way she does it. The control of blowing skills is delegated, in the spirometer, to the device itself, while with the peak flow meter, one needs a judge.

$*$

In the philosophy of technology developed by the French philosopher Gilbert Simondon (1958/1989), technical objects are taken to develop in the direction of a greater degree of 'concreteness'. With this term, Simondon indicates the number of functions necessary for the working of the device that are incorporated into it 
The size and sophistication of the equipment, and the presence of assistants make it unavoidable that patients come to the laboratory each time lung function is to be measured. A lung function laboratory cannot easily be transported. In a disease like CNSLD, characterised as it is by sudden deteriorations, instant lung function testing would need to be available, which is problematic if patients have to go to the laboratory for each test. Moreover, and that is the second source of the quest for more easily transportable lung function technology, epidemiological research involving large-scale measurements of healthy populations is inpeded by the necessity of taking along an entire laboratory. Thus, the problem is how to condense a lung function laboratory filled with machines and people into an easily transportable and usable device:

But this story of size, transportability, and condensation is far from the whole picture. Lung function measurement is transformed in the process. Peak flow meters, instead of being miniature versions of spirometers, thin out to measure their own parameter (Wright and McKerrow 1959); thus, peak flow as a characteristic of the airways was developed simultaneously with the device. Instead of providing a simplified way of measuring something 'out there' that was already measured by spirometry, it constructs its own object. This was part of the development of the device, but also in the consultation described: Susan's peak flow is made in the process of measuring it.

There is a great diversity in peak flow devices. Several have been developed at different places, in different regions of medicine, and at different times. This coexistence of different devices is the reason why the next section does not contain a linear history of Susan's peak flow meter; at most there will be patches of historical development within a metwork of interrelated devices.

The questions the next sections will discuss are the following: What forms do devices designed to measure peak flow take, how are their relative advantages and drawbacks represented, how did they spread throughout the medicall world, and how did they end up working the way they do?

\subsection{Drums and tubes}

What do peak flow meters look like? If we put them all on a table, and only look at their external appearance, they can be divided into two groups, drums and tubes. This distinction is coextensive to another; the drums are all relatively large and heavy, while the tubes are small and light.

The oldest representative in the group of drums is Hadorn's pneumometer dating from 1947 (Hadom 1948), which has a $3 \mathrm{~cm}$ wide tube of about $20 \mathrm{~cm}$ length, comnected by two rubber hoses to a cylindrical drum, which carries a

(instead of needing other devices or human beings). Peak flow meters, in his terminology, would be regarded as less developed than spirometers, not because they are smaller or simpler, but because they need more external support for their functioning. Computerized spirometers perform the check on inhalation technique without assistance. 
pointer and a row of numbers on its circumference. There also is Wright's peak flow meter (Wright and McKerrow 1959), produced in London, which looks a great deal like its neighbour but is smaller and the rubber hose has been replaced by a plastic tube (picture 2). Additionally, there is an airflow meter which has a somewhat smaller cylinder and a single curved hose connected to it (Friedman and Walker 1975).

Wright's peak flow meter was developed in 1959 to serve in epidemiological research. Although clinical usefuhess was deemed important, it was felt that a device like this was more urgently needed because of its intended application in large-scale popullation surveys. The device was developed at the time of the first terminology debates described in chapter 2 . Although there is no evidence of a direct link between the two developments, there are obvious parallels.

The designers of the peak flow meter present several reasons for developing their apparatus. The main reason being the need for instruments for epidemiological research that were at the same time practical and standardised :
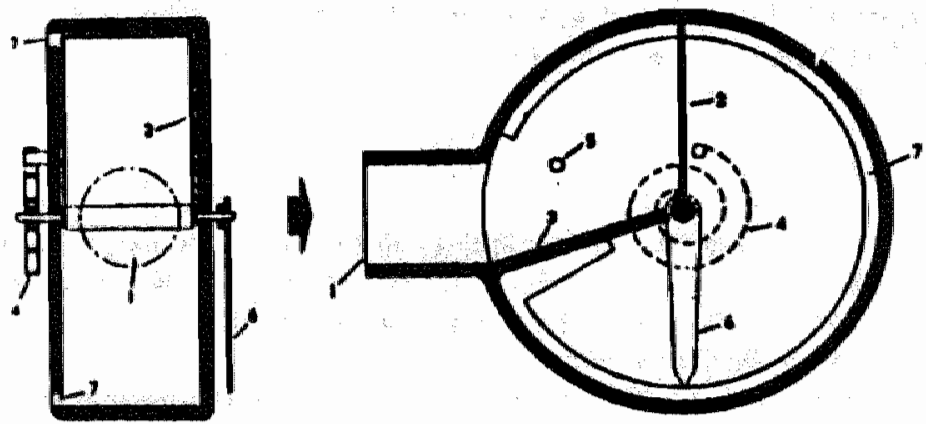

Picture 2. Wright's penk flow meter 
"Respiratory physiology is beset with measurements which are peculiar to the instrument and the laboratory where it is made, and therefore it is higluly desirable that, if possible, a measurement should be absolute, and clearly defined, so that it will be the same however and wherever it is measured." (Wright and MoKerrow 1959, 1042)

The aim, therefore, was to create unity where there was diversity. Both the new terminology and the new measurement device are designed to serve as unifiers, to provide order where confusion reigned, and to create mutual understanding between researchers at different places.

\subsection{Whistles and tubes: looking for smaller devices}

The Wright peak flow meter not as large or heavy as a classic spirometer, but still, it is awkward to carry around comtinuously. With a weight of about a kilogramme, it hardly fits into a physician's white coat together with the stethoscope, penlight, and percussor. Moreover, it might not be sufficiently robust to be transported all day long, let alone given or lent to more than a very small number of patients. Increasing the mobility of the device was a primary motive in developing smaller, more robust versions (Wright 1978).

\subsubsection{Sounds}

The first example of a peak flow whistle is the one developed by De Bono in London (De Bono 1963). It looks extremely simple: one of two cardboard tubes is provided with six openings for letting the air out and is closed at one end, and this tube is telescoped into the other, which has an opening for blowing. Other whistles, the Peak Flow Whistle (Tsakanas et al 1986) and the cone-shaped Chiaramonte whistle (Chiaramonte 1984) look very much like De Bono's.

De Bono"s whistle was first reported on in 1963 and the latest mention of it in the literature was in 1986 when a group of paediatricians reported about its use in monitoring children's asthma.

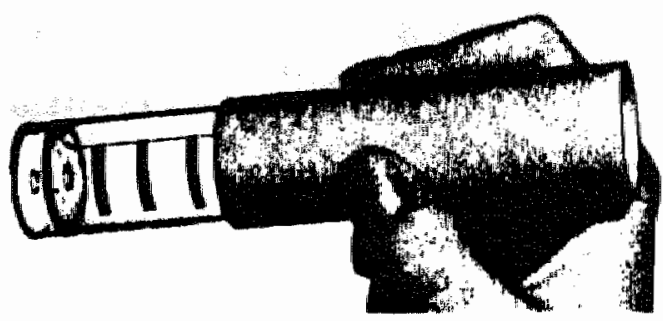

Picture 3 De Bono's peak flow whistle 
To use De Bono's device, a patient has to blow as forcefully as piossible into one end of the tube which contains, at the other end, a water kettle-like whistle. On the side of the tube is an adjustable lot through which air leaks; the more this is opened, the higher the flow that is needed to produce and. The patient's peak flow is established by finding the maximum slot opening at which a sound can be produced.

The presence of the whistle in the device signals to users whien they have given the necessary short and powerful blow. This would otherwise need several verbal and written explanations and corrections. The whistle is a clear example of inscribing spoken and written text directly into the device, of building in a seript. Instead of a physician or a parent having to encourage children to blow as forcefully as possible, the device does this itself.

Another advantage, according to its designer, is that "it is small enough to go into the pocket of all but one's best suit". That was the solution for the problem of forgetful physicians leaving their peak flow meters on their desk, which made them just as useless as when they would not have been distributed at all. One can suppose that the whistle made at least some of the subjects of this type of investigation, asthmatic children, enthusiastic users (a rare phenomenon for medicall investigations in children) and, thereby, in turn, encouraged their doctor to utilise it.

In 1965, De Bono's whistle was tested extensively as a screening instrument (Colley and Holland 1965). In a comprehensive study, the performance of the whistle was compared with standard lung function machines measuring FEV (Forced Expiratory Volume produced in 1 second), and to Wright's peak flow meter. The whistle fell short in the tests, because, according to the authors, "the major difficulty is in deciding if a whistle sound has been produced", and this was not only because of the low volume of the sound produced, but also because it was mimicked by expiratory wheezes that asthmatic subjects often produce: This is an embarrassing problem, since the asthmatic then seems to blow the best peak flow when he is severely wheezing. The other problem was that patients were quickly exhausted from trying to produce a sound by frequently repeating blows which often made them even more breathless. It appears that peak flow whistles like this one measure endurance more than lung function, and the sharpness of hearing of the observer, in some cases, more than peak flow.

The whistle was designed to encourage usage and prevent improper use, but although the device improved usage, it failed to fulfil its other purpose. The realisation that increased climical practicability had to be paid for with a dramatic decrease in precision led to the device's ultimate demise,

\subsubsection{Pointers}

Another distinctive element of the peak flow whistles is that, unlike the tubular meters, they do not have pointers. Within the group of tubular meters are Wright's mini-peak flow meter, the vitalograph (Perks et al. 1981), the Assess or Health Scan peak flow meter (Darden and Sly 1985), and the flo-scope (Spitzer and Neumann 1974). At first glance they appear even simpler than the whistles: a 
plastic tube, closed on one end, open at the other, is fitted with a longitudinal slot which carries numbers on its side and in which one can see a slidable indicator.

In 1978 the miniature device for measuring maximum outward air flow that Susan uses was developed. It consists of a cylindrical tube with a slot, a pointer moved by a piston, but without a whistle or other element that would pernit direct feedback on blowing techmique.

Two advantages of the meter, as with other miniature devices, are that it does not require assistants and that it is mobile enough for home use. The encouragement and gestures meeded to obtain a proper measurement with the spirometer condensed into a limited number of rehearsals, similar to those Susam performed.

The main advantage, as claimed by its designers, of the miniature device over the spirometer is that it is easier to transport. This makes it possible to keep track of changes in lung function in a nearly continuous maner. Without a miniature meter, this goal could only be reached by making the patient come to the hospital every few hours, where a spirometer would have to be available, and an assistant would have to be on hand to do the testing.

Thought experiments like these ('imagine what would have to be done if the device was not there') and especially the use of counterfactual statements can be useful to discover functions of devices. The use of counterfactuals is common in the work of Latour and often leads to interesting accounts of how devices perform social functions. In his 'Sociology of a Door-closer' (Latour 1992) discusses what happens when an automatic door-closer refuses to work. Only then, he argues, can its function become apparent because it suddenly has to be performed by humans. It renders unnecessary the continuous presence of a human being to close the door; it also eliminates all sorts of other problems: a door-closer does not become sleepy, does not have to go to the bathroom, and will not go on strike.

The usefulmess of counterfactuals, however, is limited. Their use presupposes that the removal of an element from a socio-technical complex would not change the characteristics of the whole, and especially that goals would remain the same, even if, without the removed object, they are more difficult to obtain. It supposes that if a device stops functioning, humans will have to take over and do exactly what the device does. The latter is questionable. For instance, if there were no peak flow meters, control of CNSLD as a whole would probably be different; for instance, intervals between control visits would possibly be modified.

\section{$3.3 \mathrm{New}$ ways of measuring new phenomena}

Wright and McKerrow state that the peak flow meter measures something else than the spirometer, which indicates, either maximum voluntary ventilation during a number of breathings or the maximum expiratory volume that can be blown out during one second $\left(\mathrm{FEV}_{1}\right)$, whereas the peak flow meter measures the absolute maximum flow a person can produce. Thus, in creating their new machine, they simultaneously created a new element in the concept of asthmatic disease; namely, the importance of maximum expiratory flow. Here is a clear example of how a new device creates a new physiological entity. 
This means that peak flow as a practical and scientific concept is produced in the same process as the device. Peak flow as a scientifie concept did not exist before the developmient and actual use of the peak flow meter (the reverse is true at the same time). What we are concerned with here is not a one-directional translation of the concept and the scientific theory into the machine, but a bidirectionall one, going from the concept to the machine and back. An idea about the measurement of lung function gets translated into a machine, but at the same time the possibilities of the machine translate the ideas about how lung function can be measured. The peak flow meter is not simply an application of theories or hypotheses about lung function, it also plays a role in the development of those theories.

This makes the very terms with which the activities of the peak flow meter are described interesting: on the one hand it measures, but it also defines what it measures. This is not exclusive to peak flow meters; a simple ruler has the same double role of defining and measuring what it designs. Neither instrument measures something entirely outside of itself but something it also brought into existence. The existence of peak expiratory flow is as much a product of, as a prerequisite for peak flow measurement.

One way to remove the sting from the criticism of imprecision levelled against the peak flow meter was to redefine its use. Instead of using it to detect CNSLD-patients, it is used to obtain person-specific information on changes in pulmonary function. Many guidelines for the treatment of CNSLD, accordingly, advise trying to find the best personal peak flow for each individual (Bottema et al. 1992). Physicians should attempt to establish the best peak flow for each person. Although charts with normal values according to age and stature may be helpful, they are necessarily vague because of the wide range of differences in people. One way of fixing the norm is to determine the personal best value by repeated blowings during a period without complaints, another is to determine the personal maximum after a sufficient amount of bronchodilators.

Either way, the peak flow meter is a materialisation of Canguilhem's concept of the normativity of disease (Canguilhem 1979). Disease, he states in a general way, imposes new norms upon a person's physiology, it not only has the negative effect of frustration as a result of not reaching a previous state, but it also creates norms of its own.

"Guérir, malgré les déficits, va toujours de pair avec des pertes essentielles pour l'organisme et en même temps avec la réapparition d'un ordre. A cela répond whe notvelle norme ind'widuelle. [...] Ce qui revient à dire que l'organisme semble viser avant tout l'obtention de nouvelles contantes. Nous trouvons éventuellement au cours de la guérison, malgré les déficits persistants, des transformations en certains domaines par rapport à autrefois, mais les propriétés sont à nouveau constantes:" (Canguillhem 1979, p 128-9)

Although Canguilhem developed the concept speaking of symptoms, it has equal relevance to lung function disturbances. Susan develops a way of life that becomes normal although differing in important respects from what she considered normal before. 
Accordingly, she has her own norm for hung function values, a norm that indicates the level to which they have to be brought back to in case of a disturbance. They denote, moreover, a point that should not be crossed: if in the future, Susan's peak flow would deviate exceedingly from her norm (some say 10 per cent, others 20), that would indicate a reason to modify treatment. Part of the management of CNSLD consists of learuing to live with new and personal physiological norms.

\subsection{Keeping devices in line by connecting them.}

There are a variety of instruments for measuring breath, they do different things, look differently; superficially, it seems that the only link existing between them is that they are blown into.

There is, however, a more substantial link between them, one that has to be made and maintained; this link is made by calibration procedures. What does each and every peak flow measurement say? How can one be sure that it says roughly the same thing in the doctor's office as it did in the lab, and not once, but hundreds of times? To ensure accuracy, the device is subjected to periodical calibration procedures. This happens in two ways: by connecting it to another apparatus that generates a known flow, and by asking subjects to blow alternately into the peak flow meter and into a pneumotachograph (the 'golden standard'), and comparing the values obtained.

In the first calibration procedure the peak flow meter is tested by another machine, that is to say it is connected to a device producing well-known peak flows that can be checked by yet another machine. Errors with regard to the standard flows are then registered (Shaw and Fisher 1980). In these procedures, the Wright peak flow meter shows considerable deviations in the lower range of peak flows, but it has an acceptable performance in the medium and higher range. This would mean that in patients with severe problems it would be less reliable than in moderate or light cases.

This procedure, however, can only tell how the device measures mechanically produced, fixed peak flows. Will it behave in the same manner with the variable flows produced by human beings? To answer that question, the performance of the instrument can be tested by human blowers with a known maximum expiratory flow; here humans, who have been tested using a pneumotachograph, an instrument of known precision and reliability, take the place of the device producing a standard flow. This calibration procedure is thought to be less reliable because of intervening factors such as the blower's fatigue, breathing technique, and so forth, but as being more valuable because it more closely resembles the ordinary use of the machine. This was the way Wright's original peak flow meter and the mini-Wright were tested (Wright and McKerrow 1959; Morrill et al. 1981). As its designers acknowledge, it remains less precise than the bigger lung function devices.

It is stated in the literature on miniature peak flow meters, that loss of precision is not specific to any of the versions (Bums 1979). Whereas the first, larger, meters of maximum flow measured something slightly, but clearly, different from what earlier lung function machines did - and as a result created their own parameter - 
the miniature meters are supposed to measure the same thing as the large ones, though less precisely. In his 1978 article, Wright frankly states that this loss of precision shouldn't bother anybody, as the original peak flow meter was "unnecessarily precise", anyway (Wright 1978). "Such a loss of information seemed amply compensated by the simplification in the use of the instrument."

This statement is remarkable, because it is not what one would expeet the outcome of a technological innovation to be According to common expectations, technology development, in medicine as elsewhere, has a tendency for greater instead of smaller precision. The pealk flow meter would lose a contest of technicall precision to most instruments used in hospital. Although it gives comparatively ambiguous indications of lung function, it is not its technical precision that is the most important. What counts is its transportability, which enables it to reach more asthma patients than the hospital devices. The peak flow meter is designed to win in distribution what it loses in precision.

But even if the device succeeds in passing the calibration test, that does not ensure its working properly. It does not guarantee that the results of blowing into it really are data about the functioning of the lungs, this can only be assured if the users use it properly.

\section{Building scripts into the object}

As we have seen in Susan's example, proper use of the peak flow meter involves standing up, grasping the device in such a way that the movement of the pointer is not obstructed, then taking a deep breath and giving a short and forceful blow.

Written like this, in one casual sentence, it looks simple, but in important ways things can and do go wrong. In any type of peak flow meter, the variability in measurements resulting from differences in bllowing technique has been estimated to range from about 90 per cent (at low flow values) to about 20 per cent (at higher ones) (Van Schayk et al 1990).

This suggests that people may have difficulty blowing properly; especially when they are breathless. They may also, consciously or unconsciously, obstruct the working of the device. "How to cheat with the peak flow meter" (Colin and Said 1984 ) is the significant title of a small contribution to the disciussions surrounding the device that describes the tricks children developed to obtain high peak flow values; instead of blowing into the instrument, they coughed into it or blew directly onto the pointer:

A more severe problem is that patients may not use the peak flow meter at all. 'Calibration' for this type of inadequacy is difficult. In general, there are two ways of ensuring people's cooperation: by persuading them with words, written instructions, oral incentives; or by building assurances against misuse into the machine, by writing scripts into the device.

\subsection{Creating an interesting device}

Both physicians and patients have to be persuaded to use the instrument: the device has to be made interesting for them, that is, the desires and interests of physicians and patients have to be made to pass through this device. It has to 
become a passage point of a more or less obligatory nature (see chapter 1, section 4.3). Susan's desire to be able to go to her favourite cafe is reformulated so that it entails the regular measuring of peak flow. That is exactly the message the physician tries to relay: "If you want to go to cafes, you will have to leatn to anticipate attacks of breathlessness with the help of your peak flow meter." At some peak flow values, however, going out may be entirely out of the question.

Similarly, physicians have to be interested in the device. If a doctor doesn't use the bigger peak flow meter on his patient visits because it is to cumbersome to carry around, then two solutions are possible: either persuade him with another barrage of implacable arguments or make the instrument less obtrusive. Their desires - supposedly, for general practitioners this is to be able to treat more patients themselves - have to be made to pass through the peak flow meter, as well. This interest is translated into the desire to be able to measure hung function. Since complete spirometers are usually not available in general practice (at least not in the Netherlands), peak flow meters are the devices they will want to use.

\subsection{Stimulating proper use}

This section will utilise a way of describing devices which is developed in a study by Madeleine Akrich (Akrich 1993). She calls this method the "de-scription of artifacts', splitting up the term into 'de-' and 'scription' to indicate that the purpose is to make explicit the script which is materialised in the device. As has been noted in chapter 1, the basic idea is that the longer and the more elaborate and complicated the oral or written instructions for the use of an instrument are, the more people, consciously or unconsciously, tend to misuse it. And following that, the more attractive it becomes to translate information and instructions into device characteristics. As the American cognitive psychologist Don Norman said, "(..) not all of the knowledge required for precise behaviour has to be in the head. It can be distributed, partly in the head, partly in the world, partly in the constraints of the world." (Norman 1988, p 54-55)

Simplifying the usage of an apparatus and diminishing the occasions for misuse or "creative" use means incorporating into it the very instructions that people otherwise would have to keep in their heads.

\subsection{The various ways in which peak flow meters can be used}

A peak flow meter can be used in various unintended ways - unintended by the standards of the designer - and this can be prevented either by verbal orders and texts or by building a script into the device.

For instance, people sometimes put their fingers on the slot instead of leaving it open to allow the pointer to move. Instead of having to ask people to take care where they put their fingers, some of the mini-peak flow meters are provided with a special plastic grip. This is the case with the most recent (1994) version of the Wright-mini meter. One of the advantages Chiaramonte mentioned in promoting his whistle was that there were no slots to put one's fingers on.

Another variety is that patients breathe into it incorrectly, for instance, by letting too much air escape from the corners of the mouth. Instead of having to say: 
"Close your mouth firmly around the tube", as was needed for the De Bono's whistle, purpose-built mouthpieces prevent this type of non-intended use.

A frequent failure in blowing technique is that patients do not blow into the device as hard and as quickly as possible; instead, they try to blow out as much air as possible, emptying their lungs, so to speak, but not as quickly as they can. Wright's miniature meter has no effective response for this potential obstacle; De Bono's whistle was more sophisticated in this respect because the sound functioned as an immediate reward for using the right technique.

Some people will simply forget to use the device as frequently as necessary. Especially in long periods without any complaints, they tend not to use it. It is difficult to build into the device an effective reminder that it needs to be used. The device itself cannot prevent people from leaving it in the back of their cupboard. Therefore, in a different register, the breathing diary such as the one Susan keeps, and which encourages regular usage, was made part of the device at a later stage.

Another potential problem with 'daily-life technology' is the possibility of unintentionally harming the device by dropping it or by letting it get wet. The obvious answer is to make the device as robust as possible while keeping its reliability, size, and weight at the same level. This has been done in the Wright mini-peak flow meter which can be dropped in water without any harm, in fact, the advice is given to wash it with the dishes.

A last potential form of non-intended use is that many users want to look inside the devices; to prevent them from doing so and to avoid 'do-it-yourself adaptations of the instrument, it has been constructed out of one piece of undetachable plastic.

Wright's mini-peak flow meter appears to have an answer to many of the obstacles mentioned above: precision and reliability have been extensively tested and found sufficient for its intended use; it is small; it is inexpensive, though more expensive than the whistle; and it contains a set of prescriptions, a scenario for those that use them. The control of this part of Susan's daily activities is taken over from the physician by the device.

\section{Subjective numbers, objective stories}

It is often stated that even experienced CNSLD-patients do not always feel how their lungs are functioning (Burrows et al. 1965; Sly et al. 1985); however, literature is not conclusive on this point. Especially the relationship between FEV, and what are called subjective complaints is unclear (Williams and Bury 1989). According to different authors, while some patients may feel fine, their lung function can actually be severely disturbed, and in subjectively breathless patients it can sometimes be normal. Symptoms and airways dysfiunction are disconnected, and the peak flow meter is an important instrument in severing the connection. The dissemination of the meter is also the spreading of an account, or viewpoint, on the capability of patients to judge their own symptoms. The peak flow meter distributes the idea that there is no correlation between the awareness patients have of symptoms and their actual lung function.

Measuring practices like peak flow measurement, then, perform a disease-illness disjunction that is different from the distinction between disease and illness as it is made in medical amthropology, and that was mentioned in section 2. In 
anthropology, the division is linked to the distinction between professionals and nom-professionalls:

"Physicians diagnose and treat diseases; that is, abnormalities in the structure and function of body organs and systems. Patients suffer illnesses; that is, experiences of disvalued changes in states of being and of social function." (Eisenberg and Kleinman 1981)

In this formulation by two of the founders of contemporary medical anthropology, disease is the language of the doctor, while the illness and suffering belong to the patient. Patients have a vocabulary that can express the experience of an illuess, while physicians talk about physiological dysfiunction. Thus, the disease-illness distinction is a socio-linguistic distinction: it specifies which people have the competence to speak which language.

The doctor-patient relationship changes with the use of devices such as the peak flow meter in a remarkable sense: the patient learns to talk almost on a par with the physician, Susan learns to talk about her bodily functions in much the same way as was hitherto reserved for doctors. The old hierarchical relationship between professionals and lay-persons gets increasingly blurred now that patients intrude in the professional domain (Willems 1992). Instead of hindering the communication between physician and patient, as some students of medical technology might claim, the mini-peak flow meter brings them closer together.

The Dutch sociologist De Swaan has designed a neologism for this intrusion of patients in the sphere of competence of the physician: 'protoprofessionalisation' (De Swaan et al, 1979). The term comes close to the ideas that have been developed here, except that De Swaan's work reflects the way in which people are led to interpret the problems they encounter in medical terms as a prelimimary for asking help from the medical profession, whereas this chapter is concerned with the way the frontiers between patients and professionals are blurred once they are well inside the medical system Moreover, the disadvantage of De Swaan's term is that it suggests patients remain in a sort of preliminary stage of professional competence. The work done in this chapter, implies that in certain areas, patients become as 'professional" as their physicians.

As we have seen in the example of Susan, the peak flow meter upsets the standard attribution of competence. With regard to peak fllow measurement, the physician in the Eisenberg/Kleinman quotation may be replaced by 'the patient'. They suffer illnesses, but they also learn to measure bodily functions, and they gradually leam to regard the untransformed signs of their body as unreliable sources for medical action. Thus, the peak flow meter cuts across distinction between professionals and lay-persons; rather, the distinction becomes one between those who use the technology and those who don't.

With the introduction of devices like the peak flow meter (the portable glucometer is another example) a new element is introduced in the medical consultation: a diary consisting of numbers representing physiological parameters, the logbook of physiology. As has been previously stated, this logbook replaces the so-called subjective account of the patient. Not that the patient's account becomes entirely unimportant but it is reduced, so to speak, to being at best half of the 
story. Instead of telling her doetor that she has been breathlless and coughing for some days, Susan hands the diary to him and says: "You see, Doctor, on Wednesday I felt badly, I did not get above 330." "And what did you do, then?" "Well, I took some salbutamol inhalations and the next day things started getting better, you see: 550, and on Friday I made 700 again. "Numerically-expressed functions have taken the place of complaints as the main topic of discussion.

At one of the control wisits, Susan tells the physician that having left her device at home when she spent a week with friends she was forced to live without it for some time. II actually realised that this was less of a disaster than I thought it would be. In fact, I have become much more attentive to my body in a way, the device has taught me to listen to it: One day, I felt a crisis beginning, and I managed to keep it under control without the device."

The point is that Susan's subjective feelings have not only been translated into peak flow values, but have also been transformed by the use of the meter. To some extent, she has internalised the device and is alert to what happens inside her body, also in the absence of the actual device (Shim and Williams 1980; Higgs et al. 1986). Keeping track of the functioning of ther airways has become a way of life and does not depend entirely on the prescriptions the device contains. Thus, Susan not only acquires the competence to speak the language of the physician, but illness itself, which, according to medical anthropology, was the domain of the patient, changes within this specific patient practice.

\section{6. "A peak flow meter on every desk"1}

The consultation described in section 2.1 took place in 1990 in a general practitioner's office in The Netherlands. This is quite remote, in time, place, and type of practice, from the laboratory in London where the first copies of the device were constricted. What is more important, the role of the device in the consultation was different from the role that was attributed to it in section 3 (monitoring was not one of its original functions). So, clearly, the device changed on its way from London to the village near Amsterdam; something happened to it on its way from epidemiology to general practice.

This is not specific for the peak flow meter. Studies of the spread of science and teclinology (Latour 1984) have shown that it is not a self-evident and automatic process, and that energy has to be expended to obtain a large distribution. Spreading information, practices, and technology throughout the globe involves work, and, consequently, it entails a modification of the distributed object and the way it functions. Enroling new users more often than not means modifying some characteristics of the device.

This title is taken from an article intending to persuade family physicians to use the peak flow meter (Tomson 1989). 
The dissemination of devices entails a manipulation of the object in the same way as with the spreading of news, diseases, money, or, for that matter ${ }_{\text {, scientific }}$ concepts, as we have seen in chapter 2 . So the first question of this section is: In what type of practices do we find the peak flow meter? the second, What does it do where we find it?

Peak flow meters, large and small, can be found in research centres, in practitioners' offices, and people's homes. In research centres, it functions in epidemiological studies as one of the instruments used to measure lung function in a population, especially in the first phase of selection where it distinguishes between the completely normal and the slightly to severely abnormal. Another research usage of the meter is in climical trials, where the effect of bronchodilating or anti-inflammatory drugs is measured by an increase of peak flow. Here, too, it functions within a network of other machines, most frequently spirometers.

The question can be asked to what extent the peak flow meter has been distributed within medical practice, and in which specific areas it operates. The only known investigation of the spread of peak flow meters among doctors was done in the Netherlands under the auspices of one of the pharmaceutical companies distributing the Wright mini-meter. They found that about 60 per cent of the Dutch general practitioners use peak flow meters, against more than 80 per cent of the paediatricians and pulmonologists. Of the general practitioners, the vast majority used the Wright mini-meter (Indumar 1990):

Apart from this investigation there is a continuous stream of publications urging general practitioners to buy and use the peak flow meter (Gregg 1964; Tomson 1984; McGuinness 1984; Kimmel 1986; Van Veen 1982). It is suggested that there are considerable international differences in the acceptance of the device:

"(..) many British general practitioners seem to make use of the Wright peak flow meter or its miniature version and some of the Vitalograph, that allows the measurement of $\mathrm{FEV}_{1}$. Our Canadian, American, and Australian colleagues constitute a good market for more advanced electronic machimes." (Van Veen $1982,74)$ [author's translation]

The Wright mini-peak flow meter does not hold a monopoly in the market of small hung function devices. In the Netherlands, it is noted in the same article, the peak flow meter is the most widely used, it is the device the guidelines advise general practitioners to use.

The interesting question, however, is not how many of these devices have been distributed in general practice, but how physicians are persuaded to use them. Potential user and device have to be brought together, and that requires a change in one or both. The user has to be convinced that the device is necessary, or maybe even indispensable. A common way to interest general practitioners is by showing them that they will be better doctors as a result of using the device. They will be better able to diagnose airways obstruction and to perform new finctions such as monitoring drug effects.

In this general framework, the 'pushing' of the peak flow meter happens along three lines of argument: individual diagnosis, mass screening, and treatment monitoring. 
The argument that the use of a peak flow meter enhances the diagnostic capabilities of the general practitioner is especially stressed in the British and American publications (Prior 1980). Although the specificity and sensitivity of the dewice for airways obstruction due to CNSLD-diseases are quite low if measured in epidemiological studies, use of the peak flow meter is advised for the confirmation of diagnosis and for the assessment of the degree of reversibility of the airways obstruction. Another inferred diagnostic advantage of the device is the possibility of establishing pattern of breathlessness in the individual patient (e.g. 'night dippers'). Dutch publications, on the contrary, advise against using the device for establishing diagnosis because of its reported unreliability (Lademacher et al. 1986).

Some publications advise the use of the peak flow meter as a screening instrument. This second 'interesting technique' is linked to a development in general practice, in which prevention and screening of the patients is becoming standard practice. There are, however, considerable doubts as to the suitability of the peak flow meter for this type of activity, for two reasons: it would fail to identify many CNSLD-patients and, at the same time, diagnose the disease in too many healthy persons (Tattersall 1978).

The third tactics to arouse interest in general practitioners is employed frequently: they are told that with the peak flow meter they will be able to treat their CNSLD-patients better. Monitoring the severity of lung function disturbance in relation to drug consumption becomes a possibility in general practice with the distribution of peak flow meters (see chapter 6 on monitoring).

\section{Conclusion: scripts and descriptions}

Devices like the peak flow meter contain pistons and rods, but they also contain seripts for their users. They guide the behaviour of patients; physicians, and sometimes of families of patients. They also prescribe a type of relationship between physician and patient, who work together on a peak flow list, whereas, with standard lung function equipment, the physician is the one who produces and interprets the outcome of the function test.

Incomparating instnutians inta the device itself means leaving less anpartuvity, for non-intended use, deliberate or unimtentional. Are inscribed instructions always more reliable than written or oral ones? An affirmative answer to this question would lead to another form of technological determinism than the one discussed in chapter 1, section 4.1. This deterministic position would state that human behaviour is more efficiently controlled by things than by texts or orders from other human beings. However, it is not necessary to take a general position in favour of such determinism: whether machines or texts are the way to guide human behaviour depends on the situation: it has to be found out empirically. In the case of Susan, for instance, technical objects cannot be said to determine her behaviour entirely. She still needs skills, she still needs to remember to use the device and write the results in the peak flow diary. Objects may be the "missing masses" in the sense that sociologists have failed to recognise their important social fimctions (Latour 1992), but it is without doubt a (rhetorical) exaggeration to say that they are "the cement, the glue that ties us together" (Latour 1991). 
Devices like the peak flow meter contain definitions of patients and physicians. They also contain a new definition of lurig function, as we have seen, peak expiratory flow was defined together with the construction of the device. Thus, they are more than simple miniature versions of larger lung function machines. They are translations of these machines and the practices comnected to them, translations in the double sense of the term: both reformulations and transformations. Translating lung function measurement into a miniature device means more than moving the practice of lung function measurement: it also means modifying it. 
$\therefore$

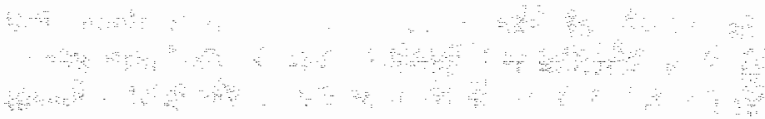


"Cet ordre (celui de latlas anatomique) n'est cependant qu'une des manières pour la médecine de spatialiser lä maladie (...) Quand pourra-t-on définir les structures que suivent, dans le volume secret du corps, les réactions allergiques? (...) Bst-ce dans une anatomie euclidienne que ces pliénomenes peuvent trouver la loi de leur spatialisation? (Foucault 1964)

\section{Turning airways into drug routes}

\section{The proliferation of drug inhalers}

For about twenty years now, an increasing number of people carry suall plastic. devices in the pockets of their waistcoats or in their handbags, regularly taking puffs from them, like others (or, sometimes, the same people) do from their cigarettes. Onlookers do not seem disturbed by such scenes - it starts to look like common behaviour.

Many of these people have obstructive airways diseases and are treated or, more precisely, treat themselves by inhalation of medications. They use different types of inhalers, in different forms, colours, and sizes.

Inthalation is an old form of drug-taking. Hippocrates is reported to have advised his patients to take drugs dissolved in hot water vapours (Miller 1971) which is still a widely used therapy for nasal congestion, laryngitis, and the like. Steam boilers - the first inhaler devices - were developed for the treatment of diseases of the airways. These were used to moisten the air in the room where a patient was lying. The first devices for the inhalation of drugs were asthma cigarettes, containing a bronchodilator. Grossman traces this usage back more than 4000 years, when the belladonna plant was smoked as a cough suppressant. Until the beginning of the twentieth century, cigarettes containing a mixture of tobacco and stramonium were smoked as an alternative to steam treatment, which was, at the end of the nineteenth century, restricted to hospitals and physicians' offices (Grossman 1994).

A next step was the development of jet nebulizers, still quite big instruments, weighing up to a few kilogrammes and needing electric current. In this type of machine, the drug is dissolved in water which is transformed from a fluid into an inhalable mist. These devices are mainly used for very small children and for adult patients with very severe attacks of breathlessness.

The development of miniature devices for inhalation is more recent. Around 1960 , the first portable inhaler devices became available. Since then, a large variety have been developed, the variance between them being largely attributable to commercial factors. The maxim still seems to be, every company its own brand of drugs in a specific inhaler. A recent review reported some twenty different devices associated with the inhalation of substances into the lungs (nebulizers included) (Deenstra 1992).

Small inhalers can be divided into two groups: aerosol devices and powder devices. Aerosol inhalers contain fifty to two hundred doses of a drug dissolved in a liquid and brought under pressure by a propellant gas. The aerosol is released by 
pushing on the bottom of the canister. Powder inhalers contain the drug in fixed doses which sometimes are linked to carrier substances. Here, the doses are released not by pushing on the canister, but by the act of inhalation itself

The alleged advantage of inhalation via these types of inhalers is that therapy is 'local" instead of 'systemic', and therefore has a quicker result and causes less sideeffects. One of the primary questions of this chapter is about the constitution of this distinction: How are the adjectives local and systemic attributed in the process of changing from one route of entry of medication to the other? What types of trajectories through the body are created in the design of drug routes and which treatment forms receive the much-desired status of local therapy? Instead of taking the distinction between local and systemic for granted and explaining the success of inhalers on that basis, this chapter will show how different forms of inhalation therapy are active in shaping a specific form of the distinction rather than building upon a contrast between local and systemic. The hypothesis is that inhallation does not simply take an existing path into the body, but it also partly re-maps it.

To support this hypothesis, it will be useful to analyze the differences between the various types of drug delivery using the semiotic concepts explained in the first chapter. In this analysis the different objects used will be regarded as translations (in the sense of shifts) of the problem of ensuring that a drug reaches the targeted receptor site. Only after having discussed the links between oral treatment and inhalation will it be possible to filly appreciate the differences between them.

In the next section, an example will be given of a sequence of different administration routes of medication in CNSLD. Section 2 is about the various instructions-for-use that accompany the inhalers and section 3 discusses how these instructions are inscribed into the devices. Section 4 addresses the extent to which the use of inhaling devices provides a new geography of the airways. The conchusion returns to the idea that technologies like drug inhalers shape patients, physicians, and airways alike.

\section{Jeffrey and Johnny}

Jeffrey is a three-year-old boy who has been treated for asthma by his general practitioner for a year. In the beginning, he was prescribed a mixture called deptropin, which, according to the physician, would alleviate his cough and combat his wheezing. A few months later, when a second episode of wheezing could not be controlled with this mixture, another substance was added, called salbutamol. This, he explained, was a more powerful drug that would widen Jeffrey's airways. Unlike the first substance, salbutamol would only be used during attacks. Jeffrey's mother had carefully followed these instructions;" she had restricted the use of salbutamol to the minimum since she noticed that he reacted to the drug by becoming extremely agitated, 'a disaster' as she called it. Not only would he tremble and become nervous after one or two doses, but worse, he would go into a rage, demolishing toys, and fighting with his brother. He was not able to sleep after having taken salbutamol. She had asked the physician repeatedly if there was no possibility of howing the benefits of the drug without the drawbacks. The answer always came that it would be just a 
matter of time whil Jeffrey would be able to inhale his medicine, like his elder brother did.

Half a year later, at one of the regular control wisits, the doctor tells her of a new device called Aerochamber. The producer claims that it can be used on very young children, even whder the age of one. It anawing simplicity makes one question why it has not be introduced sooner: it is a tube about $5 \mathrm{~cm}$ wide and $10 \mathrm{~cm}$ long with a flexible plastic mask, that covers both mouth and nose on one side, and an oval opening at the other. This opening is made to fit a drug sprayer. Now all Jeffrey, who, during the consultation, is relentlessly mowing about, has to do is to breathe in and out of the mask about ten times, after two puffs from the sproyer have been fired into the tube. The major advantage of the device, the doctor continues, is its simplicity; it iurns inhalation into a piece of cake.

"But are you sure it will help make Jeffrey less wild?" his mother asks. "AIII can say is that it is very likely, "the physician answers, "as now the medicine will travel directly to the ainways." Until now" he explains, when pills were the only available form in which Jeffrey could have the medicine, it went to other organs as well: the heart, the nervous system, and so forth. In short: the Aerochamber has the advantages of local therapy, inhalation finally turns the treatment of asthma into precision work.

Although he said it was as easy as winking, the doctor has Jeffrey practise once or twice to get accustomed to the device. After practising for some time with the boy the physician succeeds in getting him to inhale ten times from the Aerochamber:

\section{Paving a way into the airways}

\subsection{Sproys}

Aerosols is the general name for the type of drug prescribed to Jeffrey. They are produced in small canisters containing a propellant and the drug. The canister is set in a plastic covering with a mouthpiece. 


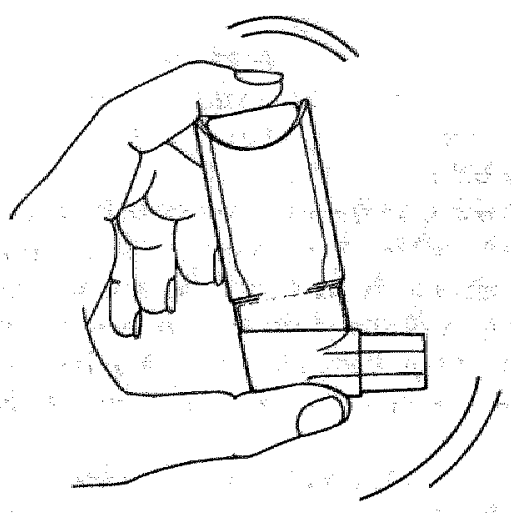

Picture 1 Aerosol inhaler

The inhaler is hell bottom up and should be pushed on to release the medication. Every push produces a fixed amount of gas in which a measured dosage of the drug is transported; for that reason, these inhallers are called metered dose inhalers (MDI). Inhaling an aerosol from an inhaller looks simple. It should not be much more than an extension of inspiration, the most continuous and automatic movement we know. Many CNSLD-patients learn how to smoke, so they should be able, one would say, to learn to inhale their drugs.

Nevertheless, a large number of people using MDIs need elaborate and repeated instructions to obtain sufficient skill for the treatment to be effective (Buckley 1989). There is some discussion about what a skilled inhalation is. According to the American consensus statement on asthma, a good inhalation consists of the following actions (National Asthma Education Program 1991):

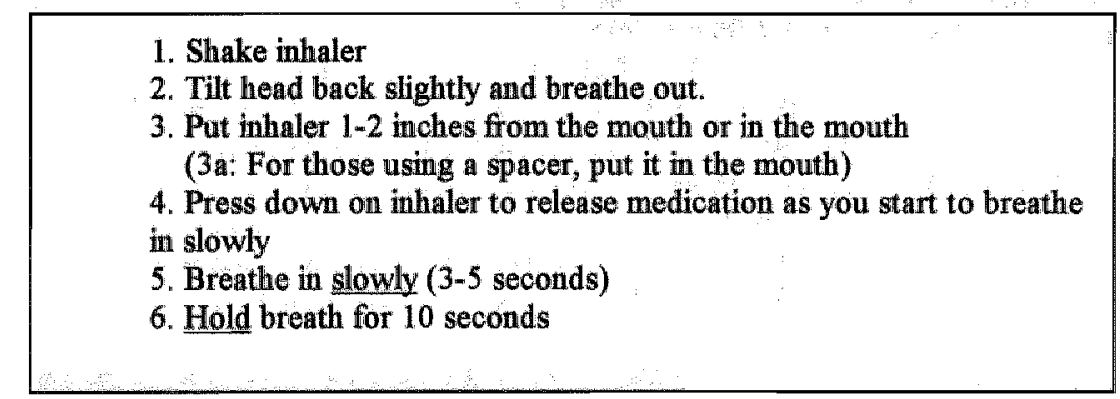

Table 1 Instructions for the use of aerosol inhalers

Jeffrey is not alone in having some trouble following these instructions: adult users often neglect these and similar guidelines entirely or for a large part (Dompeling et 
al. 1992). Things mostly go wrong at points $4-6$ : the coordination between hand and lung, as it is called. People either fire their inhalers before, or sometimes after inspiring, or they breathe in too rapidly, probably in an effort to get the medicine in as quickly as possible, or they do not hold their breath for a sufficient time. As a result, the aerosol either disappears in the air, or is deposited on the skin or in the throat, or somewhere in the large ainways, but not in the smaller airways, hidden deep inside the lungs.

Studies with aerosols and powders to which radioactive material had been attached, have shown that deposition occurs almost entirely ( 80 per cent) in the throat, while the second largest deposition area is the central bifurcation of the trachea (15 per cent); only 5 per cent of the medicine appeared in its target, the small airways (Reed 1991; Newman et al. 1989; Newman et al. 1981). And these results were obtained in persons with adequate to excellent inhalation technique (this can be said of no more than 70 per cent of the users, according to various studies (Dompeling et al. 1992; Newman et al. 1991)). It can be concluded that in: most users, this local treatment will scarcely reach its destination, while in a considerable group it will not reach it at all.

This clearly is a problem for physicians, who will lose the confidence of their patients, and for patients, who will receive no benefits from the medication. Deficiencies in imhalation technique are argued to be one of the main reasons for disappointing success in the treatment of CNSLD (Van der Palen 1994).

What can be done to avoid flaws in inhalation technique? How can a correct use of this technology be stimulated? What have designers of inhalers done to improve. proper usage?

Similar to what was stated for peak flow meters in chapter 3 , the first method physicians use is repeated instructions. Doctors are advised, in consensus statements, to check inhalation technique at every consultation in the beginning, and thereafter whenever there are indications of treatment failure (Van der Waart et al. 1992). Physicians increasingly spend their time instructing people on how to take their inhaled medication properly. It is, however, an expensive method, and one can question its effectivity, because physicians are not always the best instructors of inhalation technique (O'Connell et al. 1991). A second controlling system, intended to ensure physicians give the correct instructions would seem necessary.

The second frequently used strategy is to rely upon written instructions. Every inhaler is accompanied by a leaflet explaining in detail the various actions to be taken in order to inhale properly, with drawings for further clarification. The disadvantages of the first solution are then avoided: it is less expensive and there are no unreliable intermediaries like incompetent or hasty physicians. But it introduces a different problem: information leaflets only work if they are read, and in this case read time and again. This strategy depends very much on the cooperation of the user, or, maybe better, on a specific type of user: the one who keeps instruction leaflets and takes the trouble to read them from time to time.

There is, however, a third possible solution, the one Jeffrey's physician chooses, which may provide a way of avoiding this problem; namely, trying to delegate, as much as possible, the control of inhalation technique to the devices themselves. In the terminology of technology studies: to rely upon inscriptions in the device 
instead of in texts. This is an error-prevention strategy that has already been discussed with regard to peak flow meters: turning text into plastic, writing a script, not with words, not on paper, but into the substances the device is made of: A simple plastic tube like the Aerochamber can do a large part of the job of having Jeffrey inhale properly, and it can do it every time he takes his medicine. It does not depend on the competence of the physician or on the use a patient makes of the information.

There is a clear restriction, however, to the possibilities of inscribing human skills into the Aerochamber. This device, too, has to be used properly, and although it is closer to normal breathing then the direct use of the aerosol device, skills still have to be learned. One of the techniques parents have to leam is to put the mask of the inhalation chamber firmly over the mouth of the (often crying and thrashing) child. Another example of a skill that cannot be translated in a device characteristic: the shaking of the inhaler still has to be done by Jeffrey or his parents. Once that has been done, the device works regardless of whether or not the user of the aerosol remembers any information in the inhaler instruction leaflet. Thus, the advent of the Aerochamber does not mean that learning has become superfluous.

\subsubsection{Winning time and space}

Various forms of spacing devices, of which Jeffrey's Aerochamber is one; have been developed in the last few years. There are telescoped plastic tubes of about 15 $\mathrm{cm}$ (spacers) and egg-shaped transparent plastic balls with a maximum diameter of about $25 \mathrm{~cm}$ (Volumatic or Nebuhaler). What follows is a discussion of the latter device as it is the most frequently used by patients from the age of five.

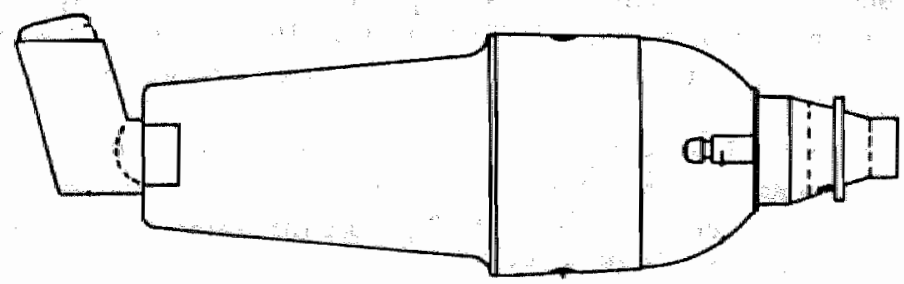

Picture 2 The big balloon: Nebuhaler 
In order to use the Nebuhaler, an aerosol inhaler is put in a hole at one end and the aerosol is fired into the chamber once or several times. As soon as the aerosol is trapped in the nebuhaler, the user puts her or his mouth around the opening and can either take a long breath or slowly breathe in and out. Proper technique is signalled by a clicking sound produced by a valve that has no other function than to serve as a reminder by producing this click. It indicates that the drug has been taken properly - after the click, no inhalation failure can be attributed to the clumsiness of the user. The importance of clicks in this type of treatment will be discussed in the section on turbuhalers (3.2.1).

The device is the translation into plastic of two measures to avoid inhalation failures: it gives the user more time, inhalation does not have to take place immediately after firing; this allows for the necessary slow inhalation. The problem of hand and breath coordination is also avoided; the movement of the hand and the thorax are disconnected. At the same time, the device allows users more space (the opening of the sprayer can be held at a larger distance from the mouth, so that the speed of the aerosol is somewhat diminished), which means they are no longer dependent on the successful inhalation of a small puff of aerosol, since the aerosol is diluted in a much larger, but isolated volume of air.

\subsubsection{The air}

Thus far, only particular obstacles to the fumctioning of the device have been discussed; namely those that lie in the user-artefact interface. An obstacle of quite a different order might, however, be more decisive for the future of aerosols in medicine: the growing concern about the use of CFC propellants, with their known damaging influence on the ozone-layer, in inhalers (Newhouse 1990). The polluted environment that gradually lost some of its importance as a causative actor in the CNSLD narrative returns as one of the consequences of its treatment. Air pollution has become only one of the factors, and not the most important, in the etiology of the disease, but inversely, the treatment of the disease has become one of the hazards to the environment. For this reason, in some countries (Sweden) the use of aerosols is forbidden (Deenstra 1992).

\subsection{Powders}

While poor Jeffrey, by becoming an aerosol user, is thus turned into a danger for the ozone layer, Johnny, his elder brother who has been using aerosols for some years already, has been quietly drawing in the much-used block in the children's corner of the office. His mother says in general he is fine the takes his three daily inhalations of cromoglycate, an anti-allergic drug, without protest and has become very dexterous in the use of the Nebuhaler. However; he does not like the procedure, especially not at school, so there he tends to skip inhalations, regardless of his parents' pleas. That might be the reason, his mother thinks, why he has periods of increased breathlessness and needs up to six inhalations of terbutalin (the bronchodilator Johnny uses) a day.

For this reason, the physician proposes to alter the administration route; Johnny may be old enough to use a powder inhaler without an air chamber. 
Letting him take cromoglycate in a so-called Spinhaler might be useful, and at the same time he could start taking his terbutalin (if necessary) from a Turbuhaler. The Spinhaler is a small yellow-and-white plastic tube in which a capsule filled with medicine is rapidly spun around if the air is drawn in forcefully. It makes a rattling sound which indicates that the procedure is successful, moreover, one feels the medicine coming in.

The other device. Turbuhaler, is a white, cone-shaped plastic device with a blue basis, it reminds one somewhat of a miniature spacecraft. The drug is stored in a large number of fixed amounts (up to 200 doses), which are released by turning the base until it gives a clicking sound. The click indicates that the device is ready for use. This is necessary beccuse the amounts of inhaled powder are so small that the patient does not feel the drug going in. This, the physician explains, is something Johnuy will need to get used to. According to the physician, afew rehearsal drows indicate that Johnwy is able to use the two devices. But, as one cannot be sure from a few attempts, he proposes to see both boys back in a few weeks instead of the usual three months.

Powder inhalers, the first types of which were developed before aerosolls, (Grossman 1994) are the most widely used inhalation devices. From these inhalers, fixed amounts of powder instead of aerosol are inhaled into the lungs. In the oldest type, Rotahaler, a capsule containing the powder is put in the device in a sort of propeller; the capsule is cut open by a tiny knife in the inside of the Rotahaler. The powder is inhaled from the fragmented capsule that is turned around by the breathactivated propeller. This propeller makes a characteristic rattling sound. Some patients are disturbed by this sound and invent an alternative technique such as opening up the capsule and inhaling the powder without the help of the Rotahaler. The device is packaged in a small plastic box with a range of hales for spare capsules.

As the propeller is driven by the flow of air inhaled by the user, this device, like the Nebuhaler, is an inanimate problem-solver. It is a translation of skills into device characteristics. The coordination between pushing the aerosol device and breathing in, hand-breath coordination, that, as we have seen, is one of the sources of failure in the inhallation of aerosols, is delegated to the device. More precisely, the work of the hand has been relegated to the propeller. At the moment the user takes a breath, the device reacts by releasing the powder from the capsule, and it does so unfailingly (except for occasional dirt preventing it from turning properly). As in the Volumatic, coordination has been translated from a skill into a mechanical phenomenon, into a characteristic of a contraption. 

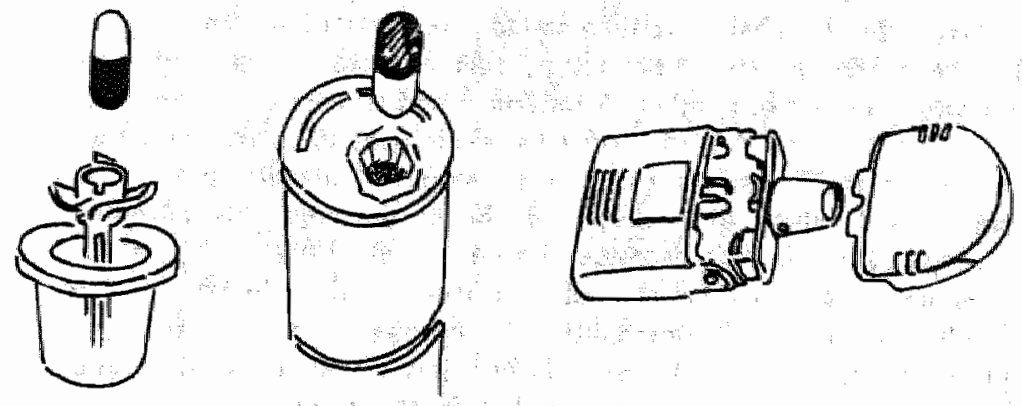

Picture 3. Rotahaler and Diskhaler

The differences between powder devices and aerosols are apparent from the instruction leaflet accompanying the former:

\section{Open the inhaler}

2. Insert a capsule in its holder on the propeller

3. Close the Rotahaler

4. Put the narrowest end of the Rotahaler in your mouth

5. Breathe in deeply and rapidly; the rattling sound from the device will inform you that you took a good inhalation

6. Hold your breath for about 10 seconds

7. Repeat puffs as directed. Waiting 1 minute between puffs may allow improved pemnetration of the second puff into the lungs [author's translation]

Table 2 Instructions for the use of powder inhalers

The most recent variety of powder inhaler is the Diskhaler, a flat half-round box, not much larger tham a matchbox, in which the same powder as in the Rotahaler is stored in four or eight depots on a disk. At every inhalation, the depot is pierced by a needle, which releases the powder in such a way as to make the use of a propeller superftuous. After inhalation, the closing, of the device imparts a quarter or an eighth rotation to the disk (depending on the number of drug depots on the disk). Thus, the device takes care of putting the next dose in place. It is a resolution to a known source of Rotahaler failure: users forgetting to take their pills with them or putting the capsules incorrectly in the device. 
But there is another claimed advantage: the absence of the rattling sound. As some users feel less conspicuous to bystanders, this is expected to enhance compliance. The interesting thing from the viewpoint of technology analysis, howewer, is that Rotahaler's rattling sound was a way of guaranteeing that the drug had been taken in. By removing it, this element of ensuring proper usage disappears in favour of another. A rattling sound stimulates proper use, but it may prevent sufficient use A silent device has exactly the opposite characteristic. It will be shown that the Turbuhaler (3.21) is a way out of this dilemma.

Latour and others have described similar developments in other fields of technology, for instance cameras (Latour et al. 1992). They argue that the development of a device is not a limear process in which increasing sophistication gradually eliminates all possibility of improper use, but an altemation of programmes and anti-programmes. Every new phase in the development is an answer to failures in earlier stages, but in the process, some of the desired characteristics of the device are lost. Every new programme means a loss of some part of the old one. Thus, the development of the Diskhaler is an answer to the anti-programmes threatening the function of the Rotahaler. The Diskhaler can be used in silence, which makes frequent use more probable; on the other hand, the loss of the sound of the Rotahaler makes imperfect inhalations go unnoticed.

A third alleged advantage of Diskhalers is that there is less risk of the powder inside the capsule becoming wet, which, if it occurred, would be another obstacle to successful inhalation. Instead of having to persuade users to keep their capsules dry, the problem is solved in Diskhaler by having it contain four or eight doses of powder in a waterproof packaging.

\subsubsection{Turbo powders}

The powder in Rotahalers and Diskhalers contains a transport substance which forms the bulk of the inhaled material. The drug is attached to this carrier in such a way that it is released at the intended receptor site.

This is different in one of the most recent devices in the family of powder inhalers, the Turbuhaler. This the device has been developed, in part, with an eye to an expected ban on aerosol inhalers, because of the CFC's they contain. The large number of doses Turbuhaler contains (up to 200) makes it comparable to the aerosol inhalers with regard to ease of use. 

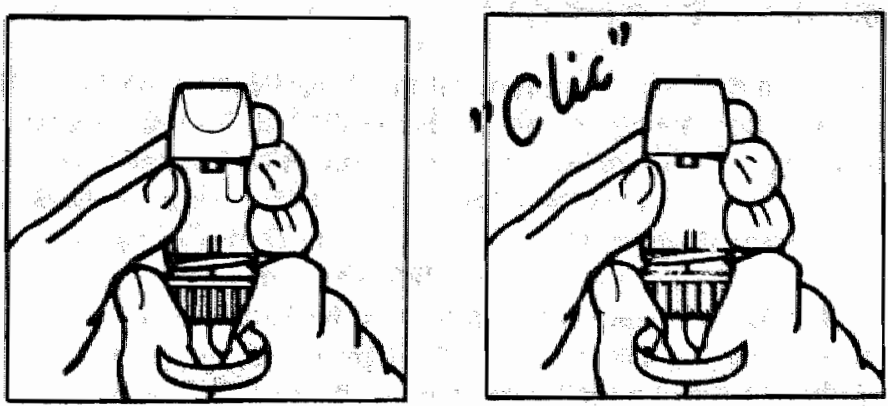

Picture 4. Turbuhaler

In order to discharge the drug, users have to impart a quarter turn to the bottom of the device, releasing a dosage, which is subsequently inhaled through the mouthpiece.

The lack of carrier substances makes the amount of powder inhaled so small that users may be led to believe they have not inhaled anything at all. To counter this potentially hazardous problem - users may be inclined to take a second dose, and so on, thinking that the device does not work because they do not feel any powder going into their ainways - the Turbuhaler has been desigmed to give a clicking sound each time a dose has been released for inhalation. As was the case with the Nebuhaler (the "big balloon"), this click ensures that patients use the technique properly and that a lack of effect cannot be attributed to a failure in technique. The moment the click sounds, responsibility shifts from the patient to the drug.

The French sociologist Laurent Thévenot has noted the moral and juridical function of these clicks in research dome on infant strollers: the sound of the click that indicates that the stroller has been unfolded properly, indicates a shift of responsibilities for accidental refolding (with the baby inside) from the user to the stroller itself (Thévenot 1993). The interesting aspect of Turbuhalers is that they contain a specific element that has no other function than to indicate to users that the proper sequence of movements was performed. Just like in Thévenot's strollers, these clicks are important for the attribution of responsibility in case of failure.

There is another similar element in the Turbuhaler: a small red-coloured piece of plastic pops up when the Turbuhaler is near depletion. This part of the device is necessary, because, again, a user does not feel the difference between inhaling from a full or an empty inhaler, and users cannot be expected to count the 100 or 200 doses it contains. Counting, here, is delegated to the device itself, it is expected to do that more accurately than its users. And again, this element of the Turbuhaler organises the accountability in case patients use an empty device. 


\section{Inscribed properties or: What is simple?}

Jeffrey's physician stated that with the advent of the Aerochamber, inhalation had turned into a 'piece of calke'. Before, it was clearly too difficult for a three-year-old child, but, as the short rehearsal at the end of the consultation showed, even with this 'amazingly simple' device it remained more difficult than simply taking tablets or a mixture. More can and does go wrong with inhalations than with ingestion.

Whether inhalation or ingestion is the more difficult technique depends largely on where one looks. Taking drugs orally can be a complicated affair: one has to free them from their protective package, take the right one at the right time; one should not forget them; sometimes pills can be difficult to swallow. Taking drugs orally may be a nuisance, especially if one has to remember to take them with or without meals, milk or water. But contrary to inhalation, once a patient has surmounted these obstacles and swallowed the pill, the effect (or side-effects) is independent of his skill. Improving the extent to which oral drugs, once they have been ingested, reach their destination means improving the drug itself; with inhaled drugs, both inhallation technique and drug design are candidates for improvement. Ensuring an oral drug reaches its target is mainly the work of the designer, whereas, with inhaled drugs, patients and physicians shoulder a greater part of the responsibility - this point will be retumed to later on.

The proper use of imhaling devices demands specific actions on the part of the patient, and also on the part of the physician. Like other devices and-machines used in the diagnosis and therapy of airways obstruction, they have characteristics of users inscribed to them, they contain scenarios of what physicians and patients typically should do - whether they actually conform to these prescribed identities is a question for chapter 7 .

When we describe these scripts (when we make a de-scription of the object, as Akrich calls it), physicians must be prepared to explain the use of the devices to their patients, but this is possible only if they have a drawer filled with inhalers and if they have enough knowledge about the use. And what is more, they have to be able and ready to actually demonstrate the use of at least a few of the existing devices. Since about twenty years airways obstruction is one of the areas of medicine in which patients need skills to follow treatment, and in which physicians, as a consequence, have to be skilled in the technicalities of drug treatment as well. They have to know, for instance, that with an aerosol inhaler one has to breathe in with moderate speed, but with a Turbuhaler, the speed of the airflow should be increased. They have to be able to demonstrate the use of a Volumatic and a Turbuhaler.

They have to accept a changing role in which an important part of helping patients cope with their disease involves helping them cope with their inhalers. On the other hand, the issue of the side-effects of medications, previously an important problem in the treatment of these diseases, has become less important with the shift from oral to imhaled medication routes. Monitoring side-effects has become a less salient part of the role of the physician in this type of treatment. 
That patients have to conform to new roles and characteristics is especially apparent in chronic diseases like CNSLD: following a treatment denands special skills from a patient. Johnny has to leam how to use his breath to be able to treat the problem he has with his breath. He has to become an expert in the use of different sorts of inhalers and he has to gain experience in the use of various medications. He has to develop a body technique to be able to follow the advice of his physician. One of the remarkable things about this disease is that the body technique needed for treatment involves precisely the function the should be treated, namely breathing. In short: to be able to follow an inhalation treatment, one has to be able to regulate one's breath properly.

Moreover, to meet the demands of the iwhaler, Johnny should be adroit enough to fire an aerosol, or, later on, to fill a diskhaler. Parents need to be able to check their childrens" use of Volumatics or Nebuhalers, and very often, they must instruct child-minder and teacher alike in proper usage.

Adult patients have to be prepared to train themselves to take drugs. Local therapy may have advantages over systemic therapy, but it requires training. Taking the time to follow the instructions is not always feasible, and it is especially difficult in urgent breathlessness.

Patients have to be organised enough to take their inhalers everywhere - this is not a problem for those with severe complaints, who feel unsafe without their inhaler, but it is for those with milder airways obstruction. And they have to disregarding their enmbarrassment when they need a puff during a meeting, or in delicate and difficult situations. They have to consent to revealing they have airways obstruction, they must becom a 'patient' not only at home but also at school or work. That, in turn, places demands on these environments, that have to allow the CNSLD patients the possibility of taking their inllalations.

In oral medication drugs have to be designed in such a way that of all the organs or systems they could possibly influence, they only, or almost, attach to the aimed ones. In inhalation, the work of ensuring that a drug is deployed at the correct place has, in part, shifted from designers to users, and from there, as was illustrated, it has sometimes shifted to the device itself (clicking).

One problem with shifting responsibility for the trajectory of the drug from designer to user is that the latter may be less capable of assuming it at the time he most needs the dng, namely, during an attack of breathlessness. The beauty of having a drug transported by the very mechanisn it is intended to beal respiration - can sometimes turn into a senseless waste of gas or powder.

\section{Different routes or changing maps?}

Thus far the emphasis has been on the prescriptions-for-use as they are given with, and, to a large extent, inscribed into inhaler devices. In the following sections, a different question will be asked: Do imhalers reconstruct the part of the body they are functioning in? To what extent do different airways emerge with the development and use of this type of device? These questions take the analysis outside the intentional work of designing technology, and move it into the area of the non-intended roles devices play. 
Michel Foucanit, in 'La Naissance de la Clinique', has argued for a study of the different spatialisations of the body that occur in medicine:

"Cet ordre (celui de latlas anatomique) n'est cependant qu'une des manières pour la médecine de spatialiser la maladie. (...) Quand pourra-t-on définir les structures que suivent, dans le volume secret du corps, les réactions allergiques?" (Foucault, 1964 )

In line with this idea, another type of ontological innovation is the establishment of, strictly drug-linked, new connections and disjunctions between regions of the body: a new regionalization. What type of map of the body is created by the inhalation of drugs?

\subsection{Increasing precision}

"The inhaled route has advantages over the oral route in the treatment of respiratory problems because the drug is delivered directly to its receptor sites within the bronchial tree. Consequently, lower doses can be used, the onset of action is more rapid, and the incidence of unwanted side-effects is reduced." (Newman 1981 p 10)

This quotation is an example of the most notable narrative incorporated in inhalation: it says that treatment of airways obstruction is increasingly precise, that drugs attach not only to the target organ but to the cells themselves. And, most importantly, this happens directly, with as little interniediaries as possible. Instead of taking a circuitous route through the stomach and the circulatory system, the drug fastens directly to its receptors. Salbutamol pills follow the route of the stomach, they have to be digested and transported to their target areas and then have to attach to these receptor sites, which they approach from the inside of the body: This is a perilous voyage; there can be problems with digestion or with the transport by the blood, the drug may be modified during its trip through the body, and, more seriously, it can attach itself to the wrong receptors. The shortcut salbutamol takes when dissolved into an aerosol is more direct, quicker, and less risky: in a matter of seconds, it passes through the mouth into the large airways, and from there into the smaller ones. As it comes directly from the outside to the surface of the airways, there are no obstacles to prevent it from reaching its goal.

The development from pills to inhalers, then, represents a decrease in the number of intermediaries; the obstacles encountered when taking oral medication disappear. For the patient, however, the decreased complexity inside the body is replaced by an increased complexity outside. Swallowing a pill is simpler than taking an inhalation.

Inhaler treatment is supposed to be more precise than conventional administration routes. As we have seen in chapter 3, the term 'precision' also played an important role in the development and distribution of peak flow meters. There, precision meant the extent to which the device gives a well-defined picture of lung function, here it means the extent to which drugs are delivered to their target organ or cells in a reliable way. 


\subsection{Making the ainways local}

There is an obvious way in which local and systemic treatment differ less tham might be expected. It has been shown that locally-applied steroids and bronchodilators reach other parts of the body, if large doses are used (Reed 1991). There is, apparently, a threshold dosage of medication at which local treatment becomes systemic. Inhaled substances do land in the airways, but they may continue to travel, albeit in small amounts. This has resulted in recent innovations in drug design, outside the realm of respiratory diseases, where the airways are the chosen porte d'entrée for drugs, for instance in the treatment of infertility or of bed-wetting.

Nevertheless, the technology of inhaler therapy hinges on the notion of local treatment as opposed to systemic or global treatment. This distinction presupposes the possibility of tracing borders inside, or on, the body. The technology presupposes that something like local action on the human lungs is possible, and that there is a common understanding of what 'local' in the lungs means, and of the kind of boundaries that can be traced in the airways. It makes the assumption that there is one and only one geography of the lungs. 'Assumption', however, is an incomplete term: the technology makes local action passible. In this way, it not only assumes boundaries, but actually draws them.

How are frontiers traced within the airways? How is one zone inside the lungs separated from another? There are several ways to do this. Anatontical investigation separates lung zones according to the aspect, resistance, and touch quality of the tissues. Thus, by cutting and separating, a difference is created between bone and nerve, between blood vessel and connective tissue. Next, parts of these tissues are examined under a microscope and a distinction is made according to the cell-types they contain: the area where muscles are found inside the walls of the airways is separated from the muscleless area in the very small airways, and so forth. Anatomists construct bodies in a very literal sense: they destruct the relationships they find and re-construct new ones based on microscopical similarities.

Another type of geography is made by roentgenograms, where lungs are subdivided according to the translucency of different areas. Pasweer has shown that the correspondence between the pathological and the roentgenological images, far from being self-evident, had to be laboriously constructed. The pathological image of the lung had to be made to parallel the roentgenological one (Pasveer 1992). The geography of X-rays is one of obstacles of different solidity. Thus, bone is equated with areas of a greater density than, for instance, skin or lung tissue, the glands at the centre of the airways are less easy to transgress than the aerated periphery. The practice of reconstructing the lungs by X-rays is clearly different from anatomy: anatomists remove obstructions by cutting them away while roentgenologists resort to more indirect ways. They can, for instance, turn their camera around the object or increase the density of the object artificially by filling it with radio-opaque materials (bronchography). The latter procedure is a particularly clear example of how an imaging technology shapes its object.

Zones in the lungs can also be defined by looking into them: bronchoscopy produces a slightly different, though on many points comparable map of the 
airways. A bronchoscope is a stiff or flexible tube that, while descending from the mouth downward, shows a series of bifurcations in a constantly narrowing tree of pinkish tubes that are in perpetual motion. At a certain point on its path through the airways it has to reverse, either because the tubes become thinner than the bronchoscope or because the curb in the airway is difficult to manoeuvre.

These are all explicit imaging techniques that have no other purpose than to forge a representation of the body, in this case the airways; it is argued that they do not merely forge an image but simultaneously reconstruct the airways. The subject of this chapter, however, is a technology that is not at all designed for making images. How do drugs configurate the body? This can first be illustrated for oral drugs. The ingestion by mouth of a sufficient amount of salbutamol, say $8 \mathrm{mg}$, forges a connection between two organs: the heart and the lungs, by dilating the lungs and quickening the heartbeat. This particular connection is different from those established in other geographies of the body. Anatomy, for instance, forges links between the heart and the lungs consisting mainly of blood vessels. Sophisticated radiological examinations show them to be made of blood streams, but salbutamol produces a connection that is made of receptors: the link between the heart and the lungs which is particular to those using salbutamol or similar drugs, is that the two organs are responsive to this drug.

To stress the point that a specific map of the body is produced, consider the example of antihistaminics, drugs that are taken to control allergic reactions. They establish a link between the lungs and the brain in the same way as salbutamol does with the heart and the lings. In this instance, both the airways and the brain are tranquillised: the effect of these drugs on the brain is to produce drowsiness, while the inflammation in the lungs and elsewhere is decreased. Here, too, the connection is one of receptors that provide a specific trajectory through the body, a section through it: Ingested drugs, in short, map the body as a geography of receptors.

Another type of mapping is made by the inhalation of drugs. Inhaled drugs ideally form a cloud of either powder or gas that is drawn inside the lungs. It is taken in as a small puff in the mouth but then dissolves within the whole space of the lungs and is capable of reaching areas in the lungs that bronchoscopes fail to reach. Not even the contrast medium of bronchography gets as far down as this cloud of drugs.

As has been stated, there is mo guarantee that, in actual usage, the gas or powder reaches its destination; much depends on the inhalation technique. Some inlialations carry a large proportion of the gas to the specified receptor site, while others only bring it halfway. Moreover, not all areas inside the lungs are equally accessible to the vapour of drugs: most of it is deposited in the central areas of the lungs, while the upper parts receive relatively less. Thus, the lungs are divided, by the geography of inhalntion, into accessible and less accessible areas.

But more importantly, they are divided into interesting and less interesting zones. The larger part of the airways, from the trachea to the medium-sized bronchi, is an area where the inhaled cloud is supposed to pass on its way, but where often a large proportion of it gets trapped. From the mouth to over halfway into the lungs is in a sense the 'waste land' of inhalation.

In order to follow drug particles inside the airways they need to be made visible. One way to do this is by radioactivity. Once drug particles have been 
treated with radioactive substances, tracers, they can be seen on a radiographic screen. In this way, radiographic investigations trace a map of the airways, and they literally go further than any of the previously existing mapping technologies by reaching previously unattainable areas of the lung. Studies have indicated that whatever inhalation technique is used, a substantial portion of the aerosol is deposited in the throat and larger airways, while the intended deposition place, the smallest airways, receives only a small portion of the spray. As much as 90 per cent of the medicine is lost underway, however perfectly the actors (patient; inhaler, carrier) coordinate and perform (Newman et al 1989).

One aspect of inhaler geography is that it contains value judgments on different regions. That can be seen in the values attached to different side-effects: the throat, including the vocal chords, where much of the inhaled drug is left behind (Toogood 1980), is judged to be of a different quality than the heart, where systemic bronchodilators have their non-intended receptor sites.

If inhalation is referred to as a local therapy, that does not mean that it is entirely site-specific, but invokes the notion that it does not extend to important unintended locations. Calling a therapy form local implies attaching different values to different places in the body.

If inhalation therapy traces its own geography of the lung alongside others, then the phrase: "Inhaler therapy is better than systemic therapy because it acts locally" is circular. It is local in its own geography, which differs from the geography of systemic therapy. Inhaler therapy is one of the ways to define relevant places inside the airways and can only be said to be a local treatment inside this particular geography. The distinction between local and global is different in different situations, one could say that it is itself a local phenomenon. Thus, inhalation therapy with turbuhalers is (physiologically) local when compared with oral therapy, but global in comparison with, for example, home nebulisers, that are rarely used. Aerosols may have a local distribution in the lungs, but they have global effects on the ozone layer. Powder inhalation may be physiologically local, but socially it is global by virtue of its general, accepted usage.

\section{Conclusion: shaping patients, physicians, and airways}

Drugs, anatomy, bronchoscopes, and X-rays all constitute their own maps of the airways. In the preceding pages, the differences between these geographies have been emphasised. This may have created the impression that the mapping of the airways is largely arbitrary, as if 'anything goes', depending on the technology used. This, however, is not the conclusion of this chapter. There are limits to the liberty of mapping, and these are imposed, not by any essential characteristics of the airways, but by the other existing mapping techniques. Anatomy prohibits drugs from going directly from the airways to the liver or kidneys. The existence of bronchoscopy prevents the cloud of drugs from disregarding the bifurcations that bronchoscopy creates and makes visible, The limits to ways of shaping the body are not imposed by a hypothetical essence of the body, but by the other patterning practices. The combination of these shaping practices constitute the body. In the end, one may say that the limitations are imposed by the real body, as long as it is clear that this real body is made, not given. 
This chapter has been about two elements of inhalation as a form of therapy: in the opening sections, the various scripts of inhalation devices were discussed. The question posed was: To what extent, and with what means, do inhalers shape the roles of patients and physicians? It was suggested that this form of medical technollogy demands new skills from both patients and physicians. On the side of the patient, it calls for a new skill, coordination of haind and breath and from physicians, it requires experience in teaching patients the intricacies of inhaling drugs. The simple prescription 'Take this pill three times a day' has been replaced by 'Stand up, breathe out deeply, put the right end of the inhaler into your mouth', and so forth.

These characteristics of physicians and patients are not only demanded by the instruction leaflet and by the pliysician's explanation, they are often inscribed into the device itself, translated into elements of the inhaler.

The last sections were devoted to what may appear to be a completely different working area of devices: the constitution of spaces and boundaries within the lungs. It was suggested that different practices involving the lungs, be they explicitly designed for representation or not, produce their own geographies, their own maps of the airways. The map of anatomy (assuming, perhaps falsely so, that anatomy produces just one map of the lungs) is different from that of X-ray investigations, and they are different from the map inhalations draw inside the lungs. The ingestion of drugs patterns yet another map of connections of the airways and body parts.

Such geographies are the result of, not the prerequisite for the use of various types of technology. The use of technologies like drug inhalers designs these different 'spatialisations', to use Foucault's term, in the user's body. They do not exist in abstracto, but emerge together with the act of inhalation. This is the link between the two parts of this chapter: the first describes the work needed for the actual realisation of the geography of inhalation described in the second part.

This implies considering the body as having multiple geographies (Mol and Law forthcoming) (the term is preferable to 'anatomies', because, as we have seen, anatomy is but one of the ways of mapping the body). Michel Foucault, in the quotation given at the beginning of this chapter, was looking for new anatomies traced by disease. Here, a different road was taken to the same goal by considering inthaler technologies as the means of tracing new maps through the body. 


\begin{abstract}
"En affirmant que les nouvelles normes biologiques ne sont pas liéquivalent des nomes antérieures la malladie Goldstein ne fait en somme que confinmer ce fait biologique fondamental que la vie ne connaît pas la réversibilitié. Mais si elle nadmet pas des rétablissements, la vie admet des reparations qui sont vraiment des innovations physiologiques." (Canguilhem 1979)
\end{abstract}

\title{
5. Drugs and the variable ontology of airways and airway disease $^{1}$
}

\section{Introduction}

The preceding chapter contained an analysis of the various inhalation devices used for the treatment of CNSLD. In the present chapter the focus will be on the substances that are transported by these devices. It is about the stuff that they are designed to launch into the lungs of those who suffer from the disease.

In chapter 2, the ways in which airways obstruction has come to be considered as a chronic disease were discussed. One form of chronicity, it was argued, is the continuous use of medication. Two or three inhalations a day are common for most people with CNSLD, although there are variations: in milder forms of the disease, the use of drugs may be interrupted for long periods, and sometimes be termimated entirely, whereas people with more severe disease often use considerably more than two or three inhalations dailly.

Thus, people with anything but the mildest form of airway obstruction are in almost constant contact with some form of medication. Their airways are virtually never without one of the several substances used to combat the disease. In this chapter, these substances will be regarded and investigated as a form of medical technology. The question about the drugs used in the management of CNSLD is the same as that posed in previous chapters: Do the different ingredients of these medications perform different definitions of their users?

The focus, then, will be on describing the way in which the drugs incorporate and help constructing new forms of the body. In a first approach, using concepts developed by the French philosopher Dagognet, attention will be paid to the diverse images of the airways that are created by different drugs. But the core of the chapter will be a description of the entities that are created when airways and drugs are linked for a considerable period of time. The argument will be, as an extension of one of the central ideas in the work of the philosopher and physician Canguilhem (discussed in chapter 3), that treatment is not merely an attempt to "get back to normal", but that it is the creation of new entities. In 'Le normal et le pathologique", Canguilhem has argued that disease is not so much a situation of

An abridged version of this chapter has been accepted for publication in: Berg $M_{n}$ Mol A (eds). Differences in Medicine. Boston: Harvard University Press, forthcoming. 
abnormal functioning, but a condition in which the body sets new norms for itself in a sense, it becomes a different body (Canguilhem 1979). Canguilhem developed his ideas in a description of the natural history of disease, before medical intervention. In this chapter, it will be argued that therapeutics form an important element in the making of what Canguilhem called physiological innovations.

Up to now, dnugs have rarely been the subject of of socio-technical or phillosophical analyses. They are a technology that has escaped from the continuing expansion of science and technology studies. Vos's study of the development of cardiac drugs (Vos 1989) and the work of Bodewitz and others (Bodewitz et al.) are rare examples. On the other hand, in regulatory procedures concerning the introduction of therapeutic innovations, drugs have been subjected to Technology Assessments avant la lettre, to a point where, as was argued in the chapter 1 , the general model of TA (the evaluation of secondary effects of technology) seems to be taken from drug regulation. Moreover, the first examples of diffusion research in medical technology were on drugs (Coleman 1957).

The chapter proceeds as follows: contemporary views on the treatment of CNSLD will be briefly discussed, largely based upon consensus statements issued during the last few years; then, a case-history will be introduced which will be followed throughout the chapter, analysing each new drug that is introducied into the treatment, together with the information the patient receives. It will become apparent that the continuous introduction of new drugs places the patient in a number of different worlds. The coordination of these differences will be the subject of a separate section. Finally, continuous treatment will be discussed as the constitution of physiological inmovations.

A notable difference between this chapter and the preceding ones lies in the materials used: apart from medications and texts describing their development, information leaflets that patients receive with the drugs will also be discussed. Instead of scientific papers, the texts used here are part of drug technology in a very visible sense: drugs are accompanied by texts which perform, as will be seen, different functions. An analysis of these texts will make it clear that they contain accounts, not only of the working mechanisms of the drugs involved, but allso of the physiology of the airways, and the treatment of CNSLD. They contain definitions telling the user what his or her airways are.

\section{Drugs and airways obstruction}

Consensus documents and treatment guidelines advocate two types of therapeutic action in the treatment of CNSLD combatting the airway spasm with bronchodilators, and fighting inflammation by decreasing hyperreactivity or allergy. Anti-inflammatory therapy in turn is divided into two sub-strategies: avoidance of triggers, for instance by eliminating allergens from the patient's house and working environment, and decreasing sensitivity with the help of medication. Both these anti-inflammatory strategies are advocated and practised, but the latter has been gaining momentum during the last ten to twenty years.

The most important drugs that are usually mentioned are bronchodilators (salbutamol and terbutalin), anticholinerg substances (ipratropium), anti-allergic 
drugs (cromoglycate), and, finally, anti-inflammatory ones (steroids such as beclomethasone). Salbutamol and terbutalin, the most widely used bronchodilators, act as $B_{2}$-agonists or sympathicomimetics, and are taken to facilitate the working of $B_{2}$-fibres of the sympathic part of the nervous system. The working of these drugs is explained by stating that these nerve fibres are specific to the airways and cause the smooth muscles in the small airways to distend. Apart from that, they are reported to moderate the allergic response of the airways to some extent (Nationall Asthma Education Program 1991).

The working mechanism of ipratropinm, which is the most widely used socalled anticholinerg drug, is explained as a blocking of the opposite type of nerves, the cholmerg or vagal pathways. This not only distends the airways, the explanation goes, but also diminishes the secretion of mucus. Its onset of action is slower than with $B_{2}$-mimetics; and it is suggested that it works better in small infants and the elderly (Van der Waart et al. 1992).

The anti-allergic drug that is advocated in most of the guidelines is cromoglycate. Some uncertainty is usually reported as to the working mechanism of this drug, but the supposition is that it blocks the release, from so-called mast cells found in the bronchi, of mediators which can provoke an allergic reaction. Through this mechanism, the drug prevents, when administered continuously, the occurrence of ailrway narrowing.

The guidelines and textbooks devote extensive coverage to what are regarded as the most effective, but also the most complex drugs used currentlly in CNSLD: inhaled corticosteroids. The American guidelines for the diagniosis and treatment of asthma mention the following three mechanisms of action: interference with the synthesis of leukotrienes and prostaglandines, two proteins that play a role in airway inflammation and constriction; prevention of migration of inflammatory cells, and, increased responsiveness of $B$-receptors which intensifies the response to $\beta_{2}$-mimetics (National Asthma Education Program 1991).

For about a decade now, the common view on the treatment of CNSLD has been that it should aim at decreasing airway hyperreactivity, temporarily or even definitively, by fighting inflammation (National Asthma Education Program 1991; British Thoracic Society 1990; Van der Waart et al 1992). Merely repairing breathlessiness has come to be considered second-hand treatment, even for those with only mild complaints (Reed 1991). According to the standard of today, genuine pharmacological treatment should be protective in character, not only in the sense that it protects the airways from toxic substances or from allergic triggers, but also in the sense of protecting them from damaging themselves by reacting too intensely to these substances. In other words: protective treatment protects the airways against triggers, but also against themselves - it influences the host factor, as it is often called (Orie et al. 1961).

Without such protection, the explanation bolds, patients would suffer more frequent attacks, but also, and more importantly, the airways would slowly, over time, destroy themselves by reacting to, triggers with the triad of swelling, secretion, and muscle contraction. It is against this gradual decay of the airways, which becomes visible as a gradual loss of ling function, that long-term protective treatment is prescribed: 
The feeling about obstructive airways diseases that emerges from these consensus documents is that, although they are incurable and progressive, their progression can be curbed or at least forestalled, and doctors are no longer entirely powerless. According to most experts, the fatalistic climate of the Sixties (Orie 1953) as to the course of the disease is passe, not only is protective treatment possible for those who suffer from fiequent attacks, it is indispensable, even for those with no more than moderate complaints.

\section{Carl"s sequence of airway drugs}

Carl, a man of forty-five years, has been developing symptoms of obstructive airways disease for two years. He has had episodes of cough and breathlessness that increased in frequency, until they came more than once a month. The first drug his physician prescribes is packaged in a flat box from which he has to take a puff every six hours. The drug, salbutamol (trade name Ventolin) opens the cramped ainways in a matter of minutes. However, the physician emphasises, salbutamol simply 'opens' the ainways, and it works for a few hours only; that is why, in acute cases, it is prescribed up to eight times a day. Although there is no doubt, he explains, that it is essential that Carl uses it, the narrowing of the airways is not, as was previously thought the basis of the disease, but an effect of another cause; namely, the inflammation of airway tissue.

After having wsed the drug for a week Call says he feels much better, but after having examining his chest and measuring peak flow, the doctor is not entirely satisfied. He says he will have to give him anather inhaler with a different substance but having the same effect, called ipratropiumbromide. This drug, he adds, has a dual function: it widens the ainwoys and it diminishes the production of mucus. However, it acts less quickly than salbutamol and therefore it usually is not the first drug prescribed.

\subsection{Cramped aimways}

\subsubsection{Salbutamol}

In the patient information leaflet Carl is given together with the salbutamol inhaler, the following explanation is offered about of the working of the drug.

"Bronchodilators relax the airway muscles, which allows the airways to widen. You will feel that normal breathing resumes. These drugs are to be used during an attack of breathlessness. Bronchodilators, however, do not influence the inflammation in the airways, if you need bronchodilators on a daily basis, drugs that control inflammation should also be used.

Side-effects.

When inhaled, these drugs rarely have side-effects. If they occur, the most frequent are trembling hands and restlessness. These side-effects are not harmful." (Nederlands Astma Fonds 1993) [author's translation] 
This small text can be read as a narrative in which a surprising number of elements play their respective roles and define each other. There are bronchodilators, airway muscles and, closely related, the ainways. Instead of literally dilating the airways; bronchodilators are said to allow airways to widen. It suggests that dilating is the normal function of healthy airways. Breathlessness, according to this text, comes in attacks, and it is during these attacks that drugs are necessary. A link is also made to other forms of treatment through a description of what salbutamol does not do: decrease inflammation. The need for other drugs is determined, in this text, by the frequency of bronchodilator use. It is worth noting that drug use is the criterion, not increasing complaints or the decreasing effectiveness of salbutamol Regardless of other factors, the daily use of bronchodilators indicates a need for further treatment.

The statements on side-effects link (although it is said that this connection is only made rarely) salbutamol to the body as a whole: it makes hands tremble and causes general unrest. Thus, salbutamol, through its possible side-effects, constructs a connection that was non-existent before, and that does not exist in non-users of the drug: a connection between airway muscles and muscles in the other parts of the body.

This text, together with the physician's explanation, has introduced Carl to a world where such things as airway muscles, bronchodilators and inflamed airways are defined in their mutual relationships. He comes to see his airways as comprised of diverse elements which act upon each other in various ways: they influence each other, one actant allows the other to distend, some drugs control inflammation, and so forth. The end result is that Carl 'can breathe again'. However, in order to achieve this, he must first pass through the series of translations depicted in the narrative.

\subsubsection{Anticholinerg drugs}

Carl's physician told him that in addition to salbutamol a second drug was needed. $\mathrm{He}$ explained that ipratropium was often given in combination with a bronchodilator, and that its effects, though roughly the same, also comprise diminishing mucus secretion in the airways.

"Ipratropium;" the imformation leaflet continues, "not only affects the small muscles of the airways, but also inhibits the production of mucus in the airways. Nowadays, ipratropium is the most important anticholinerg drug. It can only be administered through inhalation and becomes effective after twenty to forty-five minutes.

Elderly persons often react better to ipratropium than to $B$ sympathicomimetics. In treating babies, anticholinerg drugs work better than other bronchodilators.

Side-effects

Possible side-effects are: dry mouth, constipation, difficully urinating, blurred vision, and pain in the stomach. These side-effects are limited in practice to the ingested form of the drug."(Nederlands Astma Fonds 1993) [author's translation] 
A new element introduced in this text is a substance called mucus, and which ipratropum is supposed to eliminate from the airways. Mucus obstructs the airways and contributes to an increase in symptoms. Ipratropium also distinguishes between age-groups of people suffering from obstructive airways disease: the very young and the elderly have a specific form of the disease that is more responsive to ipratropium As in the case of salbutamol, the possible side-effects draw connections to the other parts of the body: the mouth, intestines, stomach and bladder.

Another similarity with the former drug is that dilating is its method of healing. But ipratropium works through another mechanism as well: curing is clearing the airways of excessive mucus; the drug prevents the body from producing more slime. It does, however, not so much help the airways eradicate excess mucus produced in periods of illness, but prevents its production. In a specific way, ipratropium displays one of the archetypes of healing, as Dagognet calls them (Dagognet 1964): cleaning the body of phlegms and mucus. But whereas some drugs claim to clear up the phlegm by diluting it, ipratropium prevents it from being produced.

The image of the airways associated with ipratropium as hardly different from that of salbutamol. It works on the airways as far as they are part of yet another sub-system within the nervous system, the parasympathic. It links the muscles in the lungs to those of the bladder, eyes, heart, and intestines; but also the glands in the airways to those in the mouth and the stomach. Ipratropium introduces slime glands as a part of the inner wall of the airways - and as subject to dysfunction.

Analysing the consultation and the text about salbutamol and ipratropium in this manner provides clues to the images and representations of the airways which drugs convey. In this an interpretation, medications are regarded as texts, as narrative structures that transmit, among other things, images of the airways. They also communicate narratives about what happens inside the lungs once the drugs have reached their destination.

\subsection{Instable cells}

A few months after the first consultation, Carl visits his physician and complains of feeling poorly. He has been using his bronchodilators more than usual, needing them almost every day, and sometimes during the night as well. And he feels like if he never completely recovers. Peak flow values stay about hundred below his maximum, and even ten minutes after spraying they do not reach normal values.

On hearing this account, the physician agrees with Carl that things are not going as they should. On auscultation, he hears a moderate degree of wheezing in both Carl's lungs.

Based on this information, the doctor says, it is time to modify the treatment. It is no longer sufficient to treat the attacks only, and therefore continuous treatment is necessary, at least for a few months. Carl is reluctant at first, but then he relents:" "I can't go on like this, taking more and more medicine - it can't be good for me." After obtaining this 
preliminary consent, the doctor explains that there are two forms of protective treatment for asthma: cromoglycate and corticasteroids. Both consist of daily inhalations of medications, and aim at decreasing inflammation in the ainways, but their working mechanism is slightly different. In Carl's treatment the inhalations contain an anti-allergic substance called cromoglycate. It makes the ainways less sensitive to the allergens. Carl should inhale three times a day, the inhaler he will be using resembles the one he uses for salbutamol.

The aim of the treatment is to protect the ainways against the attacks caused by allergic reactions. This, the physician explains, has an important implication: cromoglycate does not help in acute situations, therefore, salbutamol should be kept at hand for urgent breathlessness. These attacks, however, are likely to become more and more rare. The doctor expects this treatment to show results in a few weeks.

Through this explanation a new picture is drawn of the lungs, and Carl is introduced to a new form of treatment. The aim is no longer relieving him of his symptoms, it has become prevention.

In the leaflet on medication his physician gave him when he prescribed the bronchodilators, Carl reads the following about cromoglycate and similar drags (the cromones):

"Various stimuli are capable of constricting the airways of asthma patients. Partly, this is caused by the release of histamine and other bronchoconstrictors. Cromones hinder the release of these substances. They can only be taken by inhalation. They offer immediate protection when taken shortly before physical exertion, and before coming into contact with a trigger one is sensible to (e.g. a cat). (..) They have a short-term effect, so they need to be taken at least three times a day.

If these drugs are taken as a protection against stimuli one comes into contact with continuously (for example, house dust), it will take a long time before they become effective, about four to six weeks. In these circumstances they are to be used on a daily basis, even when there are no complaints." (Nederlands Astma Fonds 1993) [author's translation]

A marked difference with the narrative of salbutamol is the time-frame. Instead of the minutes mentioned in the salbutamol and ipratropium texts, this leaflet refers to weeks before any effect may be detected. At the same time, cromoglycate has to be taken four times a day, which suggests that the duration of its effect is short. The time-frame of cromoglycate is further complicated by its near-immediate effect in exertion-dependent complaints. Different times are present in Carl's body: the fast time of bronchoconstriction relieved by salbutamol the somewhat slower time of mucus formation on which ipratropium works, the short-term event of histamine release on exertion, and the slower process of continuously impeding histamine release.

The world depicted and defined in this narrative differs in a number of respects from the others. Important new elements and relationships emerge. Apart 
from the cromones themselves, stimuli, or triggers, are introduced that have the power to release histamine and similar substances; additionally, house dust is introduced as a daily trigger of airways obstruction. A new action, namely protection, is presented as the most important contribution of cromones to the treatment of airways obstruction. And finally, the role of complaints is modified in an interesting way: their presence is considered irrelevant for the decision to either continue or stop the use of cromoglycate.

As regards healing, cromoglycate constructs a completely different narrative. Here, curing means protection of airway surfaces against inhaled aggressors. Instead of waiting for these aggressors to act, instead of coping with things after the fact, cromoglycate proclaims the task of treatment as being the protection of the body from its adversaries. Or more precisely: as preventing the body from unchaining the forces of an allergic reaction to these triggers. Cromoglycate protects the body against an extreme reaction to a common trigger.

For this reason, cromoglycate is advocated as being more causal in nature than Carl's previous therapy, which, seen from this angle, was no more than symptomatic. This raises the question of what constitutes a cause in these diseases; this question will be returned after the discussion of steroids.

Cromoglycate contains an account in which the airways are defined as a surface - that the airways have a tubular structiure is without direct relevance here covered with components that protect it against the assault of inhaled triggers. Upon detecting such substances, these components - called mast cells - begin destroying themselves by demolishing their membranes and releasing a substance that causes constriction of the bronchi. This immediately prevents the lungs from breathing in more of the unwelcome substance. The abnormality of Carl's airways is in the selection of triggers they react to, not in the reaction itself.

In CNSLD the defence mechanisms of the airways are triggered by either harmless substances or harmless amounts of triggers that normally are deleterious only in larger amounts. In both cases the body's defence turns into an attack on itself. The body's security system turns out to be a risk to itself. Cromoglycate thus treats the lungs as risky organs that can amplify an attack rather than subdue it.

\subsection{Inflammation}

Unfortunately, even continuous treatment of Carl's airways with cromoglycate turned out to be insufficient:

About two months later, Carl returns to the office. Though he usually feels quite well, he tells his physician that, in the last three weeks, he has had regular nightly attacks and, although he has started increasing the amount of salbutamol inhalations, his peak flow is still well below his personal optimum. After consulting Carl's peak flow list, the physician agrees with this and finds it unsatisfactory. He questions Carl about his compliance with the regular inhalations of cromoglycate and realises that is not the problem. According to him, the only passible conclusion is that the disease is still resisting control. He tells Carl that the next step will have to be inhaled corticasteroids. These drugs directly treat inflammation and thereby 
prevent attacks of aimays obstruction. The propasal clearly worries Carl: "But that is a very hecry medicine, isn't it? Am I so seriously ill, doctor? I know that my father-in-low used corticasteroids, but he could not even walk up the stairs normally!"

There is no reason to worry, the doctar assures Carl, and even less reason to compare himself to his father-in-low, who has a much more severe form of the same disease. Nowadoys, moderate forms of asthma are often treated with local steroids as a protective therapy. Extensive research, he explains, has shown no important side-effects, because dosages can be kept very low in local therapy. Of course, it is still cansidered to be the mast powerful treatment - that is the reason why it is not prescribed initially. The consequences of not treating him are much greater than the negligable hazards of steroids. And perhaps if things improve, Carl will be able to stop treatment, it sometimes happens with people suffering from ainways obstruction.

Inhaled steroids are said to work in two ways: they protect and they treat at the same time. Although, up to now, the foundation for the long-term treatment of patients with COPD is weak and consists mainly of indications from research over comparatively short periods (Van der Waart et al 1992), Carl's doctor presents them as the realisation of the ideal of preventative therapy. He says they combine the advantages of salbutamol (mere treatment, wo protection) and cromoglycate (protection only, no treatment). For Carl, however, they imply a connection that frightens him: it makes his complaints look similar to those of his father-in-law. This link is promptly dispelled by his physician by declaring that modern insights urge for the use of identical drugs in treating people with different severity of the disease. It is because of these innovations in therapy that Carl is treated with the same drugs as his father-in-law, not because their disease is equally serious.

What does the information leaflet, Carl's second source of information, tell him about these drugs?

"Besides a having strong anti-inflammatory effect, inhaled steroids also provide protection to the airways. This occurs by a decrease in the production of bronchoconstrictory substances, diminishing the irritability of the airways. Inhalled steroids do not have an immediate protective effect. It can take weeks, or even months, before an effect is felt. Only after several months can the effect be assessed and during the first two years it may still increase. So do not give up too soon!

Side-effects: Inhaled steroids are safe drugs. Because they are inhaled, relatively small amounts of medicine are taken up by the blood. In normal use, the side-effects that one sees with steroid tablets do not occur. The amount of medicine in the blood may be further diminished by using an inhalation chamber and by rinsing the mouth after each inhalation. This also serves to prevent the hoarseness and soreness in the throat that sometimes occur when using this medication." (Nederlands Astma Fonds 1993) [author's translation] 
By now, a number of the elements in this account have become familiar: bronchoconstrictors, inflanmation, protection, and so forth. Significant new ones are: irritability, the blood stream, and the inhalation chamber. Furthermore, the time-frame in this text is the longest: whereas salbutamol takes a mere minute to become effective, ipratropium already meeds five to ten minutes; then, as regards protective effects, the time needed varies from the "shortly before you expect to come into contact with a stimulus' of cromoglycate, to weeks, months, or even years in the case of inhaled steroids. Irritability was not mentioned as an actant in previous narratives, although it was himted at by the mention of stimuli in the cromoglycate text. In this text, however, irritability has become a substantive. With cromoglycate, the main actors in provolking am attack of breathlessness were triggers; with steroids it is irritability. The host factor becomes even more important as with cromoglycate.

Here again, the expectations regarding the effects of treatment - and, therefore, the standards for judging therapeutical actions - are different from the other drugs. Steroids are consistent with cromoglycate concerning the importance of protection. But the most important goal of asthma treatment, according to this account, is to diminish inflammation and irritability, since that is the basis of the disease process.

Steroid treatment, then, contains an account of the disease that differs on an important point with the other protective treatments: cromoglycate constitutes a protection that is needed in case a patient comes into contact with an allergen that causes airways inflammation - it protects the lungs the way the layer of wax protects the paint of a car from possible damage. Steroids, on the contrary, treat the airways of those with obstructive airways disease as contimuously diseased. According to what these drugs tell us, the airways of these people are in continuous state of over-reaction, often without the ascertainable presence of triggers.

\section{Mythologies and narratives}

One of the ways in which the narratives of drugs have been analysed is by using the concepts developed by François Dagognet. In an early book, La Rasson et les Remedes (Dagognet 1964), which is a rare example of a philosophical analysis of medications, Dagognet asks, with respect to drugs from the past: "Quelle philosophie représentative se cache dans les infusions et les pilules, les sirops, les emplatres et les baumes du passé therrapeutique?". The influence of his teacher, the philosopher of science Gaston Bachelard is clearly present when Dagognet asks this question only with respect to past medications, which he does not hesitate to call a 'catalogue du fallacieux', and which, according to hilim, modern physicians should study if only to purge themselves of similar aberrations, as a sort of psychoanalysis (Bachelard 1954; Moulin 1984). This sounds strange to those accustomed to the principle of symmetry which has become one of the tenets of modern science studies, and which states that the distinction between the veridical and the fallacious can only be made with hindsight (Bloor 1976). For this reason, it is argued that in the study of science and technology this distinction should be put 
in brackets. To understand science and technology, the principle states, symmetrical descriptions of what has been relegated to the histoire perimee and of what has survived are needled.

Nevertheless, Dagognet's work is interesting not only in that he is the only philosopher who has taken medications as a subject of philosophy ("le llaboratoire des essais médicaux enseignera [.] au philosophe qui veut réfléchir sur son travail et son pouvoir, la valeur du minuscule ou du négligeable"), but above all in the richness of the images and mythologies that he distils from these 'fallacious' medications. Dagognet discerns five basic narratives, some of which we will have no difficulty recognising in the drugs this chapter reviews.

The first narrative portrays the drug as an expulsive force: the disease, which is viewed as an intruder, is chased (or beaten) out of the body of the diseased. "Le remède, en conséquence, tiendra du fouet, de la violence expulsive."

The second metaphor of healing which is found in the drugs of the past is the reinforcement of the diseased body, so as to enable it to counteract the disense. This, according to Dagognet, is the mythology accompanying the rich array of tonics and other invigorating substances.

A third narrative conveys the image that some medications temporarily reinforce the disease instead of the diseased, in order to hasten its disappearance. This is the explanation which is basic to homeopathic medicine. Still another metaphor - the fourth mythology - portrays the effect of a drug as its ability to reinstall a harmony in the elements of the human body; it re-instates a balance, for instance, between heat and colld or between humidity and dryness.

The fifth and final narrative, which according to Dagognet is the veritable dream of therapeutics, and a powerful one at that, views the drug as a specific agent, as the magic bullet that searches for its target deep inside the body and works exclusively upon that target.

The entire system of therapeutic mythologies, as described by Dagognet, is encapsulated in the following quotation:

"Finalement, bien que la maladie mette seulement en présence deux forces opposées, que de variétés dans cette lutte imaginaire! Le thérapeute, par surcroît, intervient de tout lui-même pour modifier le combat et son déroulement: ill peut abattre l'ennemi ou il peut soutenir l'éprouvé. Il peut accélérer le rythme de la guerre, si l'envahisseur gagne à le ralentir et à progresser dans le silence insidieux. Il peut encore rêver d'une arme miraculeuse, "le spécifique", qui anéantirait l'ennemi sans modifier le terrailı où il s'est implanté"(Dagognet 1964, 15)

Dagognet's mythologies are mirrored in the narrative of salbutamol given above. It invigorates the action of the muscles of the airways by distending them, and it reinstates the disturbed balance between tension and distension. This is the image of his airways that the first pliase of the treatment of his disease conveys to Carl.

Although Dagognet reserved his analysis for the drugs of the past, it may be fruitful to apply the symmetry principle mentioned above and use his approach (though not necessarily his terminology) for a description of the drugs Catl uses. Salbutamol, we could say, reaches into the lungs to relieve the tension of 
abnormally cramped muscles. When it succeeds, the balance between tensiom and distension is re-established. One of the classic definitions of the healing process, the restoring of balance between too much and too little tension, between agonists and antagonists, is exemplified here.

Salbutamol images the ainvays as consisting of a reversed tree of tubes that go from wide to narrow and of which the smallest parts contain muscles of the inwoluntary type. That is, muscles that spontaneously contract at every expiration to help expel the air from the hings.

Beclomethasone contains a different image steroids continuously combat inflammation which - supposedly - never entirely disappears. In the account incorporated in bronchodilators, asthma is a chronic disease in the sense of a permanent tendency to extreme constriction leading to disease; steroid treatment embodies a concept of asthma as a permanent disease process. The internuted treatments with salbutamol allowed one to think for long periods that the disease was or could be absent, but this is contradicts the very basis of steroid treatment, since this form of treatment regards asthma as a chronic disease in the strictest sense.

Moreover, inhaled steroids transmit an image in which the airways are depicted as covered with a surface of mucosa which displays a tendency to inflame at the passage of relatively normal triggers like cold, smoke, certain smells, and so forth. Therefore, the airways have to be protected against themselves. Where cromoglycate protects them against the direct effect of extemal triggers, steroids do not avert the triggers, but suppress the body"s reaction.

Two views on prevention and protection are incorporated into these forms of treatment (cromoglycate and beclomethasone): the first one takes banishing noxious elements from the environment to be fundamental, the second assumes their existence and works at making people insensitive to them These are, viewed from a different angle, also political views: amelioration of circumstances versus fortifying the individual against them circumstances. In modern therapy of asthma, the ballance seems to be struck in favour of the latter.

Here there are two different accounts $\dot{a}$ la Dagognet of the working mechanisms of asthma drugs: in one, bronchodilators distend the cramped airway muscles, in the second an inhaled steroid is doing a number of things at once: it restrains the production of the different substances (leuktrienes and prostaglandines) involved in inflammation; it decreases hyperreactivity; it makes receptors less sensitive to triggers, and, most importantly, it combats inflammation.

\section{Representations or reorganisations}

Dagognet's work, however interesting and enlightening, uses a basic vocabulary that is different from the semiotical concepts that inform this book: His is a vocabulary of symbolism and representation. It enables him to describe the extremely diverse ways people represent what happens in their body, but, by its nature, it assumes the existence of a real body, unaffected by these representations. It rests on an essentialist image of the body, which takes the configuration of the body as a preliminary of the therapeutical mythologies, not as defined in those very mythologies. 
In the remainder of this chapter, the opposite position will be taken. The relationship between the account given in the information leatlets and the state of affairs they describe will be discussed. It will be argued that the lungs are made to be what they are through such texts, instead of the other way around. This may seem a very improbable supposition. However, within the social studies of science, it has become an accepted view with regard to scientific discovery. It may be useful to explain the idea as it was developed in that field before shifting it to the area of drug information.

In Science: The Very Idea, the British sociologist Steven Woolgar discusses the problem of the relationship between an object and its scientific representation (Woolgar 1988; De Vries forthcoming). The standard view of scientific discovery, he argues, is that the representation (be it graphs produced by an pulsar scamner, an explanatory sequence, or a case-description) is based upon the characteristics of the object - the object-as-it-is generates representations. The word discovery conveys this image: it means taking away the covers that obscure the object.

Woolgar's problem with this view is twofold: first, that it keeps generating what he calls the epistemological Problem: How can the correspondence between the object 'out there' and its description be guaranteed? Second, Woolgar argues that the standard view does not reflect what actually happens in the process of discovery. With the help of examples such as the discovery of pulsars, and especially of the work done by together with Latour on the discovery of TRH (Latour and Woolgar 1986), and also using the early work of the German physician Ludwig Fleck (Fleck 1935), he shows that the object itself is constantly redescribed and redefined and made to coincide with the representation. The inversion of the relationship between object and representation, he argues, resolves both problems: if the object and the representation are produced together, their relationship can be uncovered by studying the process of 'discovery'. Put very simply, Woolgar argues that the sequence

\section{OBJECT -...--> REPRESENTATION}

has to be inverted in order to be able to describe the process of scientific discovery:

\section{REPRESENTATION -.....> OBJECT}

Now if this is what happens in the practice of science, it is also part of that practice to invert this sequence. To describe what happens once an object has been constituted within a representational practice, Woolgar develops the 'splitting and inversion model'. The presentation of scientific results, he says, first inverts the relationship (2) given above, and then splits the object from its representational origins:
"(1) document
(2) document $-\rightarrow>$ object
(3) document object
(4) document <--- object
(5) 'deny (or forget about) stages 1-3"' 
Splitting occurs at step 3, inversion at step 4 . This sequence, Woolgar insists, is basic to scientific practice; it is the way in which the standard view on the relationship between the world and its representations is reinforced in every scientific publication.

Woolgar's line of argument has ontological consequences: it discusses the way in which the world is constituted. Objects, according to this view, do not exist outside and before the production of a representation, but are constituted within the texts and documents that describe them. Studying science and technology means making visible how objects are constituted and what they become.

This is what will be done in the next section, but on a different sort of representations than the ones Woolgar describes; drug information leaflets will be studied as constituting instead of reflecting the drugs and bodily structures they describe. He explicitly favours such an extension of the model:

"Although the splitting/inversion model was developed for understanding the process of discovery, it is easy to see its application to representation in general. In other words, it is a model not just of the constitution of a discovered object but of all attempts to establish the antecedence of objects and things, to render them fixed (and objective) for a whole variety of purposes. These attempts range from strategies of causal explanation to the practical character of perception and interpretation in general."(69)

This statement can be regarded as an open invitation to use the model on whatever representation one wants. However, it may be necessary to specify the meaning of the term 'application'. Information leaflets may be regarded as representing the fifth step in the model, "deny (or forget about) the foregoing steps"; they may also (and that is how they will be studied in the next sections) be taken to be documents in Woolgar's sense, that is, they may be taken to be signs pointing to and defining states of affairs; users of these documents then follow the five steps of Woolgar's model exactly as scientists do.

One of the few examples of analyses in a similar vein can be found in a section of the work by Vos, who devotes a section of his book 'Drugs looking for Diseases' to what he calls "the intrusion of drug profiles into disease profiles" (Vos 1989): Using the example of the effect of B-blockers in post-infarct arrhythmias and infarct size, Vos shows that a new subdivision of the concept of myocardial infarction was produced by the drug: that between fresh and old infarcts. Because they show different effects according to the time elapsed after myocardial infarction, B-blockers introduce duration as a nosological criterion, thereby modifying the existing set of profilles of infarction. It is important to note that this is not a matter of differing representations or images of myocardial infarction, but the production of two distinet diseases, of new nosological entities. In other words: the introduction of B-blockers thus entailed a modification in disease ontology. The difference with Dagognet's account is obvious: where Dagognet speaks of the way drugs incorporate representations and images of disease, Vos describes the way they actually produce new sub-types of diseases. 


\subsection{Redefining ainwoys obstruction by treating it}

Similar things happen with the medications used in treating CNSLD. For instance, it is only after the introduction of bronchodilators that the distinction between reversible and irreversible airways obstruction can be made. In that sense, drugs not only represent diseases in various ways, they also reorganise them. During lung function testing, whether this happens with hospital machinery or at home with a peak flow meter, patients are asked to take two measurements: first before and then after inhaling a sufficient dosage of a bronchodilator. Patients are told that the time between two measurements should be around ten minutes. In case they perform home measurement with peak flow meters, such double measurements should be performed at least twice a day. Reversibility, then, is said to exist when the results after inhalation are significantly higher than before. ${ }^{1}$

Various guidelines for physicians speak of a difference of at least 10 or even 15 per cent. If Carl, after an inhalation of salbutamol, blows 355 instead of 345 litres per minute, he may regard this as an improvement, but his physician will not if he holds to the guidelines, that is.

Bronchodilators are indispensable elements of this diagnostic practice which leads to the production of two disease categories: reversible or irreversible obstruction. But is that enough to say that they actually make this difference? In an important sense, these drugs in fact do make the difference: they are the actors that go out and attempt to reverse the state of obstruction. But 'making the difference' should not be taken to connote 'all alone'. Salbutamol, or whatever bronchodilator is used for these tests, makes the difference in conjunction with measurement devices, with epidemiological research, and with laboratory assistants, without whose tireless encouragements no patient would ever blow a proper lung function. All kinds of actions converge to make the difference between these two types of airways obstruction - making differences is a characteristic of a practice of which drugs are an element.

They contribute to the constitution of new sub-sets of disease, new patterns of obstruction of the airways. Bronchodilators reshape airways obstruction by introducing a new type of differences, namely those between degrees of reversibility.

Similarly, cromones such as cromoglycate help produce a distinction between 'mainly allergic asthma' and 'mainly aspecific hyperreactivity'. Especially in young children, these drugs are used to classify airways obstruction. The brief history of Denise will serve to illustrate this point.

Denise is three-years old, and already has a long history of asthmatic complaints: continuous coughing and periods of tightness. Apart from that, she has had frequent episodes of ear infections, which alternated with the asthma attacks. In the beginning, giving salbutamol on an incidental basis

A topic that would merit a separate investigation is how the sigmificance of a difference is constructed. 
was enough, but her need for the drug gradtually increased. This augmented her parents' worries and at the age of three the decision is taken to start long-term treatment with cromoglycate. This drug, the physician claims, reduces the strength of the allergic response in her lungs. Although, because of her age, no allergy can yet be proven by bload tests, Denise most probably is allergic.

"I am not impressed by the results," Denise's mother scoys after a few weeks, "she still asks for the blue one' several times a day, and although I don't always give it, to me it seems a sign that she still is not better." The physician sits back for a while, looking at the computer on his desk which displays Denise's record, and finally concludes that probably Denise is not allergic, or at least not only allergic. That cromoglycate does not help her suggests that there is aspecific sensitivity in her ainways - this is not influenced by cromoglycate. "It is the sort of sensitivity to smoke, mist. sudden temperature changes that we call aspecific hyperreactivity," he points out, "in order to take care of that, she will have to start using inhaled steroids"

The Dutch guidelines for the treatment of asthma in children (Dirksen et al, 1992) advises a stepping-stone approach in which a treatment course with cromones is tried out as a first step once continuous treatment is considered - it serves simultaneously as diagnostic tool and as treatment. It establishes the difference especially in children that are too young to have allergy tests performed - between those who have an allergy and those who have generally hyperreactive airways. If cromoglycate reduces symptoms and the use of bronchodilators, then the child is supposed to have the allergic form of asthmia. If not, a treatment with inhaled steroids is started, and the child is considered to have aspecific hyperreactivity. Again, the drugs are not the sole determiners of this difference: they do so with other actors, such as a properly-inhaling chilld, a parent who has the discipline to administer the drug, and a doctor who is prepared to give these drugs even to very young children.

So far, the emphasis has been on the way in which drugs modify the arrangement of forms of obstruction of the airways. But what about the body? Does the use of medication also reorganise Carl's airways? Do they transform his luings in any way?

\section{Mnking various airways}

Cromoglycate helps in reorganising the nosology, like Vos B-blockers and salbutamol. It produces (although it does not do so alone) a subdivision in allergic and non-allergic forms of CNSLD. It also provides a new description of the airways: apart from being the entry for oxygen, they are a line of defence against undesired intruders

The usual interpretation of the differences between the various airways that emerge in differing treatment practices is couched in terminology of aspects. Thus, one aspect of the airways is their constrictability, another is that they have inflammable membranes. 'Aspects', however, is a treacherous term to describe 
these discrepancies: it suggests that one can switch at will from one aspect to the other by merely taking a different point of view, by looking from a different angle at what is essentially the same object. This visual metaphor suggests that seeing differences only requires that the observer "turns around" the object and looks at it from different vantage points. What I have argued here is that these different narratives of the airways are linked to different practices such as the various treatment regimes, and that in order to switch from one narrative to the other, one has to do different things and use different objects.

There is another reason to avoid the terminology of aspects: aspects presuppose an underlying essence. In Woolgar's terminology, using the term 'aspect' is one of the possible ways to inwert the relationship between object and representation (section 5). If an essence ("the airways are essentially the entry system for oxygen" or a similar phrase) exists, it is as much the result as the precondition for medical innovations. For instance, in the treatment of airways obstruction, the role of steroid inhalations seems to predominate at the expense of the role of bronchodilators (Reed, 1991) - as an element of this change in practice, the essence of the airways is gradually transformed: they become 'essentially' a surface of membranes with a strong tendency to inflammatory reactions rather than a tree of tubes with a tendency to constrict.

There is another sense in which treatment with cromoglycate means transforming Carl's and Denise's airways. Long-term treatment is the constitution of a new entity: airways linked to cromoglycate. More precisely, of mast cells linked to cromoglycate. For a long time, maybe forever, their lungs are going to be connected to and covered with cromoglycate. This is no less than a technobiological innovation, comparable to other innovations such as the linking of the drug to the inhaler.

Treatment with long-term medications thus not only modifies Carl's images of his airways, it also modifies his airways and changes them into novel hybrids of 'stuff, inanimate substance, and living material Contrary to short-term treatment, for instance with an salbutamol, for which the same idea could be developed, the connection between cromoglycate and the airways is intended to be a durable one.

Thus, continuous treatment with inhaled drugs tums Carl's airways into hybrids of living materiall and chemical substances. In this sense, drugs for obstructive airways disease do not, or not only, change our thinking about the lungs, or the circulating images of the airways, they literally cleave to them and thereby form new entities. The connection that is established in this way can be seen as new link between human and non-human elements. This makes medications an interesting topic for students of techmology: they do effectively, and almost visibly, construct such links.

Although the formation of hybrids is most easily described with regard to long-term treatment programmes, they come into being, temporarily, with shortterm therapeutics as well. In periods of breathlessness, Carl has to widen his airways with a continuous supply of salbutamol and other bronchodilators without which they would not be able to perform their function. In these periods his airways are a union of muscle tissue and bronchodilator, the separation of which would risk turning them into obstacles rather than freeways for the air Carl needs. 
This has implications for our thinking about the role of (long-term) medical treatment in peoples lives. Medical techmologies like drugs not only incorporate and diffuse images of disease and physiology, but their use produces new bodies, new categorisations of disease, and new entities consisting of bodies and things. Especially in chronic diseases like airways obstruction, the links between these two can become strong and long-standing. Long-term drug treatment produces a variety of body-thing hybrids. The study of "physiological innovations', to use Canguilhem's term again, developed in this chapter may reveal more ways in which living with a chronic disease is different from living without one (or with another one, for that matter):

\section{Living with different airways}

As Carl uses several drugs simultaneously, the accounts incorporated in them need to be coordinated. In the next section, two techmiques of coordination will be discussed timing and valuation. The use of the term coordination has more than a superficial relationship to recent developments in the sociology of action, notably in the work of the French sociologists, Boltanski and Thévenot (Boltanski and Thévenot 1991). Because the area in which they developed their analysis is markedly different from the one under study, some explanation is necessary.

The guiding idea of their sociological work is that people simultaneously live and act in different 'worlds' and that this requires that they coordinate their behaviour. Nicolas Dodier has nicely captured this idea in the title of a review, 'Agir dans plusieurs mondes' (Dodier 1991). The worlds Thévenot and Boltanski discuss, however, are different from the worlds that have been described in this chapter. Their worlds are constituted by the vocabularies with which persons justify behaviour. They distinguish six such vocabularies and connected worlds, or 'cités'. If the need for justifying belhaviour arises, for instance in situations of conflict, those who engage in justification use the vocabulary of these different worlds.

In this chapter, it has been argued that drugs and the texts that speak of them are also constitutive of descriptions of "worlds", in the sense of imter-related definitions of entities; ontologies, with another term. The person using different drugs simultaneously thus needs to coordinate these worlds by connecting various vocabularies. Taking different medications means acting in different worlds. The following two sections discuss two important ways of classifying the different airway-entities that emerge with the use of the drugs.

\subsection{Timing}

As we have seen, the texts accompanying the different drugs showed considerable differences in the time-frame they attributed to the working of the drugs. Inhaled steroids, to start at one extreme, are particularly slow in becoming effective: it may take weeks to months, and sometimes years before they have unfolded their full benefit, while, on the other side of the spectrum, salbutamol may take less than a minute to become effective, but then again, its effects will be short-lived. 
This demonstrates one way of avoiding conflicts between ontologies that can actually be found in the information patients receive: if you need quick relief, distend the airway muscles and, if needed, combine this with the nucus inlubitor that works within the hour. If, on the other hand, you are trying to anticipate in order to influence the disease for the next few months or even years (some physicians being comfident that it is for a lifetime), it is wise to consider lungs either as a line-up of mast cells and other depots of histamine for those who use cromoglycate; or as continuously inflamed mucous membranes, for the users of inhaled steroids. Cromoglycate treatment is accompanied by the narrative that the consolidation of cell membranes is a slow process, taking up to four weeks, while the information given with corticosteroids refers to an even slower process of diminishing inflammation and hyperreactivity.

The emphasis on time-frames results in a certain coherence: a quicklyworking drug works for a short time only, its beneficial effects not exceeding a couple of hours, even if used continuously (in which case, as we will see, it might even become detrimental); while the slower the protective drug is in unfolding its action, the longer the benefit. Dilating muscles is a quick process, mast cell stabilisation is slower, and decreasing inflammation is the slowest - in this way, the airways may be classified according to their different durations.

\subsection{Values}

Another way of bridging the gap between the three treatment forms is by assigning different walues to each of them. Thus, it can be clearly seen in patient information leaflets that bronchodilators have gradually become no more than symptomatic treatment', while the other two, and especially inhaled steroids, are now honoured as real, fundamental, or causal treatment of obstructive airways disease. They, according to what is becoming the standard view, influence the real disease.

Treatment with $B_{2}$-mimetics has long been the treatment of choice for people with asthma. They were encouraged to use these drugs whenever they felt breathless, because not using them was supposed to lead to increasing problems. In the more severe cases, drugs like salbutamol were prescribed on a daily basis for longer periods. The idea was that keeping the airways open would prevent breathlessness from worsening, not only in acute cases (Rebuck and Chapman 1987). In the last couple of years, however, there has been a change in practice. Sympathicomimetics have been relegated to the realm of symptom treatment. Not. that they have lost their importance, but they have come to be regarded as ani insufficient single method of treatment. Complete treatment of airways obstruction, in the modern view, consists of one or both of the protective drugs that Carl receives. Muscle contraction is no more than a symptom of asthma, while allergic reaction and - even more - inflammation are the disturbances that have to be subdued.

Thus, the shift in valuation of different forms of treatment mirrors a shift in the distribution of etiology and symptoms. What was once the essential feature of asthma (bronchoconstriction) has now become a derivative of the real pathophysiological problem: inflammation. But the shift in valuation of $B_{2}$-mimetics goes even further: they have gradually been discredited, first; because in different 
countries a rising number of asthma deaths have been associated with excessive use of certain $B_{2}$-mimetics (Spitzer 1992), and second, because there are indications that continuous, instead of 'on demand' use of this medication hastens rather than retards the development of hyperreactivity (Van Schayk et al. 1991). Discredit, in a sense, is shifting from steroids to bronchodilators, from one hormone to the other (Tattersfield and Barnes 1992).

One consequence of this is a shifting attribution of responsibillity to patient, physician, and disease. If things go wrong, recent treatment methods have contributed to placing blame mainly on physicians (who may have continued prescribing bronchodilators as a monotherapy) or on patients (who may have tampered with the drugs, or chose to continue smoking). The degree to which the disease itself is held responsible for deteriorations has decreased accordingly.

\section{Differences and similarities}

Drugs, it has been argued, make differences as much as they reflect them. This is, however, a one-sided way of making a point that should be made symmetrically: where differences are made, similarities emerge at the same time. If salbutamol, for instance, is one of the agents in producing a distinction between reversible and irreversible obstruction of the airways, it also establishes various links and similarities. The fact that Carl, with his periods of increased breathlessness, and Denise, the four-year old with a recurring cough, use an identical little blue inhaler makes them similar. Thus, the long-standing theoretical debate about the question of whether their diseases are different or similar (chapter 2 ) is resolved locally, through the likeness of practices. In an analogous way, salbutamol forges a connection between the occasional hay-fever patient with lung symptoms and the adolescent with a touch of asthma: these people have the use of the blue inhaler in common. The use of similar drugs defines people as being similar, at least in this respect. It contributes to the forming of a distinct group of people - a group which may be glaringly dissimilar in other respects. In other words: it is a maker of social similarities and dissimillarities.

Let us retum to the theme of ontological imnovations of the body. Do drugs

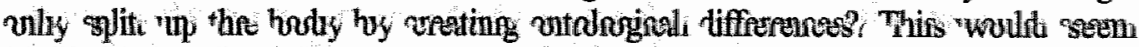
improbable. Salbutamol, to take the same example again, in its so-called secondary effects, works on the heart and the skeletal muscles as well as on the small airways. If the dosage is high enough, it increases the heartbeat and eauses tremors. This connection is most clearly felt when salbutamol is taken in pill form: as soon as the patient gets more air, the heart starts beating at a higher rhythm and light trembling begins. Various parts of the body react, albeit in different ways, to this particular drug. Thus, through the use of salbutamol, new links are forged and new similarities are made between the lungs, the heart, and the muscular system.

There is another similarity within the body which is organised through the use of drugs. Steroids are used locally in different ways: they exist in creams on the skin, in inhalations in the airways, and in injections in joints and tendons. The practice of using these drugs in these varying ways connects these parts of the body and makes them similar. One patient may use the same steroid both for his asthma and for eczema and, eventually, for an inflammation in the shoulder. Thus, 
for body parts that are quite dissimilar at first sight, the same drugs are used, making them similar: they are all liable to develop the kind of inflammation that can be treated with steroids.

Inhalation itself, it has been argued in chapter 4 , designs a specific trajectory through the body, thereby modifying its geography. Making a trajectory is forging new comnections as well as severing older ones - it involves making similarities as well as differences. In order to become a pathway into the body for drugs, the differences between the mouth, throat, and trachea are temporarily put aside. They become the same in this practice: passage-ways for drugs.

Drug therapies are among the various ways in which bodies can be made different (from some) while at the same time making them similar (to others). Drugs are therapeutic agents, but within their therapeutic action, they produce new similarities and dissimilarities. They do not merely help the body, or body parts, to resume old functions that are hampered by disease, they also reorganise the same body by creating new differences and new identities. Thus, they incorporate genuine physiological innovations. 

"Le 'nouveau malade', tyutosoignant, le malade engage dans une 'self-care Illness' est un personnage dun type nouvean dans notre culture. Patient qui n'est plus passif, usager qui a acquis la maîtrise de l'usage, il rompt avec lune des dichotomies centralas de nos sociétés: lopposition si souvent denoncée entre ceux qui savent et imposent leur savoir et ceux qui ne peuvent que le subir" (Herclich 1984)

\section{6. "Keep an eye on your airways" - self management and technology of the body}

\section{Introduction}

Medical treatment of obstructive airways disease is often said to consist of 'care' instead of 'cure'. There is widespread agreement that no curative treatment exists in the sense of freeing patients from the disease once and for all. But care in CNSLD, as in other chronic diseases like diabetes, takes a specific form: that of control, in the double sense of overseeing and regulating. Two elements of the disease are continuously controlled and checked: first, short-term developments in the course of the disease, like sudden attacks of breathlessness or an aggravating cough; monitoring in this sense is essentially the early diagnosis of flare-ups. It is done under the premise that the earlier these are diagnosed, the sooner treatment can begin, and the more effective it is Second, monitoring programmes are designed to check the progression of CNSLD and more specifically the slow deterioration of lung function. The emphasis on monitoring CNSLD reflects and at the same time reinforces the fact that it is regarded, not only as a chronic, but also as a progressive disease, one that remains with patients for the remainder of their lives and tends to worsen.

It will be argued in this chapter that the distinction between care and cure as it is often made is far from unambiguous. Although they have been developed for the care of people with an allegedly incurable disense, the monitoring and selfmanagement plans (SMP) that will be discussed contain various elements of cure not in the sense that they eliminate the basic disturbances of CNSLD, but that they attempt to restore the patient, in an attack of breathlessness or coughing, to his previous condition. Paraphrasing Georges Canguilhem (referred to in chapters 3 and 5), the aim of cure in this type of disease is not restoration in the sense of returning to some general, for instance statistical, standard, but to a personal norm. This personal norm exists as part of the course of the disease. Cure, in monitoring programmes, takes place within what he has called the normativity of the disease.

Monitoring is a relatively recent procedure and involves establishing a long-term diagnostic practice. In the context of this book, where the most important basic diagnostic device, the peak flow meter, has been analysed in its own right (chapter 3 ), monitoring can be regarded as the way in which this diagnostic teclinology is embedded in the daily life of both patients and physicians. It has been shown that 
the peak fllow meter incorporates, along with a piston, a spring, and other material elements, bethaviour prescriptions and accounts of the world. However, even a simple and convenient device like this would not realise its potential if it were not incorporated in a larger technology: the monitoring practice.

Monitoring implies submitting people to a long-term, sometimes lifelong form of medical control for a well-defined part of their bodily functions; it means keeping constant track of those functions. Originally, the term was used for a more impressive and more machinery-dependent part of medicine: the Intensive Care Unit (ICU). There, bodily functions are kept under continuous control by a host of machines and people. Monitoring chronic disease has evident parallels with what happens in the ICU, with the exception that in monitoring programmes for chronic diseases like CNSLD the time-coverage is incomplete: the surveillance of ambulant people or 'ambulant lungs' can hardly be as complete as surveillance in the ICU.

Thus, the continuity of surveillance is one of the problems that out-patient monitoring programmes face. One solution for this problem is called selfmanagement. Anything like continuous, or semi-continuous monitoring by physicians or nurses in medical settings is impractical and unfeasible, because it would imvolve very frequent visits to physicians or practice nurses. Patients themselves are in a better position to perform this task: self-management, then, is the delegation of the surveillance of bodily functions to the patient.

Not only can patients continuously keep an eye on their airways, they can also adapt treatment regimes to the results of monitoring. Where monitoring programmes are constant diagnosis, self-management programmes also are techniques for continuous adaptations of treatment.

The analysis of monitoring and self-management of CNSLD will try to answer the following two questions: first, Do these two forms of follow-up incorporate new definitions of physician and patient; and, second, To what extent do monitoring and especially self-management constitute new ways for people to deal with their body?

The first two sections of this chapter concern monitoring in medical practice and in scientific literature. They open with a case-history in which a patient is subjected to a monitoring programme. As will become evident, monitoring involves a specific type of diagnostic practice that comprises, it will be argued, specific definitions of patients and physicians. Far from being simply an extension of the accepted diagnostic process, it differs on important points; those differences will be discussed in section 3 .

The fourth section discusses the self-management plan proper. Using the continuation of the same case-history by way of illustration, it will demonstrate how self-management is incorporated into a treatment programme. Section 5 discusses some of the arguments proposed in support of self-management. In response to the question about the extent to which self-management is a new way of dealing with the body, the sixth section will review the general characteristics of self-management plans employing the concepts of "body techmique" as it has been developed, around 1940, by the sociologist Marcel Mauss, and of "technology of self" developed by Michel Foucault in his later work. The conclusion, section 7, returns to the theme of the constitution of new patients and physicians within monitoring and self-management. 


\section{Watching one's airways}

Charles is a forty-five-year-old bank employee whose complaints of breathlessness and cougling hove increased over the last two years. Al few days before the visit that will be described here, he had a very bad attack and, for the first time, called a doctor to his house.

Shortly thereafter he goes to see his physician to discuss the attack and to talk about "a more rigorous form of control" as his physician calls it. It is this part of their discussion which is of interest here.

"Your airways", the doctor explains to Charles, "have a tendency to react to all kinds of influences by constricting. When they are constantly expased to triggers, they are in a continuous state of inflammation. To prevent the ainways from worsening unnoticed, we need to monitor them. That entails regular visits; once every three months in the beginning, maybe less frequently later on. The seriousness of the constriction can in part be felt as the degree of breathlessness, but it is more reliable to measure it." The doctor adds, "To get exact information of what happens inside your lungs, it would be best to take continuous measurements, not only here, but also at home." The proposed programme consists of three peak flow measurentents a day, the first immediately upon waking, the second in the middle of the day, and the last just before going to bed. The results of these measurements should be written down in a peak flow diary. Since Charles takes bronchodilators, he should measure both before and after an inhalation of salbutamol In addition, more infrequent tests (once every two years) need to be taken at the lung fumction laboratory in the local hospital. Charles is asked to return to the office after two weeks to discusis the list to see if it shows any regularities and, if necessary, to adjust the medications. It is likely that monitoring of his ainways will have to continue for a considerable time.

On the first of his two-yearly visits to the lung function laboratory, Charles coincidentally sees what monitoring in its most intense form entails as the lab is located next to the intensive care unit. On passing, he sees an impressive assortment of beeping and buzzing machines. Every now and then, some of them produce pieces of paper with graphs on them, not unlike those produced by the lung function machine that the will be connected to. The monitors of the ICU are constantly displaying graphs of a rather monotonous kind: round-the-clock, hearts and lungs are kept under surveillance - any deterioration can be spotted immediately, far earlier than would be possible if only symptoms were relied upon for control. There are obvious simillarities between the surveillance of cardiac patients in an ICU and the surveillance Charles submits to. Both are continuous, although in different ways, they both use elaborate technology, and focus on physiological parameters rather than symptoms. The graphs produced in the ICU are equivalent to Charles" peak flow charts, and the beeps and buzzes are similar to the sudden decrease in peak flow values then an attack of breathlessness is under way.

One of the differences between the two types of montitoring is related to the time-span: the ICU is a short-term (a few days, mostly), but very intense form of 
continuous diagnosis; while monitoring CNSLD is intended to go on for longer periods, decades to sometimes a lifetime, but is less intense and involves a slower rhythm. As long as Charles' lung function is monitored by his physician, the gaps between controls are in the order of months. When he starts doing the monitoring himself, however, the time between measurements can be reduced to only a few hours. In both cases, however, similar objects, or, more precisely, similar inscriptions are produced: a specific configuration of lines on an electrocardiogram or a specific pattem on the peak flow chart.

\section{The high tide of control: monitoring and CNSLD}

Monitoring or surveillance of patients with CNSLD, in the way it is done in Charles' case, is rapidly becoming one of the standards of treatment. In the large number of protocols and consensus statements that issued recently, (National Asthma Education Program 1991, Van der Waart et al. 1992; British Thoracic Society 1990) regular controls of the course of the disease, in place of on-demand medical interventions, are put forward as being necessary to obtain two types of improvement in the care of patients: first, to avoid, or at least curb, ongoing deterioration of lung function; and second, to permit immediate and adequate reactions in the event of a threatening attack. Thus, monitoring systems aim at continuous diagnosis with regard to the (silent) progression of the disense, and at a more appropriate reaction of both patient and physician in case of an acute attack.

The Australian Asthma Management Plan of 1989, one of the first plans that were issued, states that physicians should do their best to maintain contact with their patients because "the risk of a severe attack is greatest in patients with irregular or infrequent medical care." (Woolcock et al. 1989) Patients should be offered regular control visits at which their symptoms and peak flow charts should be controlled; the importance of carrying on the treatment should repeatedly be emphasised.

The Australian plan, however, does not go into much detail about the contents of follow-up contact. Hargreave, Dolovich and Newhouse, in their report of a conference on the management of asthma (Hargreave et al. 1990), are more specific: follow-up contacts should be offered every six to twelve months once the disense appears under a reasonable degree of control. At these follow-up consultations, attention should be paid to the symptoms (at night, on exertion, spontaneously) and the use of bronchodilators at that time, to peak flow, and to the skills of the patient in manipulating the peak flow meter and the inhalers.

The Dutch guidelines for the management of CNSLD, issued by the College of General Practitioners, specify the frequency and content of controls to a large extent along the lines laid down by Hargreave. However, Dutch general practitioners want controls to be more frequent (every three months). Here again, assessment of symptoms, especially at night, interference with daily activities, and peak flow variability are considered important clues to the progression of the disease. The Dutch protocol is frank in recognising the lack of substantiation for this advice: "With regard to control policy no scientific data are available; guidelines are based on consensus within the working party" (Van der Waart et al 1992) [author's translation]. 
Although most of the documents mentioned above take monitoring as a selfevident part of the management of obstructive ainways diseases doubt is sometimes voiced by researchers in the field. Chris van Weel, a professor of general practice, expresses serious concern about the validity of the progressive course of the disease as an argument for monitoring. Poorly understood and unusually frequent complaints, he claims, can be a reason for monitoring, but the value of lung function measurement for that purpose is still unproven (Van Weel 1989). And as long as that is the case, he states that physicians should be cautious not to medicalise people"s lives unjustifiably.

\section{Different practices}

In order to piupoimt the specificity of monitoring as a diagnostic practice, a comparison between acute and continuous diagnosis is useful. Acute diagnosis is taken to mean the actions undertaken in the face of the first episode of a disease in a patient. An acute diagnostic case may be presented by a person who, for the first time, has an attack of severe breathlessness. (see the case-history of John in chapter 2).

\section{ACUTE DIAGNOSIS}

* patient history: gamering clues from a narrative

* relies on a vast array of diagnostic devices

* contact as needed by patient

* responsibility for outcome lies mainly with physician

* mostly short-term and repairable dysfunctions

\section{MONITORING}

* gathering limited specified data

* few, specific diagnostic devices:

peak flow meter, larger lung function devices

* surveillance regime, systematic contact

* responsibility shared by patient and physician

* lasting dysfunction, slow progression and sudden flare-ups

\subsection{Different meanings of symptoms}

People who visit their physician for the first time with complaints of breathlessness, coughing or sputum production may be classified under a wide range of diagnostic categories (Bottema 1993), whereas in monitoring, the diagnosis generally does not change.

One difference between the two sorts of diagnostic practice is that the role of the patient's narrative varies. In acute diagnosis, the patient's account is important for searching out clues to the underlying disease. History-taking starts from a full description of the complaint and results $\mathrm{i}$ to a variety of hypotheses about the possible diagnoses. (Sox et al. 1988). In the first minutes of a conversation, it is unclear what may be significant (literally) and what can be safely disregarded. Then, gradually, the problem becomes more defined; for example, when a patient is 
a known cigarette smoker and says he is mainly breathless upon exertion, attention is focused on his lungs, and the selection of features important in diagnosis will follow accordingly. The same step-by-step process occurs in a different case where symptoms direct a physician towards the heart as the source of dysfunction. The historian Carllo Gimzburg, with a touch of romanticism, observed that medical diagnosis resembled detective work. He has established parallels between the work of the art historian, the physician, and Sherlock Holmes, they all search for clues in what, at first sight, may appear insignificant (Ginzburg 1988).

In momitoring, on the contrary, it is clear at the onset which part of the patient's account is important - generally, patients restrict their narrative to what they kmow to be important. What the physician attempts to elicit from a patient are answers to a well-defined, reliable set of questions geared towards determining the condition of his airways, namely disturbance of sleep, the number of in bronchodilators taken, daily activities, and so forth.

Standardising of this type of diagnosis can be achieved by specific types of devices; one such device is the seal a pharmaceutical company distributed among physicians some time ago. It is an example of regulating physician's behaviour through the scenario of an object rather than through education or guidelines. Once a physician has put this stamp in the patient's file, it prescribes the questions to be asked and the actions to be performed.

\begin{tabular}{|l|l|l|l|}
\hline day & night & activities & abisent \\
\hline PFR: & inh techn: & $\beta_{2}$-use: & follow-up: \\
\hline
\end{tabular}

It is, of course, crucial for the functioning of this stamp is that the physician remembers to use it, is able to find it at the right moment, and so forth. Although currently uncommon, it is probable that in computerised files this will happen automatically when the file of a CNSLD-patient is displayed; the computer, then, takes care of the physician's obliviousness.

It should be used at every control visit. Its size, which is about half the size shown above ensures that it fits conveniently in a medical file. The items to be examined in a patient's story are: problems during daytime ('day'), during the night, the extent to which activities have been limited (activ.'), absenteeism and use of bronchodilators. For all of these points there is a small space just large enough for $a+, a-$ or a mumber. Furthermore, the stamp invites the physiciam to test peak flow, to check inhaler technique, and to fix a date for follow-up appointments.

The seal is a checklist. It specifies what a physician should ask and do in a monitoring consultation, and it also ensures or helps ensure that none of the standard actions will be forgotten. It is an auxiliary for the busy physician. However, the cognitive psychologist Don Norman has shown that the use of checklists not only increases the effectiveness of a practice (it is not a simple lubricant for the machine) but it also modifies its characteristics; in essence, his point is that following the checklist tends to become the description of the task (Norman 1993). 


\subsection{Different devices}

A second difference between acute diagnosis and surveillance diagnostics is in the devices they mobilize. In the work-up of a new breathless patient, other objects are employed to establish the diagnosis than those needed to supervise the progression of the disease. Patients who present with symptoms for the first time may be examined with the help of a stethoscope and, in some cases, with a peak flow meter; furthermore, a sample of their blood may be sent to the hospital laboratory to diagnose possible allergies. Thus, they have a short contaet with biochemical diagnostic technology. An electrocardiogram may be done to rule out the possibility of a cardiac cause of breathlessness and $X$-ray picture can be made for the same purpose. Whether these technologies are used or not depends, or should depend, largely on the indications elicited from the narrative. In short; a variety of diagnostic devices can be used in breathlessness of unknown origin; in the event a diagnosis of obstructive airways diseases is made, most of these will not return in later stages of the diagnostic process.

Charles, on the contrary, is confronted with a different, and more limited range of diagnostic machinery: apart from frequently blowing into his personal peak flow meter, he is required to go to the hospital for an hour or two every two years, where he is connected to a spirometer and blows into it with the help of lung function assistants. Other technologies he comes into irregular contact with are the stethoscope (it is only used when he complains of shortuess of breath or coughing, not on his regular visits) and, very rarely, the $X$-ray lab, where he goes when new developments in his disease occur (for example, an intercurrent pneumonia).

For the person without a history of respiratory problems who develops acute breathlessness, going to the lung funetion lab in the hospital, or going to see the physician is not envisaged to become a repeated activity. Acute diagnosis, in principle, concerns finite episodes of illness, and it is only after a diagnosis of CNSLD is produced that the patient's relationship to diagnostic technology is made durable, as in the case of Charles. Thus, subjecting someone to a monitoring programme means transforming a transient conmection between that person and elements of medical technology into a durable one.

\subsection{Organisation}

Another difference between the two forms of diagnosis lies in the networks that are established: different types of relationships emerge. Acute diaguosis demands attuning a variety of diagnostic tools such as interview techniques, protocols, diagnostic devices, some of which are only used on a short-term basis. Furthermore it requires an accessible physician who can either establish a diaguosis and initiate treatment, or can link patients to the hospital's diagnostic network ( $\mathrm{X}$ ray department or biochemistry lab).

Monitoring, on the other hand, constructs a durable link between patient, physician, and a limited portion of the davailable diagnostic instruments. Whereas acute diagnosis requires quick access to other forms of diagnosis than the ones at the disposal of the physician, long-term diagnosis requires a system that can keep track of patients, and a registration procedure that allows for comparison of results 
over time. The durable character of monitoring exacts a constant effort of organisation: Charles will, for instance, recerve reminder calls when he does mot show up for an appointment - contact with the physician is not only at his initiative, as in acute dingnosis, but as much at the instigation of the physician.

The promotion of monitoring systems in general practice means a considerable change in its structure, because, until quite recently, it was almost exclusively functioning on an on-demand basis. Most of the work of general practitioners is still done on this basis. In this mode of functioning, which is particularly suited to the treatment of new and finite disease episodes, patients like Charles would have visited or called the physician only during an asthma attack. Control would be limited to a check-up after the contuletion of a course of medication. Untill recently, long-term supervision was largely limited to specialist care. With the advent of monitoring in primary care, physicians are expected to organise their practice in such a way that regular long-term control becomes possible alongside on-demand care.

\subsection{Responsibilities}

Attribution of responsibility is another point of difference between acute diagnosis and monitoring: while in short-term contacts around an acute disease, the responsibility for diagnasis lies largely with the physician (for treatment this may be less true, but that is the subject of the next chapter), in continuous diagnosis of CNSLD it is a shared task.

In the diagnosis of new episodes of disease, much depends on the ability of the physician to decipher the evidence and to organise the appropriate diagnostic procedures such as physical examination and laboratory investigations. Although the patient's cooperation is indispensable for diagnosis, this role is more passive than in monitoring and it remains the plyysician's responsibility to make accurate inferences. In monitoring, and especially self-monitoring, the balance of responsibility is tilted toward the patient. It is Charles' responsibility to be serupulous with his peak flow diary, to blow properly, to react in an appropriate way to abnormall results, to show up at control visits. As a consequence, the patient as well as the physician will be held accountable if unnecessary deterioration occurs. If Charles has an umusually frequent occurrence of attacks of breathlessness, one of the first questions asked will be if he has been meticulous in his use of the diagnostic possibilities at his disposal. He will not only be held accountable for life-style issues such as smoking, but also for the accurateness of hỉs self-diagnosis.

While many of the physician's responsibilities are taken over, in part, by the patient, his remaining obligations are also different they concerned the quality of follow-up systems and of practice registration more than the physician's diagnostic ability (which, as has been said, involves other organisational skills).

Rapid decline or frequent dips in symptoms and in lung function could be attributed, before the existence of monitoring programmes, to a severe and intractable form of the disease. With the appearance of monitoring it is, at least partly, legitimate to attribute it to the human actors involved. Thus, shifts occur in the attribution of responsibilities among the three main actants in the treatment of 
CNSLD: disease, physician and patient. If a decline occurs, it is attributed less to the disease itself than to the patient and physician.

\subsection{Different diseases}

The final difference between acute and contimuous diagnosis concerns the distinct ontology of the disease. In an analogy to the analyses in chapter 5 , one can describe monitoring practices not as a consequence of the properties of obstructive airways diseases, but as the constitution of these properties. Monitoring can be described as a practice in which this disease acquires new characteristics.

The aim of acute diagnosis is to find a disease, that is, a disturbance in the function of the body that is primarily regarded as temporary and to try to repair it as completely as possible. Thus, in determining the reason for coughing in a patient who does not have chronic airway problems, the physician will look to various self-limiting or else treatable diseases, such as a common cold or pneumonia: the disappearance of the symptoms in these cases implies the disappearance of the disease. Finding the disease in an acute diagmostic process does not necessarily involve less sophisticated technologies than monitoring, but it is looking to a different sort of disease.

Charles is informed that he has a chronic disease that is progressing at a pace which makes it irresponsible to continue treating only its exacerbations. The frequent reoccurrences of breathlessness are alarming to both Cliarles and his physician. It becomes apparent that Charles's disease will not disappear. In addition, his physician tells him that it must be feared that the disease is causing much more than superficial damage. In other words, Charles is told by his physician and by the monitoring programme that his disease has a double face: on the one hand, there are sudden outbursts causing panic and lack of breath, but on the other hand, during the periods of apparent caim, unbeknownst to the patient, the disease contimues to affect the airways.

How is this destructive work of the disease made a reality in monitoring programmes? The first sign is a decrease in the expiratory force, observable with the help of lung function devices like the peak flow meter. But lung function deterioration is no more than the effect of this process: the monitoring programme implies that the real culprit is chronic inflammation which slowly eats away parts of the airway tissue. It tums the swelling of the internal walls of the airways, initially only temporary, into a chronic condition. The inflammation slowly breaks down the elastic tissues, eventually reducing the lungs to non-elastic pouches. Moreover, every attack of coughing or breathlessness reinforces this slow deterioration by putting repeated strain on muscles and connective tissues. In this way, the strength and elasticity of airway tissue is slowly exhausted. Years of repeated excessive strain on the airways lead to a sort of fatigue comparable to metal fatigue - and like in an aircraft, it has to be monitored.

Thus, in a surveillance programme, CNSLD is treated as a slow, barely perceivable, yet progressive demolition of the capacity to draw air in and breathe it out. It is, however, a demolition that can be halted or tempered thanks to the socio-technical network of monitoring. It is a silent predator that can spring up and 
attack when least expected but that, if watched contimuously, can be kept under control.

Does the disease acquire these characteristics only in a surveillance programme? Is monitoring necessary for the transformation of the disease? The answer to the first question is 'no': the monitoring program is one of the technologies among others that contribute to establishing the same image; for instance, information campaigns and long-term treatment regimes.

The answer to the second question is affirmative without being submitted to regular controls, even if the natural course of obstructive airways disease were explained to Charles, the disease would remain a paper tiger. There is an amalogy with Latour's analysis of the weight attached to hotel keys as a translation of the verball injunction to leave the key in the hotel (chapter 1, section 4.3): as long as the story of lung function deterioration is simply told, its impact is less powerful than when it is performed in a practice. The insidiousness of CNSLD is made real within a surveillance programme.

\section{Treating one's own airways}

Two important guidelines, those of the British Thoracic Society (British Thoracic Society 1990) and the National Institutes of Health in the United States (National Asthma Education Program 1991), attach great importance to the role of the patient in monitoring. Both guidelines contain elaborate descriptions of selfmanagement plans in which the actions to be taken in case of a deterioration are specified - deterioration either felt by the patient or measured by regular peak flow controls.

In a next consultation, this further step in the treatment of Charles's airways is taken: apart from measuring the performances of his airways, he will be empowered to treat the disturbances. 'Self-care' is extended into 'self-cure'.

The doctor proposes a "management plan" which will involve two things: regular visits to the office and self-management. Charles will learn how to control his disease to a large extent himself. "From now on," the physician tells him, "self-management will be the basis for controlling your disease, both in preventing attacks like you had a few weeks ago, and in warding off any unnecessary deterioration of your lung function. Moreover, it will make you less dependent on me." To help Charles 'treat his failing aimways', the physician produces the following bits of paper containing a self-management plan: 


\section{Your asthma is controlled

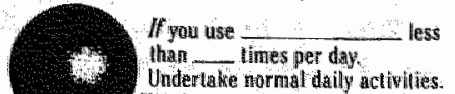 \\ Undertate normaldaily activilix.

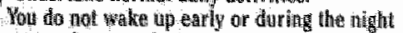 becalase of your asthma \\ Peak low is equal to or bingher than:}

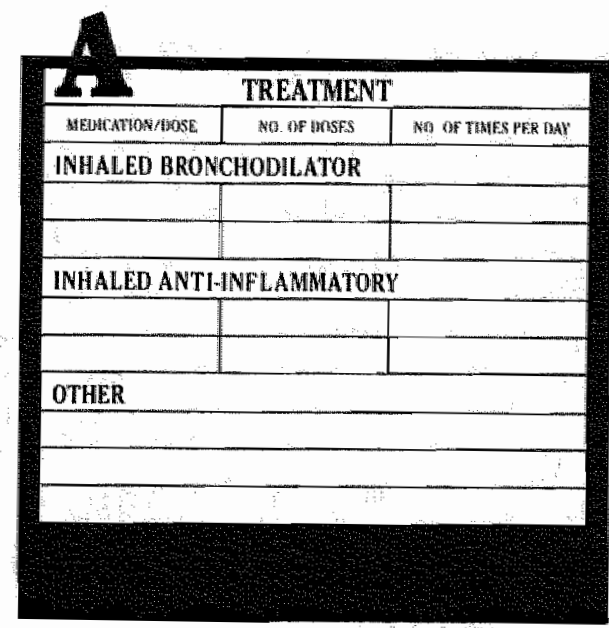

\section{Your asthma is not control} or Nornal activities are difflicull because of your asthma

or more.

\section{ADJUST YOUR TREATMENT}

\begin{tabular}{|c|c|c|}
\hline 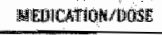 & Now of howes & NO. OF TAMES PES WA \\
\hline \multicolumn{3}{|c|}{ IWHALED BRONCHODILATOR } \\
\hline & & \\
\hline & & \\
\hline \multicolumn{3}{|c|}{ NNHALED ANTHIMF LAMMATORY } \\
\hline & & \\
\hline & & \\
\hline \multicolumn{3}{|l|}{ OTHER } \\
\hline & & \\
\hline & & \\
\hline
\end{tabular}

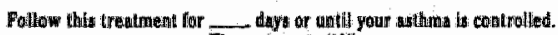
Then rewerl 60 " $A$ ".

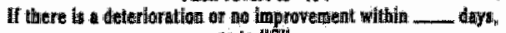
go to " thent

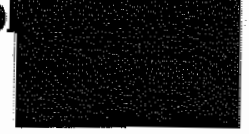

Trealment " $B$ " was not elfective

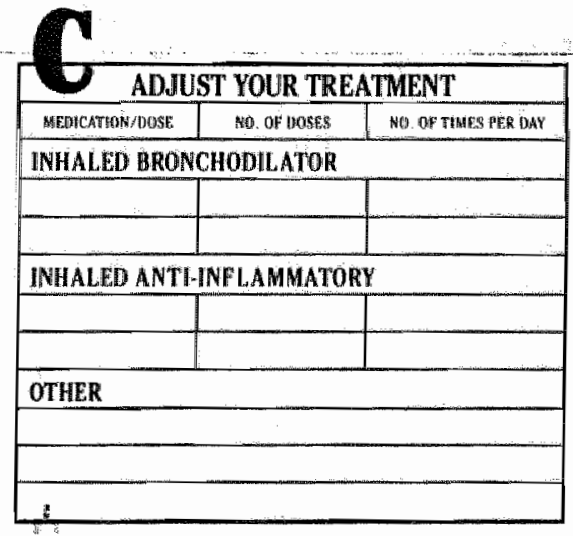

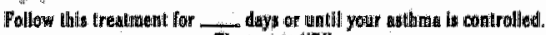

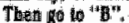

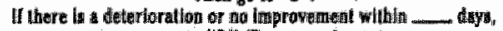

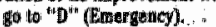


In the plan, the doctor writes down the names of the drugs Charles uses and explains that the plan works step-by-step. "This will be the basis for controlling. your condition, and you are going to be the one who controls it. You onlly will have to come and see me once every six months. Charles expresses his satisfaction with the plan:"I am glad that I will be able to control the disease myself. Maybe if I would have had a plan like this before. I could have prevented the bad attack I had same days ago."

\section{Self-management, delegation, and patient empowerment}

Self-management plans are far from being unique to CNSLD. In other chronic diseases, like diabetes, similar lists of advice regarding specific situations (e.g., a viral infection) exist. It is common practice that insulin-dependent diabetics measure their blood-sugar levels and adapt the dosage of insulin to abnormal results. People with bypertension sometimes monitor their blood pressure (although there is debate about the usefulness of this), but they generally do not adapt dosages themselves - thus, they engage in a sort of semi-self-management plan. Even the use of a thermometer to determine whether to administer antipyretics is a form of a SMP - although in this case, there is no explicit, stepby-step delegation of physician competencies as in a standard SMP.

There are other examples, outside the medical field, of systematic selfmanagement: in top-class sport, people methodically monitor their body. Breathing technique is one of the most important components of many forms of physical activity and it is, along with frequency of heartbeat, keenly observed in training programmes. Measurement of lung function may be an element of any physical examination connected with sports.

In a SMP, the activities and competencies of the physician are, to some extent at least, delegated to the programme. Or, to put it differently, the SMP is a partial translation of the physician into the little forms shown previously. Carl's physician. is in part condensed into this document. This translation thas consequences for the physician: his role and definition become different from what they were before the SMP was initiated (section 7).

Self management plans are sometimes presented as ways to empower patients by defining for them the active role they should assume in the course of their disease, and by encouraging them to use this endowment for their benefit (Netherlands Asthma Foundation 1993). The supposition is that patients become less dependent on their physician (in person, that is) for important decisions like starting new medication or increasing the dosage of an existing one. This; it is said, lias the important advantage of facilitating necessary treatment modifications without having to wait for approval from the physician. Although the use of the term 'patient empowerment' suggests an extensive transferral of competency, the power that is shifted to patients in actuality is restricted to decisions concerning a narrowly-dlefined treatment protocol.

One could describe this empowerment as an astute way of extending the physician's power into the private domain of the patient. Self-management, in this critical vein, has the appearances of patient empowerment, while in reality, it extends the influence of medicine. Although this is, to an extent, a defendable 
position, self-management may as consistently be described as an opportumity for patients to decide when and how they change their treatment regimes; moreover, they have some liberty to adlapt the SMP to their preferences. For instance, Charles may decide, when his peak flow is below 400 while he feels perfectly fine, to postpone the reaction the SMP prescribes and try again within the hour. Patients are likely to develop a certain flexibility and creativity in implementing this type of programmes. Self-management can be described, then, as a redistribution of characteristics and competencies between physicians, patients, and devices.

\section{Self-management, body technique and technologies of self}

In 1950, the French sociologist Marcel Mauss coined a term that seems particularly appropriate to the analysis of SMPs: "techniques du corps", or body techniques (Mauss 1950). In his paper, Mauss discusses the very different ways in which people in differing cultures "make use of their bodies", in everyday activities as eating, walking, sleeping, and breathing. He justifies the use of the term "techmiques" by saying that the behaviour patterns he describes are mechanical and unreflective in character and must be judged on their effectiveness, and not, for instance, on their beauty or appropriateness.

The notion of body technique, as developed by Mauss in his later work, is mainly a tool for ethnographically describing the way in which people employ their bodies - this elaboration of the notion may seem removed from the relationship to the body that people develop in SMPs. In self-management, patients are not so much concerned with a specific use of their body, as with a specific function or physiological parameter. What is lacking, more precisely, in Mauss" observations, is the notion of diagnosing one's own body. Moreover, Mauss merely indicates, but does not describe, the work people do on their body as part of a body technology. These restrictions notwithstanding, the term body technique will be retained here.

That people do work on their bodies is more explicitly discussed by David Le Breton, who speaks of "techniques d'entretien". He describes the theme of the 'maintenance of the body' as an area where sociology would find important topics for research:

"La recherche sociologique peut ainsi embrasser les 'techniques de perpétuation', c'est-à-dire l'ensemble des techniques d'entretien de la corporéitế: les soins du corps sous des formes variées qui s'exercent de façon à la fois privée (toilettes, etc.) ou publique (coiffeur, manicure, soins du visage, etc.), et les différentes valeurs quí leur sont associées selon les groupes et les classes sociales." (Le Breton 1992, p 72)

The techniques of maintenance that Le Breton points to come closer to selfmanagement than the body techniques described by Mauss. For instance, monitoring and self-management can be, described as maintenance of the respiratory function. Thus, self-management can be regarded as one of the various forms of care for the body Le Breton mentions.

But it is more than that. It is not merely a 'technicalised" form of care for an essentially unchanging body - in self-management programmes, new characteristics 
of the body emerge. To elucidate this, it is useful to analyse more extensively the work of another French theorist of the body: Michel Foucault. His llater work on technologies of self contains passages that shed light on this innovative element.

Foucault devoted himself to a description of what he calls the "Technologies of the Self". These "permit individuals to effect by their own means or with the help of others a certain number of operations on their own bodies and souls, thoughts, conducts, and way of being, so as to transform themselves in order to attain a certain state of happiness, purity, wisdom, perfection, or immortality." (Foucault 1988a) In his studies, Foucault has largely restricted himself to the ancient Greek and early Christian technology of the self. These techniques, to a large extent, are technologies of the soul. Taking care of yourself, Foucault says, was a principle of Greek civilization that has been forgotten and replaced by that other principle, knowing yourself. He sets out to show that taking care of oneself was as important an element of the good life in Hellenistic culture as knowing oneself, and that the two maxims evolved together.

Are there links between what Foucault has described as care of oneself and the modern forms of self-care that have been discussed in this chapter? Or is there no more than a superficial terminological parallel between 'technologies of the self and 'self-management'? Without suggesting that Foucault was intending describe a twentieth-century practice, and even without implying that he would agree with the use made of his work here, it can be proposed that connections are possible between his work and self-management. The first connection consists of the concept of self-care as a technology, and the second is the study of practices Foucault's basic material were not treatises on what the self is, or on what man is, but descriptions of practices in which 'selves' are produced.

Limking self-management and techniques of self is possible only if one shifts the meaning of the term 'self' in self-mamagement. In the latter, the term self originally means that a patient performs the management programme himself (instead of needing his physician for its realisation). In Foucault's use of the term, on the contrary, it means 'managing oneself. What will happen if the meaning of 'self in self-management is stretched in a Foucauldian direction? In an SMP, when a physician says to his patient: "From now on, you are responsible for the management of your disease yourself," this implies, "You have to manage your disease and your self." Self-management programmes, then, are not only the delegation of the management from the physician to the patient, they also are the constitution of a modified selfpractice. They are, in the words of Foucault, technologies of self.

Self-care in 'Le souci de sot' is a technique or, more precisely, a skill One has to 'turn into oneself and be concerned with oneself several times a day in order to learn how to speak, think, and write about one's own soul. Moreover, it is a technique of vigilance that Foucault explicitly calls medical: "The care of the seif isn't another kind of pedagogy; it has to become permanent medical care. Permanent medical care is one of the central features of the care of the self. One must become the doctor of oneself." (Foucault 1988a, p 31) Foucault stresses the importance that was attached, in the period he studied, to developing a rational way of dealing with the body: 
"[La médecine] devait aussi, sous la forme d'un corpus de savoir et de règles, définir une manière de vivre, un mode de rapport réfléchi à soi, à sou corps, à 1a nourriture, à la veille et au sommeil, aux différentes activités et à Penvironnement." (Foucault 1984,p 122)

This particularly applies to the Hellenistic form of self-care, where there is, according to Foucault, an emphasis on the continuous repairing of failures and concern for signs of diseases of the soul. For the first time in the period of early Christianity, he says, people regarded their souls as containing secrets. The emphasis in that period was on the deciphering of imner thoughts which implies that "there is something hidden in ourselves and that we are always in a self-illusion which hides the secret." (Foucault 1988 p 46) The technologies of the self, in that time, were ways to unveil the truth about oneself instead of ways to constitute a self. They were the techniques people needed to understand what was happening inside themselves. The techniques that form the SMP can also be regarded as helping people to know what is going on inside them - but inside their lungs instead of inside their souls.

The place of the body in these technologies is ambiguous, according to Foucault: "theoretically, the culture is soul-oriented, but all the concerns of the body take on a huge importance" (Foucault 1988 p 29). There is, above all in the writings of the Hellenistic period, a constant concern with eating, walking, bathing, and sleeping. It is not clear, however, whether concern for the body was an element of, or a prerequisite for, the care of oneself In the practices of the Stoies, gymnasia, the training of the body, was a way to safeguard the independence of the individual from various extermal influences. Sporting activities were one way to attain this goal. Again, there is a parallel with what happens in the treatment of airways disease. Long-term anti-allergic treatment has the same aim: hardening the individual against the outside world by making as body less responsive to triggers.

To turn to the second link between Foucault's work and this chapter: what he is concerned with, he says, is the "permament and ever-changing question: What are we today?" (Foucault 1988b), with an emphasis on 'today'. He is not interested in abstract treatises on man's immutable characteristics - as one might expect from a philosopher - but in man's characteristics as they are forged within practices. Thus, he does not study the great philosophical works of the period, but concentrates on the descriptions of the actual techniques. These techniques may sometimes be found within the larger philosophical works (for instance, Plato"s Alcibiades) but more frequently they are described in letters, diaries, and the like. Foucault's basic idea is that, if one wants to know what a human being is, one should consider what people do with their souls and their bodies. This implies that the description of 'the human' varies according to the practices - characteristics are modified according to the elements that play a role in these practices. Different forms of self emerge in different practices: "as there are different forms of care, there are different forms of self" (Foucault 1988a, p 22)

The implication for the kind of care studied in this chapter is clear: innovations in care, such as self-management programmes, involve the emergence of new forms of human beings, or of self. And although Foucault was talking about historical transformations of such technologies (from Plato through Hellenistic 
phiflosophy to early Christianity) there is no reason to assume there could not be contemporaneous differences. People with CNSLD are involved in a technology of the body that is different from, say, the one that is used by people with diabetes or with chironic arthritis, and therefore, they have different 'forms of self. The analysis performed in section 4 would yield quite different results when done with regard to other chronic diseases.

In Fourcault's techmologies of self, there is an ongoing concern with what goes on inside the mind and body. This concern is translated into various observational techniques, of which the meticulous description of bodily sensations is one. It is through writing down what one feels that one really learns how to feel what is going on. There is a parallel witli the use of peak flow as a diagnostic tool: this also is accompanied, at least in the earlier stages of a self-management plan, with the diary that was deseribed in chapter 3 ; the peak flow diary serves as a tool by which patient leam to feel what is going on inside their lungs.

Once this diagnostic skill is sufficiently developed, Foucault states that the way to influence what is going on is by training the bodily or spiritual function involved.

In the self-management programmes that were discussed, there is the same concern for a constant evaluation of what is going on, but in a specific part of the body. The introspective methods that were used in the practices Foucault describes play a subordinate role: here, kmowing what goes on in the body means measuring it. Patients need a device as an intermediary between themselves and their bodies. Although feeling what goes on is not entirely useless, it only provides preliminary knowledge: feeling breathless is a reason for patients to start measuring their lung function. On the other hand, repeated pealk flow measurements also change the quality of the feeling of symptoms, patients gradually learn to predict peak flow values.

However, what makes these techmologies of self clearly different from those studied by Foucault is their reliance on devices. Even in the simplest management plan at least two types of devices intervene: peak flow meters and inhalers. Thus, the decision to increase the dosage of inhaled steroids, or the choice to avoid certain triggers, is preceded by peak flow measurement. The self that is formed in these programmes does not rely on introspection, at least not in the usual sense of that term - although one could say, by stretching the meaning of the term, that people, by measuring peak flow, do take a look into their airways. This 'form of self is constituted, to a large extent, by taking the measure of one's lungs. The bodies of self-managing CNSLD-patients are measured bodies, not only potentially, but effectively. They are bodies linked to a network of measuring devices and of "inhalation technology. "Le souci de soi", to use Foucault's term again, is tumed into a concern for bodily function.

Another difference is in the maintenance of the body; whereas, in Foucault's examples, training is the most important technique of change, in most selfmanagement programmes the emphasis is on constant care, constant in the sense of the continuous adjustment of derailing functions. The instrument of change here is only partly the body itself, as in training, it is predominantly the inhalers and the drugs they contain - although, as has been stated in chapter 4 , even the possibility of taking extra inhalations does depend on a sufficient residue of lung function. 
One needs at least a minimum of lung function to be able to treat one's deteriorating lung function. As in Foucault's and Mauss' techniques, the body inscribed in the SMP has to be maintaimed in a meticulous way - the selfmanagement plan is an instance of the 'techniques d'entretien' that Le Breton mentions.

\section{New patients, new doctors}

The studies of Foucault, Le Breton and Mauss provide an indication of how selfmanagement programmes necessarily involve the emergence of transformed patients and doctors.

One of the characteristics an SMP demands of the physician is that he should be prepared to delegate to the patient or his family some of his authority, for instance on the decision to start a course of prednisone. He should be able and prepared to write a understandable self-management plan with minimal chances of misunderstanding. He should, therefore, be prepared to abandon medical jargon. And, moreover, he should be prepared to talk about the appropriateness of the plan at control visits, and be able to modify it as needed.

Self-management plans are translations of 'parts' of physicians into inscriptions on paper. Since translation encompasses some degree of transformation, one can expect self-management plans to redefine, to some extent, What a doctor is. The larger part of his activities can be taken over by the SMP, and only in extreme situations (for example, an attack of breathlessness that does not react to the indications of the plan) is the doctor's personal intervention necessary. Instead of delivering medical care themselves, physicians become the supervisors of the self-care of the patient. SMPs treat physicians' work with CNSLD patients as uniform enough, most of the time, to allow for a translation into a standard form.

More importantly perhaps, physicians are expected to shoulder the expectation that obstructive lung diseases can indeed be controlled by a sufficiently strict monitoring programme. This means, moreover, that physicians are required to accept, at least in part, the responsibility if the disease succeeds in breaking through the surveillance. Thus, an asthma crisis will raise doubts about the quality of the control system - it suggests cracks in the supervision. Accordingly, deteriorations cannot solely be blamed on the disease. There is some paradox in the account of the disease that is part of monitoring and self-management: on the one hand monitoring programmes, as we have seen in section 4.5 , create and maintain an image of CNSLD as a treacherous and capricious disease, while on the other hand making people and technologies accountable when it is not successfully brought under control.

Patients use the self-management plan mainly to avoid acute asthma attacks. In return, the plan demands from them that they trust peak flow values and take them as the decisive reason to take action. Moreover, they should be able to blow peak flows every now and then during the day, which means that they have to organise their work schedules to accommodate this. And, more importantly, they should master the blowing of peak flows and not become careless with it. 
Additionally, they are required to carry their peak flow meter with them all the time.

Another characteristic the programme prescribes is that Charles must have the 'nerve' to wailt a couple of hours for improvement once he has taken the medicine as prescribed. He should, moreover, - and this is not at all self-evident be prepared to decide for himself (but guided by the SMP) if oral corticosteroid medication is needed.

Charles has to be able to fill in the inevitable gaps in the programme: for instance, how long exactly should he wait for peak flow values to increase, for how long should he take extra medicine, and what if improvement sets in more quickly than expected, what if, during an exacerbation, contact with allergens is unavoidable.

In becoming professionals, Charles and other CNSLD-patients learn a new form of body technique, a new way of managing themiselves and their body.

Monitoring programmes, and especially self-management, are an immovation in the medical treatment of people with a chronic disease. Like every innovation, they involve not only the realisation of a way of dealing with chronicity, but they also encompass new definitions of both physicians and patients. Most importantly, however, these programmes transform the relationships of patients to their bodies; they become people with bodies that need more or less intensive maintenance in a specific form. Tecthrical objects are cruciall elements in this form of maintenance of the body. 
"[...] compliance is a psychosocial phenomenon, distributed more or less normally throughout the population" . (Krislow 1972)

"[..] compliance was not only required from the human components of the system. It was also expected from its inanimate parts - from the hulls and sails that made up the vessels and the environments in which those vessels sailed." (Law 1986)

\section{Advice and device - the technology of compliance}

1. Introduction: patient compliance as a problem in the treatment of chronic disease

In the previous chapter, it was shown that long-term diagnosis (monitoring) differed in important ways from short-term, or acute diagnosis. The present chapter will focus on long-term treatmert. The first question is: How, and to what extent, does long-term treatment in CNSLD differ from short-term treatment? In other words: Is long-term treatment merely a prolonging of short-term treatment or do different problems arise and different elements or actants intervene?

To start, a list of differences between short-term and long-term treatment may be useful. As therapy in CNSLD contains both forms, the comparison will be between the treatment of an acute period of breathlessness and long-term treatment of airways hyperreactivity. As always with such lists, the differences are somewhat exaggerated and over-simplified.

\section{SHORT-TERM TREATMENT}

* responds to complaints

* fast results expected

* results immediately felt by patient or seen by doctor

* clear criteria for end of treatment

* aims at complete recovery

* side-effects acceptable

* non-compliance mainly as overconsumption
LONG-TERM TREATMENT

* no necessary association with
complaints at the time of visit
* slow results
* mainlly circumstantial evidence for
results
* criteria for end of treatment
unclear
* partial recovery, only prevention
of progression
* side-eftects major obstacle, lea-
ding to non-compliance
* non-compliance as wnder-con-
sumption continuously menacing
treatment success

is

One of the most prominent differences is in the area of compliance. The problem of non-compliance is more serious in long-term than acute treatment of CNSLD attacks, and differs from the latter in important ways. In long-term care, it 
takes the form of under-consumption and related 'disobedience', whereas in the treatment of the asthma attack over-consumption is the greater problem, although under-consumption may occur.

The phenomenon that patients do not always follow the advice of their physicians as regards drug prescriptions, control visits, lifestyle changes, and so forth, has been documented since Hippocrates (Davidson 1976). They forget the advice, refuse to follow it, or invent modifications that suit them better or that seem more logical than the physician's instructions. In long-term treatment of chronic diseases, especially where it involves symptom-free periods, attaining of patient compliance with treatment is a central problem; as will be illustrated, it makes treatment of CNSLD comparable to other forms of long-distance control.

The preponderance of compliance problems in long-term treatment is the reason why this chapter is devoted to the analysis of compliance-related technologies.

The employment of compliance-enhancing strategies and especially of compliance surveillance is a logical corollary to the increased belief in the effectiveness of modern medicine: observance of the physician's instructions becomes important only if there are effective therapies to offer. Motivation falters if all that is on offer are a prognosis and treatments of sometimes dubious effectiveness. Moreover, the chronicity of treatment in chronic diseases makes compliance a more weighty issue. The link between patients and their treatment regime has to be made more durable than in acute disease. This can be seen in CNSLD, where the tendency is not only to alleviate complaints, but to contimue treatment for long periods. And, finally, the insistence that treatment continue during symptom-free periods, like in hypertension or hypercholesterolemia, contributes to the problem (Stimson 1974). Patients are expected to take their daily inhalations even when they have been without complaints for several months.

The failure of patients to follow a treatment regime, then, is no longer regarded as a consequence of disobedience or carelessness of patients, nor is it an excuse for physicians to complain about patients, or to blame them for a therapy that fails: compliance enhancement has become a basic principle of good medical practice (Phillips and Jones 1991). One could say, then, that poor patient compliance has become as much a medical problem as poor airways compliance.

As an introduction to the problem, a case will be presented of a patient who would undoubtedly be labelled non-compliant (although the restrictions of the term become apparent immediately), this will be followed by a discussion on theories of non-compliance and the solutions being offered. In the third section, some of the recent criticisms will be discussed, especially those of the sociologist Irving Zola. The fourth section will attempt to improve upon these criticisms using tools from science and technology studies. There are two reasons why this seems useful: the first is that technology plays an important role in compliance improvement strategies, and the second is that in the field of science and technology studies, scholars have been working on problems that are highly similar to patient compliance in medicine. In the final section it will be proposed that compliance can be characterised as the organisation of 'flexible networks'. 
During an episode of bronchitis, Steven, a thirby-year-old manager of a supermarket, is prescribed antibiotics and a short course of bronchodilators. His physician urges him to finish the course of antibiotics and told him to return in a week. Steven tries to follow the course, but at the end of the week, when the treatment should have been finished, he discovers he has two pills left, and he has forgotten about the doctor's visit. At the next visit, when asked about the antibiotics, Steven honestly replies that he hasn't finished the course. "But I did take most of them, and I felt so much better after a few doys - it is difficult to go on taking drugs when you feel all right!" "Well," his physician says after having examined him, "you are lucky that the bronchitis is over, but your asthma isn't. I still can hear some wheezing in your lungs. I think we had better keep that under control. I would propose that you continue the inhalations I prescribed and that you return in a fortnight to see if there is sufficient improvement. And, I must repeat it again, you really must stop smoking if you want to get any better." Steven returns after a month instead of two weeks. In response to his physician's questions, he replies that he has kept his peak flow diary quite precisely during the first ten days, then has forgotten it for some time, and started to fill it in again during the last week, when he knew he had an appointment with his physician. They discuss the peak flow values, and the physician explains that his registration results are a cause for some concern. Then, the doctor asks him if the inhalations he prescribed are finished. Steven replies that he has some left, enough for a week or two. His physician conclides that he has taken less than the prescribed dasage. "And' what about smoking?" Steven answers that he has succeeded in bringing it down from 20 cigarettes to 10 a day.

At various times, Steven has only partially followed the advice of his physician, who, allerted to the possibility of this problem, tries to assess the extent to which Steven has complied.

The following is a list of the instructions Steven received and a brief indication of the degree to which he followed them:

\section{ADVICE}

* take these antibiotics three times a day, at regular intervals, during a week

* come back in a week

* use peak flow meter properly

* make a daily registration

* come back in two weeks, even if you feel fine

* stop smoking
FOLLOW-UP

* says he followed for a few days; unknown how regular the intervals were

* came back after two weeks

* no information

* initially followed strictly, then stopped, and taken up after a fow weeiks

* came back after a month

* halwed the number of cigarettes 
Steven quite often failed to do exactly what his physician requested, but, admittedly, he did follow at least a considerable portion of the advice given. Is he compliant? Is he non-compliant? Or is he somewhere in between?

The first thing his physician, who suspects that Steven's compliance is incomplete, wants to do is to assess it. There are several ways of assessing compliance: Did Steven feel any improvement? Did he need a new prescription? Was he satisfied with the treatment? Did it pose any special problems?

\subsection{Methods for measuring non-compliance}

In an early review, Gordis eites the existence of so-called direct and indirect measurement methods (Gordis 1976). Direct methods, quite far from being direct in the accepted meaning of the term - ome would expect it to mean that the actual taking of the drug was done in sight of the physician - involve measuring concentrations of the drug or its derivatives in blood or urine. It is a well-known method in substitution programmes for drug addicts, where it is used to detect (and sanction) the contimuing use of drugs by abusers. The method is considered highly reliable. Obviously; these direct testing methods are dependent upon technical possibilities: not all drugs provide detectable concentrations of metabolites, and in many cases, measuring them is expensive and difficult to organise. In chronic obstructive lung disease, only the level of theophyllin (a rarely-used oral bronchodilator) is regularly tested in this way, partly for compliance assessment, partly to monitor drug dosage (National Asthma Education Program 1991).

Because of the restrictions of direct testing takes physicians have resorted to socalled indirect methods. These come in various forms: the first possibility is the simplest: ask the patient - this is what Steven's doctor does. Although it has the virtue of being simple and straightforward, Gordis considers it an unreliable method: most non-compliers will lie, or at least embellish the truth. Positive answers, he conchudes, are near to worthless if one wants to really know whether patients take their drugs. On the other hand, a negative response is regarded as relatively reliable, since those who 'confess' non-compliance probably have not followed instruction - except for a few overscrupulous people, who think they fail however strictly they comply. In conclusion, it seems that asking the patient about compliance serves mainly to keep everybody content (the doctor, because he thinks patients follow his well-meant advice, and the patient, because he feels free to do as he pleases). Nevertheless, it is a much-used method in everyday practice (Gerber 1986).

Another tactic is to assess compliance by measuring the outcome of treatment. This is even more suspect, as it presupposes a direct relationship between treatment and the outcome of the disease episode. It is based on the, mostly unwarranted, assumption that those who get better must have followed the treatment, while those who do not improve have been non-compliant. Gordis's criticism of this method is that the relationship is rarely clear-cut: medical treatment at best improves the chances of getting better. Thus, if a patient's health improves, that can hardly if ever be taken to be a proof of his compliance: 
Pill count is a third indirect way of assessing compliance: counting the number of pills left in the package after a period of time is supposed to give an indication of the usage: There are many possibilities to cheat with this method: there is no way to tell whether the pills that have disappeared from the package have actually been used by the patient. Various forms of this method exist, for instance the registration of repeat prescriptions, which is currently the most common way physicians scrutinize medication usage. A specific variant of the pill count in CNSLD is weighing the canisters of nebulizing devices: the heavier the canister, the more medicine has been left unused (Spector and Mawhinney 1991).

In the last decade, highly sophisticated machines for indirect compliance measurement, electronic registrators, have been introduced on an experimental basis. Epidemiologist Joyce Cramer, in a review, mentions nine types of microelectronic monitors, varying from eye-drop monitors (recording every inversion of the bottle) to nebuliser 'chronologs' that record the firings of an aerosol (Cramer 1991; Spector 1985).

The fourth and last strategy Gordis mentions is assessment by the doctor on the basis of his knowledge of his patients' previous behaviour. To the disappointment of all family physicians who feel they know their patients, this method has been proven to be as reliable as throwing dice.

The strategies described above can be described as ways to unmask the noncompliant patient. "Never believe anyone who tells you he has taken an antibiotics course exactly the way you prescribed it;" seems to be the attitude. The work on patient compliance could be summarised by the rule; that physicians should always be prepared to discover the truth behind the stories patients tell about their medications.

It is this atmosphere of unmasking, of distrust and of authority that hover around the compliance/non-compliance terminology, which was the reason for various criticists, among whom the sociologist Zola, to attack this terminology (section 3).

\subsection{Some limitations}

Apart from the problem inherent in the terminology, to which we will return, there are other debatable characteristics in the above-mentioned measurement strategies. One is that (non-)compliance is regarded as an isolated phenomenon, in whicli one particular patient is charged with not doing what has been advised. Rather, it would be productive for compliance theorists to assess the strength of medical advice to a patient in comparison with the strength of other, maybe competing counsel. In other words, to understand why a patient is compliant or not, it may be necessary to have an idea of the strength of his bonds with medical advice as compared to the strength of other bonds.

Another difficulty with the assessment of compliance is that it is not clear what the phrase: "Steven should do exactly what his physician said" means. For instance, Steven may well have wondered whether he had to take his antibiotics with an exact interval of eight hours or three times during the time he was awake. Did he have to rest before measuring his peak flow or could he do it after having gone jogging? Was it possible to blow his peak flow meter a second time if the first one 
failed? This difficulty further exposes the problematic nature of the compliance concept. Steven, in the above consultation, was more compliant with some of the instructions than with others; some he slightly modified and others he disregarded totally. In other words: Steven was almost never fully compliant, nor totally noncompliant.

\subsection{Explaining non-compliance}

That non-compliance is not a new problem can be deduced from the publication year of the first quantitative study of the phenomenon, which was published in 1954: the British family physician Jenkins showed what he considered alarming figures, namely that up to $\mathbf{5 0}$ per cent of the patients did not follow their doctor's advice (Jenkins 1954).

Since Jenkins' original article, a growing number of publications have addressed the problem of non-compliance with therapeutic advice. Initially, most were descriptive, but gradually the number of explanatory analyses increased. Until recently, most of the research has attempted to categorise indicators of noncompliant behaviour in terms of sex or age, educational status, and, most frequently, in attitudes towards the specific disease. Another category of publications can be described as trials of compliance-enhancing strategies.

Although it had been used in a small number of publications before 1976, the term compliance became part of the medical vocabulary through two collections of papers published in 1976 and 1979 (Sackett and Brian Haynes 1976; Brian Haynes et al. 1979). The following definition was given:

"the extent to which a person's behaviour (in terms of taking medication, following diets, or executing lifestyle changes) coincides with medical or health advice." (Brian Haynes 1979)

In this quotation, compliance is defined as an extent: a patient can be more or less compliant, for instance on a percentage scale ranging from 0 to 100 . Perfect compliance and total non-compliance are the two extremes on the scale, both presumably quite rare. In this early phrasing, compliance and non-compliance are not categorised as 'yes-no' phenomena, as they have often been in subsequent literature.

Various explanatory theories about non-compliant behaviour have been proposed. Relationships with level of education, socio-economic status, and with demographic variables have not been consistent. The doctor-patient relationship, on the other hand, has been shown to have a great influence, especially those forms of relationship in which "consistent care within a caring relationship" is provided seem to have a compliance-enhancing influence (Gerber and Nehemkis 1986). Negative emotional interaction between patient and physician, the combination of an authoritarian patient and a passive physician, as well as a non-informative physician (both during diagnostic and therapeutic phase) have been associated with non-compliance (Owens 1991). Additionally, patients" views and beliefs about their diseases, especially the extent to which they feel in control, have been found to be important elements influencing compliance (Jones 1987). 
Obstructive hung diseases have been one of the most thoroughly-researched fields (Horn 1990), in part because non-compliance in the form of overconsumption of medication has been associated with the recent rise in the number of asthma deaths (Sears 1986).

Various studies on compliance in asthma describe the compliance of patients as dependent upon a number of factors: their ideas about the disease and therapy; the duration and complexity of treatment; the degree of anxiety about the disense; and, the quality of the communication between physician and patient (Dieleman 1989).

\section{Compliance-enhancement}

What does the physician in our case-history do to encourage patient compliance? Without wanting to suggest that compliance assessment and enhancement are entirely separable activities, a second consultation with Steven will serve as an example of compliance- improvement strategies.

At one of the following consultations, Steven and his physician talk for some time about how things are progressing. Steven says that he feels quite well, except for some shortage of breath about once a week. In such periods, he takes four to six dases of ventolin a day, as was prescribed. He caiculates that in total he takes about wice the prescribed dosage of ventolin a week. "And I must confess, doctor, that there are times when I forget to take the inhalations from the brown inhaler you gave me last time. I just forget them. On the other hand, I'm smoking less, in the last few weeks I have stayed to around ten cigarettes $a$ day, with sometimes a few more when I'm feeling stressed, but that's not every dag."

The physician understands how difficult it often is to stop smoking. "Especially," he says, "if you do not feel there is a relationship between cigarette consumption and breathlessness." "Oh but I do," Steven protests, "the problem is, stress is just as powerful a trigger for my lungs, and cigarettes this may sound strange to you - help me restrain stress, so that is the dilemma: quitting smoking is stressfull, which in turn may increase my complaints, but not quitting may have the same result."

And as to regularly taking his medications, that is difficult to do, Sieven sapss. "I have a busy life, taking several drugs a few times a day is hard." Although he says he is cominced that it is important to do so, he finds he has more medicine left, at the end of a month, than he should. Moreover, he sometimes loses count. "As to the dilemma you mentioned," the physician says, "this looks logical at first sight, but it is not. If you quit smoking, the sensitivity of your airways will lessen - although not within a few days, certainly in a few months. so that they will become less sensitive to all sorts of triggers, stress included. And as to lasing count, that can be solved by linking the medication to other daily activittes, for instance, brishing your teeth." Steven might ask his partner to help him quit smoking by stopping himself. And as to keeping his control appointments, the physician gently but firmly remarks that it has been five instead of three months since they last saw each other; and suggests that it 
might be easier to keep the appointment by taking it nght owwo, rather than having to think of it in several wonths.

As in the assessment of compliance, it is possible to draw a hist of reinforcememt strategies used by the physician in trying to persuade Steven to be more compliant:

\section{ADVICE}

- take antibiotics three times a day, at regular intervals, during a week

* come back in three months

* keep trying to quit smoking

* use inhalers properly

* use medicine as often as prescribed

\section{STRATEGY}

* explanation of medical importance of finishing a course; suggestion to link antibiotics to daily activities (tailoring) (Sackett 1976)

* schedule appointments right away

- renewed explanation of hazards: combine efforts with partner

* demonstrate the use of inhallers during consultation

* link drugs to daily activities

As can readily be seen from this list, the strategies the doctor uses to reinforce his advice are heterogeneous: he concomitantly uses imformation, warnings, devices, and organisational tactics ("schedule your next appointment right away, so you won't forget it"). Forging durable links between patients and treatment involves what Callon has called, in the example of a hard technology, heterogeneous engineering. His argument, exposed in chapter 1 of this book, was to show that engineers not only manipulate the material parts of devices, but also the characteristics of humans (Callon 1987). The argument here is the inverse: physicians, in engineering compliance, not onlly orchestrate the desires and resistances of patients, but also organisational procedures and material objects.

\section{I Theories on compliance entiancement}

Compliance theories propose four strategies to enhance patient compliance (Brian Haynes 1976). They can be summarised in four words: information, simplification, association, and self-regulation. The suggestion is that the more a patient knows of the medical theory concerning the disease; the simpler the physician's recommendations are; the more they are associated to other daily practices; and the more patients are instructed to regulate treatment in accordance with differemt situations, the more likely it is that they will comply with medical advice.

According to these theories, knowledge about the disease is transmitted in written and oral forms: the more exhaustive a physician's explanation about the disease, the better the chances are that a patient will comply with advice. Diagnostic devices play an important role in tramsmitting this information : $X$-rays, echograms, and even curves or rows of numbers generated by machines can help to 
convey medical information about their disease to patients In Steven's example, $X$ rays can reinforce repeated wamings about the lhazards of smoking lung function curves may be instrumental in transmitting information about the effects of different types of medication.

The second compliance-enhancing strategy, simplification of treatment schemes, is one of the focuses of pharmaceutical research. One of its aims is to design simpler forms of drugs: slow-release tablets, one-pill-a-day antibiotics, and, for asthmatic diseases, ever-simpler inhaling devices. Designers of inhaling devices, accordingly, use 'better patient compliance' as a publieity slogan.

No medical advice, however well-intentioned and well-founded, has a chance of surviving unless it is linked to patients" habits and is incorporated into the personal networks of people and things a patient lives in. It is crucial, according to most compliance theories, to establish strong and durable associations between the treatment plan and other habits and interests.

The most sophisticated approach to non-compliance - high-tech compliance enhancement, so to speak - stresses the importance of self-regulation. By allowing a patient to decide about drug-dosages - as in the self-management plan discussed in chapter 6 - the result is expected to be a more complete adherence to the treatment regime. Can there be a better controller of patient compliance than the patient? In the case of CNSLD and other chronic diseases, where people are encouraged to take drugs or alter habits for a long period, sometimes for the rest of their lives, this is thought to be the most effective method.

\subsection{Is non-compliance really surprising?}

In the vast literature on the problem of non-compliance there is surprisingly little discussion about how exceptional patient non-compliance really is. This is all the more remarkable, because the extent to which people follow advice in general is probably as low or even lower than in following advice of physicians. Doctors seem to expect that patients follow their advice for $100 \%$. That this ideal is unrealistic is clear from the information about compliance problems in fields like organisational management, the legal profession, and education (Feeley 1972). In these areas, compliance and non-compliance have been shown to be distributed according to a Gauss' curve - entire compliance being as rare as complete noncompliance (Krislov 1972).

A second remarkable feature of the research on the problem is that it is thoroughly asymmetrical: only deviations from medical advice receive attention, while the fact that people often do follow medical advice could be just as surprising. That Steven actually takes most of the antibiotic pills and forgets only two of them is at least as surprising as the fact that he did not show up at the appointed day. Moreover, non-compliance on the side of patients may be a perfectly logical attitude, as was commented, with remarkable sagacity, in one of the pioneer studies on compliance in paediatrics:

"If we look dispassionately at both sides of the "complianceprescribance" axis, some sort of rough-and-ready natural law seems to be at work, balancing the interests of both the physician and the 
patient The physician will be expected to prescribe with only approximate accuracy, and the patient will be expected to comply with only modest fidelity. Thus has mankind been able to survive bleeding, cupping, leeches, mustard plasters, turpentine stupes, and Panalba." (Charney 1975)

The literature on non-compliance is replete with distinctions between rational and irrational behaviour: the compliant patient is portrayed as the rational decisionmaker (except for situations as described above, where non-compliance seems to be rational), while non-compliance is inherently irrational, based on lack of information, on emotions, and, as one paper suggests, on "indireet self-destructive behaviour" (Farberow 1986).

The asymmetry with which non-compliance has been studied is reminiscent of a more general one which formed the point of departure for modern soeiology of science: this field of study began largely as a criticism of the idea that onlly the making and diffusion of erroneous science or non-science had to be investigated sociologically, while real science was, by virtue of its truth, exempted from social analysis. Recent work in the sociology of science and technology adheres to a radical symmetry in this type of question (Bloor 1976): the spreading of, say, Newton's laws of gravitation merits a sociological study just as much as that of Goethe's doctrine of colours. In this sociological vein, compliance with medical advice, even if it is considered rational, has to be considered just as surprising, and merits just as much attention, as non-compliance. Compliance is, at least sociologically and philosophically, equally interesting as its opposite. But before turning to an investigation in which compliance is as much questioned as its opposite, two criticisms of the concept of compliance will be discussed.

\section{Allying instead of complying}

According to the sociologist I.K. Zola, the very vocabulary traditionally used to discuss the problem is responsible for the serious misunderstandings that surround it (Zola 1981). Rather, he proposes to stop speaking of patient compliance and to start speaking of an alliance between physician and patient. The concept of compliance, Zola argues, has links to an image of the patient-doctor relationship in which the latter tries to persuade the former to follow medical advice. According to Zola, much of what doctors do contributes to non-compliance instead of diminishing it, like, for instance, lack of clarity, giving impractical advices, writing prescriptions too quickly, and so forth. Perstiasion, he says, is (or should be) disappearing as a basis of the relationship between patient and physician and is increasingly replaced with negotiations between doctors and patients. Negotiations take place between unequal but equivalent partners, not between an authority and an obedient subject. The result of such negotiations is some type of alliance or agreement.

If patients disregard the advice of physicians, Zola argues, there is a problem in the alliance. This mostly is a result of insufficient sharing of information between patients and doctors. The solution, accordingly, would be found in promoting an attitude of cooperation rather than employing persuasion, or worse, anthoritary. 
The control of Steven's lung function should become his own task as much as that of his physician, and Steven's failure in quitting smoking should be a shared problem as well. Instead of a physician giving advice which patients find impractical and therefore do not heed, physician and patient should agree to a covenant about what will and what will not be done. If things do not work out as agreed upon, the problem is not one of reestablishing authority but of adapting unrealistic agreements.

Zola's terminological proposal has several advantages: it takes away the scent of servility that hovers around the word compliance, and it demonstrates that whether a patient follows an advice or not is the outcome of a two-way traffic (the physician has to follow the patient as much as the other way round). Moreover, it has an advantage over the concept of patient self-regulation in that it takes the degree of cooperation to be a social phenomenon, whereas self-regulation focuses on the individual.

However, the way Zola presents doctor-patient alliances has four important restrictions. The first is that it restricts compliance to two-person-interactions, even as Zola acknowledges that the social system a patient lives in has important influences on the strength and durability of the doctor-patient alliance, he does not elaborate on this point. This may be due, then, to the lack of a concept like a network of alliances. As has been stated in chapter 1 , the term network has the disadvantage of seeming to suggest a static structure. This, of course, is not intended here. Unfortumately, there is no term that combines the strength of the network with the ability to shift and change. The image here is not one of a flat and fixed, two-dimensional grid, but more like floating tissues that intersect at moments, that form knots remaining in place for an uncertain period of time (Serres 1989). The use of this concept would clarify that the alliance with the physician is but one, and not always the strongest, of many alliances people are involved in. Patients, on the other hand, are elements of one of the many alliances physicians work in.

Some authors would add that the doctor-patient relationship is not functioning in a vacuum, but is one of many relationships. As Conrad points out:

"Most sufferers of illness, especially chronic illness, spend a small fraction of their trves in the potient role, so it is by no means certain that the doctorpatient relationstup is the only or even the nost sigurifiant factor in their decisions about drug-takutig" (Contrd 1985).

Improving the success of a treatmeat programme not only dernands strengthenitg 羔e allince beween patient and programme, but also between the programme axd

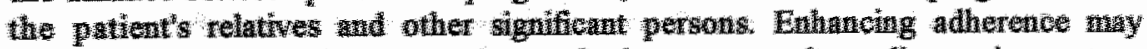
mean the use of other important actats, for ${ }^{3}$ stance, turning a disagreeing partner into an ally, or adapting the daly treatment regime to certain regularites in the workplace, hereby tuming that environment into ally as well. In short, improving the commitment to act acooding to an agreement mens bulding and nging networks of interpersonal relationships.

A second lintitation in $Z$ olas sropossil is that he not only restriots the humans

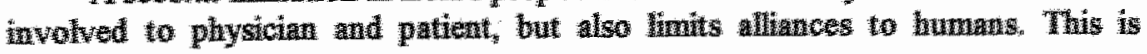


problematic in a description of medicine, where relations between humans and things become more and more important. The links in the network of medical alliamces are increasingly occupied by devices and artifacts.

Third, the use of the term 'negotiation' to describe the interaction between physician and patient has the advantage of being frank about what happens in those encoumters, but also the disadvantage of introducing a metaphor from the realm of rational, economic behaviour. Although an alliance between patient and physician may have been satisfactorily negotiated, a variety of circumstances and reasons may cause one or the other to break their commitment.

A last feature which makes Zola's proposal of limited value for the compliance/alliance problems in the treatment of CNSLD is that little attention is given to the specific demands that arise as a corollary to the chronicity of the disease. Chronic treatment programmes imply 'chronic' alliances. In other words: one of the elements that the chronicity of CNSLD consists of is the durability of the alliances. Zola does not treat the making of durable alliances as a specific problem, which it is, as will be seen in the next sections.

\section{Compliance in actor-networks}

Zola's proposal of re-conceptualising of the compliance problem as a problem of alliance-building has clear advantages, but his proposal lacks an account of networks, and of the heterogeneity and the durability of alliances. Therefore, it is worthwhile to regard the way in which these aspects are treated within the actornetwork model.

Networks of alliances, and particularly the construction of durable ones, have been studied in the Paris school of technology studies. A brief account of the theory of actor-networks ean be found in the first chapter and will not be repeated here (Callon 1986a). To summarise a few central themes: the making of technology involves the construction of networks consisting of heterogeneous elements: human, material and hybrids of the two; that is, entities comprising both human and material elements. The elements of networks are all actors or actants within it: human and non-human elements indiscriminately work upon each other. The challenge of technology construction is to forge durable alliances within these networks. Durable alliances, more often than not, are those alliances in which objects play an important role. It is the objects around us, as Latour has argued consistently, that are the binding force of society (Latour, in press). They, more than interhuman relationships, guarantee the stability of, for instance, the alliances that Zola describes.

In the case-history of Steven, a sequence of elements is being mobilised to strengthen the alliances between Steven and his treatment programme: inhalers, his partner, peak flow meters; and the toothbrush. What the 'heterogeneous physician', to paraphrase Callon again, must ensure is that Steven regards compliance with medical instructions as a preliminary to being able to do what he wants or is in the habit of doing. Inhaled medication and quitting smoking should become, in the words of actor-network models, obligatory passage poimts for Steven; if he wants to continue his weekly jogging in the future, he will have to pass through this treatment regime. 
Thus, compliance ranks as a key component in the sociology of technology. Concepts like the creation of obligatory passage points, the enrolment of individuals (people as well as things) in socio-technical networks, and the forging of durable associations between technology and human beings can be found in actor-network studies. The term compliance itself can be found in the study of the British sociologist John Law on the methods of long distance control developed in the Portuguese merchant marine; the second quotation at the beginning of this chapter was taken from that article (Law 1986).

\subsection{Compliance in people and in airways}

Since the term compliance is found in mechanics; physiology, and in sociology, it is appropriate to utilise it in reference to both human beings and things.

Until the publication of the first collection of studies on patient compliance in 1976 , the term compliance in medicine had been reserved for mechanical processes in the body. The original authors explicitly warned against confusing 'mechanical' compliance with its 'pharmacological' counterpart:

"It was also observed that the utilization of the term 'compliance' may lead to confusion with its use in the discipline of human biology. Compliance has separate, special meanings for students of lung mechanics and left ventricular function, who may view its use by students of therapeutics as usurpation." (Sackett 1976)

It is not clear whether there is any historical link between 'patient compliance' and, for example, "left ventricular compliance", but it is surely tempting to study the analogies between airways compliance and patient compliance in CSNLD. Using the term compliance both for behaviour and for the body involves abolishing the standard distinction between causes and reasons: 'causes' being what moves nonsentient and 'will-less' things, such as technical objects, but also organs, while 'reasons' apply to human beings.

For the airways, compliance indicates "the change in pressure needed to move a given volume of air" (McFadden 1976); the less pressure change (exerted by the muscles of the thorax) is needed, the better the compliance is. Patient compliance can easily be described in more or less the same way: "the amount of energy needed to persuade a patient to follow a given advice". In both the physiological and the patient cases, the higher the compliance, the less pressure or force is needed to keep things (or people) in line.

Energy is needed to ensure that people, like airways, behave in a specific way. Physiological compliance is a gradual phenomenon; non-compliance and total compliance are its virtual limits. The parallel has a double heuristic value: first, in airway pathology compliance can not only be too low, but also too bigh (in emphysema, for instance). No counterpart to the latter exists in patient compliance research; excessive compliance with medical advice, in the sense of a too rigid adherence to medical orders, could be as problematic as low compliance, but it has not received systematic attention in compliance research. Rigorous compliance, in chronic diseases, is in conflict with self-management, where patients are 
encouraged to take initiative and to muake decisions regarding their treatment. Second, the comparison between airway compliance and patient compliance shows the importance of regarding the two as gradual phenomena, not as 'yes-or-no" features: thus; it is hardly useful to refer to Steven as either compliant or noncompliant. As was shown, he followed the advice of his physician to varying degrees: in some instances almost entirely, in others less, and in still others in a slightly modiffed form. The adherence to instructions, then, is more 'fuzzy' than black-and-white distinctions allow for.

The less current symonym for patient compliance, adherence, also shows a physiological parallel in virtue of its association with the adherence of the blood platelets; since physiological adherence is defined by the force needed to separate blood platelets, therapeutic adherence could accordingly be defined as the force needed to separate a patient from her therapeutic regimen.

\subsection{Compliant subjects and compliant objects}

As has been stated previously, the need to manipulate patient non-compliance has become an ingredient of the construction of diagnostic and therapeutic devices, especially those intended to be used by patients themselves. Patient compliance, then, is not ouly a soft (psychological) label attached to the behaviour of some patients, but it has become a hard (material) fact in the form and design of things like the peak flow meter, the glucometer, the turbuhaler, and many others.

Reducing complicated medication regimes to a pill once a day, or blending separate inhalations into one (recently, a combination of a $B_{2}$-mimetic and an anticholinergic agent in one iwhaler has been introduced on the market) can partially solve the problems caused by increasingly complex treatment plans - but where this is impossible, pill containers, subdivided according to the hours of day for those who have to follow complicated regimes, are used to inerease adherence.

These are devices that thelp to persuade people to take their medicine, but quite a different question is how to ensure they take it properly (which, in the management of obstructive hung disease, often is not simple). Again, employing devices as delegates is helpful. Extensive research has been gone into constructing inhaling devices in such a way that as little as possible is left to chance, forgetfulness or neglect. A case in point is the Diskhaler that was discussed in chapter 4.

Quite another, but equally ingenious way of enforcing an alliance is by engaging the patient's habits by tailoring regimes to the patient; taking daily dosages together with other regular activities. Thus, even the toothbrush can be turned into a major ally.

Artifacts play, amongst other roles, the one of delegates of doctors. Physicians are not required to physically ensure that patients take their medicine this would not only cost too much time and energy, but would also be considered ethically unjustifiable - but they entrust this task to the inhalers. These are constructed in a way as to limit choice, thereby making it easier to be compliant. The modern doctor does not need a Panopticon (Foucault 1975) to supervise his patients and to ensure they comply to medical advice, he has reliable delegates at his disposal. In the form of these delegates, the doctor in a sense enters the 
personal realm of the patient. The device incorporates the physician and the medical regime, it has become a, mostly peaceful, Trojan horse.

In chronic diseases the device is not only an ally of a physiciam who wants to reinforce his advice; it also allows a patient to do what he wants. Whereas the doctor's information about the necessity of taking the drugs, and about the way they should be taken may lose its power in only a few days, the alliance between this information and the diskhaler makes it more powerful and prolonged. On the other hand, even a serious intention on the part of the patient to follow the treatment is easily disturbed by other obligations and interferences; linking the toothbrush to such intentions makes them resistant to these distractions:

\section{Conclusion: patient compliance and the organisation of flexible networks}

The network-buillding a physician undertakes and the actants he mobilises serve to make the passage through treatment as obligatory as possible for Steven. For example, when he advises linking steroid inhalation to brushing his teeth, an object that has nothing to do with the treatment of CNSLD per se becomes part of the network that is mobilised in such treatment. The same applies to the employment of Steven's partner in the attempts to encourage him to quit smoking.

But his partner is the only human character in the list of network elements that was drawn. That is not accidental because the response of actor-network models to the question of how to make alliances or associations durable is: delegate as much as possible to objects. They can be made to be more reliable, less forgetful, less whimsical than humans, and sometimes they can even be made more durable. If one would have to rely on Steven's partner to remind bim every morning and evening to take his steroid imhalations, one could be quite sure that, every now and then, he would forget it, or would not be there, and so on. The toothbrush, even if it gets replaced from time to time, is always there to remind Steven of his inhalations.

Durability, then, can be achieved, to a large extent, by connecting things to the instructions and reminders necessary to turn the treatment advice into an obligatory passage point for Steven. This is a useful element of the actor-network model, but the concept of obligatory passage casts some doubts. It is as black-andwhite as the compliance/non-compliance pair and does not allow for the fizziness that surrounds medical advice and compliance with it. Steven follows part of recommendations meticulously, while the overlooks other elements entirely; sometimes he follows advice, but only partially, or he interprets it in his own way. While it may be true that he usually does something that is part of the treatment plan, it is difficult to maintain that a treatment advice is something as inflexible as an obligatory passage point.

In order for an actor-network account to be of value for understanding medical alliances, it should account for the flexibility of medicall networks, allowing for the loose and often fuzzy character of medical advice. Objects do play an important role in making medical alliances durable (in that sense actor-network models are useful), but they do not necessarily succeed in making any trajectory 
obligatory for patients or doctors. Entire compliance is a fools paradise, for medicine as well as for actor-network models:

This has three important consequences. First, physicians should abandon ideals of near-perfect compliance. If entire adherence to a treatment regime, whether it is based on Zolats negotiations or on the authority of a more oldfashioned physician, is an illusion, then there is reason for modesty. This implies, in turn, that neither the patient nor the physician has to shoulder the responsibility for incomplete compliance. The difficulty of following these treatment regimes is, or better, has become part of the burden of having a disturbing disease.

Second, devices used to improve compliance should not be designed with total compliance as a goal. That, too, would interfere with other systems or networks a patient is involved in. The development of devices that register drugtaking and warn a patient who forgets to take one, for instance, could be contrary to what, in this chapter, has been argued about the inherent incompleteness of compliance. Inhalation devices should incorporate scripts with a considerable amount of freedom with room for creativity for those who use them.

Lastly, it has been stated that devices may be used to circumvent potential ethical criticism to strategiles of compliance improvement. For instance, continuous control over patients to see if they take their medicine or are otherwise compliant would not only be extremely time-consuming it would also be ethically debatable. Seemingly, this can be avoided by having both the control and the persuasion done by devices. But the translation of ethically-debatable physician behaviour into apparently neutral device characteristics such as automated inhalation counters moves rather than resolves the moral problem of the control of patient behaviour. Assessments of such techniques need to address the ethical question of the extent to which compliance enforcement is defendable. 
"Modern medicine is also full of cyborgs, of couplings between organism and machine, each conceived as coded devices, in an intimacy and with a power that was not generated in the history of sexuality (Haraway 1991)

\section{Conclusion: technology in chronic disease}

\section{Introduction}

In this book, a new way of analysing medical technology has been developed based on examples taken from the diagnosis and management of CNSLD. In this cliapter, the balances will be drawn by discussing four points: first, whether the approach developed here is fruitful in answering the questions and criticisms raised in the first chapter concerning medical technology assessment and the philosophy of technology (section 1 and 2). Second, whether this type of analysis can be instrumental in developing an ethics of medical technology (section 3). In these three sections, it will be argued that a semiotic approach is not only a component of the study and assessment of medical technology, but that it also questions some of the basic distinctions of the existing methods, such as the cause-and-effect relationship basic to MTA and the distinction between social (secondary) and medical (primary) effects. Third, the question will be asked whether, inversely, the use of a semiotic vocabulary in the area of medicine has implications for that vocabulary (section 4). Finally, fields of future research will be delineated (section 6).

Chronic diseases like CNSLD are increasing in frequency and there is little doubt that this growth will continue for some decades (Stuurgroep Toekomstscenario's Gezondheidszorg 1990). Health care, accordingly, will increasingly become involved with the care of people with these diseases. Most of the time, people suffering from chronic diseases are taken care of in the home. Hospitalization is uncommon and usually concerns only a small period in the duration of the disease. This implies that medical technology, in so far as it is associated with day-tomday monitoring and treatment, is moving from the hospital or doctor's office into the homes. Examples for this can be found in diabetes, hypertension, and in CNSLD. More and more, medical technology enters into the life-world of those who have these ailments.

This alone makes the social study of medical technology necessary. For less continuous forms of contact between humans and medicall technology, as in acute diseases, such analyses will also be fruitful.

\section{The dehumanization thesis revisited}

As we have seen in chapter 1 , the expanding presence of technology in health care delights and at the same time worries philosophers of technology. In a discussion of the work of Stanley Reiser, which was taken as a aprticularly clear example, it 
has been argued that the thrust of the criticism is that the invasion of devices into medicine and the lives of patients brings with it a dehumanization of disease - that it warps the natural, human interaction between physician and patient and that it distorts living with disease by turning it into a technical competence. This, the criticism continues, obscures those important elements of disease, and especially of chronic disease, that cannot be deall with in the language of machines and procedures. Breathlessness, to take an example that has served as a guiding line throughout this book, is transformed, through the dissemination of lung function technology, from an experience of existential impact into a dip in peak flow.

In chapter 1, these analyses have been criticized, in the first instance, as being too abstract and insufficiently grounded in empirical data about what actually occurs when patients themselves begin using medical technology. What the amalyses often lack, it was argued, is insight into the concrete use of devices and other techniques. But a second and more fiundamental criticism concerns a tacit distinction that is basic to these approaches: namely, between the human and material dimensions of technollogy. This distinction, it was argued, obscures rather than enhances our understanding of the relationships between human beings and technical objects.

It was proposed that the distinction between human and technical elements is part of the development of technology itself. Innovations usually are introduced in practice without notice of all the arrangements that were negotiated as part of their development. In other words: the social and human ellements of technology are blackboxed. Blackboxing is a necessary phase in the development and distribution process. For a given technology to work, it is indispensable that the negotiations and decisions about what, in a technological network, belongs to humans and what to things, are made invisible. Constant re-opening of black boxes would prevent the technology from functioning. On the other hand, any analysis of technology that leaves black boxes unopened takes one of the crucial phases in technology development for granted.

The extent to which the distribution of competencies between human beings and technical objects may change as a part of the development and distribution of an innovation was shown (in chapter 4 ) in the discussion of the inhaler devices. To repeat the argument briefly: aerosol inhalers demand a specific skill, hand-breath coordination. This fovolves a hand that pushes the aerosol bottle downward the instant the user starts the inhalation manoeuvre. The skill is strictly linked to the use of the inhaler - there is not another human activity where hand-breath coordination is as decisive as here. In another type of inhaler device, the Rotahaler, this skill has been made superfluous by translating it into an action of the device: a capsule containing the drug is attached to a propeller which is activated by the flow of air itself. The hand is assigned a much less prominent role: it merely has to hold the device in the right position. Thus, a mewly-imvented, and technology-linked human characteristic (proper hand-breath coordination) is transformed into a component of a device. This is not to say, however, that less net skill is needed for the Rotahaler - different skills need to be learned, for instance, inserting the capsule in the right way.

Another example of the redistribution of human characteristics and competencies of technical objects can be seen in the compliance techniques 
discussed in chapter 7. At first sight, compliance seems a perfectly human element within the treatment of CNSLD. Only humars, one is tempted to say, have the capability to either comply or not comply with advice or instructions. There are at least two reasons, however, to think about this differently. First, human compliance becomes translated (in the linguistic sense as well as in the physical sense of shifting), to a large extent, into the characteristics of devices; second, objects, like human beings, are often said to be more or less faithfil to their function - more or less compliant, that is. One of the clearest examples of the first, the translation of compliance into a device, is the recently-developed inhaler called Diskhaler, that, as has been argued, through its form (a flat container, not much larger than i matchbox) enhances the compliance of those who use it because they will be less bothered by the object or by the inconvemience of its use. The diskhaler is made flat and unobtrusive because it has to be taken everywhere the user goes. It is the translation of "never forget to take your inhaler wherever you go" into the form and substance of the device - remarkably, it is the exact opposite of the weight attached to the hotel key Latour studied (chapter 1), which is a translation of the verbal order "never take this key outside the hotel" into an object.

Thus, a technical object like an intraler can be made to be more or less compliance-enhancing; and it can be more or less compliant. The drug-containing reservoir, for example, may not revolve the way it is supposed to, or the perforator that should open the drug depots may malfunction. Another example: peak flow meters gradually become obstructed by an accumulation of dust and saliva: This results in unreliable values: an unreliable peak flow meter does not perform its function properly - it is non-compliant. Now the objection may be raised that speaking about non-compliance for objects as well as for humans is a confusion of categories, in other words: in such statements, human characteristics are erroneously attributed to inanimate objects. Thus, the spectre of anthropomorphism is brought to life. Such an objection may (and often does) lead to blind-alley discussions about whether objects have wills, whether they can be said to disobey in the same way a patient can. In attributing compliance to technical objects, it is not suggested they be considered as having wills and prejudices and so on. When speaking about the compliance of things, no metaphysical point is made - no more is done than emphasising the heuristically fruitfiul similarities between human beings and technical objects. For instance, comparing human compliance with compliance in things leads to the hypothesis that compliance with medical advice can be too large as well as too small insufficient compliance, however, has been the focus in compliance researcli: Diskhalers are, without inconsistency, called non-compliant, and so are human beings. The parallel is complete: objects are spoken of in terms that are used for humans, but at the same time, humans are spoken of in the same terms as objects. This latter point doubtlessly is the reason for the vehemence of the criticisms raised against the so-called anthropomorphism of technology semiotics.

With the development and the implementation of everyday medical technology, the dividing line between whrat is human and what is technical moves. This in itself weakens much of the criticisms and fears addressed at the development of medical teclnology, as it is based on the assumption that there is a fixed set of human characteristics that is intruded upon by developments in medical 
and other forms of technology - this basis is quicksand. The suggestion made in this book is that the study of medical technology should not take as its basis some assumed realm of human characteristics and then look for ways to either protect these against the intrusion of technollogy or stimulate their development with technology, but, on the contrary, showld inchude an analysis of the way in which the design and the use of techniques involve the making of new definitions of what precisely is a human characteristic. Apart from building new objects; designing mew technology means shaping new attributes for human beings.

One of the more specific forms of what will be referred to as the dehumanization thesis is the statement that the encounter between two human beings, physician and patient, becomes supplanted by machines, and that, therefore, the story of the patient loses its relevance. It is a concern about the direction medicine has taken that is worded in R. Baron's phrase, "I can't hear you while Im listening", that was quoted in chapter 1 and that poignantly describes a doctor who is unable to hear what a patient says because he is listening to what his stethoscope is telling him (Baron 1985): However, it would be surprising if this phrase was the only piece of verbal communication exchanged between the physician and his patient. Interestingly, if one goes beyond Baron's sentence, the example can be rewritten as one of the instances of redefining of human characteristics that this book is about. Presumably, physician and patient have been talking afterwards about what was heard through the device. Thus, a stethoscope does not supplant talling, thereby delhumanizing the relationship between physician and patient, but it significantly alters the content of the conversation. Similarly, the physician and patient presented in chapter 3 did not stop talking because of the use of the peak flow meter, but started discussing different things than before: rows of numbers instead of panicking for lack of breath, peak flow blowing technique instead of sounds heard upon auscultation. Here again, the standard critical descriptions of medical technology assume that there is a natural and unspoiled narrative of the patient that becomes inaudible because of all the noise the machines of medicine make.

In this book, that assumption was abandoned in favour of an explicit description of the way in which new technology helps in shaping new, different, and not necessarily inferior or de-humanized patient narratives. So, instead of inevitably impoverishing doctor-patient communication, or, even worse, eliminating it, the use of technological devices transforms it, gives it new content. It also changes the roles of the people involved - as has been demonstrated in chapter 3, patients may become more similar to biomedical experts as regards their disease than was the case before these devices were available.

Thus, technieal imnovations not only involve a transformation of what it is to be human, but they also bring along new types of relationships between people: the divide that separated the physician as the one who controls knowledge from the presumably ignorant patient is bridged. Patients, in the socio-techmical networks that have been studied here, may be more instead of less knowledgeable about their disease than their physicians. Not simply because they have become knowledgeable about what it is like, subjectively, to have a disease (as was discussed in chapter 3, this is the knowledge about illness that anthropologists have reserved for the patient as distinguished from disease-knowledge, the domain of the physician), but 
because the technology has helped them to penetrate into the area of competence of the physician. In this redistribution of competencies there is a central role for devices.

In conchusion: the dehumanization thesis rests on a philosophy that considers technology and people in a 'separatist' way. This is crucial if one wants to develop an understanding of the two-way traffic between human beings and technical objects. Being able to study technology as simultaneously shaping things and humans - even if only temporarily and locally, not definitively and ubiquitousty makes it possible to study technical and social elements at the same time.

\section{Assessing technology - MTA revisited}

Chapter 1 contains an overview of the burgeoning field of medical technology assessment. On the basis of an analysis of the recent literature, it is shown that within MTA, there is a strong interest in studies of social and ethical effects of technology, but the number and quality of analyses of its social and ethical corollaries is very limited. There is a very limited array of available tools to understand such effects of technology and to incorporate them into an assessment. Let us look again at the examples of MTA discussed in chapter 1, in order to investigate the extent to which semiotic approaches could provide some of the tools that are needed to study social and ethical aspects of medical technology. The first example concemed an assessmemt of a screening programme for cervical cancer which was criticised on three points: first, it was argued that the researchers failed to take into account social elements other than cost or organisation, and, second, they did not question the development of the technology in order see where, in the process, important social elements where incorporated in the device; third, it was argued that the analyses failed to give insight into ethical elements embodied in technology. The latter point will be addressed in the next section. Here the question is: To what extent would the use of the approach develloped in this book be helpful to MTA with respect to the first two points?

A semiotic approach would allow technology assessment to uncover the scripts incorporated in devices. Just as in the example of the peak flow meter, it is possible to spell out the scenario of the devices and the paperwork that constitute screening for cervical cancer. This would make visible the changes in behaviour and in relationships demanded of both the women who are tested and the healthcare workers performing the test. The complex of brushes, glasses, lab forms, invitation systems, and testers performs a scenario for the human beings involved (or enrolled) in it. The desigm and distribution of this socio-technical network involves a translation of the original aims (detecting operable stages of cervical cancer) into devices and procedures; these aims are not merely reformulated in technological terms, they are also transformed: for instance, instead of performing a cervical smear on all women, the procedure is restricted to certain age groups at a standard and negotiated frequency. This 'reformulation/transformation' is the double sense of the term 'translation' as it his been used in this book.

A similar analysis can be made concerning the second example of MTA that was discussed in chapter 1: the portable oxygea container. Once the scenarios this machine sets up for the user, the family, and the physician, have been described 
using the semiotic approach developed here, it is possible to make such scenarios a part of an assessment procedure.

Within most studies, social aspects of technology are seen as the effect of the introduction and diffusion of an innovation. In this book, the emphasis has been different: a technology or a procedure is analysed as being simultaneously an object and a prescription for human beings. More precisely, as a way to connect specific materiall actors and specific human ones. Innowations, in this analysis, are inherently theterogeneous, mixing social elements with material ones, making assemblies, not only of material parts, but also of people and things.

Making device or a procedure means "making" users, but also distributors or vendors, assistant personnel, and even family members. It means defining people as well as things. This was clear in the example of the self-management programme discussed in chapter 6 . This device consists of various instructions or directives and of the rules to apply them: "If you feel out of breath, start taking more of this drug, and if that does not help, go on taking the next one." But it also contains definitions of people: it defines physicians as being prepared to share their decision-making capability with patients, to the point of allowing them to make important medical decisions (for instance, in some cases, to start taking a course of oral steroids). Patients, on the other hand, are made, within this technology, into beings that take peak flow numbers as criteria for action, and that are prepared to take the responsibility for changes in treatment - they become medically selfcoufident people. In this way technological developments like these change the characteristics of people as well as of objects.

\section{Norms in the device - ethics revisited}

Throughout this book, two sorts of moral elements incorporated into devices were defined and have been elaborated: first, role and behaviour prescriptions; and second, attributions of responsibility for the subsequent course of events. It was suggested that, in order to become relevant for the assessment of medical technology, ethics should not only engage in the study of 'classic' ethical issues such as the distribution of resources or the relationships between technological innovation and autonomy, but also on the way behaviour prescriptions and attributions of responsibility are 'packed' into medical technology. Thus, the ethics of technology should not only be concemed with the way an innovation enlarges or limits a patient's autonomy, but also with the way it redefines that autonomy. In other words: the ethics of technology should involve the study of how basic ethical concepts like 'justice' and 'autonomy' change as part of technological development. Technical objects and medical procedures contain descriptions of what a virtuous life looks like. Ethics would have to disassemble medical innovations in order to pinpoint such moral elements.

\subsection{Prescriptions}

To what extent would such a dismantling of incorporated moral elements modify ethical reflection on medical technology? Let us reconsider the example from chapter 1 concerning life-sustaining techmologies and the elderly. As noted, the 
ethical analysis was concerned with problems external to the technologies proper; such as: Who should decide about their use in individuall cases? and What distribution criteria are available on the societal level?

If the prescriptions and the shifts in accoumtability that are internal to this technology are to be taken into account in the ethical analysis, then clearly a closer look at their constituents is required. The morals of renal dialysis, to take one of the procedures discussed in the report on life-sustaining technology, are not limited to questions concerning its withholding or withdrawal, but also the extent to which - for instance - it demands from family members that they participate in the treatment; thereby making them in part responsible for the life and health of the family member. Thus, it is proposed that a moral prescription is asserted as strongly and as specifically by home dialysis technology as it could possibly be by an ethicist or other human being issuing ethical statements: the machine asserts that family members have an obligation to take care of a diseased family member. Home dialysis presupposes that family members shoulder a considerable extent of the responsibility for their diseased next-of-kin. Not generally speaking, but specifically: they have an obligation to leam how to handle this technical object. The moral statement that family members have a large responsibility is not only issued by the dialysis technology, it is also transformed and reformulated in a very specific way.

This technology not only presupposes such an obligation, it also states and reinforces it as a norm. In this sense the morals and politics of technology are not, as it is often said, in their users, they also are in the devices. This book has tried to challenge the idea that technology itself is a-moral and a-political, and that politics and ethics merely concern the way it is used. The 'moral of the book is that devices and machines, but also procedures and standards, make ethical statements and contain the scripts that reinforce the impact of these statements.

\subsection{Responsibilities}

As we have seen in the example of the turbuhaler (chapter 4), new dlevices carry with them new distributions of responsibilities. The turbuhaler demonstrates this very clearly because it contains a specific gadget to signal such a shift: the clicking sound heard after the completion of a quarter turn indicates that the user hais performed the task and that from this point on, success or failure is attributed to the functioning or malfinctioning of the device or to the severity of the asthma attack. It can no longer be ascribed to the person using the device. The turbuhaller thus transfers responsibility in the same way that it moves terbutaine or budesonide.

Compliance strategies are another case in point. As was stated in chapter 7, there have always been patients who were lax with or simply resisted medical instructions. It is only recently, however, that physicians have considered this: a problem they had to deal with as a part of their professional responsibilities. Improving patient compliance has increasingly become the responsibility of the physician. The conscientious doctor, by this token, has become, what in technology studies, is called a "heterogeneous emgineer': professionalism not only involves reaching a sensible diagnosis and giving sound medical advice, it also requires 
organising follow-up - which may comprise constructing a network that establishes relationships between elements such as a partmer, a specific type of packing, and long-term drugs.

On the other hand, the use of clearly-defined compliance enhancement schemes and devices makes it possible to shift responsibility to those schemes or, for that matter, back to the patient. Once such a strategy has been followed (for instance, by reducing medication to once a day), the failure of a treatment regime may be attributed to the technology (the drug does not work), or to an intractable patient, but not to the physician for failing to address the problem of noncompliance. It gives the physician the right to say, "I have done what I should - it is no longer my responsibility." Thus, compliance-improvement schemes are also devices to regulate the repartition of - in this case, recently acquired responsibilities. Such schemes often function in the same way as Norman's checklists; they not only alleviate the responsibility ascribed to their users, but also transform their task (Norman 1993).

When technology, both in its developmental stage and in its implementation, is studied using semiotic or similar types of analysis, social and moral elements can be incorporated into the debate about the direction medical innovation should take. Without deciding these issues beforehand, semiotic heuristics make it possible to ask questions like: Is this a desirable distribution of responsibilities? Are these the kind of demands and obligations we want to place on patients and upon their famillies?

It may be necessary to emphasise that semiotic methods like these make it possible to pose new questions rather than merely providing a different kind of data that can be processed in the assessment procedure. It becomes possible to question artifacts and other innovations with regard to their ethics and politics. Approaches like this open up new areas for debate; they do not pretend to decide whether this or that innovation should be developed or distributed. And it is exactly this kind of debate that is necessary for the evaluation of developments in medical technology.

\section{Second thoughts on semiotics of (medical) technology}

In this book, the word 'application' has been avoided in describing the relationship of the semiotic heuristics to the area of study. To apply a theory means, literally, to overlay it on the part of the world to be studied, in order to see whether the world is conform to the theory - the theory itself is left untouched. In other words: application in the strict sense means blackboxing the theory or the method, or whatever it is that is applied. In this book, a field of medicine and a specific form of technology analysis have been brought together to "see what happened" on both sides. So now, the question is: Does the anallysis of medical technology outlined in this study make a difference for the semiotics of technology? Three ways in which it can be shown to do so will be outlined.

First, semiotic tools have been used, in this book, for the analysis of both diagnostic and therapeutic devices. As in the original texts describing semiotical analysisis, the focus was initially on objects: only, instead of Latour and Akrich's hotell keys, safety-belts, and electricity kits, peak flow meters and inhalers have 
been studied. So far, no difference. But the function of the devices studied takes the semiotics a step further than in its original formulation: the weights attached to hotel keys described by Latour have no other role than restraining people from taking the keys outside the hotel. In other words, they are nothing but behaviourmodifying objects. There is something trivial about 'discovering' that role in these objects. Their function could have been described with an intentionalistic vocabulary just as well as with a semiotic one.

In this respect, the devices discussed in this book are different. The fact that the introduction of systematic peak flow measurement by patients transforms the structure of medical consultations was not inscribed into the device in any intentional way. Whereas the weight attached to Latour's hotel key is the direct translation of the desire of the hotel owmer from words into metal, the peak flow meter brings along completely new desires, new definitions of the interest of both patients and physicians, and new relationships between them - for instance, relationships between physicians and patients that do no longer conform to a layperson/professional distinction. This study retrieves from the devices what nobody consciously hides into them: ontologies, ethics, social relationships. Secondary effects, then? No: neither secondary nor effects. These components of devices are unintentionally but unavoidably 'baked into' them - if anything, they are primary characteristics, not secondary effects.

A second difference with original semiotical analyses is the concept of empirical ontologies. The original texts on techmique semiotics have been predominantly concerned with human behaviour and relationships as they were wired into devices - their interest was principally sociological. However, in various chapters of this book the extent to which the regular use of devices gives rise to new disease entities, new definitions of the airways, and new hybrids consisting of a human body and an object has been highlighted. It has been argued that the use of medication inhalers is also a modification of the geography of the airways in the persons who use them - and only in these persons, which means that the users of inhalers have lings with a different geography from those using no airway drugs, or, for that matter, from those who have undergone several bronchoscopies (see chapter 4). These innovations, then, have a highly local character.

Thus, one of the ingredients of medical innovations are ontologies. With this term, reference is made to the definitions of new entities that materialise with the use of medical innovations: they deseribe the innovated bodies that surface with the use of new technical objects and procedures, the transformations of the characteristics and roles of persons, and so on. Very often, these innovations have the form of hybrids of objects and bodies: the hybrid, for instance, of airways and inhaled bronchodilators, or of a person and a peak flow device.

Rather than fabricating new representations of a supposedly iudependent world, innovations in medicine produce new elements in the world. This is not meant in any metaphorical sense, but quite literally: medical innovation is the continuous production of novel entities, hybrids of bodies and objects or, as the philosopher Donna Haraway, in the quotation that opens this chapter, calls them: "creatures simultaneously animal and machine, who populate worlds ambiguously natural and crafted." 
A third point of departure between this book and the existing technology stwdies concerns the type of techniques studied. The analyses herein involve not only technical objects, the usual 'stuff' of technology studies, but also procedures that have a less evident material support - although they are, of course, supported by texts and inscriptions of various sorts. In the chapters on monitoring and compliance; it has been shown that a semiotical approach raises fruitful questions regarding the investigation of this technology. In so doing, the intent was to strive for symmetry: treating devices as texts, but also treating texts as devices.

Innovations in medicine can and should be studied as transforming the body and the standards of good medical practice; as re-ordering the allocation of tasks between specialised and general physicians, and between physicians and patients. Such materialisations rarely are deliberate elements of the design process, but rather, they are co-produced with the device. In order to uncover them, talking to the designers and reading their publications may be very helpful - for this book, the latter was done extensively - but the analysis itself requires studying the objects and following their trajectory through practice. To regard these sometimes inconspicuous objects not only as tools to realise medical intentions, but as carriers of ontologies in their own right is remimiscent of what Heracleitos is reported to have said to a group of visitors who wanted to discuss lofty questions of philosophy and, on finding him sitting in the kitchen, were ready to wait for him to come to a more suitable place: "Please, gentlemen, do come in! The gods are in here, tool"'

\section{Prospects}

The heuristics developed in this book will have to prove its value in other areas as well. There is no reason why larger forms of medical technology, such as sophisticated imaging techniques or complicated therapeutic innovations, could not be studied with this method as fruitfully as the more mundane ones that were analysed in this book. The latter ones were chosen, in part, because family medicime is the author's professional field of interest, but also because these smaller technical objects accompany people everywhere they go - this makes them both sociologically and philosophically fascinating.

A number of areas within medical low-tech' would profit from semiotical studies. First, other diseases in which self-management is an important element of treatment; the most frequently encountered examples in primary care are diabetes and hypertension. For more than a decade now, people with diabetes measure their blood-sugar levels, in some cases up to several times a day, and may adapt the amount of insulin they take without the intervention of a physicjan. Here, like in CNSLD, self-management plans telling patients when to increase or decrease their dosage of insulin, are common. The parallel with the use of peak flow as a criterion for adaptation of medication dosages is clear, but the differences are extensive enough to make such a study more than a repetition of the present one.

Another, but more contentious self-management area is hypertension, where people measure a physiologic parameter similar to that in CNSLD and in diabetes, but unlike these diseases, patients do not, or are not supposed to, modify their medication dosages as a direct consequence of measurements. 
A second area of interest could be rehabilitation. The parallel with CNSLD is that here, too, people enrol in a continuous relationship with medical technology; again, both in the form of devices and of treatment procedures. This is an area where the idea that people become hybrids of objects and human bodies is more readily acceptable than in CNSLD. Many devices, from thumb splints to electronic prostheses, are designed to become one with the human body - visibly hybrids. Living with medical technology becomes continuous for people who use these devices and who learn to adopt the lifestyle that is part of the technology. It would be useful, both for technology assessment and for the social study of medical technology, to review the scripts and scenarios that can be retrieved from rehabilitation devices.

As a third example, it would seem that a semiotic heuristic is useful for the study and assessment of technology in an area that is currently in full development: home care. The shift from hospital care to home care has generated, and will continue to generate, an explosive growth in devices to be used in the home by patients with all sorts of chronic health problems (Steering Committee 1988). Thus, intravenous infusion systems, injection pump systems, and peritoneal dialysis are among the techniques that, until a short time ago, were reserved for the hospital, but are now used at home. It would be of interest to analyse these forms of technology with respect to the questions raised in this book: To what extent do the features of, for example, an apparatus for peritoneal dialysis transform the characteristics and the roles of the people who use them, that is, patients, families; physicians and all others involved? What sort of relationships emerge in the use of this technology, and what sort of body is it that is linked, several hours a day, to a dialysis machine (Kohrman 1994)?

The three areas mentioned are examples of continuous interactions between human beings and medical technology. This is not to suggest that the semiotic heuristics is exclusive to such areas. On the contrary, to assess its usefulness, it would be necessary to study an area where there is a short but intense contact between human beings and a specific type of medical technology. An operation, or a short course of medication would, then, have to be studied with the same type of questions in mind: To what extent does the technique in question incorporate scenarios for human beings, their relationships, and their bodies?

The last question that needs to be asked in this conclusion is, Would such studies be of purely academic interest, or are they likely to yield policy implications, both for the individual and on a more general level - that, after all, is what technology assessment strives for. As has been said before, explicit policy implications are not to be expected and would even be contrary to the basics of this approach, but it can be expected to enrich debates about new forms of practice or new technical objects. Such debates can be found at every level of the health-care system: from the group practice of two physicians through the guideline development bureau to the health-care policy-makers people question the use of technology in medicine. Introducing the elements discussed in this book would highlight the socio-ethical or political character of choices in MTA, not only as regards resource allocation, but also with regard to the sort of practice and the 'good life' that is constructed along with a technology. One of the questions of technology assessment would then become: Do we want a technology being used 
and diffused that contains such-and-such a definition of a patient (for instance, the patient as a 'self-manager'), and that defines physicians in a specific way (for instance, as a professional allongside the patient)? Do we want, ultimately, swch patients and such physicians to be produced with the technology?

Again, this can be illustrated with the peak flow meter. If a debate on the appropriateness of introducing this device in the day-to-day management of children with asthma would occur, the question would not only be whether it is sufficiently cost-effective, but also whether the patient and doctor that are part of this device are desirable. In this technology, a patient is defined as the person that measures breath several times a day and titrates the use of medication to the dips in peak flow values. It defines the proper medical consultation as a discussion of numbers and of curves between doctor and patient. It is not suggested that these are undesirable elements in the introduction of the peak flow meter, but only that in discussing the use of a technology, attention must be paid to such elements.

The same is relevant for another of the technologies discussed in this book: self-management plans. Apart from their medical effectivity, and apart from the costs or the opportunities for cost-containment involved - and the relation between these two - an assessment of self-management plans should raise the question as to whether the definitions of patients and physicians that are part of these programmes are desirable.

The debates about medical technology that are going on at different levels within the health-care system should not only concern outcome data and economic evaluations of innovations, but also require semiotical analysis. In order to conduct such debates, we need stories about patients living with new forms of medical technology, but we also need careful observations about what can be read from an artefact or a new medical procedure. Not only, then, do we need to know what people say about technology, we also need to know what technology says about people. And in the same way that people have an infinite variety of stories about technology, technical objects and medical procedures tell an endless variety of stories about people and about other elements of socio-technical networks. They describe, define, and relate people and objects in various ways. We need to learn to listen to this multiplicity of narratives as they are told by the techniques themselves. 


\section{Summary}

In chapter 1, the central question of the book is introduced: How does the introduction of medical innovations, both in the form of new technical objects and new diagnostic or therapeutic procedures, change users, their ideas and their relationships? And how are the technical innovations themselves altered in the process of distribution and implementation? These questions are specified in a discussion of the most important theories about medical imnovations, namely the philosophy of medical technology and medical technology assessment (MTA). It is argued, first, that social and ethical elements of innovations have received insufficient attention; and second, that both the philosophical study, represented by the work of Stanley Reiser, and MTA need a theory about the nature of the connection between human beings and technical objects or procedures. The social and ethical aspects of innovation are regarded as secondary effects, comparable to the secondary effects of drugs.

In this book, a different approach is sought in the field of innovation sociology. The different schools of research in the sociology of teclinology are reviewed, with an emphasis on the rare examples of studies of medical technology: The recent work of the sociologist of science Stuart Blume on the development of medical technology is discussed and the points of departure with his book are highlighted. The core of the chapter focuses on the strand of research in the sociology of technology that provides the central concepts of this book: the actornetwork approach which has been developed by the French sociollogists Callon and Latour in studies of the development and distribution of innovations. Key concepts such as actor-network, translation, 'interessement', and programme/antiprogramme are explained. Special attention is given to studies of the uses of innovations, in which the concept of a semiotics of technollogy has been developed and employed - especially the notion that technologies contain scenarios for their users. It is argued that the connection between the social and technical aspects of an innovation consists of these scenarios or, as they are called within the actornetwork approach, the inscribed users of the technology.

The questions of the book are further specified by a short description of the area of medicine that serves as a source of case-histories, namely chronic airways obstruction. The method used in the book is presented: it consists of a combination of case-studies and a discussion of the literature on the development of the techmiques in question. The final part of the chapter discusses a problem of method associated with the professional position of the author: as a family physician, he is both a user and an observer of the techmologies studied in this book.

In chapter 2, the controversy over the definition and terminology of chronic obstructive airway diseases is described. The premise of the chapter is that terminology not only defines and describes but also re-organises and re-orders the world and, thus, needs to be studied as a technollogy, as a tool in its own right. A double case-history is introduced to show how two seemingly dissimilar patients end up with similar diagnoses.

Since the late Fifties, there have been discussions about whether asthma; chronic bronchitis, and emphysema are separate diseases with partly similar symptoms or, inversely, one disease with partly dissimilar symptoms. The problem 
of classification became acute when British and American researchers, wamting to collaborate in epideminological studies, discovered that the terminology they used for diagnosis was dissimilar in important ways. Several conferences were devoted to the issue, and in the beginning of the Sixties; the so-called Dutch Hypothesis was formulated by a group of researchers from that country; they stated that asthma, chronic bronchitis, and emphysema are essentially identical diseases with no more than quantitative differences in symptoms and test results - they proposed the term Chronic Non-Specific Lung Diseases (CNSLD) (Dutch Chronische Aspecifieke Respiratoire Aandoeningen, CARA), Adherents to this terminology are teferred to as 'humpers'. They are opposed by 'splitters', most of them researchers and clinicians from Britain and the United States, who claim that a fundamental difference exists between asthma and the other two diseases. The debate is presented with a focus on the definitions of patient and physician incorporated in the two positions.

After addressing the various arguments of the debate, the distribution of lumper terminology throughout the Dutch medical profession, and particularly to general practitioners, is discussed. The significance of the difference for patients (whether they are diagnosed from a lumping or a splitting approach) is examined. It is suggested that apart from discussions about terminology, the practical similarities in diagnosis, monitoring, and treatment support the lumping rather than the splitting approach.

Since the concept of reversibility of dysfunction plays a crucial role in the debate, there is a separate discussion on this concept and the related notion of chronicity. It is shown that at least three notions of chronicity are brought forward in the discussion: lifelong disease; lifelong disposition to disease; and an attenuated form of chronicity: lasting, but not necessarily lifelong dysfunction.

Chapter 3 discusses the development and use of a recent technical innovation in the management of obstructive airway diseases: the peak flow meter. Starting from a case-history describing the introduction of the device to a patient, the various forms of mini-peak flow meters are reviewed, with an emphasis on the difference between peak flow whistles and meters. It is demonstrated that peak flow meters measure something differemt than other lung function devices: they create the parameter they measure. Peak flow measurement, moreover, provides personal results that are difficult to generalise; in a discussion of the work of Canguilhem, it is proposed that peak flow measurement is a different form of what he has described as the normativity of disease.

The scenarios for physicians and patients incorporated in the device are outlined as well as the manner in which the peak flow meter alters the distribution of competencies between physicians and patients. Finally, the impact of the use of self-measurement technology on the distinction between subjective (illness) accounts and objective (disease) descriptions is discussed. It is argued that this distinction, prominent in medical anthropology, is invalidated in CNSLD and similar diseases by the fact that patients, as part of self-measurement, use the vocabulary of disease and dysfiunction in conjunction with the language of complaints and symptoms.

In chapter 4, the spotlight is on the various forms of drug inhalers that have been developed in the last two decades. The most important justification for their 
development was that they allowed therapy to become local and to influence onlly the targeted region; a second advantage expected from inhalation was the rapidity of effect. The core of the chapter is a discussion of the concept of 'local therapy'.

In a case-history of two boys who are treated for CNSLD following different administration routes, the various inhaler types are presented. The following section discusses these systematically: Inhalation chambers, aerosol devices, and the different forms of powder inhallers are described with a focus on the scenarios they contain, especially for patients. It is demonstrated that the trajectory ingested drugs follow within the body is almost entirely inscribed into the tablet or mixture, whille with inhalation, much depends on the skills of the user, who therefore becomes responsible, to a higher degree, for treatment success or failure. The role of devices in the attribution of responsibility is discussed with the aid of recent work of the sociologist Laurent Thévenot. It is shown that some inhalers contain special accessories to shift responsibility from patients to the device.

Rather than assuming that medications follow pre-established trajectories through the body, it is demonstrated in this chapter that different administration routes are created in the design and use of different drug forms. Following Michel Foucault's idea of a variety of 'spatialisations' of the body, it is argued that, to a certain extent, drug therapies create their own map of the body alongside the maps created by anatomy, $X$-rays, and other forms of investigation. In the final section this is extrapolated to suggest that the forms in which drugs are administered generate new definitions of patients, physicians, and also of airways.

Chapter 5 is about the different medications that are used in these inhalations. A patient is described who, in the course of his disease, uses a variety of inhaled drugs: bronchodilators, anticholinerg medication, cromoglycate, and corticosteroids. Following the patient information on medication that is issued by the Nederlands Astma Fonds (Dutch Asthma Fund), the different accounts that are given of the airways and of CNSLD are highlighted. In a first approach, these accounts are analysed with the help of concepts developed by the philosopher/physician François Dagognet: Although helpful in describing the imagery ('mythologies', as he calls them) associated with the drugs, Dagognet's work is criticised as being based on an unwarranted distinction between the body and its representations.

The idea is elaborated; in the remainder of the chapter, that representations form the body rather than giving an image of it; that innovations in the medication of patients are simultaneously innovations in their bodies. This shows a parallel to the "splitting and inversion model' developed by Steven Woolgar in the sociology of scientific discoveries. Scientific representations, he states, rather than being the consequence of characteristics of the objects described, are constitutive of these objects. Objects are not the antecedents of representation, but its results. Thus, in the terms of Canguilhem, the type of representations studied in this chapter carry with them physiological innovations. It shown that bronchodilators make the airways into a series of bifurcating constrictable tubes, while cromoglycate treats them as a more or less stable line of defence against noxious substances and allergens.

Moreover, the different drugs introduce different time-frames in the actions of the airways; bronchodilators treating constriction in a matter of minutes, while 
steroids introduce changes of a much slower character, months to years. Another difference is how the different drugs establish the relationship between cause and symptom. Steroids and cromoglycate are introduced as causall drugs, while bronchodilators and, to a lesser extent cholinerg drugs, 'merely' treat symptoms. At the end of the chapter the idea that different drugs incorporate and bring about different airways, is qualified by proposing that they do so within different forms of practice. It is argued that this linking to practices counters the possible criticism of excessive relativism.

The description of drugs as physiological innovators in their own right leads to the difficulty that a patient using different drugs necessarily lives with different bodies. Two ways of coordinating these differences are described: timing and valuation. Furthermore, it is argued in the last section that drugs create similarities as well as differences:

In the next two chapters, the focus is not on technical objects, but on procedures; these chapters are on social technologies.

In chapter 6, monitoring programmes, and especially self-management as a part of such programmes, are discussed with regard to a similar question as in the other chapters: What kind of patient and physician, and what relationship between the two is designed within these programmes? The first half of the chapter is devoted to monitoring, which is described as long-term diagnosis. Different guidelines concerning obstructive airway diseases are reviewed as to the extent and organisation of monitoring they recommend. The structural difference in the diagnosis of acute illness episodes is highlighted: symptoms acquire a different meaning; different devices are used; a different practice organisation is required; and a different distribution of responsibilities between physician and patient occurs. Finally, the concept of disease is different in monitoring than in acute diagnosis.

Self-management plans are an important ingredient of all known monitoring programmes. As part of such plans, patients are not only taught to survey their airways, but also to treat them. Self-management instructions have been issued in different countries. The basis for the discussion is an Australiam plan published in 1989. The concept of delegation pervading this programme is analysed and the issue of patient empowerment, one of the justifications for self-management, is briefly discussed.

The next section draws parallels between self-management in CNSLD and anthropologicall and historical work on the way people deal with their bodies, focusing on Foucault's work. Concepts such as body techmique and technology of the self are scrutinised to better understand self-management in medicine. In the final section, it is shown that self-management entails new definitions of physicians and patients.

The 7th chapter focuses on the related, and much-debated issue in longterm treatment of chromic airways obstruction (and of other chronic diseases): the management of non-compliance. Since this problem is particularly prevalent in chronic disease, the chapter begins with a comparison of the structure of short- and long-term treatment. A case-history of non-compliance is analysed as an introduction to the problem. Then, a review is given of the various methods proposed for assessing the extent to which a patient is compliant. The limitations of these methods are discussed, particularly the implicit assumption that 
compliance and its opposite are individual and isolated phemomena. The scarce explanatory theories of non-compliance are briefly discussed and commented upon.

The case-history is then expanded to demonstrate some of the different strategies a physician has at his disposal to enhance compliance. These are shown to be heterogeneous; warnings, devices, and organisational adaptations play a role. The question is raised whether non-compliance with medical advice is sufficiently remarkable to justify the thoroughly asymmetrical research on the problem - there is evidence that every kind of professional advice has a considerable chance of resulting in non-compliance. Thus, compliance becomes as surprising as noncompliance.

In the mext section, the criticisms Irving $\mathbb{K}$. Zola has raised against the compliance/non-compliance terminology are reviewed. He urges speaking of the quality of the alliance between physician and patient rather than of non-compliance, because this makes it the patients' problem only. Zola's proposal is important, but hardly satisfactory as it still considers the outcome of advice withim the binary relationship of physician and patient. It is suggested that the concept of network could be useful here, especially because it allows for a description of the similarities between human compliance and compliance in objects. The role of technical objects in compliance-enhancement is highlighted in this approach. The chapter concludes that the extent to which medical advice is followed may fruitfully be studied with an actor-network heuristics. The consequences of the realisation that perfect compliance is hardly ever possible are outlined.

To evaluate the usefulness of the proposed semiotic approach as a contribution to both the philosophy of medical technology and medical technology assessment, the 8th and final chapter returns to the discussion in the opening chapter. Particular attention is paid to the productiveness of the approach for examining the ethical elements of medicall innovations. Technology contains ethically relevant behavioural prescriptions and many technical devices have accessories or elements that re-distribute responsibilities between people and between people and objects. The implications of the study for the field of innovation sociology are described in this chapter. Three of these are mentioned: that devices contain umintended scenarios besides intended ones; that they contain what has been called, in this book, ontologies; and that social techmologies as well as technical objects can be studied with semiotical methods. It is argued that the ethical and social elements of medical technology not only need to be studied more extensively, but that this can be done effectively using the approach developed in this book. A brief list of possibly fruitful areas for further study closes the chapter and the book. 


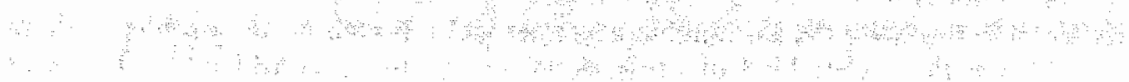

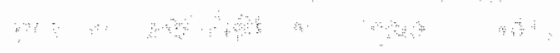

a क व

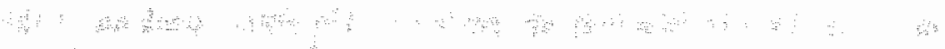

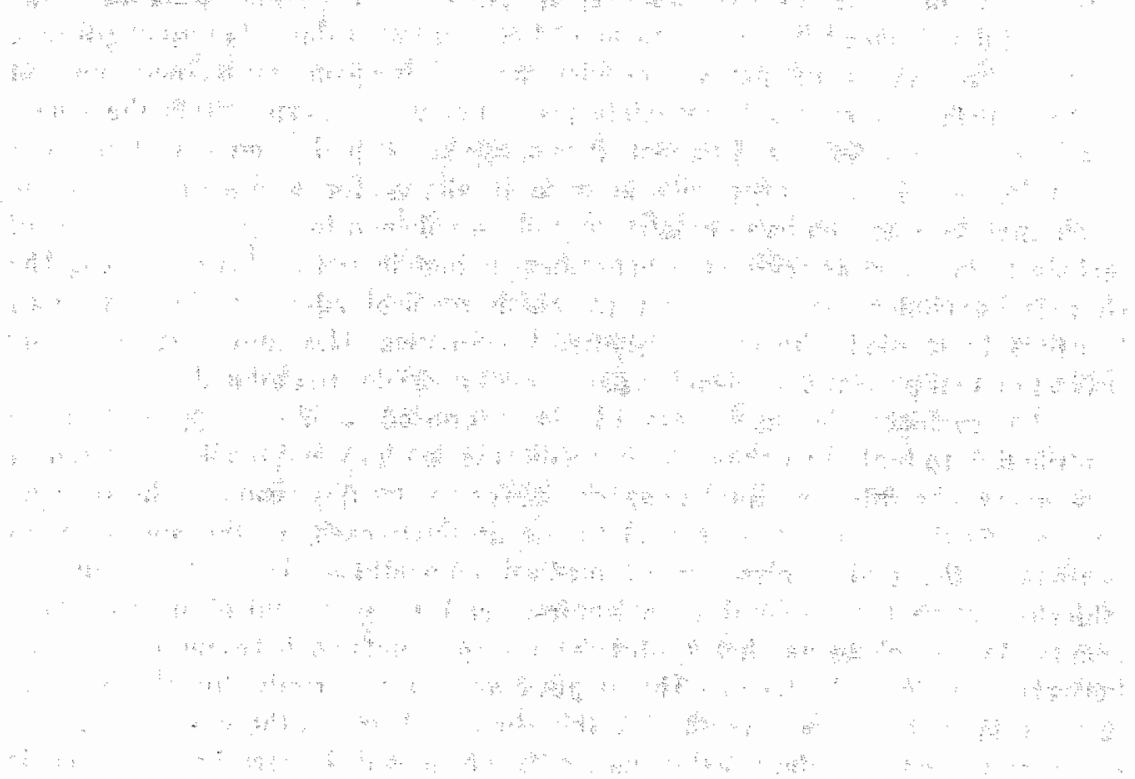




\section{Samenvatting}

In hoofdstuk 1 wordt de algemene vraagstelling van het boek uiteengezet: hoe verandert de introductie van vernieuwingen in de geneeskunde - vernieuwingen zowel in de vorm van technische objecten als in de vorm van diagnostische en therapeutische procedures - de gebruikers daarvan, hun ideeenn en hun onderlinge relaties? En hoe veranderen de innovaties zelf gedurende hun verspreiding en implementatie? Deze vragen worden nader gespecificeerd in een bespreking van de belangrijkste theorieën over medische technologie, namelijk de filosofie van de medische techniek en medische technology assessment (MTA). Betoogd wordt ten eerste dat sociale en ethische elementen van innovaties onvoldoende bestudeerd zijn, en ten tweede dat zowel de techniekfilosofie, vertegenwoordigd door het werk van Stanley Reiser, als MTA een een theorie nodig hebben over de aard van de verbindimg tussen mensen en technische objecten. Sociale en ethische elementen worden meestal beschouwd als secundaire effecten van technologie. vergelijkbaar met de bijwwerkingen van geneesmiddelen.

Dit boek kiest een andere benadering, die wordt ontleend aan het terrein van de sociologie van innovaties. De verschillende scholen van onderzoek op dat gebied passeren de revue, waarbij de nadruk ligt op de (zeldzame) voorbeelden van onderzoek van medische technologie. Het recente boek van de wetenschapssocioloog Stuart Blume over de ontwikkeling van medische technologie wordt besproken en de verschillen met het onderhavige werk worden belicht. De kerm van het hoofdstuk omvat een bespreking een onderzoekslijn in de technieksociologie die de belangrijkste concepten van dit boek heeft geleverd, namelijk de actor-netwerk benadering, ontwikkeld door de Franse sociologen Callon en Latour in studies van de ontwikkeling en verspreiding van innovaties.

Kernconcepten, zoals actor-netwerk, translatie, interessement en programma/antiprogramma worden besproken. Onderzoek in de sfeer vam het gebruik van technieken, waarin het begrip van een semiotiek van de techniek is ontwikkeld, krijgt speciale aandacht. Binnen dit onderzoek is vooral het idee belangrijk, dat techniekem scenario's of scripts voor gebruikers bevatten. De verbinding tussen sociale en technische aspecten van technologie die, zoals uiteengezet, in het werk van Reiser en in MTA betrekkelijk mysterieus blijft, wordt gevormd door dergelijke scenario's, die binnen de actor-netwerk benadering ook wel worden angeduid als de ingeschreven gebruikers van een techniek.

$\mathrm{Na}$ deze bespreking volgt een nadere specificatie van de vragen waarop in dit boek een antwoord gezocht wordt aan de hand van een korte omschrijving van het geneeskundige terrein waaruit de gevalsbeschrijpingen afkomstig żjn, namelijk chronische obstructieve luchtwegaandoeningen. De gevolgde methode thestaat steeds uit een combinatie van gevalsstudies en literatuuronderzoek naar de ontwikkeling van de technologie in kwestie. Het laatste deel van het hoofdstuk bespreekt een methodisch probleem dat samenhangt met de positie ven de auteur: hij is tegelijkertijd een gebruiker en een onderzoeker van de technologieën die in dit boek beschreven worden.

Hoofdstuk 2 is gewijd aan de controverse over de definitie en naamgeving van chronische obstructieve longziekten. De basis van het hoofdstuk wordt gevormd door de gedachte dat woorden miet alleen gebruikt worden om de wereld 
te beschrijven, maar ook om te handelen en de wereld te organiseren - dat maakt het mogelijk ze te bestuderen als een techniek, als gereedschap.

Vanaf de laatste helft van de jaren " 50 is gediscussieerd over de wraag of astma, chronische bronchitis en longemfyseem werschillende ziekten zijn met gelijksoortige symptomen, of, omgekeerd, éen ziekte met verschillende symptomen. Het probleem van de classificatie deed zich gelden toen Britse en Amerikaanse onderzoekers, die wilden samenwerken in epidemiologisch onderzoek, ontdekten dat er belangrijke verschillen bestonden in de gebruikte diagnostische terminologie. $\mathrm{Er}$ werden verschillende conferenties aan het onderwerp gewijd. Aan het begin van de jaren 60 formuleerde een groep Nederlandse onderzoekers de zogenaamde Dutch Hypothesis die inhoudt dat astma, chronische bronchitis en longemfyseem in essentie dezelfde ziekten zijn, en dat verschillen niet anders dan kwantitatief van aard zijn. $\mathrm{Zij}$ stelden voor om te spreken van Chronische Aspecifieke Respiratoire Aandoeningen (CARA) (Engels: Chronic Non-Specific Lung Diseases, CNSLD). De aanhangers van deze terminologie worden 'lumpers' (op-één-hoop-gooiers) genoemd. Hun tegenstanders zijn 'splitters' (splijters), meestal onderzoekers en clinici uit Groot-Brittanniề en de Verenigde Staten. Zij menen dat er fundamentele verschillen bestaan tussen astma en de twee andere ziekten. Het debat wordt in dit hoofdstuk beschreven met nadruk op de opvattingen over arts en patiënt die in de twee posities geincorporeerd zijn.

$\mathrm{Na}$ een beschrijving van de verschillende argumenten die in dit debat naar voren worden gebracht volgt een beschrijving van de verschillende manieren waarop de terminologie van de 'lumpers' is verspreid in de Nederlandse geneeskunde, in het bijzonder onder de huisartsen. De vraag wordt daarbij gesteld welk verschil het maakt voor patiënten of zij vanuit het standpunt der 'lumpers' of vanuit dat der 'splitters' worden gediagnostiseerd. De stelling wordt verdedigd dat, los van de discussie over terminologie, de praktische overeenkomsten op het vlak van diagnose, monitoring en behandeling het standpunt van 'lumpers' sterker steunen dan dat van 'splitters'.

Omdat het begrip reversibiliteit een belangrijke rol speelt in de discussies, wordt daaraan speciaal aandacht besteed en aan het ermee samenhangende concept chroniciteit. Tenminste drie chroniciteitsbegrippen spelen een rol: levenslange ziekte, levenslange dispositie tot ziekte, en - een zwakkere vorm van chroniciteit langdurige, maar niet bij voorbaat levenslange ziekte.

Hoofdstuk 3 bespreekt de ontwikkeling en het gebruik van een recente technische movatie in de behandeling van obstructieve longziekten: de piekstroommeter Een gevalsstudie beschrijft hoe de piekstroommeter wordt geïntroduceerd bij een patiënt en hoe zelf-meting wordt uitgelegd door de arts. Vervolgens passeren de verschillende vormen van mini-piekstroommeters de revue, waarbij de nadruk ligt op het verschil tussen piekstroommeters en -fluitjes. Piekstroommeters, zo blijkt, meten iets anders dan andere longfiunctie-apparatuur; ze creëren de parameter die ze meten.

Bovendien leveren piekstroommeters persoonsgebonden en weinig generaliseerbare informatie op; in aansluiting aan het werk van Canguilhem wordt betoogd dat piekstroommeting uitdrukking geeft aan wat hij heeft aangeduid als de normativiteit van ziekte. 
De scenario's voor patięnten en artsen, die in de apparaatjes zijn vervat, worden beschreven, evenals de manier waarop ze de arts-patiënt-relatie veranderen. Een bespreking van de consequenties van zelf-meet-technologie voor het onderscheid tussen subjectieve en objectieve informatie over ziekte beshuit het hoofdstuk. Dit onderscheid, dat in de medische antropologie verwoord is als het verschil tussen 'illness' en 'disease', is onhoudbaar bij CARA en soortgelijke ziekten omdat patiënten, als zij zelf metingen gaan verrichten, zowel het vocabulaire van (objectieve) dysfunctie als dat van (subjectieve) klachten en symptomen gebruiken.

In hoofdstuk 4 gat het om de verschillende vormen van inhalatie-apparaten die in de laatste twintig jaar zijn ontwikkeld. De belangrijkste rechtvaardiging voor die ontwikkeling was dat daardoor de plaatselijke behandeling mogelijk werd en alleen het doelwit van de behandeling bereikt zou worden. Een tweede voordeel is de snelheid waarmee effect intreedt. De kern van dit hoofdstuk is een bespreking van het begrip 'plaatselijke behandeling'.

De gevalsbeschrijving in dit hoofdstuk gaat over twee broertjes die voor CARA behandeld worden en hun medicatie via verschillende toedieningswegen krijgen. Enkele verschillende imhalatoren komen aan de orde, De volgende paragraaf bevat een systematische beschrijving, waarin voorzetkamers, aërosol- en poederinhalatoren beschreven worden. De nadruk ligt daarbij op de scenario's die ze bevatten voor patiënten. Bij oraal gebruikte geneesmiddelen, zo wordt betoogd; is het traject dat door het lichaam moet worden afgelegd vrijwel geheel in thet geneesmiddel zelf ingeschreven, terwijl het bij inhalatie in sterke mate aflangt van de vaardigheden van de gebruiker of het geneesmiddel zijn doel bereikt. De patiènt heeft daardoor een grotere verantwoordelijkheid voor het lukken of mislukken van de behandeling. De vraag hoe de verdeling van verantwoordelijkkeid onderdeel is van een technisch object wordt besproken aan de hand van recent werk van de socioloog Laurent Thévenot. Sommige inhalatoren bevatten speciale accessoires voor het verschuiven van verantwoordelijkheden van gebruiker naar apparaat.

In dit hoofdstuk wordt een alternatief ontwikkeld voor de gedachte dat medicijnen voorafgegeven trajecten door het lichaam volgen. Tijdens de ontwikkeling en het gebruik van verschillende vormen van geneesmiddelen worden, zo luidt de stelling, verschillende toedieningswegen gecreëerd. In mavolging van Foucault's opvatting dat er verschillende vormen van ruimtelijkheid ('spatialisations") in het lichaam bestaan, betoogt dit hoofdstuk dat medicaties tot op zelkere hoogte hun eigen kaart van het lichaam maken, naast de kaarten die gemaakt worden in de anatomie, het röntgenonderzoek en andere onderzoeksmethoden. De slotparagraaf trekt deze gedachte door naar de stelling dat toedieningsvormen van geneesmiddelen nieuwe definities van patiënten, artsen en luchtwegen genereren.

Hoofdstuk 5 gaat over de medicijnen zelf die in inhalatoren gebruikt. worden. Er wordt een patiēnt beschreven die in de loop van zijn ziekte verschillende geneesmiddelen per inhalatie krijgt voorgeschreven: luchtwegverwijders, anticholinergica, cromoglycaat en inhalatiesteroiden. Aan de hand van de tekst van de informatiefolder 'Medicijnen' van het Nederlands Astma Fonds wordt nagegaan welk beeld van de luchtwegen en van CARA in de informatie bij ieder van de geneesmiddelen besloten zit. De eerste analyse van deze teksten gebeurt met concepten ontwikkeld door de filosoof en medicus Dagognet. 
Hoewel zijn werk behulpzaam is bij het beschrijven van de voorstellingswereld ('mythologieen', zoals hij ze noemt) die wordt opgeroepen door de medicijnen, is de kritiek dat het gebaseerd is op een ongefindeerd onderscheid tussen het lichaam en zijn verbeeldingen.

In de rest van het hoofdstuk wordt het idee ontwikkeld dat representaties hun object niet zozeer weergeven als wel vormen en dat innovaties in de medicatie die patienten gebruiken tegelijk innovaties in hun lichaam zijn. Deze gedachte vertoont een duidelijke parallel met het 'splitting and inversion model dat is ontwikkeld door de wetenschapssocioloog Steven Woolgar. Deze stelt dat wetenschappelijke representaties niet het uitvloeisel ziju van kenmerken van hun object, maar deze objecten juist vormen. Objecten gaan niet vooraf aan de voorstelling, maar vloeien enit voort. In de woorden van Canguilhem: tegelijk met de beelden van de luchtwegen die in dit hoofdstuk besproken worden ontstaan fysiologische vernieuwingen. Zo wordt getoond dat lachtwegverwijders de luchtwegen maken tot voortdurend splitsende contraheerbare buizen, terwijl cromoglycaat ze behandelt als een min of meer stabiele verdedigingslinie tegen schadelijke stoffen en allergenen.

Bovendien introduceren de verschillende geneesmiddelen verschillende tijden in de luchtwegen: verwijders werken met mechanismen die slechts enkelle minuten in beslag nemen, terwijl steroiden veranderingen aanbrengen die veel langzamer gaan - maanden tot jaren. Een ander verschil tussen de geneesmiddelen is het onderscheid tussen oorzaak en gevolg dat ze met zich meebrengen. Steroiden en cromoglycaat worden beschouwd als oorzakelijke geneesmiddelen, terwijl bronchusverwijders en anticholimergica 'slechts' symptomen bestrijden Aan het eind van het hoofdstuk wordt het idee dat geneesmiddelen verschillende luchtwegen incorporeren en uitdragen gekoppeld aan de praktijken waarin ze worden gebruilkt. De band met praktijken ontkracht thet mogelijke bezwaar van te ver doorgevoerd relativisme.

Het voorafgannde leidt tot de vraag hoe een patiènt kan leven met verschillende geneesmiddelen als die alle hun eigen definitie van de luchtwegen bevatten. Deze verschillen worden, zo luidt het antwoord, van hun strijdigheden ontdaan middels coördinatiemechanismen. Twee hiervan worden beschreven: timing en het aanbrengen van een hiërarchie. Bovendien, zo wordt betoogd in de laatste paragraaf, creëren geneesmiddelen behalve verschillen ook overeenkomsten binnen het lichaam.

In de volgende hoofdstukken worden geen technische objecten onderzocht, maar procedures. Het gaat om sociale technologieën.

In hoofdstuk 6 gaat het om monitoring programma's, en meer specifiek om het concept self-management (zelfbehandeling) dat doorgaans deel is van zulke programma's. De vraag van het hoofdstuk is dezelfde als van de voorafgaande: wat voor patiënt, wat voor arts en wat voor arts-patięnt verhouding wordt er binnen dergelijke programma's gecreëerd?

De eerste helft van het hoofdstuk bespreekt monitoring van mensen met CARA als een vorm van diagnostiek op de lange termijn. Verschillende richtlijnen worden onderzocht met betrekking tot de monitoring die ze adviseren en de organisatie daarvan. De structurele verschillen met de diagnostiek van acute ziekteepisoden wordt beschreven: symptomen krijgen een andere betekenis, er worden 
andere technische hulpmiddelen gebruikt, de praktijkorganisatie is verschillend, en de toedeling van verantwoordelijkheid aan arts en patiënt is anders:

Plannen voor self-management zijn een belangrijk bestanddeel van alle bestaande monitoring programma's. Patiënten wordt niet alleen geleerd hun luchtwegen te controleren en te surveilleren, maar ook om ze te behandelen. Als basis wordt een Australisch self-management plan genomen, gepubliceerd in 1989. Het begrip 'delegeren', dat van bijzonder belang is in dit plan, wordt nader geanalyseerd en een korte bespreking wordt gewijd aan het onderwerp van het vergroten van de macht van de patiënt, eéén van de rechtvaardigingen van selfmanagement.

Er is, zo blijkt in de volgende paragrafen van dit hoofdstuk, een parallell tussen self-management bij CARA en resultaten van antropologisch en historisch werk over de manier waarop mensem met hun lichaam omgaan. De voontaamste bron hierbij is het late werk van Foucault. De begrippen "lichaamstechniek' en 'techniek van het zelf blijken vruchtbaar voor het begrijpen van self-management bij chronische ziekten.

Het hoofdstuk beshuit met een bespreking van de manier waarop selfmanagement nieuwe definities van artsen en patiënten genereert.

Het $7 \mathrm{e}$ hoofdstuk bespreekt een verwant probleem, dat onderwerp is geweest van veel discussie, en dat van belang is in de behandeling van CARA en andere chronische ziekten, namelijk het omgaan met non-compliance. Omdat dit probleem vooral aan de orde is bij chronische ziekten, begint het hoofdstuk met een vergelijking van de structunur van korte- en lange-termijnbehandeling. Als introductie in het probleem fungeert een gevalsbeschrijving. Deze wordt gevolgd door een bespreking van de verschillende methoden die zijn ontwikkeld om een beeld te krijgen van de mate van compliance. De beperkingen van deze methoden worden aangegeven, in het bijzonder de aanname dat compliance en zijn tegendeel individuele, op zichzelf staande verschijnselen zijn. De weinige verklarendle theorieën omtrent het verschijnsel worden kort besproken en van commentaar voorzien.

De gevalsbeschrijving wordt dan voortgezet om enkele van de strategieën te laten zien die een arts ter beschikking staan om de compliance te verhogen. Het wordt duidelijk dat deze heterogeen zijn; waarschuwingen, technische objecten, en veranderingen in de organisatie spelen een rol.

De vraag wordt opgeworpen of non-compliance met betrekking tot medische adviezen wel voldoende bijzonder is om te rechtvaardigen dat het probleem doorgaans asymmetrisch wordt onderzocht - redenien voor compliance worden minder onderzocht dan redenen voor non-compliance, terwijl er aanwijzingen zijn dat non-compliance frequent voorkomt bij iedere soort van advisering. Compliance is even verbazend als non-compliance.

Vervolgens wordt de kritiek van de socioloog Zola op het gebruik van de termen compliance en non-compliance besproken. Fij pleit ervoor te spreken van de kwaliteit van de alliantie tussen arts em patiënt in plaats van over de compliantie van de patiënt, aangezien die term het probleem geheel bij de patiënt legt. Het voorstel van Zola is van belang, maar niet bevredigend, omdat het compliance beperkt tot de interactie van patiënt en arts. Geopperd wordt dat het begrip netwerk nuttig zou kumnen zijn, in het bijzonder omdat het een integratie toestat 
tussen compliantie bij mensen en bij dingen. De rol van objecten bij het verbeteren van compliantie wordt in een netwerk-benadering benadrukt.

Het hoofdstuk sluit met de conchusie dat de heuristiek van de actor-netwerk benadering vruchtbaar kan zijn voor dit probleem. De consequentie van de stelling dat volledige compliantie een illusie is, worden besproken.

Het slothoofdstuk (8) keent terug naar de discussies in thet beginhoofdstuk met de bedoeling om de vruchtbaarheid van de voorgestelde semiotische benadering te beoordelen. Daarbij wordt speciaal aandacht besteed aan het nut van deze benadering voor de ethische elementen van medische innovaties. Technologie bevat ethisch relevante gedragsvoorschriften, en daarnaast bevatten veel technische objecten accessoires voor het verdelen van de verantwoordelijkheid tussen mensen onderling en tussen mensen en dingen.

Ook de implicaties van de in dit boek verrichte analyses voor de technieksemiotiek worden besproken: technische objecten bevatten naast bedoelde ook onbedoelde scenario's, ze bevatten wat in dit boek ontologieẽn genoemd is, en sociale technieken verdienen een semiotische benadering net zo goed als technische objecten.

Tenslotte wordt de stelling verdedigd dat sociale en ethische elementen van medische technologie uitgebreider bestudeerd moeten worden, en dat de benadering die in dit boek ontwikkeld is daar de mogelijkheden toe geeft. Een opsomming van gebieden waar zulks met vrucht kan worden geprobeerd besluit het hoofdstuk en het boek. 


\section{Literature}

Akrich M, Latour B. 1992. A Summary of a Convenient Vocabulary for the Semiotics of Human and Non-human Assemblies. In: Bijker WE, Law J (eds).

Akrich M. 1992. The De-scription of Technical Objects. In: Bijker WE, Law I (eds).

Akrich M. 1993. Inseription et coordination sociotechniques. Anthropologie de quelques dispositifs énergétiques. Thèse. Paris: Centre de Sociologie de l'Innovation, Ecole des Mines de Paris.

Aretaeus. 1856. On Asthma. In: Adams F (ed). 1856. The Extant Works of Aretaeus, the Cappadocian. London: The Sydenham Society.

Augé, $M_{3}$ Herzlich C (eds). 1984. Le sens du mal - anthropologie, histoire, sociologie de la maladie. Paris: Editions des Archives Contemporaines.

Austin J. 1975. How to Do Things with Words. Cambridge, Mass: Harvard University Press.

Bachelard G. 1954. La Formation de l'Esprit Scientifique. Contribution à une psychanalyse de la connaissance objective. Paris: Vrin.

Banta HD. 1984. Embracing or Rejecting Innovations: Clinical Diffusion of Health Care Technology. In: Reiser SJ, Anbar M (eds).

Banta HD, Luce BR. 1993. Health Care Technology and Its Assessment. An International Perspective. Oxford: Oxford University Press.

Baron RJ. 1985. An Introduction to Medical Phenomenology: I. Can't Hear You While I'm Listening. Ann Int Med 103;606-11.

Bartelds A. 1982. Hoestende snotneusjes. Huisarts Prakt 6:63.

Barthes R. 1985. Sémiologie et médecine. In: L'aventure sémiologique. Paris: Seuil.

Bassett K. 1993. Taming Chance and Taking Chances; the Electronic Fetal Heart Monitor in a Rural Canadian Hospital and Comanunity. Doctor Thesis, McGill University.

Beasley R, Cushley M, Holgate ST. 1989. A Self Management Plan in the Treatment of Adult Asthma. Thorax 44:200-4.

Bijker WE, Hughes TP, Pinch T (eds). 1987. The Social Construetion of Technological Systems. New Directions in the Sociology and History of Technology. Cambridge, Mass: The MIT Press.

Bijker W, Law J (eds). 1992. Shaping technology / Building society. Cambridge, MA/London: The MIT Press.

Bijker W. Forthcoming Socio-historical Technology Studies Illustrated with Examples from Coastal Engineering and Hydraulic Technology.

Bloor D. 1976. Knowledge and Social Imagery. London: Routledge Kegan Paul.

Blume S. 1992. Insight and Industry - On the Dynamics of Technological Change in Medicine. Cambridge, Mass.: MTT Press.

Bodewitz JH, Buurma H, De Vries GH. 1987. Regulatory Science and the Social Management of Trust in Medicine. In Bijker, Hughes, and Pinch (eds).

Boltanski $L$, Thévenot $L$. 1991. De la justification. Paris: Gallimard.

Bottema BJAM, Fabels EJ, Van Grunsven PM, et al. 1992. NHG-standaard CARA bij volwassenen: Diagnostiek. Huisarts Wet 35:430-436.

Bottema BJAM. 1993. Diagnostiek van CARA in de huisartspraktijk. Amsterdam: PhD Thesis.

Brian Haynes R. 1976. Strategies for Improving Compliance: a Methodological Analysis and Review. In: Sackett DL, Brian Haynes R (eds).

Brian Haynes R, Wayne Taylor D, Sackett DL (eds). 1979. Compliance in Health Care, Baltimore/London: The Johns Hopkins University Press. 
British Thoracic Society. 1990. Guidelines for the Management of Asthma in Adults. L. Chronic Persistent Asthma. Br Med J 301 651-3.

Brown S, Lee N. 1993. The Unexplored Country: Actor Network Theory and Otherness. Unpublished paper presented at Surrey Conference in Theory and Method "NonHuman Agency: A Contradiction in Terms?".

Buckley D. 1989. Assessment of Inhaler Technique in General Practice. Ir J Med Se 158(12):297-9.

Burns KL. 1979. An Evaluation of Two Inexpensive Instuments for Assessing Airway Flow. Ann Allergy 43:246-9.

Burrows B, Niden A, Barcaly WR, Kasik JE. 1965. Chronic Obstructiwe Lung Disease; II Relationship of Clinical and Physiologic Findings to Severity of Airway Obstruction. Am Rew Respir Dis 91:665-678.

Callon M, Law J, Rip A. 1986. Mapping the Dynamics of Science and Technology. London: The Macmillan Press:

Callon M. 1986. Some Elements of a Sociology of Translation: Domestication of the Scallops and the Fishermen of St Brieuc Bay. In: Law J (ed). 1986, 196-234.

Callon M. 1987. Society in the Making: The Study of Technology as a Tool for Sociological Analysis. In: Bijker WE, Hughes TP, Pinch T (eds).

Callon M, Latour B. 1992. Don't Throw the Baby out with the Bath School! A Reply to Collins and Yearley, In: Pickering A (ed).

Canguilhem G. 1979. Le normal et le pathologique. Paris, Presses Universitaires de France.

Canguilhem G (dir) 1984. Anatomie d'un épistémologue: Francois Dagognet. Paris: Vrin.

Charney E. 1975. Compliance and Prescribance. Am J Dis Child 129:1009-1010.

Chiaramonte LT; Goldstein S; Rockwell W, 1984, Report of a Newly Redesigned Peak Flow Whistle. Ann Allergy 52:155-8.

CIBA Guest Symposium 1959. Terminology, Definitions, and Classification of Chronic Pulmonary Emphysema and Related Conditions, Thorax 14;286-299.

Coleman $\mathrm{J}$, et al. 1957. The Diffusion of an Innovation. Sociometry 20:258-70.

Collin A, Said E 1984. How to Cheat with the Miniature Wright Peak Flow Meter Chest 86(1):156.

Colley JRT, Holland WW 1965 , Evaluation of the De Bono Whistle as a Screening Test of Lung Function. Lancet II;212-213.

Collins H. 1985. Changing Order: Replication and Induction in Scientific Practice. London and Los Angeles: Sage.

Collins H, Yearley S. 1992. Epistemological Chicken. In. Pickering A (ed),

Conein B, Dodier N, Thévenot L (réd). 1993. Les objets dans laction - De la maison au laboratoire. Raisons Pratiques 4. Paris: Editions de l'École des Hautes Études en Sciences Sociales.

Conrad P. 1985. The Meaning of Medications Another Look at Compliance. Soc Sc Med 20:29-37.

Cramer JA, Spilker B (eds). 1991. Patient Compliance in Medical Practice and Clinical Trials. New York: Raven Press.

Cramer JA. 1991. Overview of Methods to Measure and Enhance Patient Compliance. In: Cramer JA, Spilker B (eds).

D'Arcy PF, Kirk WF. 1971. Development of a new device for inhalation therapy.

Pharmaceutical I 206:306-7.

Dagognet F. 1964/1984, La Raison et les Remedes. Paris: Presses Universitaires de France.

Darden MD; Sly RM. 1985. Evaluation of HealthScan Assess. Peak Flow Meters. Ann Allergy 54(6):486-8.

Davidson P. 1976. Therapeutic Compliance. Can Psych Review 17(4):247-59.

De Swaan A, Van Gelderen R, Kense V. 1979. Sociologie van de psychotherapie 2. Het spreekuur als opgave. Utrecht/Antwerpen: Het Spectrum. 
De Swaan A. 1982. De mens is de mens een zorg. Amsterdam: Meulenhoff.

De Bono EF. 1963. A Whistle for Testing Lung Function. Lancet II:1146-7.

De Vries G. 1989. Ethiek en medische technologie. Kennis en Methode 13:278-294.

De Vries G. Forthcoming. De Ontwikkeling van Wetenschap. Een inleiding in de wetenschapsfilosofie. $3 \mathrm{~d}$ edition,

De Wachter M 1989. Ethische aspecten. In: Habbema J et al (red).

Deenstra M. 1992. De inhalatie als toedieningsvorm van geneesimiddelen. Geneesmiddelenbulletin 26:44-7.

Dieleman FE, Dekker FW, Kaptein AA. 1989. Compliantie bij astmamedicatie. Huisarts Wet 32:43-7.

Dirksen WJ, Geyer RMM, De Haan M, et al. 1992. NHG-Standaard astma bij Kinderen. Huisarts Wet 35(9) 355-62:

Dodier N. 1991. Agir dans plusieurs mondes. Critique 47:427-59.

Dompeling E, Van Grunsven PM, Van Schayk CP, et al. 1992. Treatment with Inhaled Steroids in Asthma and Chronic Bronchitis: Long-term Compliance and Inhaler Technique. Fam Pract 9(2):161-6.

Eco U. 1985. Lector in Fabula. Paris: Grasset. (originally published in Italian under the same title. Milan. Bompiani, 1979.)

Eisenberg L, Kleinman A (eds). 1981a. The Relevance of Social Science for Medicine. Dordrecht/Boston/London: Reidel.

Eisenberg L, Kleinman A 1981b. Clinical Social Science. In: Eisenberg L, Kleininan A (eds).

Elsinga E, Rutten FFH. 1995. Medische technology assessment. Toepassing in de Nederlandse gezondheidszorg. Medisch Contact 50(1): 13-8.

Farberow NL. 1986. Noncompliance as Indirect Self-Destructive Behavior. In: Gerber' KE, Nehemkis AM (eds):

Feeley M. 1972. Coercion and Compliance - A New Look at an Old Problem. In: Krislov S, Boyum KO, Clark N, et al (eds)

Feeny D, Guyatt G, Tugwell P. 1986. Health Care Technology Effectiveness, Efficiency \& Public Policy. Montreal: The Institute for Research on Public Policy.

Fleck L. 1935. Entstehung und Entwicklung einer wissenschaftlichen Tatsache. Einführung in die Lehre von Denkstill und Denkkollektiv. Basel: Benno Schwabe \& Co.

Fletcher C, Jones NL, Burrows B, Niden AH, 1964. American Emphysema and British Bronchitis. Am Rev Resp Dis 90:1-13.

Fletcher CM, Pride NB. 1980. Asthma can be Distinguished from other Forms of Airflow Obstruction: In; Querido A, Roos J (red.).

Fletcher CM, Pride NB 1984. Definitions of Emphyserna, Chronic Bronchitis, Asthma, and Airflow Obstruction: 25 Years on from the Ciba Symposium. Thorax 39:81-85.

Foucault M. 1984. Le souci de soi. Histoire de la sexualité 3. Paris: Gallimard.

Foucault M. 1964. Naissance de la clinique. Paris: Presses Universitaires de France:

Foucault M. 1975. Surveiller et punir. Naissance de la prison. Paris: Gallimard.

Foucault M. 1988a. The Political Technology of Indjviduals. In: Martin LH, Gutman H, Hutton PH (eds).

Foucault M. 1988b. Technologies of the Self. In: Martin LH, Gutman H, Hutton PH (eds).

Fox RC, Swazey JP. 1992. Leaving the Field Hastings Center Report 22(5):9-17.

Friedman M, Walker S. 1975. Assessment of Lung Function Using an Airflow-meter. Lancet 310-1.

Fuchs VR, Garber AM. 1990. The New Techinology Assessment. N Engl J Med 323(10):673-7.

Gabbay J. 1982. Asthma Attacked? In: Wright P, Treacher A (eds).

Gerber KE, Nehemkis AM (eds). 1986. Compliance - the Dilemma of the Chronically IIll. New York: Springer Publishers. 
Ginzburg C. 1988. Onweg als methode. Essays over verborgen geschiedenis, kunst en maatschappelijke herinnering. Nijmegen: SUN (originally published as: Miti emblemi sple: morfologia e storia Turin: Eimaudi, 1986).

Good BI. 1994. Medicinie, Rationality, and Experience. Cambridge MA. Cambridge University Press.

Goodman C. 1992. It's Time to Rethink Health Care Technology Assessment. Int J Techn Ass Health Care $8(2), 335-58$.

Goodman N. 1978. Ways of Worldmaking. Indianapolis: Hackett:

Gordis $\mathbb{L}$ 1976. Methodological Issues in Measurement of Patient Compliance. In: Sackett DL, Brian Haynes R (eds).

Grordon G, Fisher GL (eds.): 1975. The Diffusion of Medical Technology Cambridge, MA Greenfield S. Yr? Challemges and Opportunities that QA raises for TA In: Lohr KN, Rettig RA (eds.). YT?

Greimas AJ, Courtés J. 1984. Semiotics and Language. An Analytical Dictionary.

Bloomington: Indiana University Press.

Gregg I. The Measurement of Peak Expiratory Flow Rate and its Application in General Practice. J Coll Gen Pract 7:199-214.

Gross NJ. 1980. What is This Thing Called Love- Or, Defining Asthma. Am Rev Resp Dis 121:203-4.

Grossman J. 1994. The Evolution of Inhaler Technology. I Asthma 31.55-64.

Guyatt GH, Feeny DH, Patrick DL. 1993. Measuring Health-related Quality of Life.

[Review] Ann Int Med 15;118(8);622-9.

Habbema JDF, Lubbe JThN, Van Agt HME, et al, 1989. Kosten en effecten van

bevolkingsonderzoek op baarmoederhalskanker Rotterdam Instituut Maatschappelijke Gezonsheidszorg. Erasmus Universiteit

Habbema J, et al (red). 1989. Medische Technology Assessment en gezondheidsbeleid. Alphen a/d Rijn. Samson Stafleu.

Hadom W. 1948. Ein neues Pneumometer zur Bestimmung des Expirationssstosses (maximale Ausatmungsstromstarke) Schweiz Med Wochenschr 35:946-950.

Haraway DJ. 1991. A Cyborg Manifesto: Science, Technology, and Socialist-Feminismin the Late Twentieth Century: In: Haraway DJ 1991. Simians, Gyborgs; and Women. New York: Routledge.

Hargreave FE, Dolovich J, Newhouse MT. 1990. The Assessment and Treatment of Asthma: a Conference Report. J Allergy Clin Immunol 85:1098-111.

Herzlich C. 1984. Médecine moderne et quête de sens. In. Auge, M, Herzlich C. (eds).

Higgs CMB, Richardson RB, Lea DA, Lewis GTR, Laszilo G. 1986. Influence of Knowledge of Peak Flow on Self Assessment of Asthima: Studies with a Coded Peak Flow Meter. Thorax 41:671-5.

Hirschauer S. 1991. The Manufacture of Bodies in Surgery. Social Studies of Science 21:279.319.

Hoffmaster B 1992. Can Ethnography Save the Life of Medical Ethics? SocSciMed 35(12): 1421-31.

Horn CR, Clark TI, Cochrane GM 1990. Compliance with Inhaled Therapy and Morbidity from Asthma. Respir Med 84(1) 67-70.

Hughes EC. 1960. The Place of Field Work in Social Science in. The Sociological Eye Selected Papers: New Brunswick/London : Transaction Books.

Huygen FJA, Eijk J van, Hoogen $\mathrm{H}$ van de, et al. 1977a. Een praktijk doorgelicht op CARA. I. Huisarts Wet 20:383-6.

Huygen FJA, Eijk J wan, Hoogen $H$ van de, et al. 1977b. Een praktijk doorgelicht op CARA. II. Huisarts Wet 20:434-7.

Huygen FJA, Eijk J van, Hoogen $H$ van de, et al. 1977c. Gevolgen van doorlichting op CARA. III. Huisarts Wet 20:438-44. 
Huyggen F. 1978. Een praktijk doorgelicht op CARA (antwoord). Huisarts Wet 21:155.

Illich I. 1975. Medical Nemesis. The Expropriation of Health. London: Marion Boyars.

Indumar. 1990. Het gebruik van de Piekstroommeter - een onderzoek in opdracht van Glaxo BV. Amsterdam.

Institute of Medicine. 1985. Assessing Medical Technologies. Washington, D.C. National Academy Press.

Jenkins W. 1954. Are Patients True to ti.i. and q.i.d. doses? Gen Pract 9:66.

Jennings B. 1991. Ethics and Ethnography in Neonatal Intensive Care. In: Weisz G (ed).

Jones PK, Jones SL, Katz J. 1987. Improving Compliance for Asthmatic Patients Visiting the Emergency Department Using a Health Belief Model Intervention: I Asthma 24(4):199-206.

Kamer RE. 1978. COPD, COLD, CAO, ete - Anachronistic Acronyms. Chest 74:241-2.

Keeney EL. 1964. A History of Asthma from Hippocrates to Meitzer. J Allergy 35:215-26.

Kimmel SR 1986. Use of the Peak Flow Meter in Office Practice. Am Fan Pliysician 34(6):107-11.

Kohrman AF. 1994. Chimeras and Odysseys. Toward Understanding the TechnologyDependent Child. Hastings Center Report Suppl S4-6.

Krisiov S. 1972. The Perimeters of Power: The Concept of Compliance as an Approach to the Study of the Legal and Political Processes. In: Krislov S, Boyum KO, Clark JN, et al (eds). 1972, 333-350.

Krislow S, Boyum KO, Clark JN, et al (eds). 1972. Compliance and the Law; Beverley Hills/London: Sage.

Lachmund J, Stollberg G. (eds). 1992. The Social Construction of Illness. Stuttgart: Franz Steiner Verlag.

Lademacher DS, De Haan M, Spreeuwenberg C. 1986. Preventie van CARA in de huisartspraktijk Huisarts Wet 29 (suppl H\&P10):33-35.

Lagerwij EW. 1993. De lezers van het Nederlands Tijdschrift voor Geneeskunde. Ned Tijdschr Geneesk 137(8):402-4.

Latour B. 1984. Les Microbes: guerre et paix. Paris: Métaillé.

Latour B, Woolgar S. 1986. Laboratory Life: the Construction of Scientific Facts. Princeton: Princeton University Press.

Latour B. 1987. Science in Action. Milton Keynes: Open University Press.

Latour B. 1988. The Pasteurization of France. Cambridge, Mass: Harvard University Press. (translation of: Les microbes, guerre et paix; suivi de Irréductions, Paris 1984).

Latour B. 1991. The Impact of Science Studies on Political Philosophy. Science, Technology, \& Human Values, 16(1):3-19.

Latour B, Mauguin P, Teil G. 1992. A Note on Socio-technical Graphs. Social Studies of Science 22:33-59:

Latour B. 1992. Where are the Missing Malsses? Sociology Of A Door-closer. In: Bijker WE, Law J (eds). 1992.

Latour B. 1993. "Le groom est en grẻve, pour l'amour de Dieu, fermez la porte." In: La clef de Berlin et autres leçons d'un amateur de sciences. Paris: La Découverte.

Latour B. In press. Objet de la sociologie - sociologie des objets:

Law J. 1986. On the Methods of Long-distance Control: Vessels, Navigation and the Portuguese Route to India. In: Law J (ed).

Law J (ed). 1986. Power, Action and Belief - A New Sociology of Knowledge? London/Boston: Routledge \& Kegan Paul, 196-234.

Le Breton D. 1992. La Sociologie du Conps. Paris: Presses Universitaires de France (coll. Que sais-je).

Lohr KN, Rettig RA (eds.). Yr? Quality of Care and Technology Assessment; Report of a Forum of the Council on Health Care Technology. Washington, DC: National Academy Press. 
Lubar S, Kingery WD. 1993 . Introduction. In: Lubar S, Kingery WD (eds).

Lubar S, Kingery WD (eds). 1993. History from Things - Essays on Material Culture. Washington/London: Smithsonian Institution Press.

Martin LH, Gutman H, Hutton PH (eds). 1988. Technologies of the Self - A Seminar with Michel Foucault Amherst: University of Massachusetts Press:

Mauss M Les techniques du corps. 1950. In: Sociologie et anthropologie. Paris: Presses Universiltaives de France.

McF adden ER Jr. 1976. Respiratory Mechanics in Asthma. In. Weiss EB, Segall MS (eds). MoGuinness BW 1982. A Wright Peak Flow Meter in Practice. Practitioner 226:21.

Meyboon R 1984. Onverwachte sterfte van astmapatiënten. Een enquête: Ned Tijdschr Gencesk $128(10): 457-8$.

Meyers DA, Freidhoff LR, Zwollo P, al. 1989. Approaches to the Study of the Geneties of Allergic Diseases. In: Sluiter HJ, Van der Lende R, Gerritsen J, Postma D (eds). 1989.

Miller WF, 1973. Aerosol Therapy in Acute and Chronic Respiratory Disease. Arch lntern Med 131:148-55.

Mol A, Law J. Forthcoming. Networks and Fluids: on the Topography of Anemia.

Morrill CG, Dickey DW, Weiser PC, Kinsman RA, Chai H, Spector SL 1981: Calibration and Stability of Standlard and Mini-Wright Peak Flow Meters. Ann Allergy 46:70-3.

Moulin A-M 1984. Biologie sans vivant, médecine sans malade. In: Canguilhem G (dir).

National Asthma Education Program Expert Panel Report: 1991. Guidelines for the

Diagnosis and Management of Asthma. Bethesda: National Institutes of Health, Publ nr $91-3042$.

Nederlands Astma Fonds. 1993. Medicijnen. Leusden.

Neijens HJ, Duiverman EJ, Kerrebijn KF. 1982. Samenwerking met de tweede lijn bij de behandeling van känderen met CARA. Huisarts Prakt 6:66-8.

Netherlauds Asthma Foundation. 1993. Patient Self-management in Asthma and COPD. Internal document nr. 37,00 .

Newhouse MT. 1990. Metered Dose Pressurized Aerosols and the Ozone Layer. Eur Resp J 3:1232-3.

Newman SP, Pavia D, Clarke SW. 1981. How Should a Pressurized B-Adrenergic Bronchodilator be Inhaled? Eur J Resp Dis 62:3-21.

Newman SP, Morén F, Trofast E, et al 1989. Deposition and Clinical Efficacy of

Terbutaline Sulphate from Turbuhaler, a New Multi-dose Powder lnhaler Eur Resp J $2: 247.52$.

Newman SP, Weisz AWB, Talaee N, et al. 1991. Improvement of Drug Delivery with a Breath Actuated Pressurised Aerosol for Patients with Poor Inhaler Technique. Thorax 46:712-6.

Nord E, Richardson J, Macarounas-Kirchmann K. 1993. Social Evaluation of Health Care versus Personal Evaluation of Health States. Int J Techn Ass Health Care 9(4): 46378.

Norman D. 1988. The Psychology of Everyday Things. New York. Basic Books.

Norman D. 1993. Les artefacts cognitifs. In: Conein B, Dodier N, Thevenot Li (eds). 1993.

O'Connell MB, Hewitt JM, Lackner TE: 1991. Consistency of Evaluators Assessing Inhialer Tochnique Ann Allergy 67,603-8.

Orie NGM: 1953. Het probleem wan het asthma AVAK-berichten 3.7 (reprinted in Sluiter HJ, Do Vreis $K$, Peset R. Van Asthma naar CARA. Leusder: Nederlands Asthma Fonds 1978).

Orie NGM 1960. Een patient met bronchitis. Ned Tujdschr Geneesk 104:1021:

Orie NGM, Sluiter HJ, De Vries K, Tammeling GJ, Witkop J. 1961. The Host Factor in Bronchitis. In: Orie NGM, HJ Sluiter (eds).

Onie NGM, HJ Sluiter (eds). 1961. Bronchitis. Assen: Royal Van Gorcum. 


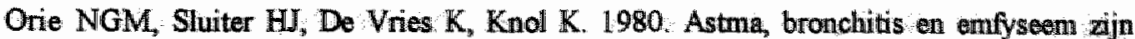
ziektebeelden veroorzaakt door dezelfde ziekmakende factoren. In: Querido A, Roos J (red.)

Owens NJ, Larrat EP, Fretwell MD. 1991, Improving Compliance in the Older Patient In: Cramer JA, Spilker B (eds). 1991.

Pasveer B. 1992. Shadows of Knowledge - Making a Representing Practice in Medicine X ray Pictures and Pulmonary Tuberculosis, 1895-1930. Thesis, University of Amsterdain.

Perks WH, Cole M, Steventon RD, Tams IP, Prowse K. 1981. An Evaluation of the Vitalograph Pulmonary Monitor. $\mathrm{Br} J$ Dis Chest 75(2);161-4.

Petty TL. Editorial. 1978. Chronic Bronchitis versus Asthma - or What's in a Name? J All Clin Immunol 62:323-324.

Phillips GM, Jones JA. 1991. Medical Compliance. Patient or Physician Responsibility? American Behavioral Scientist 54(6); 756-68.

Pickering A (ed). 1992. Science as Practice and Culture. Chicago: University of Chicago Press.

Pinch T, Ashmore M, Mulkay M, 1992. Technology, Testing, Text: Clinical Budgeting in the U.K. National Health Service. In: Bijker WE, Law J (eds). 1992.

Pride NB, Vermeire P, Allegra L. 1989. Diagnostic Labels Applied to Model Case Histories of Chronic Airflow Obstruction. Responses to a Questionnaire in 11 North American and Western European Countries. Eur Resp J 2:702-9.

Prior JG, Cochrane GM 1980. Home-monitoring of Peak Expiratory Flow Rate Using Mini-Wright Peak Flow Meter in Diagnosis of Asthma. J Royal Soc Med 73:7311-3.

Querido A, Roos J (red.); 1980. Controversen in de geneeskunde II. Utrecht: Bunge.

Raad voor Gezondheidsonderzoek 1988. Medical Technology Assessment (MTA). Advies aan de Ministers van WVC en van Onderwijs en Wetenschappen. "s-Gravenhage.

Rahtz P. 1991. Invitation to Archeology Oxford Blackwell.

Rebuck AS, Chapman, KR. 1987. Asthma: 2 Trends in Pharmacologic Therapy. Can Med Ass J 136:483-488.

Reed C. 1991. Aerosol Steroids as Primary Treatment of Mild Asthma. N Engl J Med 325:425-6.

Reiser SJ. 1978. Medecine and the Reign of Technology Cambridge: Cambridge University Press.

Reiser SJ. 1984. The Machine at the Bedside: Technological Transformations of Practices and Values. In: Reiser SJ; Ambar M (eds);

Reiser SJ, Anbar M (eds). 1984. The Machine at the Bedside. Cambridge Ma: Cambridge University Press.

Reiser SJ. 1986. Assessment and the Technologic Present. Int J Techin Ass Health Care 2:712.

Revicki DA. 1993. Health Care Technology Assessment and Health-related Quality of Life. In: Banta HD, Luce BR.

Rogers EM. 1962. Diffusion of Innovations. New York: Free Press of Glencoe:

Rutten-Van Mölken MP, Van Doorslaer EKA, Rutten FFH. 1992. Econonic Appraisal of Asthma and COPD Care: a Literature Review 1980-1991. Sic Sci Med 35(2):161-75.

Sackett DL. 1976. Introduction. In: Sackett DL, Brian Haynes R (eds).

Sackett DL, Brian Haynes R (eds). 1976. Compliance with Therapeutic Regimens.

Baltimore: Johns Hopkins University Press.

Scadding JG. 1976. Definition and Clinical Cátegorization. In: Weiss EB, Segal MS (eds).

Schadé E, IJzermans CJ. 1989. Huisarts en patiënten met chronische aandoeningen. Nieuw kompas voor de huisarts IV:11-1 - 11-18.

Schot JW. 1992. Constructive Technology Assessment and Technology Dynamics: The Case of Clean Technologies. Science, Technology, \& Human Values 17:36-56. 
Sears MR 1986. Why are Deaths from Asthma Increasing? Eur I Respir Dis Suppl $147(10): 175-81$.

Serres M. 1926. Les cinq sens Paris: Grasset.

Serres M. 1989. Préface qui invite le lecteur à ne pas négliger de la lire.. In: Serres M (dir.) Eléments dhistoire des sciences. Paris: Bordas.

Shaw A, Fisher J. 1980. Calibration of Some Instruments for Measuring Peak Expiratory Flow J Med Eng Tech 4:291-294.

Shim CS, Williams MH 1980. Evaluation of the Severity of Asthma: Patients versus Physicians. An J Med 68,11-3.

Simondon G. 1989. Du mode d'existence des objets techniques Paris: Aubier (oniginally published in 1959).

Singleton V, Michael M. 1993. Actor-networks and Ambivalence General Practitioners and the UK Cervical Screening Program. Social Studies of Science 23:227-64.

Sluiter $\mathrm{HJ}$, De Vries K. 1974: Therapie van de CARA. Ned Tijdschr Geneesk 118(28):108492 .

Sluiter HJ, Van der Lende R, Gerritsen J Postma D(eds). 1989. Bronchitis IV. Assen; Van Gorcum.

Sluiter HJ, Koeter GH, De Monchy JGR, Postma DS, De Vries K, Orie NGM 1991. The Dutch Hypothesis (Chronic Non-specific Lung Disease) Revisited Eur Respir J 4.479-489.

Sly PD, Landau LI, Weymouth R. 1985. Home Recording of Peak Expiratory Flow Rates and Perception of Asthma. Am I Dis Child 139:479-82.

Sox HC, Blatt MA, Higgins MC, Marton KI. 1988. Medical Decision Making. Boston: Butterworths.

Spector SL, Mawhinney H: 1991. Aerosol Inhaler Monitoring of Asthmatic Medication. In: Cramer JA, Spilker B (eds)

Spector SL. 1985. Is Your Asthmatic Patient Really Complying? Ann Allergy 55:552-6.

Speight ANP, Lee DA, Hey EN. 1983. Underdiagnosis and Undertreatment of Asthma in Childhood. Br Med J 286; 1253-8.

Spitzer SA, Neuman E. 1974. New Expiratory Flow Meter: Preliminary Report. Chest $66: 440-441$.

Spitzer WO, Suissa S, Emst P, et al. 1992. The Use of B-Agonists and the Risk of Death and Near-death from Asthma N Engl J Med 326:501-6.

Steering Committee on Future Health Scenarios, 1988. Anticipating and Assessing Health Care Technology. Vol 8: Potentials for Home Care Technology. Dordrecht: Kluwer.

Stimson GV. 1974. Obeying Doctor's Orders: a View from the Other Side. Soc Sc Med 8:97-104.

Strom K, Boe J, Herwa M, Boman G, Gustavil A. 1990. Assessment of Two Oxygen

Treatment Alternatives in the Home. Int J Techn Ass Health Care 6:489-97.

Stuurgroep Toekomstscenario's Gezondheidszorg 1990. Chronische ziekten in het jaar 2005. Deel 2: CARA. Houten/Antwerpen: Bohn, Stafled, Van Loghem.

Tattersall SF, Benson MK, Hunter D. 1978. The Use of Tests of Peripheral Lung Function for Predicting Future Disability from Airflow Obstruction in Middle-aged Smokers. An Rov Resp Dis 118: 1035-50.

Tattersfield AE, Barnes PJ. 1992. B -Agomists and Corticosteroids: New Developments and Controversies: Am Rev Resp Dis 146.1637-41.

Terpstra G, Kreukniet J, Raaijmakers JAM, et al 1984. Luchtweginfecties en CARA. Ned Tijdschir Geneesk 128(20):954-7.

Tomson P. 1984. Use of Mini-Wright Peak Flow Meter [letter] J Fam Pract 18(3):374.

Tomson PR. 1989. A Peak Flow Meter on Every Desk. Practitioner 227:1299-303.

Toogood JH, Jennings B, Greenway RW, et al. 1980. Candidiasis and Dysphonia 
Complicating Beclomethasone Treatment of Asthma. J Allergy Clin Immunol 65:14353.

Tsanakas IN, Bannister OM, Boon AW, Milner RDG. 1986. The Peak Flow Whistle Simple Device for Monitoring Peak Flow in Children. Brit Med J 293:1410.

U.S. Congress, Office of Technology Assessment. 1987. Life-sustaining technologies and the Elderly. OTA-BA-306. Washington, D.C.: U.S. Government Printing Office.

Van der Lende R, Orie NGM, Sluiter H. 1978. Een praktijk doorgelicht op CARA (ingezonden), Huisarts Wet $21: 154$.

Van Schayk CP, Dompeling E, Van Weel C, et al. 1990. Accuracy and Reproducibility of the Assess Peak Flow Meter. Eur Resp J 3:338-341.

Van Schayk CP, Dompeling E, Van Herwaarden CLA, et al. 1991. Bronchodilator treatment in moderate asthma or chronic bronchitis." continuous or on demand? $\mathrm{Br} \mathrm{Med} J$ 303:426-31.

Van Schayk C. 1994. Het eindle van de term CARA in zicht? Ned Tijdschr Geneesk 28:1405-8.

Van der Palen J, Klein JJ, Kerkhoff AHM. 1994. Matige techmiek bij het gebruik wan inhalatiemedicatie door patienten met chronische bronchitis/longemfyseem. Ned Tijdschr Geneesk 138(28):1417-22.

Van Veen W. 1982. De bruikbaarheid van piekstroombepaling door de huisarts. Huisarts Prakt 6:69-75.

Van Weel C. 1989. Monitoring van patienten met CARA? Huisarts Wet 32(2):42.

Van der Waart MAC, Dekker FW, Nijhoff $S_{n}$ et al: 1992. NHG-standaard CARA bij volwassenen: Behandeling. Huisarts Wet 35:437-443.

Vermeire PA, Pride NB. 1991. A "Splitting" Look at Chronic Nonspecific Lung Disease (CNSLD): Common Features but Diverse Pathogenesis. Eur Resp J 4:490-496.

Von Uexküll T. 1982. Semiotics and Medicine. Semiotica 38:205-15.

Voorhorst R. 1966. Verschillende wijzen van bestudering van het astriaprobleem. Ned Tijdschr Geneesk 110:2012-2014.

Voom T. 1983. Chronische ziekten in de huisartspraktijk. Utrecht: Bunge.

Vos R. 1989. Drugs looking for Diseases. Thesis. University of Groningen.

Weiss EB, Segal MS (eds). 1976. Bronchial Asthma. Boston: Little, Brown, and Company.

Weisz G (ed). 1991. Social Science Perspectives on Medical Ethics. Philadelphia: University of Pennsylvania Press.

Willems D. 1992. Susan's Breathlessness - The Construction of Professionals and Laypersons. In: Lachmund J, Stollberg G (eds).

Williams S, Bury MR. 1989. Impairment, Disability and Handicap in Chronic Respiratory Iliness. Soc Se Med 29(5):609-616.

Woolcock AJ, Rubinfeld AR, Seale JP et al. 1989. Asthma Management Plan 1989. Med J Aust 151:650-3.

Woolgar S. 1988. Science: The Very Idea. Chichester/London/New York: Ellis Horwood/Tavistock.

Wright, BM. 1978. A Miniature Wright Peak-flow Meter. Br Med J II: 1627-8.

Wright BM, McKerrow CB. 1959. Maximum Forced Expiratory Flow Rate as a Measure of Ventilatory Capacity. Br Med J II:1041-7.

Wright P, Treacher A (eds). 1982. The Problem of Medical Knowledge. Edinburgh: Edimburgh University Press.

Zola IK. 1981. Structural Constraints in the Doctor-patient Relationship: the Case of Noncompliance. In: Eisenberg $\mathbb{L}_{y}$, Kleinman $A$ (eds). 


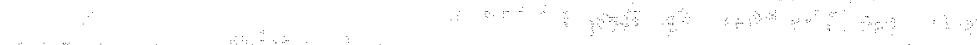

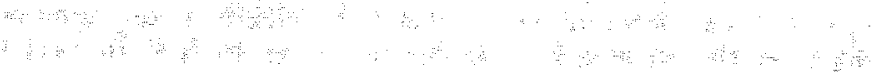
$\therefore$ a $\therefore$

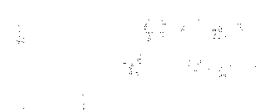
a $\therefore \quad \cdots$

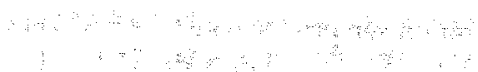

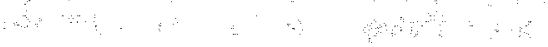
m $\because \quad \because \quad \therefore \quad$ औन

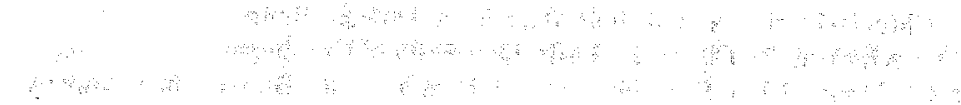

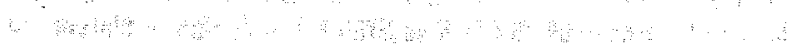

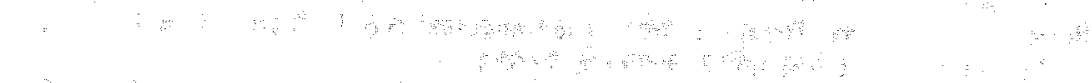

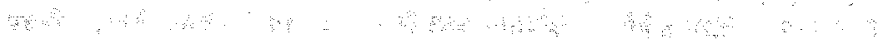

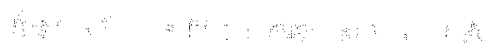




\section{Curriculum Vitae}

Derk Ludolf (Dick) Willems was bom on september 1st, 1954 in Grootegast. He received his secondary education at the Willem Lodewijk Gymnasium in Groningen, became M.D. at Groningen University in 1981, on an extended essay on the history of the hygienic movement in late nineteenth century Dutch medicine (with Henk Havinga and Eddy Houwaart). M.A. in Philosophy at the same University in 1986 on a joint essay with Rein Vos on the semantics of medical concepts, especially Minimal Brain Dysfunction. During his studies, he was active in the students' movement. Studied philosophy and history of science at the Sorbonne in Paris, with Mirko Grmek and Georges Canguilhem, in 1982 (Diplôme d'Etudes Approfondies).

From 1982 till 1983, he was trained as a general practitioner at Groningen university, and since 1984, he has been working as such in a health centre in Huizen, about 30 kilometers from Amsterdam.

He has published in both medical and philosophical journals.

From 1991 untill today, he has been a participant in the SGO Core Training for general practitioners, a fellowship program that allows a small group of experienced general practitioners to acquire supplementary clinical and theoretical training, both in the Netherlands and abroad. As a part of this programme, he has done scholarships in Paris (Centre de Sociologie de l'Innovation), Montreal (Palliative Care at the Jewish General Hospital), and New York (The Hastings Center for Bioethics). 